\title{
Investigation of Remote Sensing for Dike Inspection
}
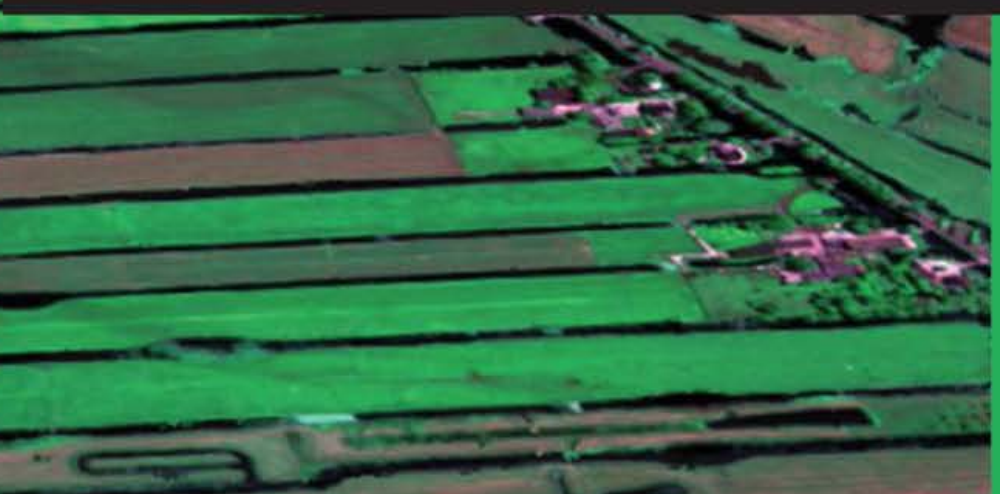

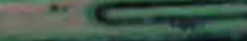
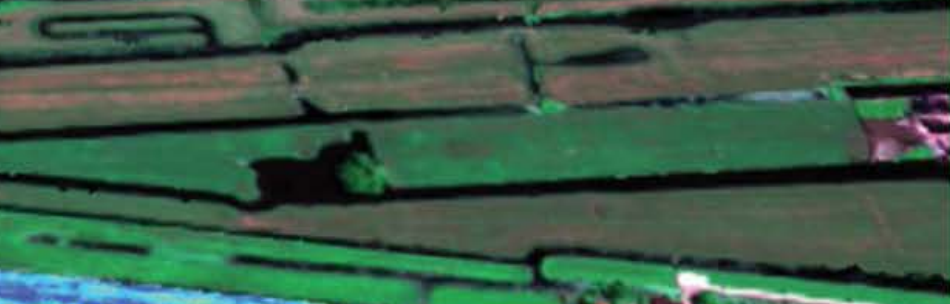

$-2-1$ -

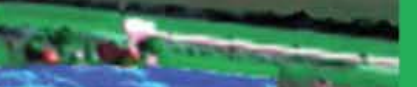

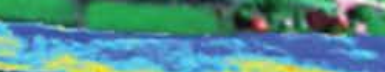

Wate

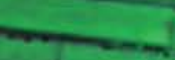

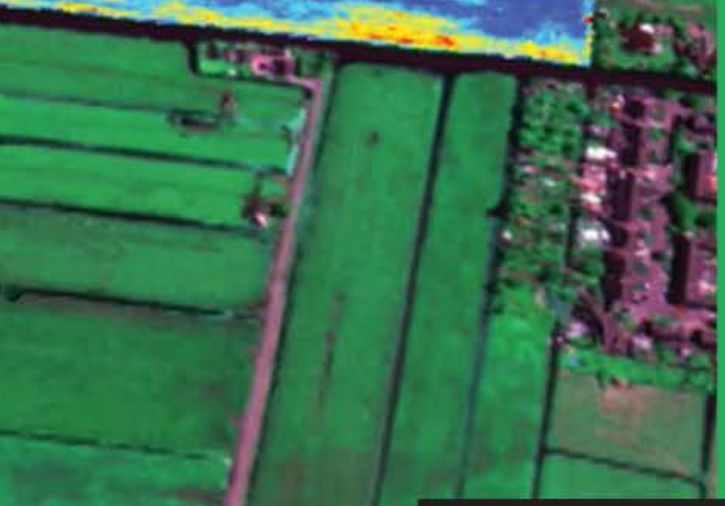

Sharon L. Cundill 


\section{INVESTIGATION OF REMOTE SENSING FOR DIKE INSPECTION}

Sharon Leigh Cundill 


\section{Examining committee:}

Dr. J. V. Aanstoos

Iowa State University

Prof.dr. S.M. de Jong

Utrecht University

Prof.dr. S.J.M.H. Hulscher

University of Twente

Prof.dr.ir. M. Kok

Prof.dr.ing. W. Verhoef

Delft University of Technology

University of Twente

The work described in this thesis was financially supported by the government of the Netherlands through the Flood Control 2015 programme (RSDYK project) and by the University of Twente.

ITC dissertation number 283

ITC, P.O. Box 217, 7500 AA Enschede, The Netherlands

ISBN 978-90-365-4036-0

DOI 10.3990/1.9789036540360

Cover designed by Job Duim and Sharon Cundill (RVI product on natural colour WorldView-2 image draped over AHN2 DEM. Image:C DigitalGlobe, Inc. All Rights Reserved)

Printed by ITC Printing Department

Copyright (C) 2016 Sharon Leigh Cundill

All rights reserved. No part of this publication may be reproduced in any form without written permission from the author.

In reference to IEEE copyrighted material which is used with permission in this thesis, the IEEE does not endorse any of the University of Twente's products or services. Internal or personal use of this material is permitted. If interested in reprinting/republishing IEEE copyrighted material for advertising or promotional purposes or for creating new collective works for resale or redistribution, please go to http://www.ieee.org/publications_standards/publications/rights/rights_link.html to learn how to obtain a License from RightsLink. 


\title{
INVESTIGATION OF REMOTE SENSING FOR DIKE INSPECTION
}

\author{
DISSERTATION
}

to obtain

the degree of doctor at the University of Twente, on the authority of the rector magnificus, prof.dr. H. Brinksma, on account of the decision of the graduation committee, to be publicly defended

on Friday 12 February 2016 at $12.45 \mathrm{hrs}$

by

Sharon Leigh Cundill

born on 3 April 1974

in Durban, South Africa 
This thesis is approved by

Prof. dr. Freek D. van der Meer, promoter Prof. dr. Mark van der Meijde, promoter Dr. H. Robert G. K. Hack, co-promoter 


\section{Summary}

This thesis investigates the use of optical remote sensing as proxies for the inspection indicators of cover quality and soil moisture so as to facilitate the inspection of grass covered dikes. The proof of concept showed that significant relationships exist between various ground-based optical remote sensing data and the two indicators. These were refined for use with airborne and spaceborne sensors and suggestions for operational implementation for dike inspection are given.

Dikes (also called levees or flood embankments) are common water defence structures that provide protection against inundation and flooding. Dikes are found all over the world, with thousands of kilometres of dikes protecting millions of people. Their function is becoming increasingly important due to the expected consequences of subsidence (e.g., from increased loading on compressible soils) and of climate change (e.g., sea level rise, more extreme weather events). It is essential that dikes be inspected regularly to ensure they remain reliable and functioning. Dike inspections are typically done by visual examination of dike components, ideally on foot. In view of the large number of dikes that need to be inspected, dike inspection is clearly a slow, costly, manhour intensive process. Remote sensing has been proposed as a tool that could facilitate faster dike inspection by screening large areas in a relatively short space of time using objective measurements. Over the last decade, remote sensing studies for dike inspection, monitoring and assessment have largely focused on the inspection indicators of deformation, slides and seepage. There are, however, other indicators that inspectors consider, such as cover quality and soil moisture.

The cover quality indicator is used to evaluate the quality of the grass cover, which is one of the most common forms of surface cover on dikes, where it protects against erosion, infiltration and sliding. The cover quality indicator takes into account the cover density, grass health, the presence of weeds, standing litter (dead plant material) or debris as well as the absence of vegetation. The absence of vegetation can be indicative of other issues (e.g., slides, animal activity). The soil moisture indicator is broad, encompassing not only excessive moisture (e.g., seepage) but also dryness. In this study, the vegetation response to available soil moisture is examined. The current research was conducted for an in situ peat dike.

The proof of concept showed significant relationships between four types of ground-based remote sensing data (i.e., broadband thermal, broadband visible, broadband multispectral and narrowband hyperspectral) and both inspection 
indicators. For the cover quality indicator, broadband multispectral data exhibited the strongest relationships. After testing a large number of indices across a range of spectral response functions, the Red/Green Index (RGI), Green/Red Ratio (GRR) and Normalized Green/Red Ratio (NGRR) are recommended for potential use by dike inspectors as proxies for the cover quality indicator, with a preference for GRR (based on similarity between field and actual image data). For the soil moisture indicator, afternoon thermal data exhibited the strongest relationships. These relationships have not been further tested and developed for airborne or space-borne implementation since no very high spatial resolution thermal imagery was available for this study. Nevertheless, it was observed that the optimal time for thermal measurements of grass covered dikes is between solar noon and apparent sunset and that for both indicators, illumination and weather conditions can be problematic, with non-uniform cover problematic for the soil moisture indicator. From the reflected data, the strongest relationships to the soil moisture indicator were for ratios using near-infrared and red bands or green and red bands. A large number of indices were tested across a range of spectral response functions and later refined using actual image data. The dike inspector could potentially use the Ratio Vegetation Index (RVI), Modified Simple Ratio (MSR) and Green/Red Ratio (GRR) as proxies for the soil moisture indicator for long-term moisture processes (e.g., weeks to months) for grass covered dikes, where vegetation growth and health have sufficient time to respond to available soil moisture.

In order to achieve the results, technical issues relating to the comparison of data from different sensors were addressed. This research confirmed that the change in spectral response functions (SRFs) between sensors noticeably altered index values, with the extent of change being sensor and index specific. SRF translations functions can usually be modelled, where the coefficients of determination $\left(\mathrm{R}^{2}\right)$ should be as close to perfect (i.e., 1) as possible in order to reduce biases. Translation functions were proven to reduce differences (i.e., improve similarity) between index values obtained from different sensors and thus translation functions should be used to correct for SRF differences before comparing data across sensors. Translation function coefficients for a number of indices and sensors are presented. This research fills the knowledge gap regarding SRFs of very high spatial resolution sensors specifically for the cover type of cultivated grasslands, which are typically found on dikes that do not have a hardened cover.

Dike inspectors could use indices RVI, MSR and GRR as proxies for the soil moisture indicator for long-term moisture processes (e.g., weeks to months) for grass covered dikes to identify potential problem areas for further investigation and similarly, indices RGI, NGRR and especially GRR for the cover quality 
indicator. For the study site, the remote sensing index values and observed spatial patterns were sufficiently clear to identify and delineate a comparable area (which is affected by a possible upwelling process) to that observed in the data of the soil moisture and cover quality indicators. This was true for data from different sensors. The true soil moisture or cover quality conditions may not always be evident in the remote sensing data and may be masked (e.g., by management practices). Also, soil moisture conditions in the subsurface may not necessarily be reflected at the surface and the absolute values of the indicators might not be retrieved from the remote sensing proxies. The remote sensing information is thus not definitive but rather indicative, with not all potential problem areas necessarily being identified. A number of suggestions are made for operational implementation of remote sensing data for dike inspection, which include regular image acquisition (e.g., every 1-3 months) with extra campaigns during times of drought or high water; very high spatial resolution imagery (i.e., less than $2 \mathrm{~m}$ ) and adequate image correction (such as atmospheric correction, SRF adjustments and radiometric normalization). Remote sensing proxies for inspection indicators can be valuable screening tools for dike inspection as well as contributing to traditional inspections by identifying potentially problematic areas that may have been over looked in the field or manifest between traditional inspections. 


\section{Samenvatting}

Dit proefschrift, 'Onderzoek van aardobservatie voor dijkinspectie', beschrijft het onderzoek naar het gebruik van optische aardobservatie als proxies voor inspectie indicatoren voor de kwaliteit van de dijkbedekking en de bodemvochtigheid van dijken, om zo de inspectie van gras begroeide dijken te vergemakkelijken. De 'proof of concept' toonde significante verbanden aan tussen verschillende optische aardobservatie data vanaf de grond en de twee indicatoren. De verbanden zijn verbeterd voor het gebruik vanuit de lucht en vanuit de ruimte, en suggesties voor implementatie in dijkinspectie worden gegeven.

Dijken, ook wel waterkeringen of kaden, zijn waterkerende structuren die bescherming tegen overstroming en wateroverlast bieden. Duizenden kilometers dijk zijn te vinden over de hele wereld, waar ze miljoenen mensen beschermen. Dijken worden steeds belangrijker door de verwachte gevolgen van bodemdaling (bv. door verhoogde belasting op samendrukbare grond) en klimaatverandering (bv. stijging van de zeespiegel en meer extreem weer). Het is belangrijk dijken regelmatig te inspecteren om ervoor te zorgen dat ze betrouwbaar zijn, en blijven functioneren als waterkering. Dijkinspecties worden meestal gedaan door visueel onderzoek van dijk componenten, meestal te voet. Gezien het grote aantal dijken die moeten worden geïnspecteerd, is dijkinspectie duidelijk een traag, duur, en manuren intensief proces. Aardobservatie is daarom voorgesteld als een methode die dijkinspectie kan versnellen en vergemakkelijken door het screenen van grote gebieden in een relatief korte tijd op basis van objectieve metingen. In de afgelopen tien jaar waren aardobservatie studies voor dijkinspectie, monitoring en evaluatie grotendeels gericht op inspectie indicatoren voor het detecteren van vervorming, afschuiving en kwel. Er zijn echter ook andere indicatoren die de inspecteurs gebruiken, zoals de kwaliteit van de dijkbedekking en bodemvochtigheid, die zich mogelijk lenen voor inspectie met aardobservatie.

De indicator voor de kwaliteit van de dijkbedekking wordt gebruikt om de kwaliteit van de grasmat te evalueren. Gras is een van de meest voorkomende vormen van oppervlaktebedekking van dijken. Het gras beschermt de dijk tegen erosie, infiltratie en afschuivingen. Deze indicator houdt rekening met de dichtheid van de bedekking, gezondheid van het gras, de aanwezigheid van onkruid, strooisel (dood plantenmateriaal) of afval, en de afwezigheid van vegetatie. De afwezigheid van de vegetatie kan een indicatie zijn van andere problemen, bijvoorbeeld afschuivingen en activiteit van dieren. De bodemvochtigheid indicator is breed definieert en omvat niet alleen vocht (bv. 
kwel), maar ook droogte. In deze studie wordt de respons van de begroeiing op beschikbare bodemvochtigheid onderzocht. Het huidige onderzoek werd uitgevoerd op een in situ veen dijk.

De test studie toonde significante verbanden aan tussen de data van vier types grond-aardobservatie (d.w.z., breedband thermische, breedband zichtbaar, breedband multispectrale, en smalband hyperspectrale data) en de beide inspectie indicatoren. De indicator voor kwaliteit van de dijkbedekking vertoonde de sterkste relaties met breedband multispectrale data. Na het testen van een groot aantal indices in een heel scala van spectrale responsfuncties, worden de 'Rood/Groen Index' [Red/Green Index] (RGI), 'Groen/Rood Ratio' [Green/Red Ratio] (GRR), en 'Genormaliseerde Groen/Rood Ratio' [Normalized Green/Red Ratio] (NGRR) aanbevolen voor mogelijk gebruik door dijk inspecteurs als proxy voor de indicator voor kwaliteit van de dijkbedekking, met een voorkeur voor GRR (op basis van overeenstemming tussen actuele veld- en beeldgegevens). Voor de bodemvochtigheid indicator, thermische data van de middag vertoonde de sterkste relaties. Deze relaties zijn niet verder getest en ontwikkeld voor implementatie in lucht- of ruimtevaart omdat er geen thermisch beeldmateriaal met zeer hoge ruimtelijke resolutie beschikbaar was voor deze studie. Toch werd wel vastgesteld dat de optimale tijd voor thermische metingen van gras begroeide dijken tussen solar noon en apparent sunset is en dat voor beide indicatoren verlichting en weersomstandigheden problematisch kunnen zijn. Voor de bodemvochtigheid indicator kan een niet-uniforme bedekking ook problematisch zijn. Van de gereflecteerde data, de sterkste relaties tot de bodemvochtigheid indicator is geconstateerd voor ratios die nabij-infrarode en rode banden of groene en rode banden gebruiken. Een groot aantal indices werd in een heel scala van spectrale responsfuncties getest en later verfijnd met behulp van echte beeldgegevens. De dijk inspecteur zou gebruik kunnen maken van de 'Ratio Vegetatie Index' [Ratio Vegetation Index] (RVI), 'Gemodificeerde Eenvoudige Ratio' [Modified Simple Ratio] (MSR), en 'Groen/Rood Ratio' [Green/Red Ratio] (GRR) als proxy voor de bodemvochtigheid indicator voor de lange termijn vocht processen (bv. weken tot maanden) voor gras bedekte dijken, waar de groei en gezondheid van de vegetatie voldoende tijd hebben om te reageren op beschikbaar bodemvocht.

Om de resultaten te behalen, zijn technische problemen in het vergelijken van gegevens van verschillende sensoren onderzocht. Dit onderzoek bevestigde dat de verandering in spectrale responsfuncties (SRFs) tussen sensoren tot een aanzienlijk verandering van indexwaarden kunnen leiden, waarbij de mate van verandering sensor en index specifiek zijn. SRF translatie functies kunnen meestal gemodelleerd worden, waarbij de determinatiecoëfficiënt $\left(\mathrm{R}^{2}\right)$ zo dicht 
mogelijk aan perfect zou moeten zijn (d.w.z. 1) om vertekening te verminderen. Er is bewezen dat translatie functies het verschil verminderen (d.w.z. de gelijkenis verbeteren) tussen indexwaarden verkregen uit verschillende sensoren. Dus translatie functies moeten gebruikt worden om SRF verschillen te corrigeren voordat data van verschillende sensoren vergeleken kan worden. Translatie functie coëfficiënten voor een aantal indices en sensoren worden gepresenteerd. Dit onderzoek vult de kenniskloof met betrekking tot SRFs van zeer hoge ruimtelijke resolutie sensoren, die specifiek zijn voor de bedekking met gecultiveerd grasland, wat doorgaans te vinden is op dijken zonder verharde bedekking.

Dijk inspecteurs kunnen de indices RGI, NGRR en vooral GRR gebruiken als proxies voor de indicator voor de kwaliteit van de dijkbedekking voor gras begroeide dijken om potentiële probleemgebieden te identificeren voor verder onderzoek. De indices RVI, MSR en GRR kunnen als proxies voor de bodemvochtigheid indicator gebruikt worden, voor de lange termijn vocht processen (bv. weken tot maanden) voor gras begroeide dijken. Voor de onderzoekslocatie, de aardobservatie indexwaarden en waargenomen ruimtelijke patronen waren voldoende om een vergelijkbaar oppervlak (dat wordt beïnvloed door mogelijke water opwelling) te identificeren en af te bakenen, dat ook in de data van de indicatoren voor de bodemvochtigheid en de kwaliteit van de dijkbedekking waargenomen wordt. Dit geldt voor gegevens van verschillende sensoren. De ware bodemvochtigheid of de kwaliteit van de dijkbedekking wordt niet altijd duidelijk in de aardobservatie data en kunnen gemaskeerd zijn door, bijvoorbeeld, beheersmaatregelen. Ook bodemvochtomstandigheden in de ondergrond worden niet noodzakelijkwijs aan het oppervlak gereflecteerd en de absolute waarden van de indicatoren is misschien niet beschikbaar uit de aardobservatie proxies. De aardobservatie informatie is dus indicatief en mogelijk worden niet alle probleemgebieden geïdentificeerd. Een aantal suggesties voor de operationele implementatie van aardobservatie gegevens voor dijkinspectie worden gedaan, waaronder regelmatige beeldacquisitie (bv. elke 1-3 maanden) met extra data acquisitie in tijden van droogte of hoog water, zeer hoge ruimtelijke resolutie beeldmateriaal (d.w.z., minder dan $2 \mathrm{~m}$ ) en voldoende beeldcorrectie (zoals atmosferische correctie, SRF aanpassingen en radiometrische normalisering). Aardobservatie proxies voor inspectie indicatoren kunnen waardevolle screeningsinstrumenten voor dijkinspectie zijn en zo bijdragen aan de traditionele inspecties door het identificeren van potentieel problematische gebieden, die mogelijk zijn gemist in het veld of tussen de traditionele inspecties zijn verschenen. 


\section{Zusammenfassung}

Diese Doktorarbeit ,Untersuchung von Fernerkundung für Deichinspektionen untersucht die Anwendung optischer Fernerkundung als Proxies für die Inspektionsindikatoren der Bodenbedeckungsqualität und Bodenfeuchte, um so die Inspektion von grasbedeckten Deichen zu erleichtern. Die Machbarkeitsstudie hat gezeigt, dass signifikante Beziehungen zwischen verschiedenen bodengebundenen optischen Fernerkundungsdaten und den genannten Inspektionsindikatoren bestehen. Diese sind für die Verwendung von luft- und weltraumgestützten Sensoren verfeinert worden und es werden Vorschläge für die operative Umsetzung für Deichinspektionen gegeben.

Deiche (manchmal auch Dämme genannt) sind Verteidigungsstrukturen, die Schutz vor Hochwasser und Überschwemmung bieten. Deiche sind auf der ganzen Welt zu finden; Tausende Kilometer Deiche schützen weltweit Millionen von Menschen. Die Funktion der Deiche wird immer wichtiger aufgrund der $\mathrm{zu}$ erwartenden Folgen durch Bodenabsenkungen (z.B. durch erhöhte Belastung auf kompressible Böden) und den Klimawandel (z.B. Anstieg des Meeresspiegels, Zunahme extremer Wetterereignisse). Ein wesentlicher Punkt zur Sicherstellung der Funktionalität der Deiche ist eine regelmäßige Überprüfung. Deichinspektionen erfolgen üblicherweise durch eine visuelle Untersuchung der verschiedenen Deichkomponenten, idealerweise zu Fuß. Angesichts der großen Anzahl von Deichen, die überprüft werden müssen, ist diese Form der Deichinspektion eindeutig ein langsamer, kostspieliger und sehr intensiver Prozess, der den Einsatz zahlreicher Inspektoren voraussetzt. Die Fernerkundung bietet sich in diesem Punkt als ein Instrument an, welches eine schnellere Inspektion der Deiche ermöglicht, indem große Deichabschnitte in relativ kurzer Zeit durch objektive Messungen untersucht werden. Im Laufe des letzten Jahrzehnts haben sich Fernerkundungsstudien für Deichinspektionen vornehmlich auf die Inspektionsindikatoren Verformung, Rutschung und Durchsickerung konzentriert. Es gibt aber auch noch andere Indikatoren, die Deichinspektoren prüfen, wie z.B. Bodenbedeckungsqualität und Bodenfeuchte.

Der Indikator der Bodenbedeckungsqualität wird verwendet, um die Qualität der Grasbedeckung des Deiches zu bewerten. Grasbedeckung ist eine der häufigsten Formen der Oberflächenbedeckung von Deichen, da sie vor Erosion, Infiltration und Abgleiten schützt. Der Indikator der Bodenbedeckungsqualität berücksichtigt die Deckdichte, Gesundheit des Grases, das Vorhandensein von Unkraut sowie die Anwesenheit von abgestorbenem Pflanzenmaterial oder Treibgut als auch das Fehlen von Vegetation. Das Fehlen von Vegetation kann auch eine Indikation sein für andere Themen (z.B. Rutschungen oder 
Tieraktivität). Der Indikator der Bodenfeuchte ist breit und umfasst nicht nur übermäßige Feuchtigkeit (z.B. durch Durchsickerung), sondern auch Trockenheit. In dieser Studie wird die Reaktion der Vegetation auf verfügbare Bodenfeuchte untersucht. Die vorliegende Studie wurde an einem in-situ Torfdeich durchgeführt.

Die Machbarkeitsstudie weist signifikante Zusammenhänge zwischen vier Arten von bodengestützten Fernerkundungsdaten (Breitband thermisch, Breitband sichtbar, Breitband multispektral und Schmalband hyperspektral) und den beiden Inspektionsindikatoren auf. Für den Indikator der Bodenbedeckungsqualität zeigen die Breitband multispektralen Daten die stärksten Beziehungen. Nach Prüfung einer großen Anzahl von Indizes für eine Reihe von spektralen Antwortfunktionen werden der ,Rot/Grün-Index ${ }^{*}$ [Red/Green Index] (RGI), das ,Grün/Rot Verhältnis‘ [Green/Red Ratio] (GRR) und das ,normalisierte Grün/Rot Verhältnis‘ [Normalized Green/Red Ratio] (NGRR) für den möglichen Einsatz durch Deichinspektoren als Proxies für den Indikator der Bodenbedeckungsqualität empfohlen, mit einer Präferenz für GRR (basierend auf der Ähnlichkeit zwischen Feld- und tatsächlichen Bilddaten). Für den Indikator der Bodenfeuchte zeigen in den Nachmittagsstunden aufgenommene thermische Daten die stärksten Beziehungen. Im Rahmen dieser Arbeit wurden diese Beziehungen nicht weiter geprüft oder für die Anwendung von luft- oder weltraumgestützten Methoden weiterentwickelt, da keine räumlich hochaufgelösten thermischen Daten zur Verfügung standen. Dennoch war zu beobachten, dass die optimale Zeit für die thermischen Messungen an grasbedeckten Deichen zwischen solarem Mittag und scheinbarem Sonnenuntergang liegt, und dass für beide Indikatoren die Beleuchtung und Wetterbedingungen problematisch sein können. Für den Indikator der Bodenfeuchte kann zusätzlich die ungleichmäßige Bedeckung problematisch sein. Bei Verwendung der reflektierten Daten waren die stärksten Beziehungen des Indikators der Bodenfeuchte mit dem Verhältnis von nahen Infrarot und roten Bändern oder dem Verhältnis von grünen und roten Bändern. Eine große Anzahl von Indizes wurde in einer Reihe von spektralen Antwortfunktionen getestet und unter Verwendung der tatsächlichen Bilddaten später verfeinert. Für langfristige Feuchtigkeitsprozesse von grasbedeckten Deichen (z.B. Wochen bis Monate - wobei die Vegetation genug Zeit hat, um auf die verfügbare Bodenfeuchte zu reagieren) könnten die Deichinspektoren potentiell den ,Vegetationsindex“ [Ratio Vegetation Index] (RVI), das ,modifizierte einfache Verhältnis' [Modified Simple Ratio] (MSR) und das ,Grün/Rot Verhältnis“ [Green/Red Ratio] (GRR) als Proxies für den Indikator der Bodenfeuchte verwenden. 
Um die präsentierten Ergebnisse $\mathrm{zu}$ erreichen, wurden die technischen Probleme hinsichtlich eines Vergleichs von Daten verschiedener Sensoren adressiert. Diese Studie bestätigt, dass die Änderung der spektralen Antwortfunktionen [spectral response functions] (SRF) zwischen den Sensoren zu deutlichen Veränderungen der Indexwerte führt; wobei das Ausmaß der Veränderung als Sensor- und Index- spezifisch bezeichnet werden kann. SRFÜbersetzungsfunktionen [translation functions] können in der Regel modelliert werden. Dabei müssen die Bestimmtheitsmaße $\left(R^{2}\right)$ einen Werte um 1 annehmen, um Verzerrungen zu reduzieren. Übersetzungsfunktionen reduzieren nachweislich Unterschiede (d.h. Verbesserung der Ähnlichkeit) zwischen Indexwerten, die mit verschiedenen Sensoren ermittelt wurden. Es sollten also Übersetzungsfunktionen verwendet werden, um SRF Unterschiede zu korrigieren, bevor Daten von verschiedenen Sensoren verglichen werden. Übersetzungsfunktionskoeffizienten für eine Anzahl von Indizes und Sensoren werden dargestellt. Diese Studie füllt somit eine Wissenslücke bezüglich SRFs von räumlich hochaufgelösten Sensoren, speziell für den Bedeckungstyp des bewirtschafteten Graslandes. Dieser Bedeckungstyp ist in der Regel auf Deichen zu finden, welche nicht über eine gehärtete Bedeckung verfügen.

Deichinspektoren können die Indizes RVI, MSR und GRR als Proxies für den Indikator der Bodenfeuchte für langfristige Feuchtigkeitsprozesse (z.B. Wochen bis Monate) für grasbedeckte Deiche verwenden, um mögliche Problembereiche für die weitere Untersuchung zu identifizieren. Weiterhin können die Indizes RGI, NGRR und insbesondere GRR für den Indikator der Bodenbedeckungsqualität verwendet werden. Für den Untersuchungsbereich dieser Studie waren die aus den Fernerkundungsdaten ermittelten Indexwerte und beobachteten räumlichen Muster ausreichend deutlich, um einen vergleichbaren Bereich (welcher möglicherweise von Auftriebsprozessen betroffen ist) zu identifizieren und abzugrenzen, wie er auch in den Daten der Indikatoren für die Bodenfeuchte und die Bodenbedeckungsqualität beobachtet werden konnte. Dies gilt für die Daten verschiedener Sensoren. Die wahre Bodenfeuchte oder Bodenbedeckungsqualität wird aus den Fernerkundungsdaten nicht immer ersichtlich und kann möglicherweise verdeckt sein (z.B. durch Managementpraktiken). Auch die Bodenfeuchtigkeit im Untergrund muss nicht unbedingt an die Oberfläche reflektiert werden und die absoluten Werte der Indikatoren könnten möglicherweise auch nicht aus den Fernerkundungs-Proxies abgerufen werden. Die Fernerkundungsinformation ist daher nicht endgültig, sondern indikativ. Nicht alle potenziellen Problembereiche werden notwendigerweise identifiziert. Eine Reihe von Vorschlägen für die operative Umsetzung von Fernerkundungsdaten für Deichinspektionen werden daher gegeben, wie z.B. die regelmäßigen 
Bildaufnahmen (z.B. alle 1-3 Monate) mit zusätzlichen Kampagnen in Dürreund Hochwasserzeiten, Aufnahme von Daten mit sehr hoher räumlicher Auflösung (d.h. weniger als $2 \mathrm{~m}$ ) und eine passende Bildkorrektur (wie atmosphärische Korrektur, SRF Anpassungen und radiometrische Normalisierung). Fernerkundungs-Proxies für die Inspektionsindikatoren können wertvolle Kontrollwerkzeuge für Deichinspektionen darstellen sowie einen Beitrag $\mathrm{zu}$ den traditionellen Inspektionen leisten, durch die Identifizierung von potentiell problematischen Bereichen, die eventuell im Feld übersehen werden oder sich zwischen den traditionellen Inspektionen entwickeln. 


\section{Acknowledgements}

A work such as this is never completed in isolation. Thank you to all who contributed in any way toward this thesis. Specific acknowledgements are given below, but to those who have slipped through the cracks (in my mind, not the dike), please accept my sincere thanks.

A special thank you goes to my supervisors Robert Hack and Mark van der Meijde (now promotor). I am indebted to you both for your invaluable support, guidance and advice throughout my research.

Mark, thank you for always believing in me-for your confidence in my scientific ability even as early as during my Masters. Thank you for allowing me the freedom to pursue my ideas but redirecting my focus when I was absorbed by the details. Thank you for your knowledgeable and constructive insights and for cultivating my scientific thinking; for your encouragement as well as for your always open door.

Robert, thank you for having the vision and for your trust that the job would get done. Thank you for sharing your extensive geotechnical knowledge, connecting me with a wide range of experts and assisting during fieldwork (even through the wee small hours). Thank you for open discussions and asking the necessary questions.

I am grateful to my promotor, Freek van der Meer, for his insightful, critical and scientific guidance and advice on my research, his constructive comments on my chapters and for his confidence in the final product. I am also grateful to Victor Jetten for his support and input during many discussions throughout my research. A special thanks goes to Harald van der Werff, for his technical expertise on remote sensing matters and for being co-author on many of my research papers. Harald, thank you for your generous support and advice in patiently working out technical details and for your kind encouragement.

I acknowledge the Flood Control 2015 programme and the University of Twente for providing the funding for this research. I am grateful to the RSDYK project members, partners and stakeholders: Royal Haskoning, specifically Joost van der Schrier; Fugro Water Services, specifically Martin van der Meer and Leo Zwang; Stichting IJkdijk; Gemeente Bodegraven-Reeuwijk, specifically Jan Rupke; and Hoogheemraadschap van Rijnland. Thanks to Paul Borgh and Niek van Leeuwen for allowing access to their land and for clearing it of livestock during field measurements. A special thanks goes to Dominique Ngan-Tillard of the Delft University of Technology, who, often at short notice 
and despite her busy schedule, supported with equipment and field measurements.

For advice and guidance at various stages of my research, I would like to thank Iris van Duren, Stefan Flos, Chris Hecker, Cristina Jommi, Norman Kerle, Gerald van der Kolff, David Rossiter, Menno Straatsma, Rens Swart, and Harm Matthijs van der Worp.

For support in diverse shapes and forms, I would like to thank Abdulmohsen Alamry, Bashar Alsadik, Hanneke Arnoldus (incl. lots of laughs and warding off goats), Wim Bakker, Sally Barrett, Petra Budde, Loes Colenbrander, Job Duim, Markus Gerke, Carla Gerritsen, Brummer Grobbelaar, Jaap van t'Hof (TNO), Marga Koelen, Sabine Maresch, Benno Masselink, Mike McCall, Edwin Morsink (Lankelma Geotechniek Almelo B.V.), Marleen Noomen, Rebecca Retzlaff (Universität Trier), Gilles Rock (Universität Trier), Martin Schlerf, Roelof Schoppers, Boudewijn de Smeth, Desirée Snoek, Wim Timmermans, Murat Ucer, Thomas Udelhoven (Universität Trier), Zoltan Vekerdy, Rogier van der Velde, Christine Wesche, Henk Wilbrink, and Rana Wiratama.

I would like to thank my paranymphs Jelle Ferwerda and Petra Weber for their support during my defence. A heartfelt thank you to you both for your friendship and support over the years and for providing me with a home away from home during the last years of my research. Your generosity is overwhelming.

To Alison du Plessis: Chicken, thank you for your friendship over the many years and many miles, and for your unwavering belief in my abilities. Your friendship is treasured.

To my dear friends and fellow doctoral candidates Fan Xuanmei, Yu Fangyuan, Sanaz Salati, Anandita Sengupta and Nynne Lauritsen: Thank you for the laughs, the tears, the good food and the distractions.

For friendship and encouragement I would like to thank Nicky Knox, Christine Wesche, Iris van Duren, Sabine Maresch, Sumbal Bahar Saba, Irena Ymeti, Fekerte Yitagesu, Andre Stumpf, Byron Quan Luna, Khamarrul Azahari Razak, Marleen Noomen, Tang Chenxiao, Li Weile, Muhammad Shafique, Tolga Gorum, Thea Turkington, Matthew Dimal, Janneke Ettema, Efthymia Pavlidou, Islam Fadel, Yijian Zeng, the directors and staff at GeoTerraImage, and many other fellow $\mathrm{PhD}$ candidates.

I give glory to God, Father of our Lord Jesus Christ, for my ability and strength. 
I am grateful to my parents, John and Isabell Cundill. Mom and Dad, thank you for your unconditional love, for instilling confidence in my ability and the perseverance to push through. Thank you to my family for their love and encouragement, particularly to my brother Gary as we together shared our doctoral experiences. Vielen Dank an Familie Tegtmeier für die Aufnahme in die Familie und Ihre Liebe und Unterstützung. I am especially grateful to my wife, Wiebke, for her unfailing love, support, encouragement, faith and patience throughout the doctoral process. Wiebs, I love you more than words can say and am so looking forward to the next phase of our lives together. 


\section{Contents}

Summary

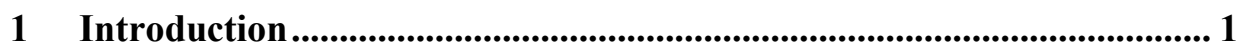

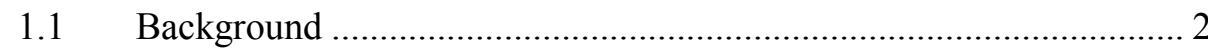

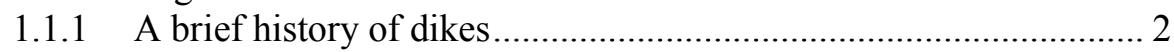

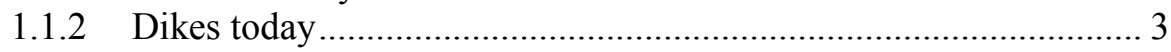

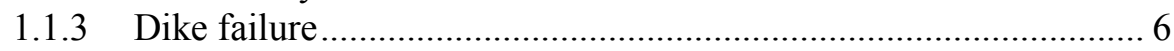

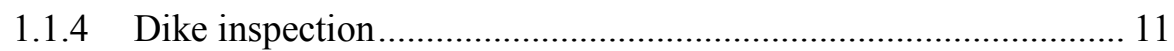

1.1.5 Remote sensing for dike inspection............................................. 12

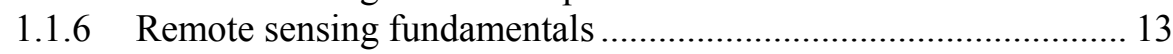

1.1.7 Remote sensing research for dike inspection ............................... 18

1.1.8 Other research for dike inspection................................................. 21

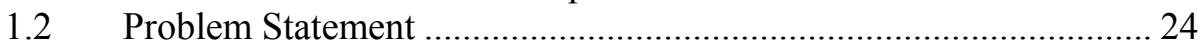

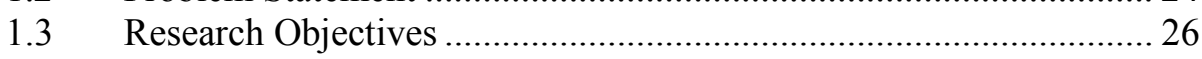

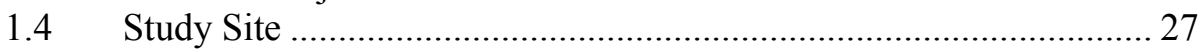

1.5 Structure of Thesis........................................................................... 30

\section{Investigation of Remote Sensing for Potential Use in Dike Inspection 33}

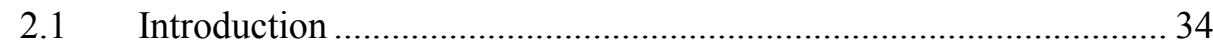

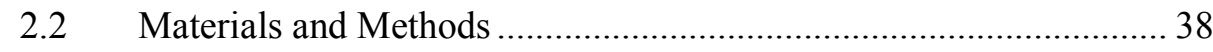

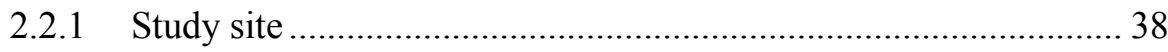

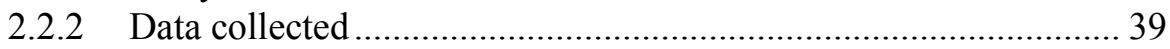

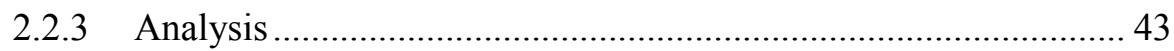

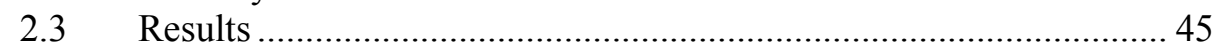

2.3.1 Soil moisture and remote sensing data …………………................. 45

2.3.2 Cover quality and remote sensing data........................................ 48

2.3.3 Relationships between remote sensing data ................................. 48

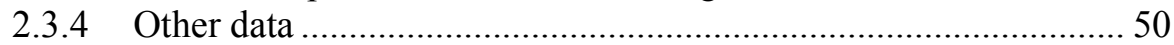

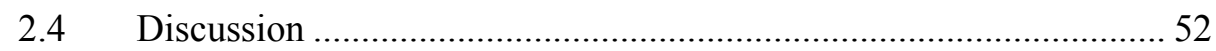

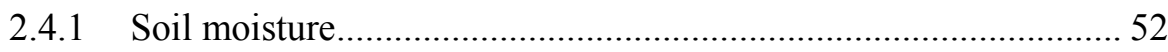




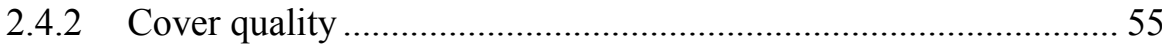

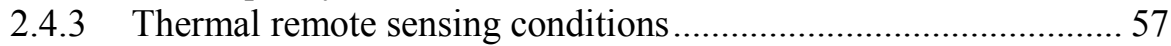

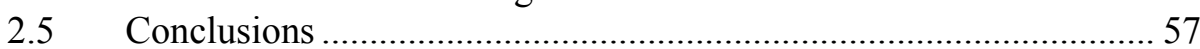

3 Adjusting Spectral Indices for Spectral Response Function Differences of Very High Spatial Resolution Sensors Simulated from Field Spectra

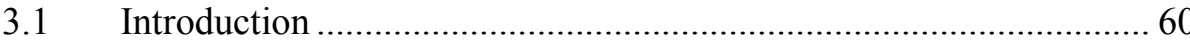

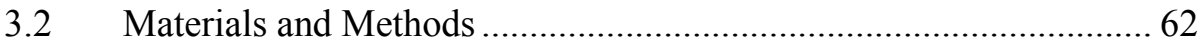

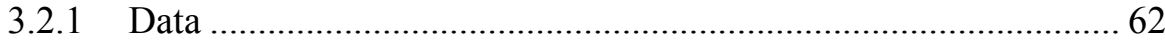

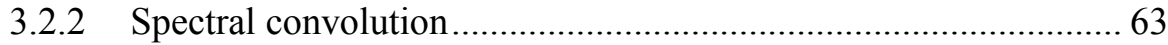

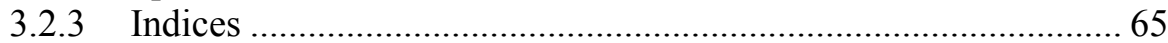

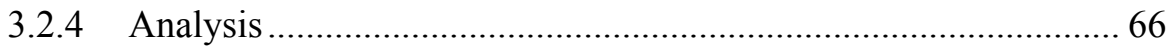

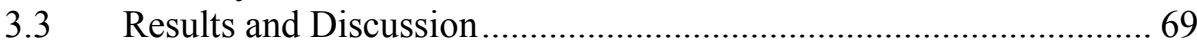

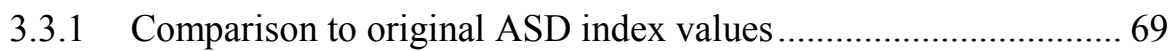

3.3.2 Correlation to inspection indicators.............................................. 73

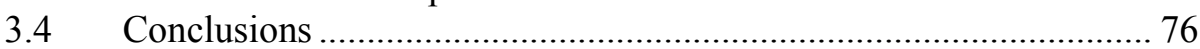

4 Comparison of Indices from Field Spectral Measurements and Satellite

Imagery as Proxies for Dike Inspection Indicators ................................. 79

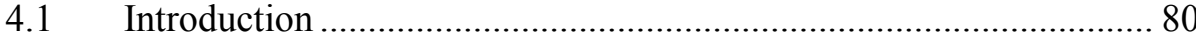

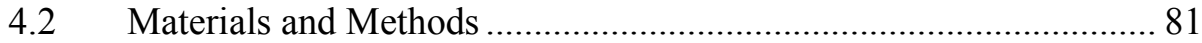

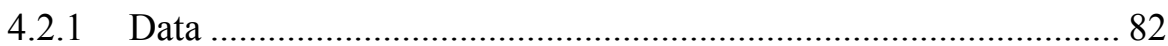

4.2.2 Translation functions ....................................................... 85

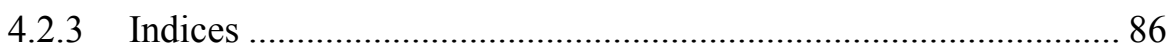

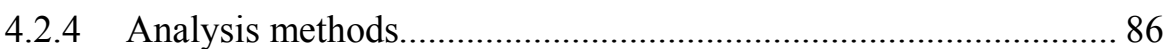

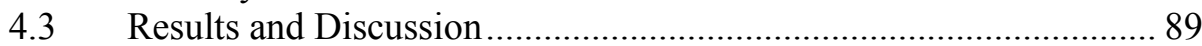

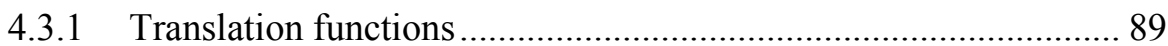

4.3.2 Comparison of field and image data............................................. 89

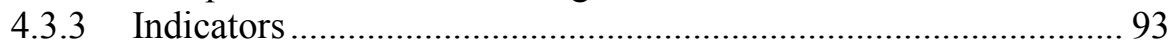

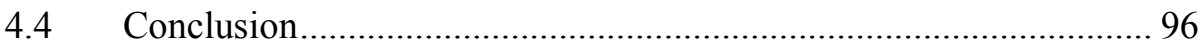

5 Usability of Multi-Date Image Data for Dike Inspection........................ 97

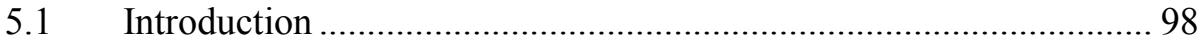

5.2 Materials and Methods ..................................................................... 99

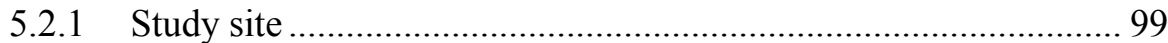

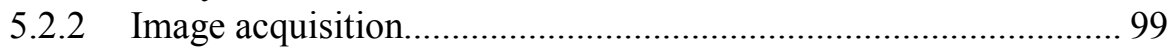

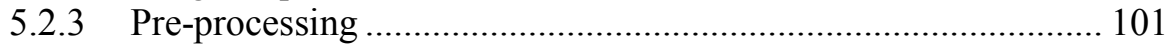

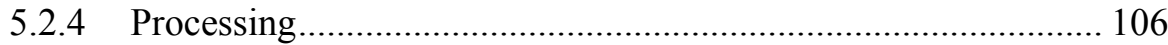

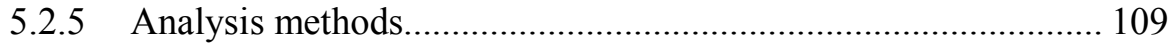

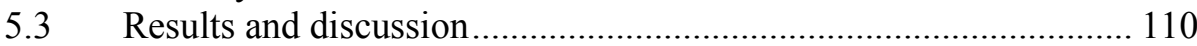




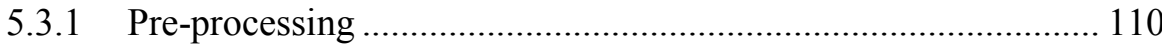

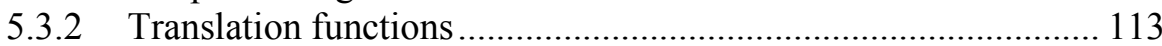

5.3.3 Comparison of multi-temporal and multi-sensor image index data

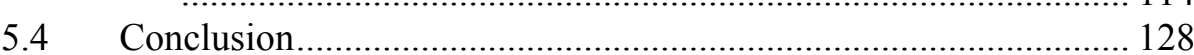

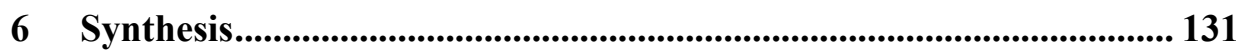

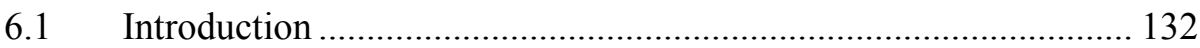

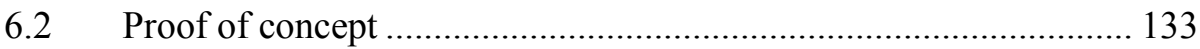

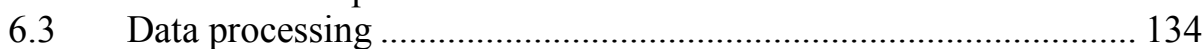

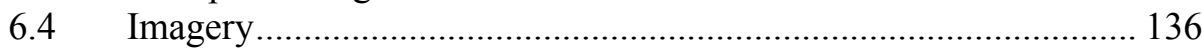

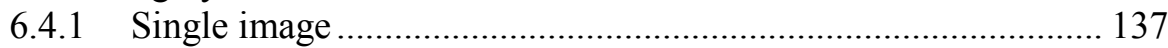

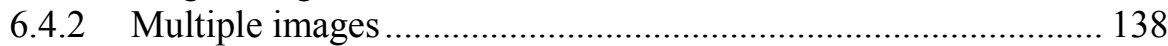

6.5 Remote sensing for dike inspection............................................. 138

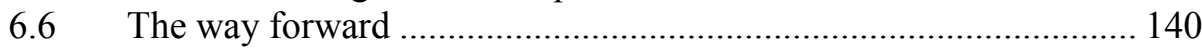

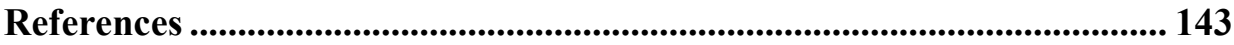

Appendix A: Indices used in this study .......................................................... 171

Appendix B: Statistical measures per index, comparing index values generated from convolved narrow- and broadband data to index values obtained from original narrowband ASD data........................... 181

Appendix C: Correlation coefficients between inspection indictors and index values for simulated data sets used in Chapter 3 ....................... 191

Appendix D: Bivariate statistical measures for the ten indices investigated

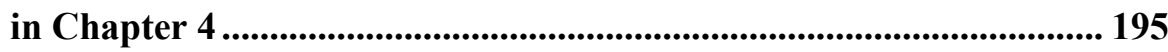

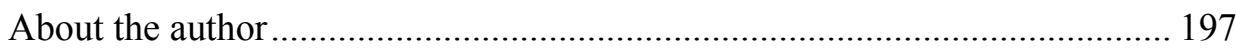

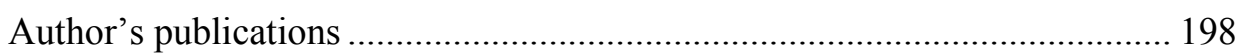

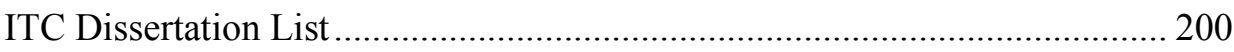




\section{List of figures}

Figure 1.1: Simplified cross-sections of (a) a raised structure dike (modified after CIRIA et al., 2013) and (b) an in situ dike, showing basic functional (black text) and non-functional (grey text) components.

Figure 1.2: Dike failure chain, with key terms and processes (modified after CIRIA et al., 2013: Fig. 3.163 \& 3.166 by R. Tourment)............ 9

Figure 1.3: Sketches illustrating various failure mechanisms (modified after Allsop et al., 2007; CIRIA et al., 2013; Moser and Zomer, 2006; Schelfhout, 2011). Thin arrows represent water flows and underpressures while thick arrows represent movements of dike earthfill or foundations. Dashed lines indicate dike cross-section prior to failure mechanism. Dike components are labelled in Figure 1.1. 10

Figure 1.4: The electromagnetic spectrum showing general major divisions (modified after Blacus, 2012).

Figure 1.5: The remote sensing process. A: energy source, B: atmospheric interactions, C: interactions with target, D: recording of energy by sensor, E: transmission, reception and processing, F: interpretation and analysis, G: application (Source: Canada Centre for Remote Sensing, 2007). 15

Figure 1.6: Spectral reflectance curves for three types of vegetation and one soil type showing their distinctive spectral signatures. The broad spectral regions of blue, green and red are shaded accordingly, with the near-infrared without shading. (Data from John Hopkins University Spectral Library provided by Jack Salisbury)............ 16

Figure 1.7: Location map of study site (Cundill et al., 2014). (C) 2014 IEEE. 28

Figure 1.8: Schematic diagram of a reclaimed peat-excavated area (vertical scale exaggerated) (Cundill et al., 2014). (C) 2014 IEEE. ............. 28

Figure 1.9: Study site section of dike, with ditches on both sides of the dike (vertical scale exaggerated $3 \mathrm{x}$ ). The red dot indicates the location from which the panoramic photo (Figure 1.10) was taken......... 29

Figure 1.10: Panoramic photo of study site. Approximate directions from observer: ditch South to North and fence West to East (photograph: Hack, H.R.G.K., taken 21 February 2013)............. 29

Figure 1.11: Subsurface model showing the lithography of the study area, based on two boreholes and 17 cone penetration tests (CPTs). In order to distinguish between the lithographic units, numbers have been appended to lithographic names.

Figure 2.1: Section of dike showing the study area, with ditches at the top and the bottom of the dike. The black dots on the dike indicate the data location points. (C) 2014 IEEE. 38 
Figure 2.2: Maps showing spatial distribution of the two validation data sets, namely (a) soil moisture and (b) cover quality and four of the remote data sets from the four different types of sensors, namely (c) the thermal camera, (d) the multispectral camera, (e) the visible light digital camera and (f) the hyperspectral spectrometer. The dashed line indicates where the bottom part of the dike manifests differently from the rest of the dike. (C) 2014 IEEE..... 47

Figure 2.3: Thermal time series plot showing the diurnal variation in thermal measurements and the differences between wetter and drier soil locations. (C) 2014 IEEE.

Figure 2.4: Resistivity and (simplified) lithology data: (a) map of resistivity at the surface, where the dashed line indicates where the bottom part of the dike manifests differently from the rest of the dike and with the location of cross-section $\mathrm{A}-\mathrm{A}^{\prime}$ indicated by the solid line; (b) resistivity cross-section $\mathrm{A}-\mathrm{A}^{\prime}$ showing horizontal layering on the right and higher resistivity values on the left (bottom of the dike) with horizontal layering absent; (c) lithology cross-section $\mathrm{A}-\mathrm{A}^{\prime}$ showing horizontal layering of peat, clay and silt, with sand layers starting at about -11 m NAP. (Note: the lithology descriptions are simplified, indicating the most important constituents for this research). (C) 2014 IEEE. 51

Figure 2.5: Schematic diagram of ground water flows in a peat excavation environment (modified after Oude Essink et al., 2012: Fig. by P. de Louw). The black rectangle indicates an area representative of the study site. (C) 2014 IEEE.

Figure 3.1: Summary workflow of the materials and methods used in this chapter. 62

Figure 3.2: Band positions and widths for the sensors used in this chapter... 65

Figure 3.3: Scatterplots for representative indices, showing the relationships between the original ASD data and the spectrally simulated data of various sensors. (a) DVI, (b) GEMI, (c) ARI, (d) $\mathrm{CTR}_{1}$, (e) $\mathrm{BGI}_{2}$ and (f) MSR. The dashed line represents the $1: 1$ line......... 71

Figure 4.1: $\quad$ Maps of (a) the Netherlands showing the location of the study site and (b) the dike and surrounding area, with (c) the section of dike (vertical scale exaggerated). WorldView-2 panmerge image (C) DigitalGlobe, Inc. All Rights Reserved) draped over the Actueel Hoogtebestand Nederland AHN2 digital elevation model data. The black dots represent the locations for which field measurements were recorded................................................... 82

Figure 4.2: Maps showing the spatial distribution and values for the two indicators used in this study, namely (a) soil moisture indicator and (b) cover quality indicator. The values are interpolated from the point data for the 54 locations (black dots) using natural neighbour algorithm. The study area is outlined by the black 
rectangle and the background image is the panchromatic WorldView-2 image (C) DigitalGlobe, Inc. All Rights Reserved).

Figure 4.3: Boxplots for selected indices (selection based on $R^{2}$ values in Table 4.4). The grey line is at the position of the mean for the ASD data sets. The shaded area indicates the area above or below the mean (depending on the direction of the correlation to the indicators). For example, the $\mathrm{GM}_{2}$ index values tend to increase with increasing soil moisture, while the RGI index values tend to decrease with increasing soil moisture.

Figure 4.4: Bar graphs for the three bivariate measures for selected indices (selection based on $R^{2}$ values in Table 4.4). The coefficient of determination to the 1:1 line (denoted as $\mathrm{r}_{1: 1}^{2}$ ) has been subtracted from 1 in order that the graph may be more easily interpreted with the value 0 representative of no difference from the field ASD data sets

Figure 4.5: Maps showing the spatial distribution and values for selected indices (selection based on $R^{2}$ values in Table 4.4) for (left) the interpolated ASD point data (ASD data sets); (centre) the interpolated WorldView-2 spectrally-translated image point data (Img54Adj data sets) and (right) the actual WorldView-2 spectrally-translated pixel data (ImgAdj data sets). The study area for the 54 locations is outlined by the black rectangle and the 54 locations are indicated by the black dots. The background image is the panchromatic WorldView-2 image (C) DigitalGlobe, Inc. All Rights Reserved).................................................................. 94

Figure 5.1: Image acquisition timeline, showing sensor (bold black text), date of acquisition (blue text) and nominal spatial resolution of the specific multispectral product in metres (black text in parenthesis) for the six images used in this chapter. Bar graphs show daily precipitation and daily potential evapo-transpiration for the 30 days prior to and including the respective image acquisition date. Line graphs show daily mean temperatures for the 30 days prior to and including the respective image acquisition date. Weather information is for the nearest official weather station and obtained from the Royal Netherlands Meteorological Institute (KNMI). 100

Figure 5.2: Summary workflow of the image pre-processing and processing steps applied in this chapter. Data are indicated as black text and processes as bold blue text.

Figure 5.3: Location of the training and verification invariant targets on the background of the panchromatic WorldView-2 image dated 5 September 2013 (C DigitalGlobe, Inc. All Rights Reserved). Data from invariant target 32 (as indicated on the map) are included in the results shown in Figures 5.12 and 5.13. 105 
Figure 5.4: Spectral response functions (SRFs) for the sensors used in this chapter. The sensor is indicated by a solid or dashed line while colours are used to differentiate bands.

108

Figure 5.5: Map showing the four locations used for spectral behaviour analysis. The location identification numbers correspond to those defined in Chapter 2. The volumetric soil moisture and cover quality values are those measured on 15 July 2010 in the field, with cover quality assessed using the classification described in Table 2.1. The dike segment is outlined in black on the background of the 14 July 2010 WorldView-2 image (RGB:532; (C) DigitalGlobe, Inc. All Rights Reserved). 110

Figure 5.6: Adjusted Ratio Vegetation Index (RVI) values of the various atmospherically corrected images for the dike segment. QB: QuickBird, WV2: WorldView-2, GE: GeoEye-1, IK: IKONOS, PL: Pléiades-1B (Pléiades: (C CNES 2013, Distribution Airbus DS / Spot Image; Remaining images: (C) DigitalGlobe, Inc. All Rights Reserved). 115

Figure 5.7: Adjusted Modified Simple Ratio (MSR) values of the various atmospherically corrected images for the dike segment. QB: QuickBird, WV2: WorldView-2, GE: GeoEye-1, IK: IKONOS, PL: Pléiades-1B (Pléiades: (C) CNES 2013, Distribution Airbus DS / Spot Image; Remaining images: (C) DigitalGlobe, Inc. All Rights Reserved). 116

Figure 5.8: Adjusted Green/Red Ratio (GRR) values of the various atmospherically corrected images for the dike segment. QB: QuickBird, WV2: WorldView-2, GE: GeoEye-1, IK: IKONOS, PL: Pléiades-1B (Pléiades: (C) CNES 2013, Distribution Airbus DS / Spot Image; Remaining images: (C) DigitalGlobe, Inc. All Rights Reserved).

Figure 5.9: Ratio Vegetation Index (RVI) values of the various radiometrically normalized images for the dike segment (normalized to the reference WorldView-2 image dated 14 July 2010). QB: QuickBird, WV2: WorldView-2, GE: GeoEye-1, IK: IKONOS, PL: Pléiades-1B (Pléiades: C CNES 2013, Distribution Airbus DS / Spot Image; Remaining images: (C) DigitalGlobe, Inc. All Rights Reserved). 118

Figure 5.10: Modified Simple Ratio (MSR) values of the various radiometrically normalized images for the dike segment (normalized to the reference WorldView-2 image dated 14 July 2010). QB: QuickBird, WV2: WorldView-2, GE: GeoEye-1, IK: IKONOS, PL: Pléiades-1B (Pléiades: C CNES 2013, Distribution Airbus DS / Spot Image; Remaining images: (C DigitalGlobe, Inc. All Rights Reserved). 119 
Figure 5.11: Green/Red Ratio (GRR) values of the various radiometrically normalized images for the dike segment (normalized to the reference WorldView-2 image dated 14 July 2010). QB: QuickBird, WV2: WorldView-2, GE: GeoEye-1, IK: IKONOS, PL: Pléiades-1B (Pléiades: (C CNES 2013, Distribution Airbus DS / Spot Image; Remaining images: (C) DigitalGlobe, Inc. All Rights Reserved) 120

Figure 5.12: Dot graphs showing the spectral behaviour of the adjusted RVI, MSR and GRR atmospherically corrected image products for four locations on the dike segment (Figure 5.5) and one verification invariant target (IT 32, Figure 5.3) for the six image time series.

Figure 5.13: Dot graphs showing the spectral behaviour of the RVI, MSR and GRR radiometrically normalized image products for four locations on the dike segment (Figure 5.5) and one verification invariant target (IT 32, Figure 5.3) for the six image time series. 122

Figure 5.14: Scatterplots of the radiometrically normalized RVI image products for (a) 9 April 2008 QuickBird versus 14 July 2010 WorldView-2 and (b) 24 March 2011 GeoEye-1 versus 14 July 2010 WorldView-2 125

Figure 5.15: The effects of spatial aggregation on spatial patterns in the reference 14 July 2010 WorldView-2 RVI image products, with a) original atmospherically corrected RVI image product at $2 \mathrm{~m}$ spatial resolution; b) RVI image product using atmospherically corrected image aggregated to $4 \mathrm{~m}$ spatial resolution using bilinear resampling and c) RVI image product using atmospherically corrected image aggregated to $8 \mathrm{~m}$ spatial resolution using cubic convolution resampling. Black line indicates general spatial pattern of the bottom of the dike segment being different from the rest of the dike segment. (C) DigitalGlobe, Inc. All Rights Reserved). 


\section{List of tables}

Table 1.1: Summary of key terms in Sections 1.1.3 Dike failure and 1.1.4 Dike inspection.

Table 1.2: Remote sensing research for dike inspection................................ 19

Table 1.3: Recent geophysical research for dikes......................................... 21

Table 1.4: Recent in- or on-dike sensor technology research for dikes........ 23

Table 2.1: Cover quality classes and assessment criteria used for this study (modified after Bakkenist et al., 2012a). (C) 2014 IEEE

Table 2.2: Summary of remote sensing measurements from 15 July 2010 $12 \mathrm{~h} 00$ to 16 July $201010 \mathrm{~h} 00$ (in local time). (C) 2014 IEEE. ...... 43

Table 2.3: Hyperspectral indices specifically mentioned in the results and discussion of this chapter. (C) 2014 IEEE.

Table 2.4: Correlation coefficients for selected data sets. Resistivity (mean) refers to the mean resistivity value for the top $0.5 \mathrm{~m}$. See Table A.1 for definitions of hyperspectral indices. (C) 2014 IEEE......... 46

Table 3.1: Details of sensors used in this chapter (in order of maximum band width from narrowest to broadest)

Table 3.2: Individual statistical measures per sensor for representative

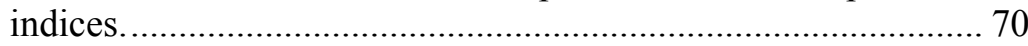

Table 4.1: $\quad$ Sensor characteristics of the ASD FieldSpec Pro spectrometer and WorldView-2 sensor................................................................ 83

Table 4.2: Summary of data sets, and their abbreviations, used in this

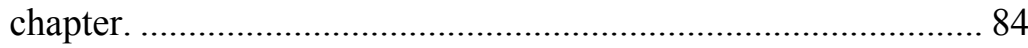

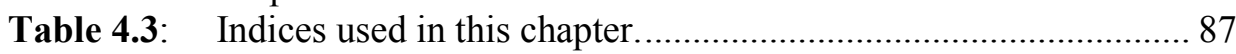

Table 4.4: Best-fit translation functions for correcting differences in spectral resolution between the ASD FieldSpec Pro and WorldView-2 sensors for grass cover of varying conditions, where $\mathrm{x}$ is the WorldView-2 value and y the ASD-equivalent value. 90

Table 4.5: Correlation coefficients to the indicators, with the Pearson correlation coefficient for the soil moisture indicator and the Spearman correlation coefficient for the ordinal cover quality

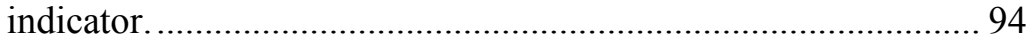

Table 5.1: ENVI FLAASH atmospheric correction module settings for images used in this chapter. 103

Table 5.2: Coefficients for linear relative radiometric normalization of the five subject images to the reference WorldView-2 image (dated 14 July 2010) obtained from 16 training invariant targets; $y=a+b x$ where $a$ is the intercept, $b$ is the slope, $x$ is the input subject image reflectance value and $y$ is the normalized reflectance value. .... 111

Table 5.3: Root mean square error (RMSE) and mean absolute error (MAE) for each band per image relative to the reference WorldView-2 image (dated 14 July 2010) obtained from 16 verification invariant 
targets for both the atmospherically corrected images and the radiometrically normalized images (expressed in reflectance).. 111

Table 5.4: Best-fit translation functions for correcting differences in spectral response functions between WorldView-2 and GeoEye-1, IKONOS, Pléiades-1B and QuickBird sensors for grass cover of varying conditions, where $y$ the WorldView-2-equivalent index value and $x$ is the subject sensor index value. 114 


\section{List of appendix tables}

Table A.1: Full list of hyperspectral indices used in Chapter 2. (C) 2014 IEEE.

Table A.2: The 48 indices selected based on whether applicable to at least three of the ten sensors investigated in Chapter 3

Table B.1: Mean values (per index) of the statistical measures for the ten sensors studied in Chapter 3, comparing index values generated from convolved narrow- and broadband data to index values obtained from original narrowband ASD data. 182

Table B.2: Individual values (per index) for the statistical measures for the ten sensors studied in Chapter 3, comparing index values generated from convolved narrow- and broadband data to index values obtained from original narrowband ASD data. 184

Table C.1: Pearson correlation coefficients between soil moisture indicator and index values for simulated data sets used in Chapter 3....... 192

Table C.2: Spearman correlation coefficients between cover quality indicator and index values for simulated data sets used in Chapter 3....... 193

Table D.1: Values for the three bivariate statistical measures for the ten indices investigated in Chapter 4, comparing index values generated from WorldView-2 simulated and image data to index values obtained from original narrowband ASD data. Data sets are defined in Table 4.2. 


\section{List of abbreviations and symbols}

\begin{tabular}{|c|c|}
\hline${ }_{1: 1} \mathrm{R}^{2}$ & $\begin{array}{l}\text { variant of coefficient of determination, calculated as a function } \\
\text { of the 1:1 line (Eq. 3.2) }\end{array}$ \\
\hline AHN & $\begin{array}{l}\text { Actueel Hoogtebestand Nederland [Actual Height model of the } \\
\text { Netherlands] }\end{array}$ \\
\hline ARI & Anthocyanin Reflectance Index \\
\hline ASD & $\begin{array}{l}\text { Analytical Spectral Devices; in this manuscript, usually used in } \\
\text { reference to data from the ASD FieldSpec Pro spectrometer }\end{array}$ \\
\hline $\mathrm{B}$ & blue (electromagnetic spectrum division; approx. 400-500 nm) \\
\hline $\mathrm{BRI}_{2}$ & Blue/Red Index 2 \\
\hline $\operatorname{ccR}^{2}$ & $\begin{array}{l}\text { square of correlation coefficient (variant of coefficient of } \\
\text { determination; Eq. 3.1) }\end{array}$ \\
\hline CIRIA & Construction Industry Research and Information Association \\
\hline $\mathrm{CPT}$ & cone penetration test \\
\hline $\mathrm{CRI}_{550}\left(/{ }_{700}\right)$ & Carotenoid Reflectance Index 1 (/ 2) \\
\hline $\mathrm{CTR}_{1}\left(/{ }_{2}\right)$ & Carter Index 1 (/ 2) \\
\hline DEM & digital elevation model \\
\hline $\mathrm{DN}$ & digital number \\
\hline DVI & Difference Vegetation Index \\
\hline EVI & Enhanced Vegetation Index \\
\hline FAO & Food and Agricultural Organization of the United Nations \\
\hline FLAASH & $\begin{array}{l}\text { Fast Line-of-sight Atmospheric Analysis of Hypercubes } \\
\text { (atmospheric correction software package) }\end{array}$ \\
\hline G & green (electromagnetic spectrum division; approx. $500-600 \mathrm{~nm}$ ) \\
\hline GE & GeoEye-1 \\
\hline GEMI & Global Environmental Monitoring Index \\
\hline GI & Greenness Index \\
\hline GIS & geographic information system \\
\hline $\mathrm{GM}_{2}$ & Gitelson and Merzlyak Index 2 \\
\hline $\operatorname{GRR}\left(/{ }_{2}\right)$ & Green/Red Ratio (/ 2) \\
\hline $\mathrm{IK}$ & IKONOS \\
\hline KNMI & $\begin{array}{l}\text { Koninklijk Nederlands Meteorologisch Instituut [The Royal } \\
\text { Netherlands Meteorological Institute] }\end{array}$ \\
\hline LAI & leaf area index \\
\hline MAE & mean absolute error (Eq. 5.2) \\
\hline $\mathrm{mNDVI}_{705}$ & Modified Red Edge Normalized Difference Vegetation Index \\
\hline
\end{tabular}

xxviii 


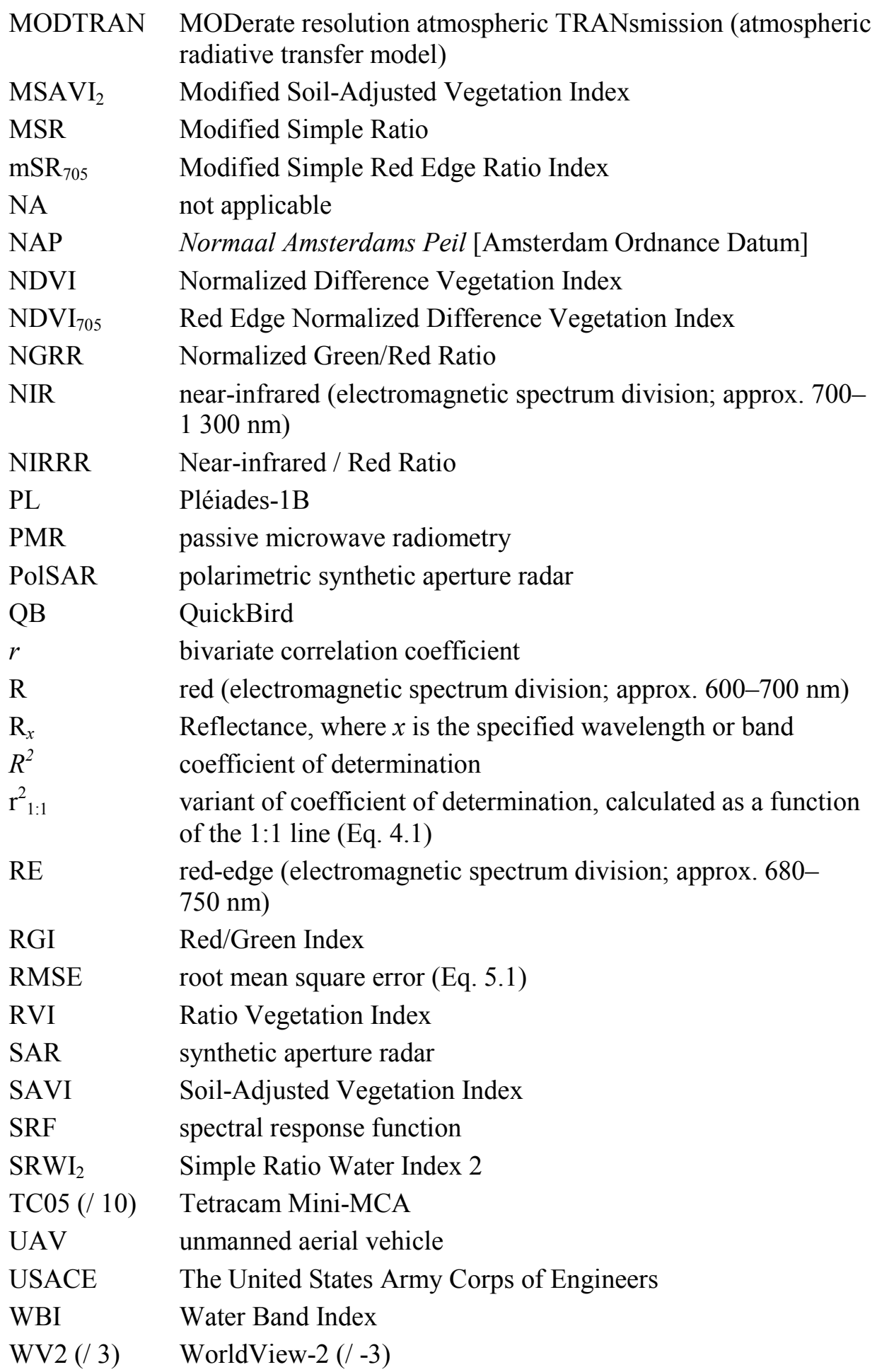




\section{Introduction}




\subsection{Background}

Dikes, which are also called levees or flood embankments, are common water defence structures and have formed part of flood defence systems since the earliest human settlements thousands of years ago. They are natural or manmade raised structures, such as along rivers or coasts. A peculiar form of flood protection also frequently called dike or levee, are the slopes of high areas around an excavated area forming a barrier for water, such as slopes along a pit or quarry. Raised structures consist of transported soil, rock, and man-made materials, while the topographical highs around excavated areas consist of the natural subsurface materials. The main purpose of dikes is to provide protection against inundation or flooding (CIRIA et al., 2013; Mayer, 2012; Mériaux and Royet, 2007). Dikes can be found in most countries worldwide, such as Bangladesh, Belgium, Brazil, Canada, China, Columbia, Czech Republic, France, Germany, Indonesia, Ireland, the Netherlands, Suriname, Taiwan, Thailand, the United Kingdom, the United States of America and Vietnam.

\subsubsection{A brief history of dikes}

Evidence of dikes has been found dating back to the Sumerian civilization in Mesopotamia, during the Uruk period (3800-3100 B.C.) (Algaze, 2001). Later, the city of Mari, built in about 2900 B.C. in the border area of Syria and Mesopotamia, was surrounded by a dike to protect it from floods (Margueron, 2003). The dike remained part of the city design until the city's destruction in about 1760 B.C. (Margueron, 2003; Viollet, 2007). The city of Harappa of the Indus Valley civilization was at its peak around 2300 B.C., where dikes and walls protected the city against floods (Frazee, 1997). Around 2100 B.C. in China, Gun (the father of $\mathrm{Yu}$ the Great) is said to have built dikes along the banks of the Huang He (Yellow River) to control flooding, which unfortunately failed (Viollet, 2007). In the second millennium B.C., Egypt expanded their irrigations schemes, which included dike construction (Viollet, 2007). As early as the Ur III period (2047-1940 B.C.), a 'dike manager' is mentioned in a letter dated from that period found in the Sumer city of Kish, Mesopotamia (Cole and Gasche, 1998).

Hammurabi, the Babylonian king who reigned circa 1792-1750 B.C. and whose empire controlled all of Mesopotamia, built a dike around Sippar (Abū Habbah) by mounding up earth around the city. During the reign of his son, a dike was also constructed around the neighbouring city of Sippar-Amnānum (Tell ed-Dēr). Letters to Zimri-Lìm, King of Mari and a contemporary of Hammurabi, report on the reinforcing of dikes in the region of Mari in anticipation of the Euphrates and Habūr rivers flooding (Cole and Gasche, 
1998). Hammurabi even included an edict requiring citizens to maintain their dikes in The Code of Hammurabi (Babylonian laws):

$\S 53$ - If a man neglect to strengthen his dyke and do not strengthen it, and a break be made in his dyke and the water carry away the farm-land, the man in whose dyke the break has been made shall restore the grain which he has damaged (Harper, 1904, p. 29).

The construction of dikes spread from these ancient centres of civilization as trade and travel increased and as empires arose and expanded (for example the Roman Republic and Empire, circa 500 B.C. - A.D. 500). In addition, more isolated populations also developed dike construction as their need and technical development increased. In the Middle Ages, dikes were constructed in western Europe with dikes being built in the $11^{\text {th }}$ century A.D. in the Rhine and Meuse Delta of the Netherlands (Knol, 1991 as cited in Nienhuis, 2008, p. 40) and in the north-western coastal region of Germany and the Netherlands (Bagus, 2006; Ey, 2005). In the United States of America, dikes for flood prevention were introduced in the mid to late $19^{\text {th }}$ century (FEMA, 2012). To this day, dikes continue to be built, utilized, reconstructed, reinforced and maintained in the regions of ancient and new civilizations.

\subsubsection{Dikes today}

Throughout the following three sections (i.e., Sections 1.1.2, 1.1.3 and 1.1.4) extensive use has been made of The International Levee Handbook (CIRIA et al., 2013) and various reports and documents. Although most of these documents are not scientific documents but rather technical reports, the contributors to these documents are leading experts in their respective fields and countries relating to dikes.

Dikes are increasingly becoming structures of major importance and concern due to the expected consequences of climate change (such as sea level rise and more extreme weather events) and of subsidence (CIRIA et al., 2013; Mayer, 2012). With $10 \%$ of the world population living in the Low Elevation Coastal Zone (i.e., less than $10 \mathrm{~m}$ above sea level) (McGranahan et al., 2007), often in subsiding sedimentary areas, dikes are critical barriers against storm surges, sea level rise and flooding by rivers. The failure of a dike can result not only in substantial economical and infrastructural losses but also in significant loss of lives. It is therefore essential that dikes are monitored for weaknesses and kept in optimal condition (van Westen, 2005).

Three types of dikes are often referred to depending on the environment in which the dike is located. The first two are sea dikes and river dikes, which are 
the main types of dikes. The third encompasses all other kinds of dikes. Sea dikes are usually located perpendicular to the incoming water with gentler waterside slopes to reduce wave run-up and erosion. River dikes are generally parallel to the flow-direction of the water and often have steeper waterside and gentler landside slopes. Other kinds of dikes include dikes which provide a secondary line of defence (either perpendicular or parallel to the incoming water), canal dikes, lake dikes, and closed protection, ring or polder dikes. The environment of the dike will determine the design of the dike.

Modern raised structure dikes are constructed following specific engineering principles, where the composition and structure is known. Nevertheless, dikes are often built with locally available materials which may not be ideal and on alluvial or estuarine plains with soft soils (e.g., peat) which are prone to settlement (subsidence). However, the majority of dikes have been in place for a long time and may have been built up over tens or even hundreds of years. These dikes are typically composed of multiple materials, often in layers as they have been added with materials on hand. Usually, the composition of these dikes is unknown, unless a specific site investigation has taken place (e.g., van Geel et al., 1983).

A peculiar form of dike exists in that the dike is not constructed per se but rather what remains of the original in situ earth material after surrounding materials have been removed, subsided or compacted. Examples of such dikes can be found in the Netherlands, where the in situ earth material is predominately peat (see Section 1.4). This specific form of dike is under investigation in this thesis. Since its composition and relation to the landscape is different from other forms of dikes, the results in this thesis are specifically for in situ peat dikes. It is possible that results can be extrapolated to other dike forms with a grass cover but that has not been tested in this thesis.

The principal functional components of raised structure dikes are crest, soil or rock foundation and earthfill (consisting of transported soil and/or rock, and which may include other materials such as rubble; Figure 1.1a). The principal functional components of in situ dike structures are crest and soil or rock foundation, where the "earthfill" component is merely in situ earth material continuous with the foundation (Figure 1.1b). Depending on the type of dike (based on its environment, see above), its expected loads, the foundation and earthfill, further possible components for a dike could include revetment (protective cover), berm, trench or ditch (Figure 1.1), impermeable core or mask, filter layer, wall, and drainage and seepage system (CIRIA et al., 2013; Mayer, 2012; Moser et al., 2008a). Grass cover is one of the most common forms of surface cover or revetment on dikes (CIRIA et al., 2013; Mériaux and Royet, 2007; Muijs, 1999), where it protects against external erosion, inhibits 
infiltration and the roots help prevent sliding (CIRIA et al., 2013). Further terms, which refer to non-functional parts of a dike, are slope, toe, water level, waterside and landside (Figure 1.1).

Although the primary function of dikes is flood protection, they typically also have other functions which may impact on this primary function. These multifunctional roles include access and transportation (especially important for evacuation during flooding), recreation, agriculture, utility crossings, housing and (small) industry, and environmental and ecological provisions (CIRIA et al., 2013; Bezuijen et al., 2011).

Waterside Landside

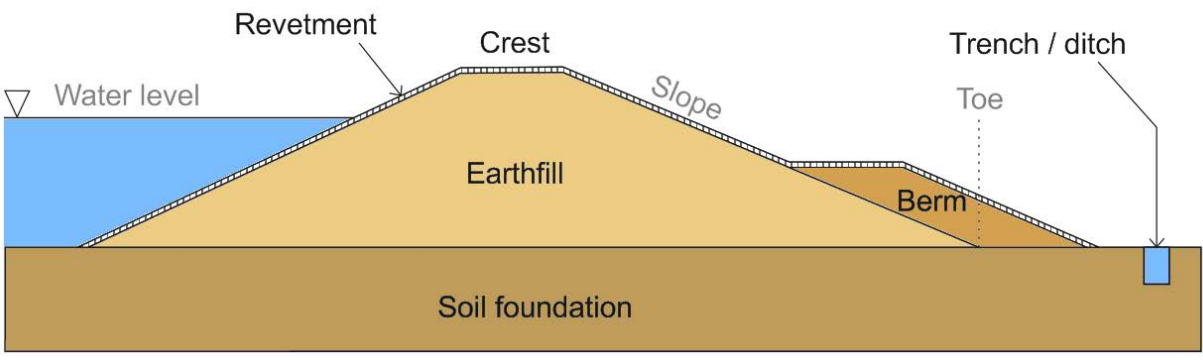

(a) Raised structure dike

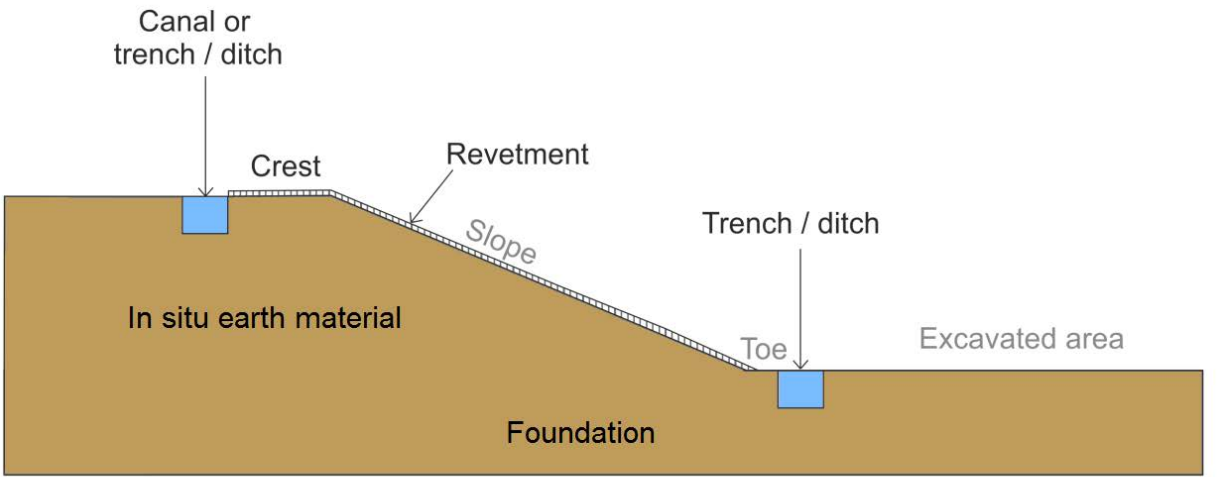

(b) In situ dike

Figure 1.1: Simplified cross-sections of (a) a raised structure dike (modified after CIRIA et al., 2013) and (b) an in situ dike, showing basic functional (black text) and non-functional (grey text) components. 


\subsubsection{Dike failure}

Before discussing dike failure it is necessary to introduce the dike system. A dike system is generally made up of both dikes and other structures, such as dunes, sluice gates, spillways, walls, pumping stations, etc. Since the main function of the system is flood risk reduction, the failure of the system can be defined as the unintentional inundation of the protected area. The system can fail due to the failure of any of its elements (e.g., dike, wall, spillway, etc.). There are two types of failure that can result in the failure of the dike system. Hydraulic failure occurs when water enters the protected area without the element itself being damaged beforehand. This can happen when there is overflow or overtopping of a dike or when there is through- or under-flow of a dike. Structural failure occurs when damages to one or more elements result in a breach of the system. One type of failure can induce the other. For example, structural failure such as settlement (subsidence) can result in hydraulic failure due to water flowing over the top of the lowered crest and hydraulic failure due to through-flow or seepage can result in structural failure by internal erosion and then to breach.

For the dike itself, a failure is defined as "the inability to achieve a defined performance threshold (response to a given loading) or performance indicator, for a given function" (CIRIA et al., 2013, p.156), that is, the dike is unable to satisfy its functional criteria (Moser and Zomer, 2006; Schelfhout, 2011). Failure can be either a gradual decline (deterioration) or a sudden decline (break) of a component such that it is no longer able to achieve its function (CIRIA et al., 2013).A dike can fail without breaching. For example, if water enters the protected area (by through-flow, overflow or overtopping of the dike) then the dike has failed (CIRIA et al., 2013; Schelfhout, 2011).

A summary of the key terms presented in the following paragraphs is given in Table 1.1.

The chain of events and processes leading to dike failure can be complex and multi-relational (Figure 1.2). The chain is activated by initiators and aggravated by contributing factors (Table 1.1). These both include currents, waves, tides, wind, precipitation, runoff, high water levels, high rates of flow, human and animal activities, seepage, loading and unloading, roots of woody vegetation, decline of material properties, settlement/subsidence, sea level rise, impacts and seismic activity (Allsop et al., 2007; CIRIA et al., 2013). While most of these initiators and factors are external in origin, it should be noted that the earthfill and foundation materials of the dike itself are subject to decline over time. 


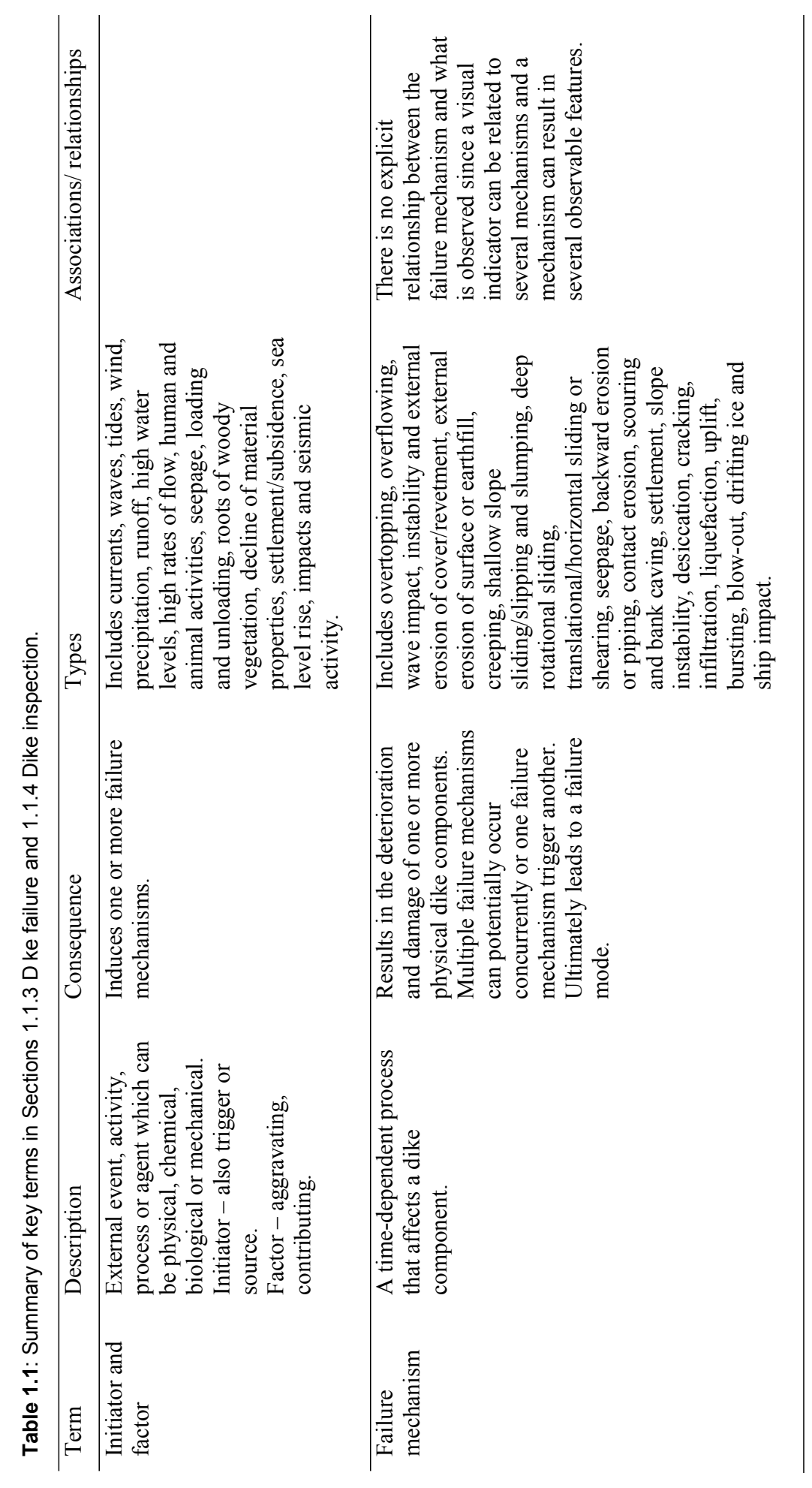




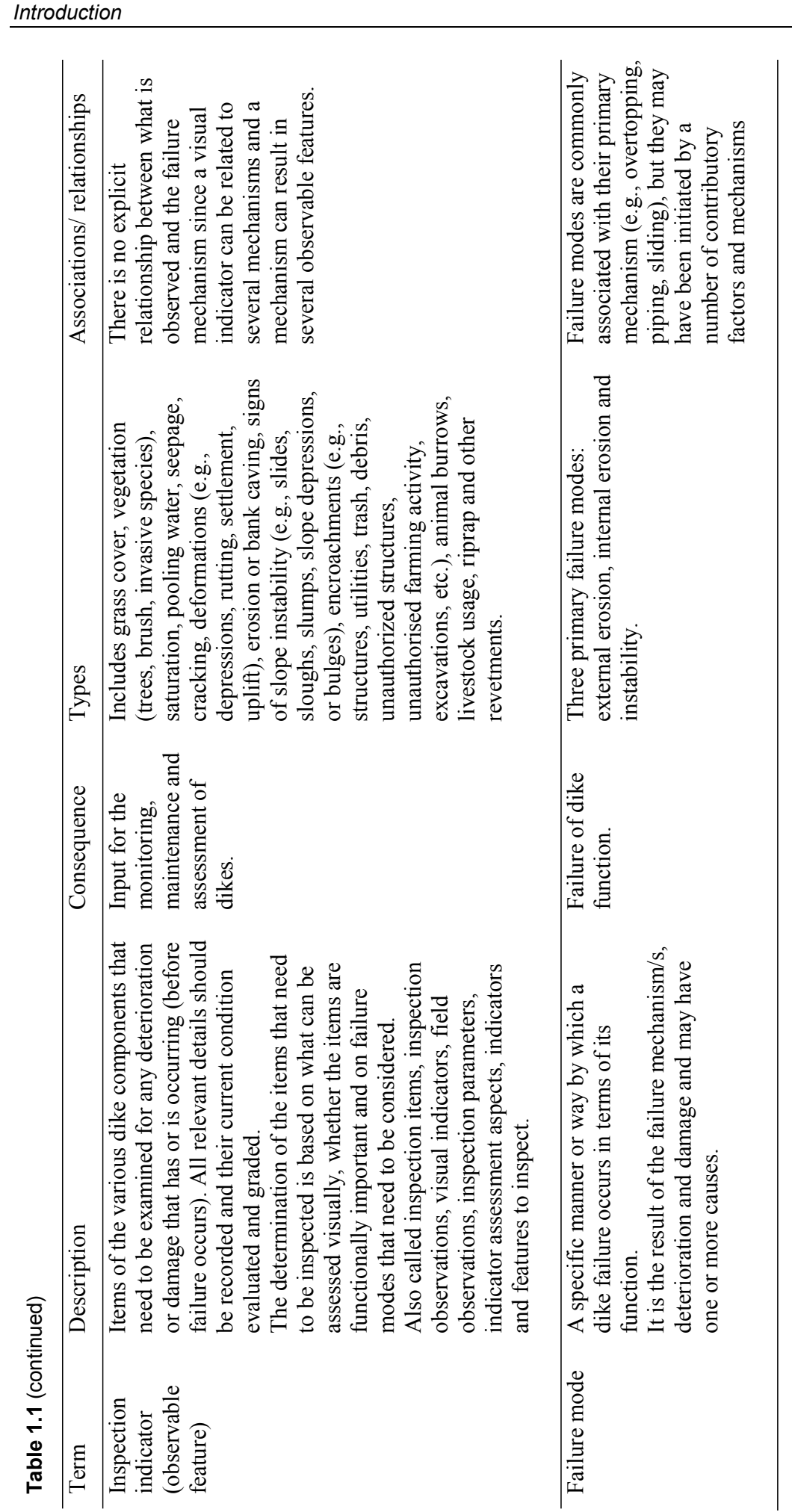




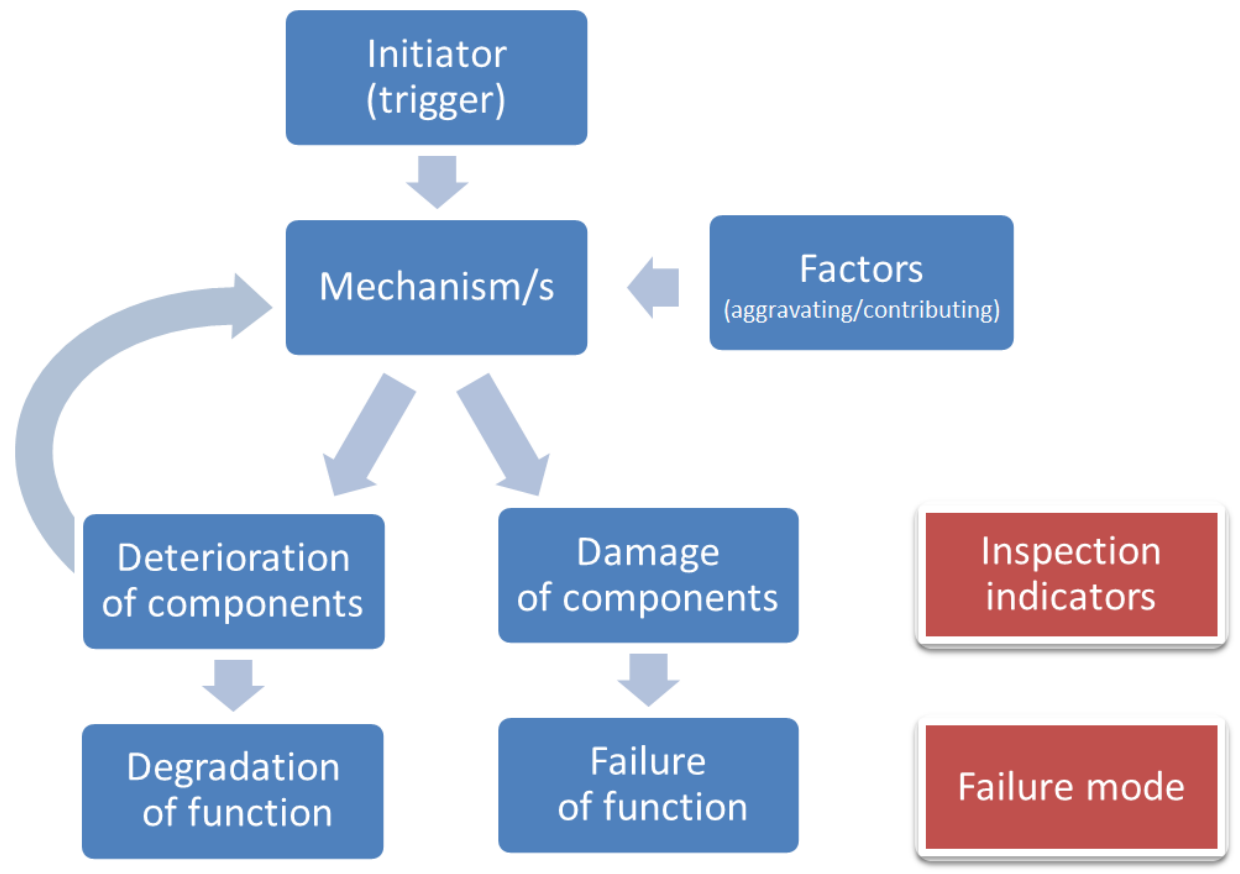

Figure 1.2: Dike failure chain, with key terms and processes (modified after CIRIA et al., 2013: Fig 3.163 \& 3.166 by R. Tourment).

In particular, being organic, peat decomposes or rots via oxidation notably when exposed to surface processes or percolating oxygen bearing gas or water, resulting in weight and height reduction of the dike. The initiators and/or factors, such as those listed above, induce one or more failure mechanisms.

A failure mechanism (Figure 1.2 and Table 1.1) is a time-dependent process that results in the deterioration or damage of one or more physical dike components and ultimately leads to a failure mode (see Figure 1.2 and Table 1.1). There are a wide range of failure mechanisms, which include overtopping, overflowing, wave impact, instability and external erosion of cover/revetment, external erosion of surface or earthfill, creeping, shallow slope sliding/slipping and slumping, deep rotational sliding, translational/horizontal sliding or shearing, seepage, backward erosion or piping, contact erosion, scouring and bank caving, settlement, slope instability, desiccation, cracking, infiltration, liquefaction, uplift, bursting, blow-out, drifting ice and ship impact (Allsop et al., 2007; CIRIA et al., 2013; Moser and Zomer, 2006; Schelfhout, 2011). For peat dikes, common failure mechanisms are translational/horizontal sliding or shearing, creeping or shallow slope sliding, deep rotational sliding, settlement, desiccation, cracking, infiltration, uplift and bursting (Bezuijen et 
al., 2011; CIRIA et al., 2013; Moser et al., 2008a; Schelfhout, 2011; van Baars, 2005). Several common failure mechanisms, including those associated with peat dikes, are illustrated in Figure 1.3.

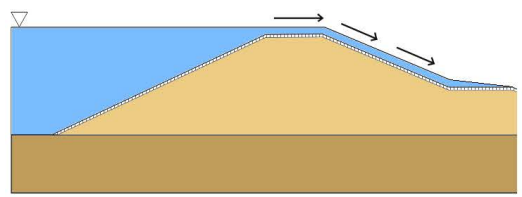

(a) Overflow

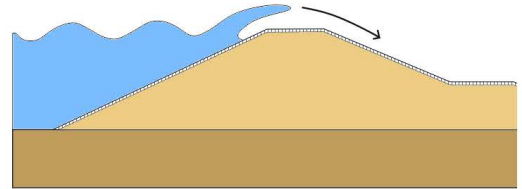

(c) Overtopping

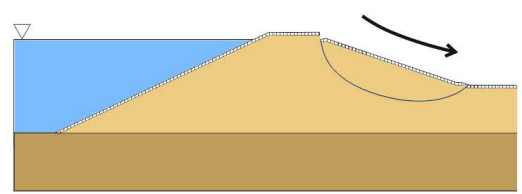

(e) Shallow sliding

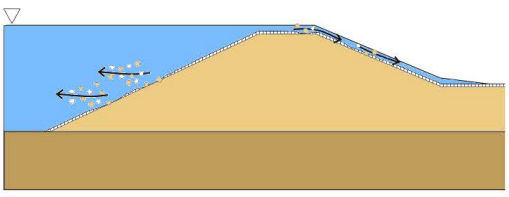

(g) External erosion

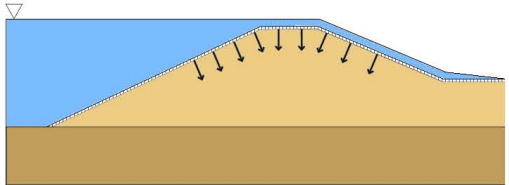

(i) Infiltration

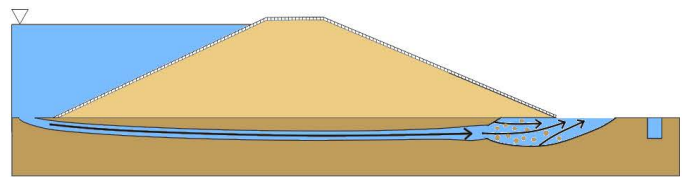

(b) Piping and backward erosion

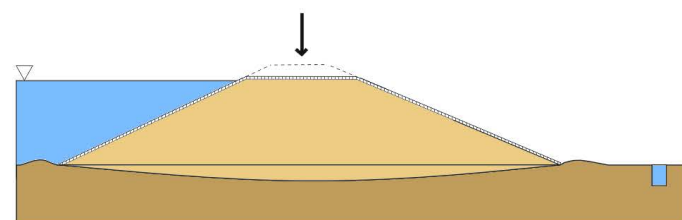

(d) Settlement

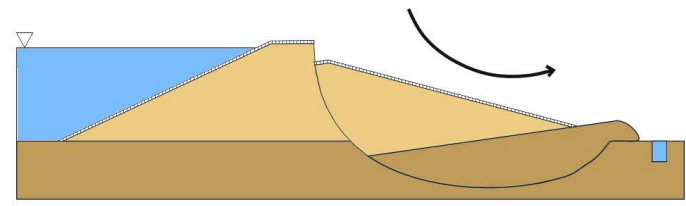

(f) Deep rotational sliding

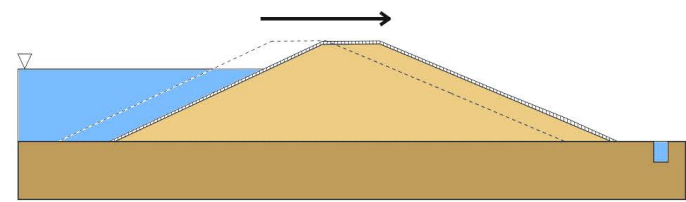

(h) Translational sliding

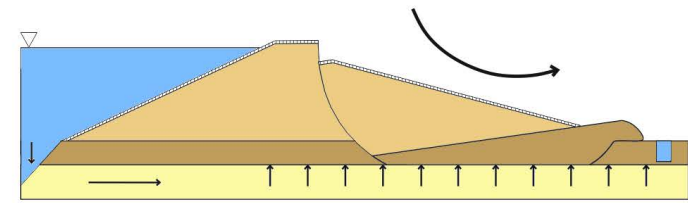

(j) Uplift

Figure 1.3: Sketches illustrating various failure mechanisms (modified after Allsop et al., 2007; CIRIA et al., 2013; Moser and Zomer, 2006; Schelfhout, 2011). Thin arrows represent water flows and under-pressures while thick arrows represent movements of dike earthfill or foundations. Dashed lines indicate dike cross-section prior to failure mechanism. Dike components are labelled in Figure 1.1. 
Deterioration of a dike component (Figure 1.2) is the gradual decline in the component's structural or physical properties. Severe deterioration is referred to as damage and requires immediate repair or emergency action. Deterioration and damage manifest in observable features (inspection indicators; see Section 1.1.4, Figure 1.2 and Table 1.1) such as cracks or fissures, depressions, ruts, slides, slumps, pooling water and lack of vegetation (CIRIA et al., 2013; Moser and Zomer, 2006). There is no explicit relationship between what is observed and the failure mechanism since a visual indicator can be related to several mechanisms and a mechanism can result in several observable features. Deterioration or damage of a dike component can aggravate a failure mechanism or initiate additional failure mechanisms.

Deterioration or damage of a dike component results in the degradation or failure of one or more of its functions (Figure 1.2). The relations between components and functions can be multiple. A dike function is classified as degraded or failed depending on pre-determined thresholds. The specific manner or way by which a dike failure occurs in terms of its function is called the failure mode (Table 1.1). There are three primary failure modes, namely external erosion, internal erosion and instability. Failure modes are commonly associated with their primary mechanism (e.g., overtopping, piping, sliding), but they may have been initiated by a number of contributory factors and mechanisms (CIRIA et al., 2013; Mériaux and Royet, 2007). Circumstances leading to the structural failure of a dike can be complex, with multiple failure mechanisms potentially occurring concurrently or one failure mechanism triggering another. Deterioration and damages can also result in dike breach, which is failure of the hydraulic function of the dike.

\subsubsection{Dike inspection}

Since dike structures can be susceptible to deterioration and the consequences of their failure potentially catastrophic, dikes need to be inspected regularly to ensure they remain reliable and functioning. Dike inspections provide valuable data input for monitoring, maintenance and assessment of dikes (CIRIA et al., 2013; Mériaux and Royet, 2007; Moser et al., 2008b). Dike inspection involves observing if any deterioration or damage has or is occurring (before failure occurs) and recording all relevant details (Bakkenist et al., 2012a; CIRIA et al., 2013; Moser et al., 2008b). Dike inspection procedures, regulations and processes (including objectives, frequency, types, criteria and grading) vary between (and even within) countries (Bakkenist et al., 2012a; CIRIA et al., 2013; Mériaux and Royet, 2007). Inspections are normally conducted on a regular and recurring basis, and may be conducted relative to a loading event or season (Bakkenist et al., 2012a; CIRIA et al., 2013). 
Dike inspections are generally done by visual examination of all components of the dike, ideally on foot (CIRIA et al., 2013; Environment Agency, 2006; Moser et al., 2008a; Perri et al., 2014; Radzicki, 2014). These visual inspections consist of observing the various components of the dike and recording details for indicators of deterioration and damage (CIRIA et al., 2013; Moser et al., 2008b; Mériaux and Royet, 2007). This may lead to more detailed or specialist investigations and measurements or the installation of instruments to provide information necessary for proper assessment. These could include topographical, geometric, geotechnical, geophysical, morphological hydraulic and hydrological investigations and could be either intrusive or non-intrusive (Bakkenist et al., 2012a; CIRIA et al., 2013; Environment Agency, 2006).

Dike inspections usually involve the observation of items along a dike (Table 1.1), and the evaluation and grading of their current condition. The determination of the items that need to be inspected is based on what can be assessed visually, whether the items are functionally important and on failure modes that need to be considered (CIRIA et al., 2013; Moser et al., 2008a). A variety of terms are used by different countries and agencies (sometimes interchangeably) and include inspection indicators (Bakkenist et al., 2012b), inspection items (USACE, 2008), inspection observations, visual indicators, field observations (CIRIA et al., 2013), inspection parameters, indicator assessment aspects (Moser et al., 2008a), indicators (Mériaux and Royet, 2007; Moser et al., 2008a) and features to inspect (Mériaux and Royet, 2007). In this thesis, the term 'inspection indicator' will generally be used.

Items to be checked or considered during an inspection include (but are not limited to) grass cover, vegetation (trees, brush, invasive species), saturation, pooling water, seepage, cracking, deformations (e.g., depressions, rutting, settlement, uplift), erosion or bank caving, signs of slope instability (e.g., slides, slumps, sloughs, slope depressions, or bulges), encroachments (e.g., structures, utilities, trash, debris, unauthorized structures, unauthorised farming activity, excavations, etc.), animal burrows, livestock usage, riprap and other revetments, etc. (Bakkenist et al., 2012b; CIRIA et al., 2013; Environment Agency, 2006; Mériaux and Royet, 2007; Moser et al., 2008a; USACE, 2008; USACE, 2006).

\subsubsection{Remote sensing for dike inspection}

The number of dikes in the world is immense. There are some $260000 \mathrm{~km}$ of dikes in China (Zhang, 2001) and more than $150000 \mathrm{~km}$ of dikes in the United States of America (Aanstoos et al., 2012). Even in the smaller countries of France, Poland and Vietnam, there are some $8000 \mathrm{~km}$ (Mériaux and Royet, 2007), about $8500 \mathrm{~km}$ (Radzicki, 2014) and over $3000 \mathrm{~km}$ (Hillen et al., 2010) 
of dikes respectively. In the small country of the Netherlands alone, there are about $17200 \mathrm{~km}$ of dikes (Knoeff et al., 2008; van Baars, 2004). Visual inspection of these thousands of kilometres of dikes on foot is clearly a slow, costly and time-consuming process which can be limited by accessibility, especially during times of flooding.

Remote sensing has been proposed as a tool that could facilitate faster dike inspection (Bishop et al., 2003; Givehchi et al., 2002; Kühn and Brose, 1998; van der Schrier et al., 2004), since large areas can be covered in a relatively short space of time and measurements are not subjective. However, it should be noted that the use of remote sensing data is envisaged to complement rather than replace traditional visual inspection. Remote sensing data could be used to identify locations where further inspection should be focused, thereby streamlining and improving the inspection process.

\subsubsection{Remote sensing fundamentals}

Remote sensing, in its broadest sense, is the acquisition of information from a distance without making physical contact. In a more restricted sense, remote sensing traditionally refers to the acquisition of information by means of reflected or emitted electromagnetic radiation (Campbell, 2002; Lillesand et al., 2008; White, 1977). This excludes most of the methods usually associated with geophysics (which are often associated with fields) such as gravimetric and magnetic methods, as well as other methods such as sonar. For the purpose of this research, remote sensing is further limited to the observation of the earth's land and water surfaces. This excludes other applications such as meteorological, extraterrestrial and medical.

The remainder of this section is predominately based on information from Campbell (2002) and Lillesand et al. (2008), with additional information obtained from Canada Centre for Remote Sensing (2007).

Electromagnetic radiation is a form of energy which classically consists of electromagnetic waves. Electromagnetic waves are synchronized transverse oscillations of electric and magnetic fields that propagate at the speed of light (c). That is, the electric and magnetic fields are at right angles to each other and perpendicular to the direction of motion. The orientation of the electric field, or polarization of radiation, is important when discussing microwave radiation (defined in following paragraph). There are three characteristics of electromagnetic waves that are particularly important for remote sensing. These are wavelength, frequency and amplitude. Wavelength $(\lambda)$ is the length of one wave cycle and is measured as the distance from one wave crest to the next (usually in metres or a factor thereof). For remote sensing, the units are often in 
micro- or nanometres because the distances are so small. Frequency $(v)$ is measured as the number of crests passing a fixed point per unit of time and is usually measured in hertz ( $\mathrm{Hz}$, cycles per second) or a factor thereof. Wavelength and frequency are inversely related and thus either term can be used to characterise a wave. Amplitude is the maximum displacement (e.g., height of each peak) from the equilibrium (or resting) point and is related to the amount of energy being transported by the wave. While electromagnetic radiation can be described by wave theory, it has a dual nature and can also be described by particle theory, where electromagnetic radiation is described in terms of discrete units or particles called photons. In particle theory, energy is related to frequency or wavelength. In remote sensing, energy levels are often rather reported as spectral irradiance (in $\mathrm{W} \cdot \mathrm{m}^{-2} \cdot \mathrm{nm}^{-1}$ ).

The electromagnetic spectrum is the entire range of wavelengths or frequencies over which electromagnetic radiation extends (Figure 1.4). Since the spectrum is a continuum, subdivisions of the spectrum are used for convenience and are somewhat arbitrarily defined. Divisions have grown out of traditions within different disciplines and thus may have different definitions. In general, the major divisions of the electromagnetic spectrum (Figure 1.4) can be defined as gamma rays (less than $0.03 \mathrm{~nm})$, x-rays $(0.03 \mathrm{~nm}$ to $10 \mathrm{~nm})$, ultraviolet $(10 \mathrm{~nm}$ to $400 \mathrm{~nm}$ ), visible (blue: $400 \mathrm{~nm}$ to $500 \mathrm{~nm}$; green: $500 \mathrm{~nm}$ to $600 \mathrm{~nm}$; red: $600 \mathrm{~nm}$ to $700 \mathrm{~nm}$ ), red-edge $(680 \mathrm{~nm}$ to $750 \mathrm{~nm}$ ); infrared (near: $700 \mathrm{~nm}$ to $1300 \mathrm{~nm}$ or sometimes $3000 \mathrm{~nm}$; mid: $1300 \mathrm{~nm}$ to $3000 \mathrm{~nm}$ or sometimes $3000 \mathrm{~nm}$ to $8000 \mathrm{~nm}$; thermal: $3000 \mathrm{~nm}$ to $14000 \mathrm{~nm}$ or sometimes $8000 \mathrm{~nm}$ to $15000 \mathrm{~nm}$; Far: $14000 \mathrm{~nm}$ to $1 \mathrm{~mm})$, microwaves $(1 \mathrm{~mm}$ to $1 \mathrm{~m})$ and radio waves (greater than $30 \mathrm{~cm}$, overlapping with microwaves). Three other categories of the electromagnetic spectrum are often used in remote sensing. The first category is optical, which is generally from $300 \mathrm{~nm}$ to $14000 \mathrm{~nm}$. The other two categories are related and are reflected $(400 \mathrm{~nm}$ to $3000 \mathrm{~nm})$ and emitted (greater than $3000 \mathrm{~nm}$ ).

Remote sensing involves many elements and processes (Figure 1.5). The two main processes are data acquisition (Figure 1.5A-E) and data analysis (Figure 1.5F-G). The first element of data acquisition is the source of the electromagnetic energy (Figure 1.5A). This is usually the sun (i.e., for passive remote sensing systems), but may also be from the sensing system itself (i.e., for active remote sensing systems). As the energy passes though the atmosphere, the atmosphere interacts with the energy (Figure 1.5B) resulting in scattering and absorption of energy. This is valid both for when the energy travels from the source to the target and from the target to the sensor. Scattering is caused by particles and gases in the atmosphere and is dependent on the size of particle or gas molecule, the wavelength of the energy, the abundance of 
particles or gases and the distance the energy travels through the atmosphere (path length). Absorption is caused by gases in the atmosphere and effectively results in the loss of energy to these molecules. A specific gas absorbs energy in specific wavelengths. The wavelengths where there is the least atmospheric absorption (i.e., the most atmospheric transmittance or the most energy passes through the atmosphere) are called atmospheric windows. Earth observation sensors are designed to detect and record energy in the wavelengths associated with these atmospheric windows.

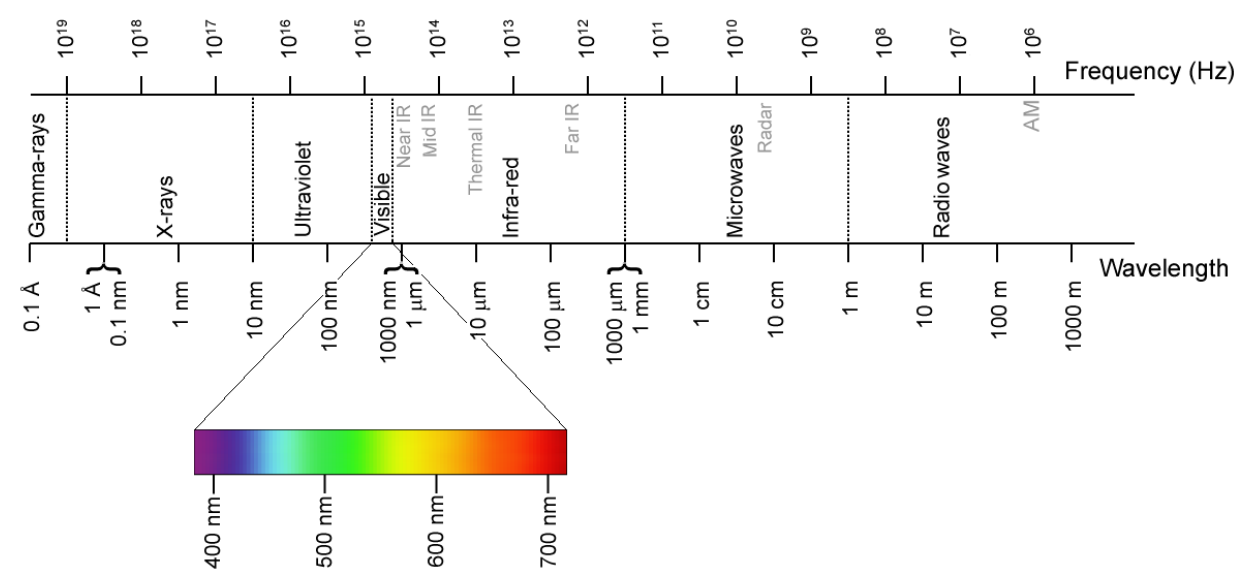

Figure 1.4: The electromagnetic spectrum showing general major divisions (modified after Blacus, 2012).

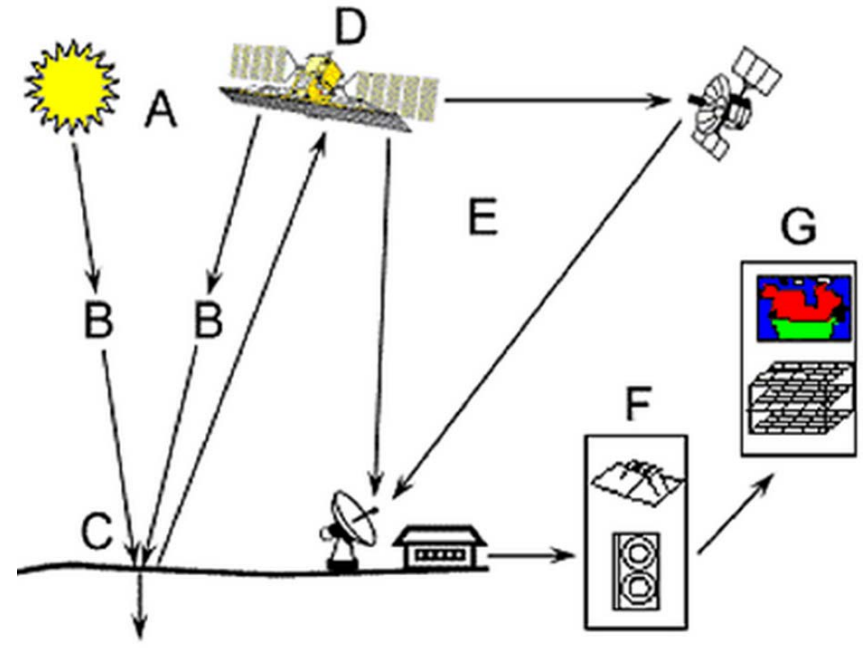

(c) CCRS / CCT

Figure 1.5: The remote sensing process. A: energy source, B: atmospheric interactions, C: interactions with target, D: recording of energy by sensor, E: transmission, reception and processing, F: interpretation and analysis, G: application (Source: Canada Centre for Remote Sensing, 2007). 
The electromagnetic energy that reaches the earth's surface is reflected, absorbed or transmitted (Figure 1.5C). Reflection occurs when the energy is redirected unchanged when it strikes the target. Remote sensing is mostly concerned with measuring this reflected energy. There are two extremes in the way energy is reflected from a target and these surfaces are referred to as specular reflectors (which redirect all energy in a single direction) or diffuse reflectors (which redirect energy equally in all directions, the so called Lambertian surface). Most target surfaces lie somewhere between these two extremes. Reflectance is the ratio of energy reflected to that striking the target (incident energy). Absorption occurs when energy is absorbed by the target through electron or molecular reactions. The energy may be re-emitted, usually at longer wavelengths (e.g., thermal infrared) and this is also of interest for remote sensing as the strength and wavelength of the emitted radiation is largely a function of the temperature and material attributes of the target. Transmission occurs when energy passes through the target. The proportions of reflected, absorbed or transmitted energy will vary depending primarily on the wavelength of the energy and on the target's material type and condition. It is the proportion of reflected energy for each wavelength that gives targets their distinctive spectral response, which is sometimes referred to as their spectral signature (Figure 1.6).

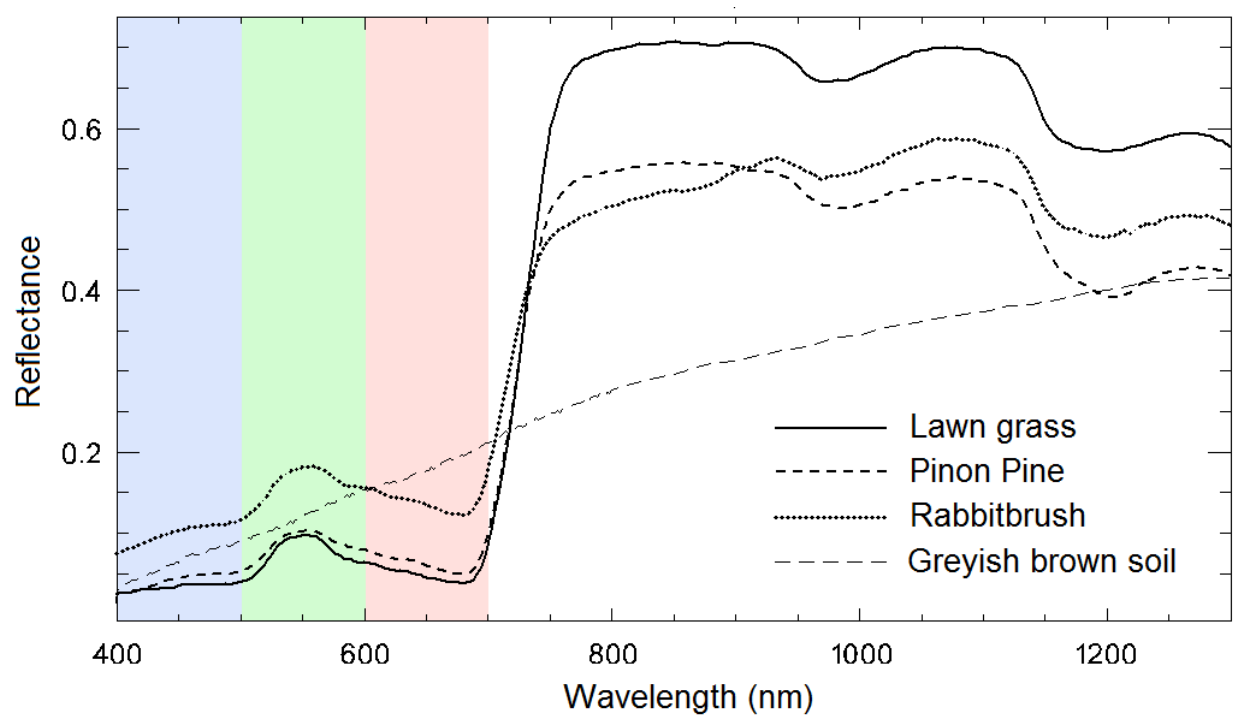

Figure 1.6: Spectral reflectance curves for three types of vegetation and one soil type showing their distinctive spectral signatures. The broad spectral regions of blue, green and red are shaded accordingly, with the near-infrared without shading. (Data from John Hopkins University Spectral Library provided by Jack Salisbury). 
The reflected or emitted electromagnetic energy from a target is recorded by the sensing system (Figure 1.5D). The sensing system is mounted on a platform which can be ground-based (e.g., tripod, crane), airborne (e.g., airplane, unmanned aerial vehicle) or space-borne (e.g., satellite, space shuttle). A platform may carry multiple sensors. Sensors have many characteristics which can be used to categorise and distinguish them. Perhaps the most obvious characteristic is to which part of the electromagnetic spectrum is the sensor sensitive (e.g., visible, near-infrared, thermal, microwave). Another characteristic is whether the sensor records data for a single range (or band) of wavelengths (i.e., panchromatic), multiple, discrete bands (i.e., multispectral) or numerous, (almost) contiguous bands (i.e., hyperspectral). This is linked to the spectral resolution of the sensor, which deals with the width and position of each spectral band. Other characteristics include spatial resolution (the level of spatial detail), radiometric resolution (sensitivity to energy intensity/brightness), temporal resolution (revisit time), scanning type (along or across track), swath (width of surface imaged), etc. A sensor usually detects the electromagnetic energy electronically (although photographic film may still be used). These electronic signals are stored by the sensing system as data, which is often in a digital image form.

Data recorded by sensors on satellite platforms need to be transmitted electronically down to the earth's surface (Figure 1.5E). This may be either directly to a ground receiving station or via a communications satellite. Data recorded by sensors on ground-based or airborne platforms can be retrieved relatively easily, either directly or once the aircraft has landed. The technologies used for satellite platforms can also be used for the other platforms should urgency require it or should the data need to be sent to a processing centre. Usually some processing (often called pre-processing, e.g., systematic, radiometric and geometric corrections) is required to get the data in a usable form and is the final step in the data acquisition process.

The first stage of the data analysis process is interpretation and analysis of the data in order to extract information (Figure 1.5F). This may be done manually by visual interpretation or digitally. Digital processing, interpretation and analysis can be relatively simple or highly complex and can include enhancements (e.g., filtering), transformations (e.g., indices), classifications, and data integration. Information is often extracted using a combination of many digital and manual processes. Finally, the information is used for an application to solve practical problems or help in decision making (Figure 1.5G). 


\subsubsection{Remote sensing research for dike inspection}

Over the last decade, there have been several studies on remote sensing for dike inspection, monitoring and assessment. The studies are largely motivated by this idea of providing a screening process which is faster than manual visual inspection, since remote sensing can cover large areas in a relatively short time. These studies have largely focused on deformation, slides and seepage (see Table 1.2 for summary). Both LiDAR (Bishop et al., 2003; Haarbrink and Shutko, 2008; Moser and Zomer, 2006; Royet et al., 2013) and synthetic aperture radar (SAR) (Closson et al., 2003; Hanssen and van Leijen, 2008; Jones et al., 2011; Jones et al., 2012; Lv et al., 2013) have been investigated for deformation detection on dikes. Both LiDAR (airborne) and radar interferometry (satellite borne) are offered commercially for dike deformation detection. The detection and prediction of shallow surficial failures or slough slides are the focus of a number of on-going studies. Along the Mississippi River, anomalous vegetation is associated with probable slide-affected areas (Hossain and Easson, 2012; Hossain et al., 2006). Satellite multispectral imagery has been used to develop a slide detection model (Hossain et al., 2006) and airborne hyperspectral imagery has been used to develop a slide prediction model (Hossain and Easson, 2012). Polarimetric SAR imagery (both from airborne and satellite platforms) is being investigated for slide detection to aid in the dike screening process and thus far appears to be promising (Aanstoos et al., 2012; Aanstoos et al., 2011; Aanstoos et al., 2010; Dabbiru et al., 2012; Dabbiru et al., 2014; Lee et al., 2012). In addition, polarimetric SAR also shows potential for the prediction of slides (Sehat et al., 2014a; Sehat et al., 2014b). Research on seepage detection with remote sensing has taken diverse approaches. Passive microwave radiometry (PMR) is sensitive to soil moisture and has been used for monitoring soil moisture condition in dikes (Haarbrink and Shutko, 2006; Swart, 2007). Nevertheless low spatial resolution and complex calibration and interpretation (especially for vegetated surfaces) remain issues (Lillesand et al., 2008; Shutko et al., 2006; Swart, 2007). SAR operates in the same range of wavelengths as PMR and is thus likewise sensitive to soil moisture (Aanstoos et al., 2010) but also experiences problems with vegetated surfaces (Mahrooghy et al., 2011). Polarimetric SAR has been investigated for soil moisture estimation for dikes (Aanstoos et al., 2010; Mahrooghy et al., 2011) and more recently, for seepage detection (Jones et al., 2012). In the Netherlands, various studies have tested thermal remote sensing for seepage detection but have shown mixed findings (Givehchi et al., 2002; Moser and Zomer, 2006; Swart, 2007; van Hemert, 2004). 


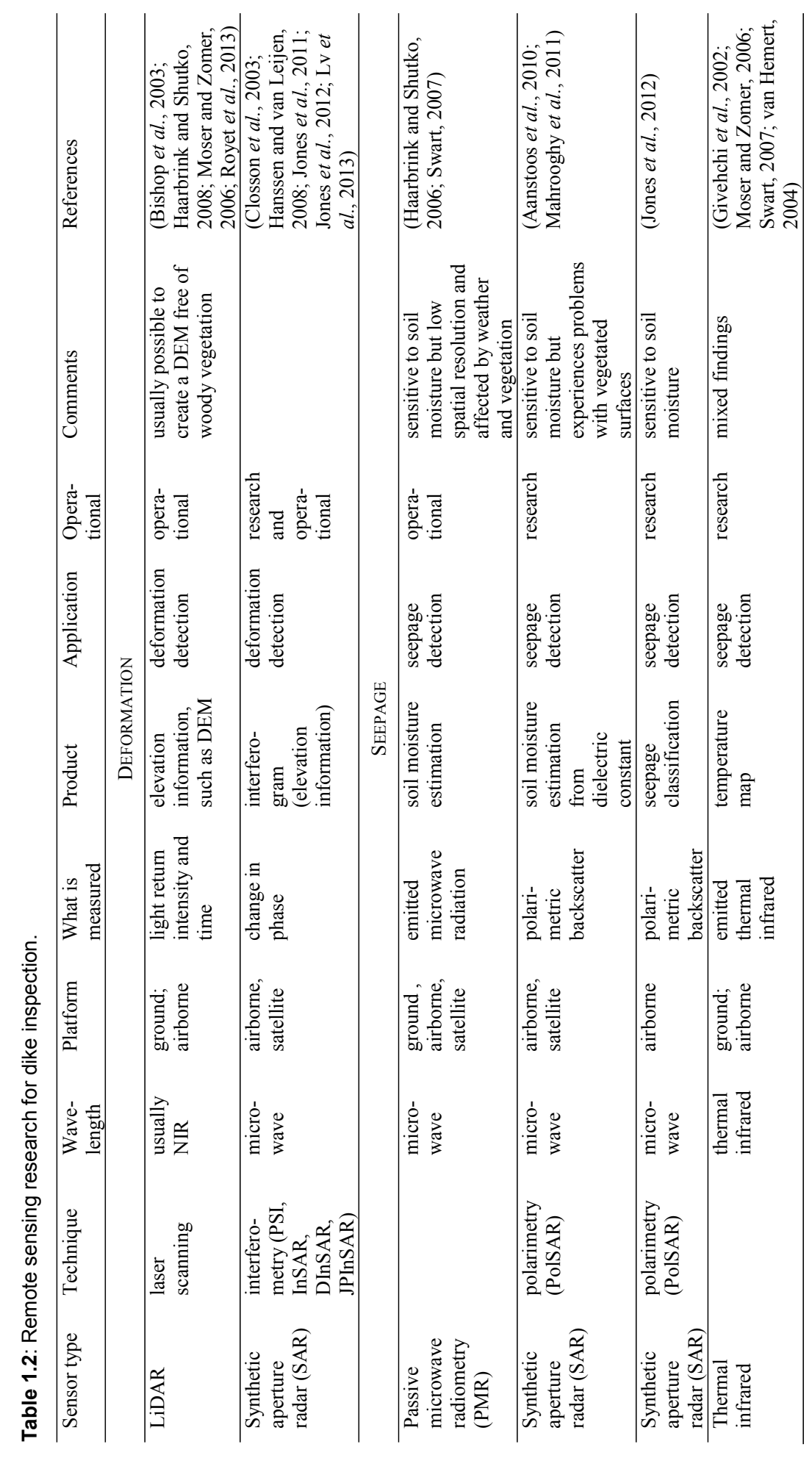




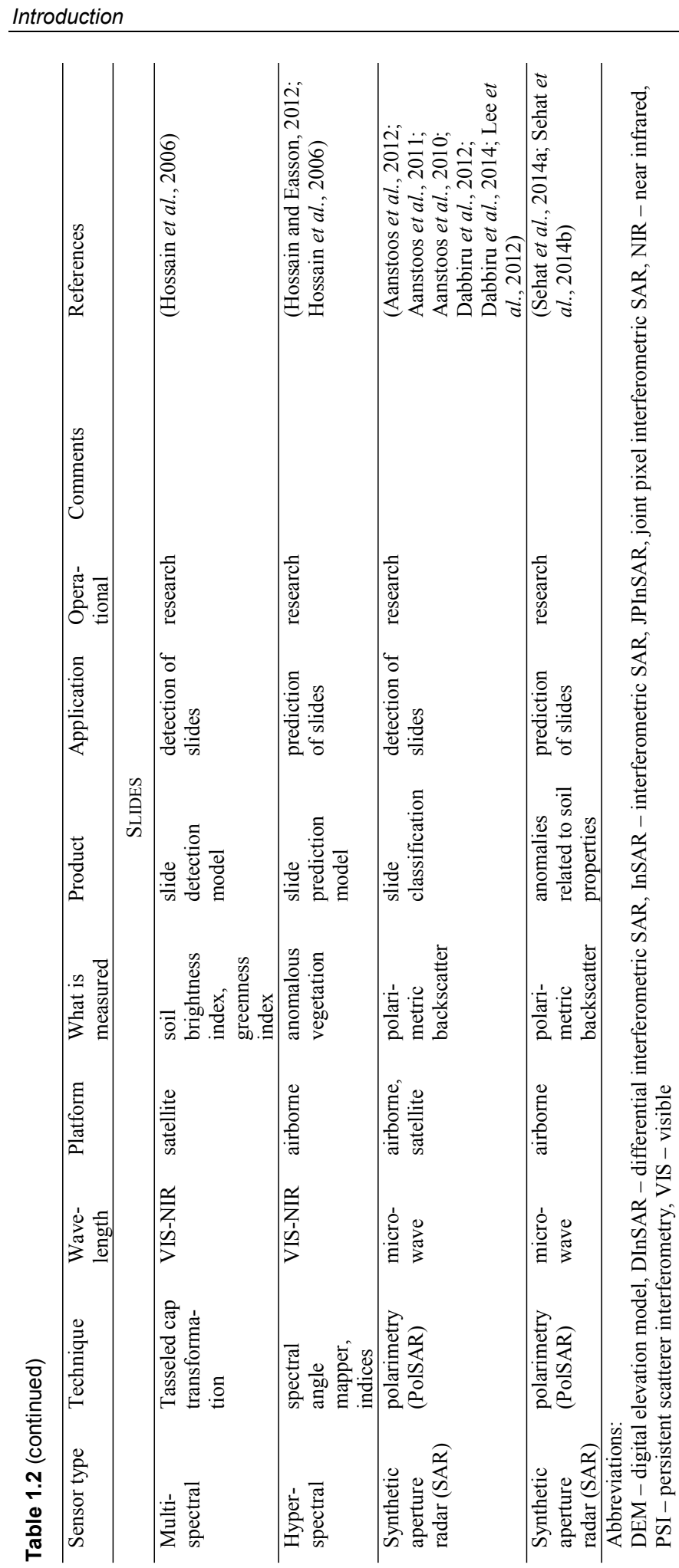




\subsubsection{Other research for dike inspection}

Other research for dike inspection, monitoring and assessment appears to focus on either geophysical techniques or in- or on-dike sensor technology.

Geophysical exploration is concerned with measuring and mapping physical properties of the subsurface from the surface, in this case of the dike body and its foundations. The techniques enable larger areas or volumes to be investigated compared to conventional geotechnical testing and exploration, although the interpretation of geophysical measurements should be integrated with geotechnical measurements (Fargier et al., 2012; Niederleithinger et al., 2012; Royet et al., 2013). The geophysical methods that are receiving the most attention for dikes are electrical resistivity imaging or tomography, electromagnetic induction, ground penetrating radar (GPR) and seismics. An outline of some recent geophysical research for dikes is given in Table 1.3. Although these methods cover areas larger than those of geotechnical investigations, they are still rather limited in areal extent with only electromagnetic induction being used on an aerial platform (Bishop et al., 2003).

In- or on-dike sensor technology requires sensors to be installed in or on the dike for continual or "live" monitoring of the dike. There are a wide range of sensors that have or are being developed and tested for dike inspection, monitoring and assessment. A standard classical measurement of groundwater levels in dikes makes use of standpipes or more sophisticated piezometers for pore water pressure measurements that may be used to indicate instability,

Table 1.3: Recent geophysical research for $\mathrm{d}$ kes.

\begin{tabular}{lll}
\hline Method & Information & References \\
\hline $\begin{array}{l}\text { Electrical resistivity } \\
\text { imaging or tomography }\end{array}$ & $\begin{array}{l}\text { lithological layers, water } \\
\text { content }\end{array}$ & $\begin{array}{l}\text { (Fargier } \text { et al., 2012; Niederleithinger } \\
\text { et al., 2012; Perri } \text { et al., 2014; van } \\
\text { Leeuwen } \text { et al., 2007) }\end{array}$ \\
\hline $\begin{array}{lll}\text { Electromagnetic } \\
\text { induction }\end{array}$ & $\begin{array}{l}\text { dike material } \\
\text { composition/type, intrusions, } \\
\text { material interfaces, water } \\
\text { content }\end{array}$ & $\begin{array}{l}\text { (Bishop } \text { et al., 2009; Niederleithinger } \text { et al. } \\
\text { 2012; Perri } \text { et al., 2014; Viganotti } \text { et } \\
\text { al., 2013) }\end{array}$ \\
& intrusions, voids, & (Di Prinzio et al., 2010; \\
Ground penetrating & discontinuities & Niederleithinger et al., 2012; Perri et \\
radar (GPR) & & (Lorenzo et al., 2014; \\
& lithological layers, bedrock & Niederleithinger et al., 2012)
\end{tabular}


seepage or groundwater flow (e.g., vibrating wire; $\mathrm{Ng}$ and Oswalt, 2010; Pengel et al., 2013). Other established sensor technologies used for geotechnical measurements which are investigated or used for dikes include voltmeters (connected to electrodes) for measuring self-potential indicative of water flow (Mooney et al., 2014; Ng and Oswalt, 2010; Rittgers et al., 2015); tensiometers for measuring soil water potential related to instability or seepage (Weller et al., 2014); inclinometers for local or global tilt indicting displacement or deformation (e.g., coaxial cable); strain and stress measuring devices (e.g., pressuremeters) and geophones and microphones (e.g., luisterbuis or listening tube) for passive seismic monitoring of vibrations and acoustic emissions related to seepage and internal erosion (Mooney et al., 2014; Rittgers et al., 2015; Weijers et al., 2009).

Table 1.4 provides an overview of some recent research on newer in- or on-dike sensor technologies. The research seems to focus on two main classes of sensors, namely micro electro-mechanical systems (MEMS) and fibre optics. MEMS sensors include piezometers, thermal sensors, inclinometers and accelerometers (Melnikova et al., 2013; Ng and Oswalt, 2010; Pengel et al., 2013; Pyayt et al., 2014; Zeghal et al., 2013; Zeghal et al., 2011), while fibre optic sensors are usually distributed optical fibre temperature or strain sensors (Bersan et al., 2014; Henault et al., 2010; Khan et al., 2008; Naruse, 2001; Pengel et al., 2013; Pyayt et al., 2014; Radzicki, 2014; Su and Kang, 2013; Thiele et al., 2008; Xiao and Huang, 2013; Zhu et al., 2008a; Zhu et al., 2011). Other sensors being investigated included global navigation satellite systems (e.g., Global Positioning System or GPS) sensors (Pengel et al., 2013; Zeghal et al., 2013; Zeghal et al., 2011). Depending on the sensor, it has been proposed that the spacing between sensors should be between $1 \mathrm{~m}$ and $30 \mathrm{~m}$ (Bersan and Koelewijn, 2015; Bersan et al., 2014; Ng and Oswalt, 2010). Optical fibre sensors often run along a length of dike in one or more lines (Pengel et al., 2013; Pyayt et al., 2014). Multiple sensors, often of different types, are connected to form a sensor network (Melnikova et al., 2013; $\mathrm{Ng}$ and Oswalt, 2010; Pengel et al., 2013; Pyayt et al., 2014; Su and Kang, 2013). Although these sensors provide continuous data for monitoring, they do require calibration, and the development of methods for data cleaning, processing, analysis and interpretation (Melnikova et al., 2013; Pyayt et al., 2014; Radzicki, 2014; Thiele et al., 2008). Due to the costs and infrastructure required, these systems are more suited to structures still to be constructed or to relatively important dikes which warrant the expense. With thousands of kilometres of dikes already in place, remote sensing still potentially has an important role in current and future dike inspection, monitoring and assessment. 


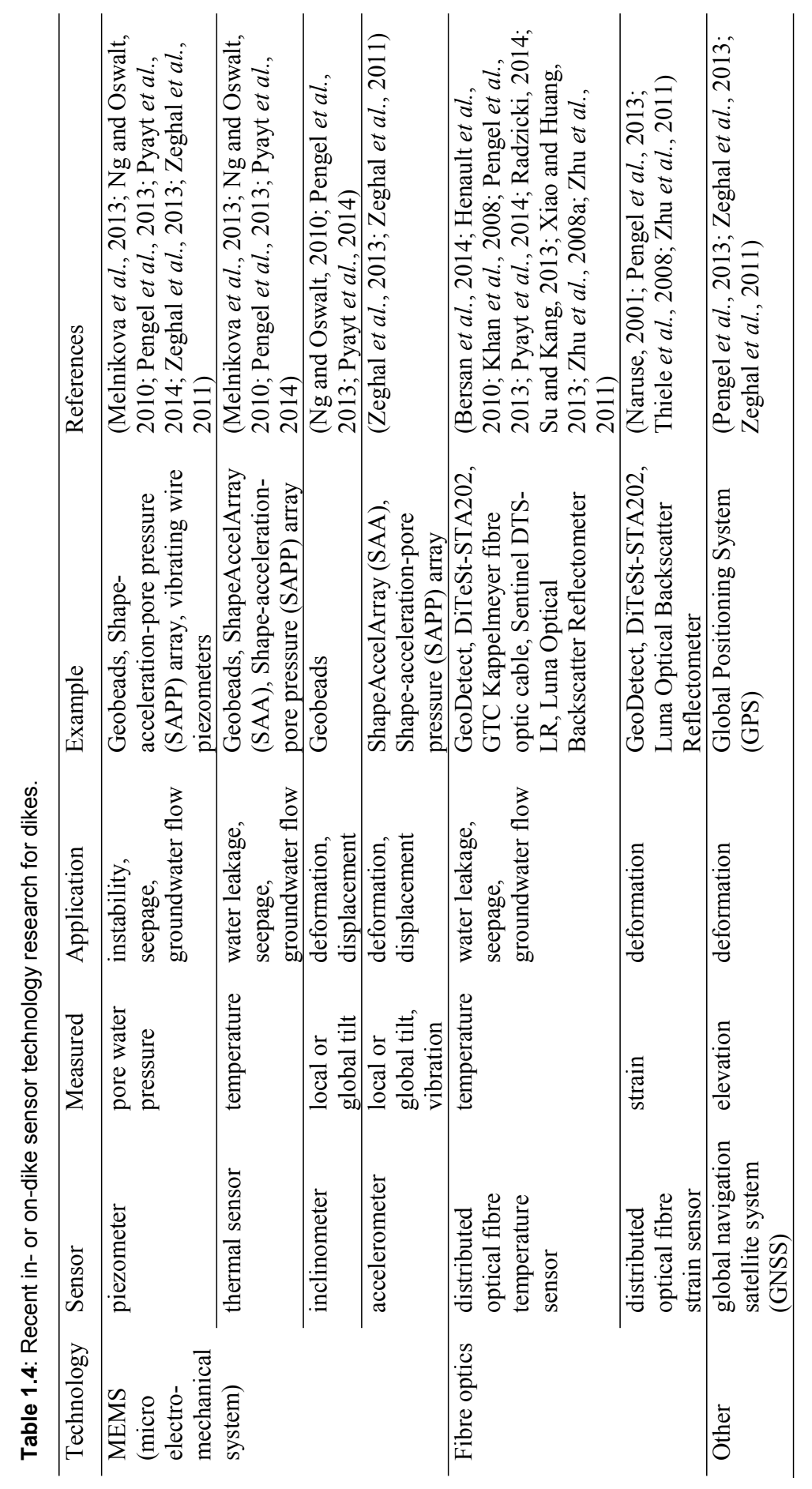




\subsection{Problem Statement}

Dikes are found all over the world and provide necessary protection against inundation. There are hundreds of thousands of kilometres of dikes and their function is becoming increasingly important as a result of the expected consequences of subsidence and of climate change, such as sea level rise and more extreme weather events. These structures need to be regularly inspected for signs of deterioration so that their required level of functionality can be maintained. However, inspections are usually done visually and on foot (CIRIA et al., 2013), which is clearly a slow, costly and man-hour intensive process for the large number of dikes that need to be inspected. If the inspection of dikes could be expedited, areas of deterioration could be identified and repaired sooner, reducing expenditure and more importantly leading to improved dike safety.

Although remote sensing has been proposed as a tool that could facilitate dike inspection by increasing efficiency, objectivity and coverage, in the literature, dike related remote sensing studies have only looked at the inspection indicators of deformation, slides or seepage (see Table 1.2). There are, however, other indicators that inspectors observe. One of these indicators is the quality of the grass cover. Grass cover is one of the most common forms of surface cover on dikes, where it protects against external erosion, inhibits infiltration and the roots help prevent sliding (CIRIA et al., 2013). Inspectors evaluate the quality of the grass cover taking into account such attributes as the cover density, grass health, the absence of grass and the presence of weeds, dead vegetation or debris (Bakkenist et al., 2012a; CIRIA et al., 2013; USACE, 2006). Additionally, discontinuous grass cover may be indicative of other issues (e.g., erosion, slumps, slides, burrowing animals). If remote sensing data can be used as a proxy for cover quality of grass covered dikes, then a faster inspection process for this indicator is possible without limitations on accessibility.

Remote sensing data are widely used as proxies for various parameters, notably relating to vegetated surfaces (e.g., Daughtry et al., 2000; Gitelson et al., 2014; Hall et al., 1992; Houborg et al., 2013). Multispectral, and more recently hyperspectral, remote sensing data are widely used in vegetation studies (Jensen, 2007; Lillesand et al., 2008; Thenkabail et al., 2012). Vegetation health can be assessed by the amount of biomass and is influenced by water availability, the presence of diseases and nutrient availability. The multispectral based Normalized Difference Vegetation Index (NDVI) was developed and is still used for biomass estimation (Broge and Leblanc, 2000; Rouse et al., 1973). Hyperspectral remote sensing is also found to be useful for the estimation of biomass (Broge and Leblanc, 2000; Darvishzadeh et al., 2009; Haboudane et 
al., 2004). Remote sensing has proven useful for estimating nutrient deficiencies in vegetation. Nitrogen, one of the key nutrients for plants, has been extensively researched (Ramoelo et al., 2012; Skidmore et al., 2010; Zhao et al., 2005), with some research being done on micronutrient deficiency (Adams et al., 2000). Plant types can often be distinguished with the use of remote sensing since their spectral signatures differ (Bentivegna et al., 2012; de Castro et al., 2012; Kandwal et al., 2009). Remote sensing can therefore potentially be used to discriminate between grass and weeds. The spectral signature of healthy vegetation is quite distinct especially when compared to those of bare soil, standing litter (dead plant material) and water (Aguilar et al., 2012; Asner, 1998; Jensen, 2007; Lillesand et al., 2008). In addition, remote sensing data are used for the estimation of cover fraction (Gitelson, 2013). Remote sensing could therefore prove useful for evaluating the grass cover of dikes. However, to date, this application has not been specifically investigated.

Dike inspection indicators such as seepage, saturation, deformations (e.g., depressions and rutting which can pond water) and desiccation cracks relate to soil moisture. Excess soil moisture may soften soils, weaken shear strength and decrease stability, while also being indicative of other possible issues such as internal erosion (CIRIA et al., 2013). Desiccation of dike soils may lead to the loss of weight, soil shrinkage and the formation of cracks, which in turn can decrease stability, reduce crown height and increase the risk of seepage. Desiccation due to drought is a particular problem if the dike soils contain peat or highly organic clay, which can lead to horizontal displacements such as in Wilnis, the Netherlands in 2003 (van Baars, 2004), which resulted in about 600 houses being flooded and material damages amounting to about EUR 10 million. Peat dikes occur not only in the Netherlands but also, for example, in France, Ireland, Italy, the United Kingdom and the United States of America (CIRIA et al., 2013). Cracks may also cause increased infiltration resulting in further instability (CIRIA et al., 2013). Inspectors look for standing or pooling water, saturated soils, increased vegetation growth due to increased water availability, yellowing or dead vegetation due to water deficiency and the presence of cracks (Bakkenist et al., 2012b; CIRIA et al., 2013; USACE, 2006). If remote sensing data can be used as a proxy for soil moisture content, then a faster inspection process for this indicator is possible without limitations on accessibility.

Although remote sensing has been investigated for seepage, low spatial resolution and vegetation are often problems. Further, the more generic issue of soil moisture for dikes has not been investigated. Although vegetation is often considered a complicating factor for soil moisture studies, it is highly responsive to changes in soil moisture (Hopkins and Hüner, 2009). Remote 
sensing is researched extensively for assessing vegetation water content and thermal, multispectral and hyperspectral remote sensing are actively researched for detection of water deficit stress in plants, particularly for agriculture (Caccamo et al., 2011; Chen et al., 2005; Fensholt and Sandholt, 2003; Fitzgerald et al., 2006; Govender et al., 2009; Grant et al., 2007; Hunt and Rock, 1989; Jimenez-Bello et al., 2011; Jones et al., 2009; Kim et al., 2010; Moller et al., 2007; Rodríguez-Pérez et al., 2007; Sepulcre-Canto et al., 2006; Zhang et al., 2012b). Further, soil-oxygen deficiency (e.g., as a result of waterlogging) has been detected in vegetation using hyperspectral remote sensing (Smith et al., 2004). Remote sensing of vegetation could therefore prove useful for evaluating the soil moisture of grass covered dikes.

Although remote sensing conceptually shows potential for use as proxies for cover quality and soil moisture in order to facilitate dike inspection, the literature shows no studies investigating remote sensing of vegetation for these indicators for grass covered dikes. This subject requires investigation to establish whether relationships exist between remote sensing data and the cover quality or soil moisture indicators and, if so, whether remote sensing imagery can be used to facilitate the inspection of these two dike inspection indicators.

\subsection{Research Objectives}

The general objective of the research presented in this thesis is to evaluate whether optical remote sensing data could be used as proxies for the cover quality and soil moisture indicators so as to facilitate the inspection of grass covered dikes.

To achieve this goal, the following specific objectives were defined:

- to identify if, when using field measurements, there are significant relationships between 1) soil moisture indicator and 2) cover quality indicator, and a) broadband thermal, b) broadband visible, c) broadband multispectral and d) narrowband hyperspectral remote sensing data for grass covered dikes,

- to investigate the effects of differing spectral response functions (SRFs) of various very high spatial resolution sensors on the cross-calibration of numerous spectral indices for cultivated grasslands that are typically found on dikes that do not have a hardened cover,

- to compare and evaluate remote sensing measurements obtained from imagery to those obtained in the field for assessing soil moisture and cover quality indicators for the inspection of grass covered dikes, 
- to compare and evaluate remote sensing image data obtained from different very high spatial resolution satellite imaging sensors for a section of dike in the context of facilitating the inspection of dikes.

\subsection{Study Site}

The study site is a section of a grass covered dike located near Gouda in the Netherlands (Figure 1.7). It was selected as the study site since it is reported to have problems by the local authorities. The surface of the dike is uneven, showing signs of subsidence. In addition, the dike surface varies in firmness, with some areas feeling spongy when pressure is applied and there are signs of extruding water in the ditch and at toe of the dike.

The dike is a peat dike. Peat dikes occur in a number of countries over the world and are either constructed on peat foundations or the dike earthfill is peat. When the earthfill is peat, the dike may either be constructed out of peat (e.g., Grand Canal, Ireland) (McInerney et al., 2007) or consist of in situ material that is left in place around an excavated area. The dike in this case is an in situ peat dike. In the $17^{\text {th }}$ and $18^{\text {th }}$ centuries, peat in the Netherlands was excavated for fuel (Schuetze, 2008) and sometimes salt production (Post, 2004). The resulting lowlands filled with water to create lakes. As the demand for land increased with population growth, these lakes were later drained, and the land reclaimed, by pumping the water out using windmills (now electric pumps) and constructing a system of ditches and canals to drain the water to rivers and out to sea (Figure 1.8). The water level in these ditches is controlled and maintained at constant levels (Moria, 2008; Querner et al., 2008; Schuetze, 2008; ten Cate, 1982; van Baars, 2005). The dike in this study has ditches on both sides of the dike (Figure 1.9). The dike section is about $60 \mathrm{~m}$ wide and westerly-facing with a gentle slope over about $45 \mathrm{~m}$ (Figures 1.9 and 1.10). The crest of the dike is at about -1.6 m NAP (Normaal Amsterdams Peil or Amsterdam Ordnance Datum) while the toe of the dike is at about $-5.7 \mathrm{~m}$ NAP. The elevations are based on the data of the Actueel Hoogtebestand Nederland [Actual Height model of the Netherlands] AHN2. The dike has a grass cover which is cultivated pasture/grasslands and is used for hay production as well as directly for grazing.

According to the Köppen-Geiger climate classification, the Netherlands has a warm temperate, fully humid with warm summer climate (Kottek et al., 2006). The temperate maritime climate is associated with cool summers (mean temperature of $16^{\circ} \mathrm{C}$ ) and mild winters (mean temperature of $3^{\circ} \mathrm{C}$ ) with rainfall throughout the year (annual average $770 \mathrm{~mm}$ ) (KNMI, n.d.). 


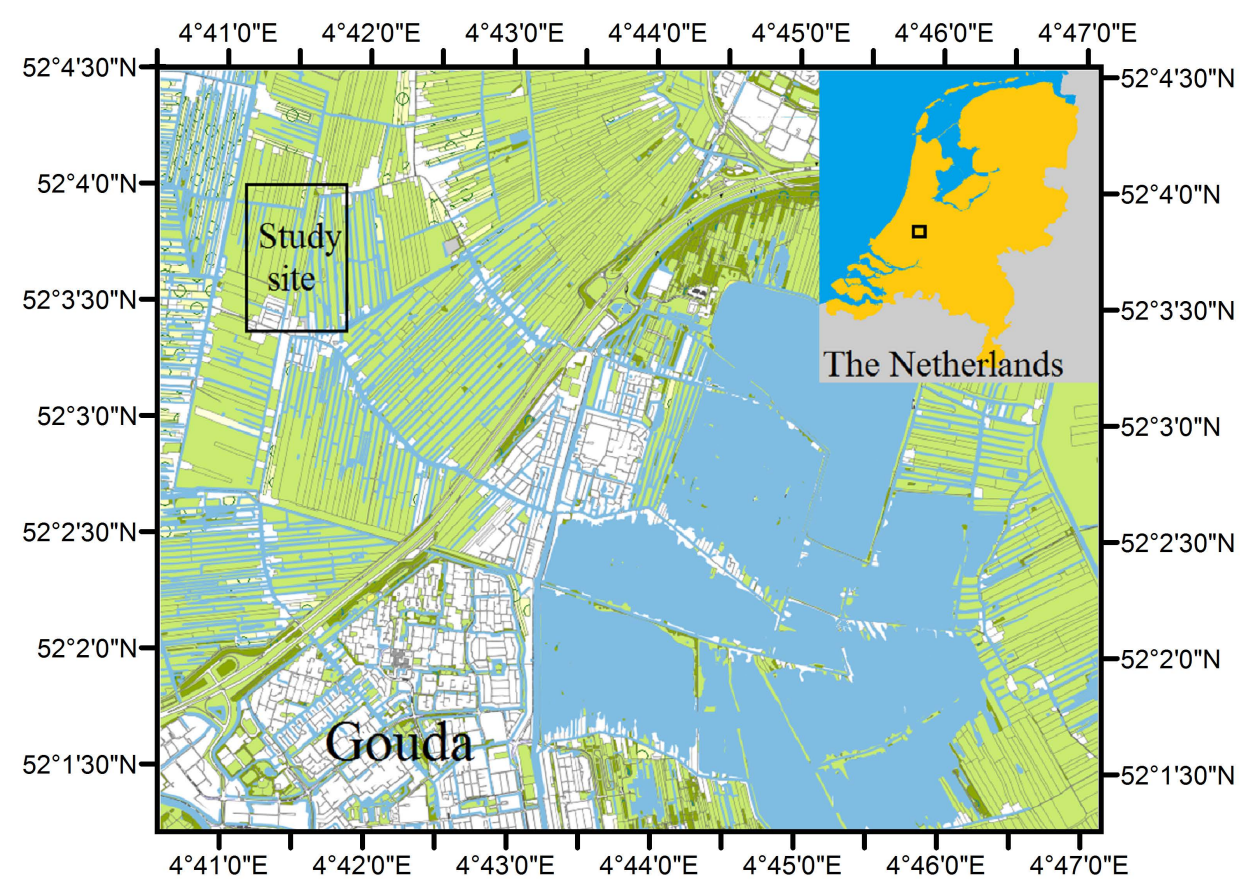

Figure 1.7: Location map of study site (Cundill et al., 2014). (C 2014 IEEE.

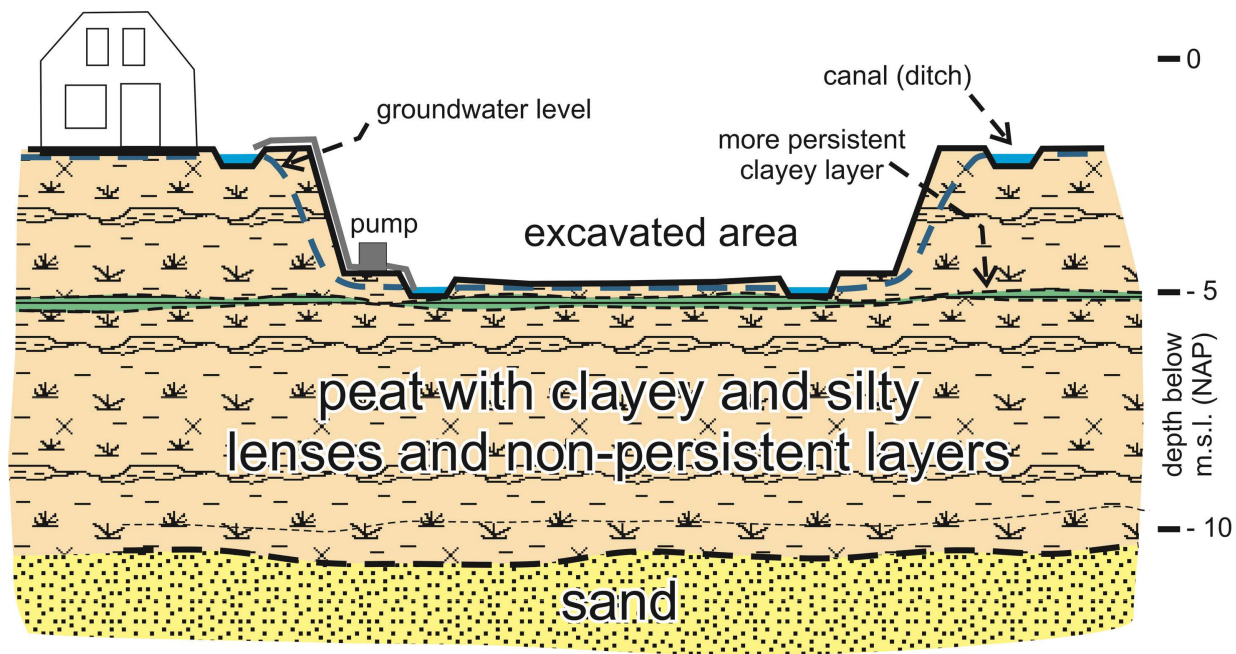

Figure 1.8: Schematic diagram of a reclaimed peat-excavated area (vertical scale exaggerated) (Cundill et al., 2014). (c) 2014 IEEE. 


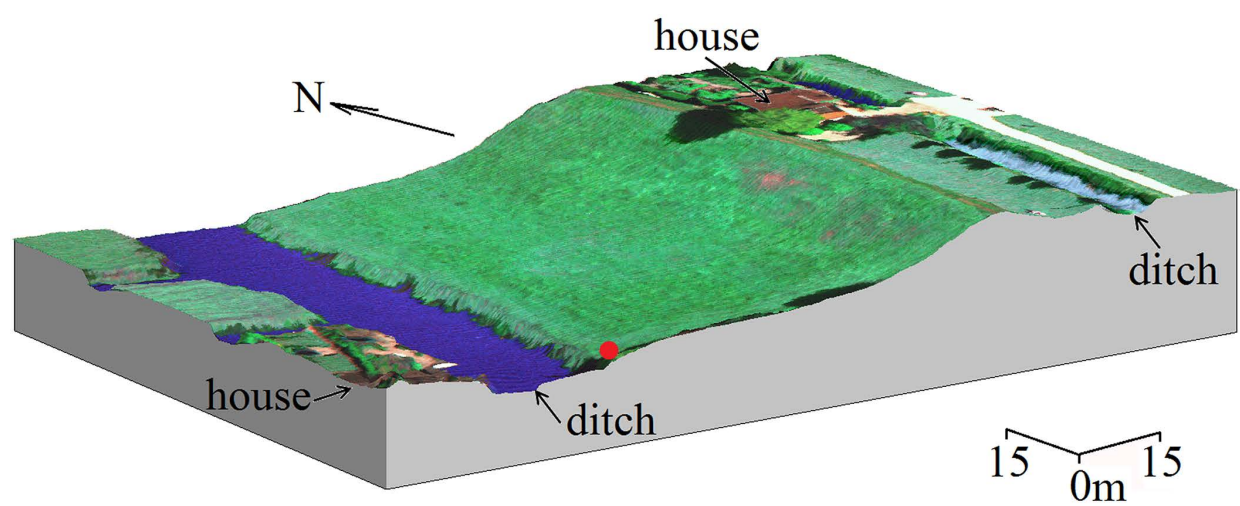

Figure 1.9: Study site section of dike, with ditches on both sides of the dike (vertical scale exaggerated 3x). The red dot indicates the location from which the panoramic photo (Figure 1.10) was taken.

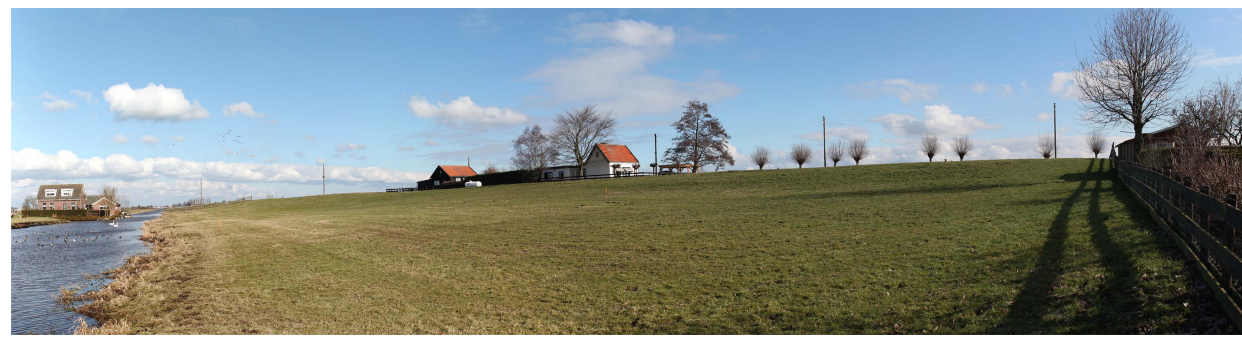

Figure 1.10: Panoramic photo of study site. Approximate directions from observer: ditch South to North and fence West to East (photograph: Hack, H.R.G.K., taken 21 February 2013).

Geologically the area is a rather flat deltaic environment. The geology of the area consists of Holocene deposits (mainly peat and clay) on top of Pleistocene sandy deposits (Bosch and Kok, 1994; de Mulder et al., 2003; ten Cate, 1982). The Holocene deposits consist of a fairly consistent peat layer ('Nieuwkoop; layer Hollandveen' formerly Hollandveen) on and partially interbedded with mainly clay layers and marine and fluvial fine sand channel fill ("Naaldwijk; layer Wormer' formerly Calais III) and with sandy and silty clay with thin sand layers and lenses ('Echteld' formerly Gorkum). The underlying Pleistocene formation consists mainly of marine sandy deposits ('Boxtel'), with its base at about $250 \mathrm{~m}$ below surface and with a thickness of about $240 \mathrm{~m}$ (Bosch and Kok, 1994; de Mulder et al., 2003). A subsurface model, based on two boreholes and 17 cone penetration tests (CPTs), for the study area is shown in Figure 1.11 illustrating the local lithography. 


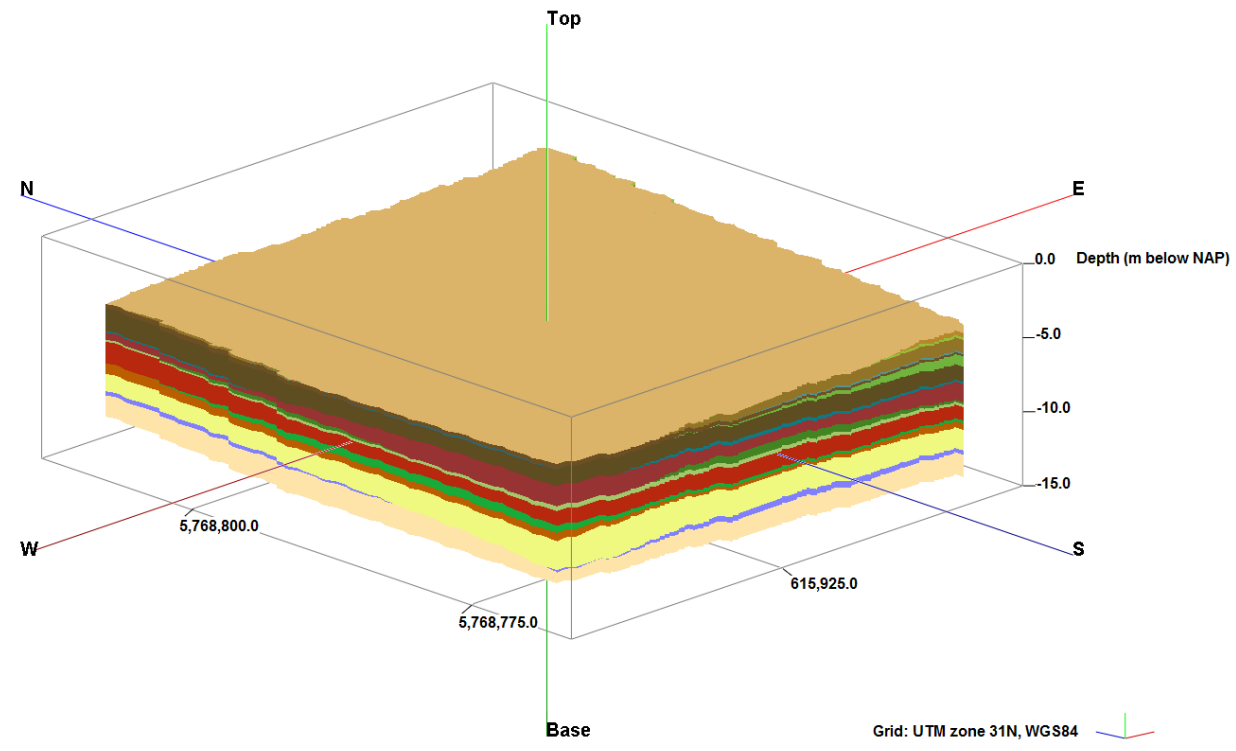

Lithography

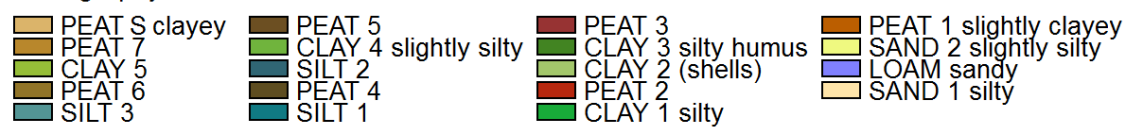

Figure 1.11: Subsurface model showing the lithography of the study area, based on two boreholes and 17 cone penetration tests (CPTs). In order to distinguish between the lithographic units, numbers have been appended to lithographic names.

\subsection{Structure of Thesis}

This thesis consists of a total of six chapters. Apart from the introduction and synthesis, the four remaining core-chapters have either been published in peerreviewed journals (Chapters 2 and 3), are under review (Chapter 4) or are for submission (Chapter 5).

Chapter 1 introduces the research, providing the necessary background, defining the research objectives, describing the study site and summarising the structure of the thesis.

Chapter 2 presents the proof of concept for the potential use of remote sensing data to facilitate the dike inspection process for grass covered dikes, specifically considering two dike inspection indicators, namely soil moisture indicator and cover quality indicator. Measurements from ground-based, hand-held remote sensing sensors are used. The findings are compared with the subsurface composition of the dike to assist in the understanding of processes that could be manifesting at the surface. 
Chapter 3 investigates the effects of differing spectral response functions (SRFs) of ten very high spatial resolution sensors on the cross-calibration of numerous spectral indices for cultivated grass covers. The results of this chapter provide the necessary basis for the subsequent work of comparing the field and satellite image measurements, as well as comparing measurements from multiple satellite imaging sensors in the context of dike inspection.

Chapter 4 evaluates the remote sensing measurements obtained from satellite imagery to those obtained in the field for assessing soil moisture and cover quality indicators for the inspection of grass covered dikes. The results of this chapter also provide the groundwork for the follow-up work of using images from multiple satellite imaging sensors.

Chapter 5 examines data of six satellite images from five different sensors recorded between 2008 and 2013 for their usability in dike inspection of grass covered dikes, specifically for the soil moisture and cover quality indicators.

Chapter 6 summarises and synthesizes the results of Chapters 2 to 5 , providing general conclusions, an outlook for the use of remote sensing data for dike inspection and recommendations for future work. 


\section{Investigation of Remote Sensing for Potential Use in Dike Inspection ${ }^{1}$}

${ }^{1}$ This chapter has been published as: Cundill, S. L., van der Meijde, M. \& Hack, H. R. G. K. (2014). Investigation of remote sensing for potential use in dike inspection. Selected Topics in Applied Earth Observations and Remote Sensing, IEEE Journal of, 7 (2), 733-746. (C) 2014 IEEE. Reprinted, with permission. 


\subsection{Introduction}

Dikes are increasingly becoming structures of major importance and concern due to the expected consequences of subsidence and of climate change, such as sea level rise and more extreme weather events. With $10 \%$ of the world population living in the Low Elevation Coastal Zone (i.e., less than $10 \mathrm{~m}$ above sea level) (McGranahan et al., 2007), often in subsiding sedimentary areas, dikes are critical barriers against storm surges, sea level rise and flooding by rivers. The failure of a dike can result not only in substantial economical and infrastructural losses but also in significant loss of lives. It is therefore essential that dikes are monitored for weaknesses and kept in optimal condition (van Westen, 2005).

As in many countries across the world, dikes in the Netherlands are monitored by inspectors walking the dike looking for a variety of qualitative indicators that reflect a change or loss in the coherence of the dike structure (Boukalová et al., 2009; Dupray et al., 2010; Givehchi et al., 2002; Mériaux and Royet, 2007; Moser and Zomer, 2006; Swart, 2007). With about $14000 \mathrm{~km}$ of regional or inland water barriers in the Netherlands alone (Knoeff et al., 2008; van Baars, 2004), this is clearly a slow, costly, time-consuming process and is limited by accessibility to the areas to be inspected, especially during times of flooding. Remote sensing has been proposed as a tool that could facilitate faster dike inspection (Givehchi et al., 2002; Hack et al., 2008; Hanssen and van Leijen, 2008; Swart, 2007; van der Schrier et al., 2004).

Over the last decade, there have been several studies on remote sensing for dike monitoring and assessment. The studies are largely motivated by the idea of providing a screening process which is faster than manual inspection, as remote sensing can cover large areas in a relatively short time. Other research for dike monitoring and assessment appears to focus on in-dike solutions (Pengel et al., 2013; Xiao and Huang, 2013; Zhu et al., 2010; Khan et al., 2008; Naruse, 2001; Zhu et al., 2008a). This requires sensors to be installed in or on the dike for continual or "live" monitoring of the dike. Due to the costs and infrastructure required, these systems are more suited to structures still to be constructed or to relatively important dikes which warrant the expense. With thousands of kilometres of regional and secondary dikes already in place, remote sensing most likely still has an important role in current and future dike monitoring and assessment.

The remote sensing studies of the last decade have largely focused on deformation, slides and seepage. Both LiDAR (Bishop et al., 2003; Haarbrink and Shutko, 2008) and synthetic aperture radar (SAR) (Closson et al., 2003; Hanssen and van Leijen, 2008; Jones et al., 2011; Jones et al., 2012) have been 
investigated for deformation detection on dikes. Both LiDAR (airborne) and radar interferometry (satellite borne) are offered commercially for dike deformation detection. The detection and prediction of shallow surficial failures or slough slides are the focus of a number of on-going studies. Along the Mississippi River, anomalous vegetation is associated with probable slideaffected areas (Hossain and Easson, 2012; Hossain et al., 2006). Airborne multispectral imagery has been used to develop a slide detection model (Hossain et al., 2006) and airborne hyperspectral imagery has been used to develop a slide prediction model (Hossain and Easson, 2012). Polarimetric SAR imagery (both on airborne and satellite platforms) is being investigated for slide detection to aid in the dike screening process and thus far appears to be promising (Aanstoos et al., 2012; Aanstoos et al., 2011; Aanstoos et al., 2010; Dabbiru et al., 2012; Lee et al., 2012). Research on seepage detection with remote sensing has taken diverse approaches. Passive microwave radiometry (PMR) is sensitive to soil moisture and has been used for monitoring soil moisture condition in dikes (Haarbrink and Shutko, 2006; Swart, 2007). Nevertheless low spatial resolution and complex calibration and interpretation (especially for vegetated surfaces) remain issues (Lillesand et al., 2008; Shutko et al., 2006; Swart, 2007). SAR is likewise sensitive to soil moisture (Aanstoos et al., 2010) (as it operates in the same range of wavelengths) but also experiences problems with vegetated surfaces. In the Netherlands, various studies have tested thermal remote sensing for seepage detection (Swart, 2007). These have shown varying degrees of success. Recently, airborne polarized radar was investigated for seepage detection (Jones et al., 2012). It showed promising results but the authors themselves note that this may be as a result of the size and duration of the flood specific to this study.

The dike inspection process, including frequency and inspection criteria, varies from country to country and sometimes even between smaller administrative authorities. However, dike inspection is usually done by visual inspection of the dike by an expert. Potential problems areas are identified for further investigation and measurements, after which necessary remediation measures are taken. International collaboration, such as The International Levee Handbook, aims to provide mutual benefit from learning from other countries' experience and expertise, also in the area of dike maintenance. The inspection process of dikes with grass covers could be aided by the results of the research reported here.

In the Netherlands, there are nine damage parameters for grass covered dikes that dike inspectors need to evaluate (Bakkenist et al., 2012b). Six of these relate, either entirely or partially, to the quality of the grass cover. Two of the damage parameters relate to the moisture content of the dike, either to wet 
patches or to dryness. Thus two key criteria that dike inspectors consider when assessing grass covered dikes are the moisture content of the dike and the quality of the dike cover (Moser and Zomer, 2006; van Baars and van Kempen, 2009). Soil moisture is one of the most important factors affecting surface stability in soil structures (Mukhlisin et al., 2011) of which regional dikes are an example. Soils in dikes can develop cracks and lose structural integrity if they become very dry (van Baars and van Kempen, 2009). Conversely, localised areas of high soil moisture content, where water is seeping through the soil, may indicate weaknesses in a dike (Moser and Zomer, 2006). If remote sensing data can be used as a proxy for soil moisture content, then a faster inspection process for this indicator is possible without limitations on accessibility.

Thermal remote sensing is often favoured for soil moisture studies (Lillesand et al., 2008). In addition, vegetation is highly responsive to changes in soil moisture (Hopkins and Hüner, 2009). Remote sensing is researched extensively for assessing vegetation water content and thermal, multispectral and hyperspectral remote sensing are actively researched for detection of water deficit stress in plants, particularly for agriculture (Caccamo et al., 2011; Chen et al., 2005; Fensholt and Sandholt, 2003; Fitzgerald et al., 2006; Govender et al., 2009; Grant et al., 2007; Hunt and Rock, 1989; Jimenez-Bello et al., 2011; Jones et al., 2009; Kim et al., 2010; Moller et al., 2007; Rodríguez-Pérez et al., 2007; Sepulcre-Canto et al., 2006; Zhang et al., 2012b). Thermal remote sensing has also been investigated for seepage detection in canals (Huang et al., 2010; Nellis, 1982) and concrete dams (Abakarov et al., 2000). In addition, thermal imaging has been tested specifically for dike seepage monitoring but with mixed responses (Givehchi et al., 2002; Moser and Zomer, 2006; Swart, 2007; van Hemert, 2004). Further research is required particularly with regards to time of observation and environmental influences.

The quality of the cover of a dike is another key feature for dike inspection. The quality of the dike cover is important for resistance against erosion and water infiltration in the case of overtopping. In addition, a grass cover can also be influenced by processes taking place within the dike structure, such as seepage or cracking. If remote sensing data can be used as a proxy for cover quality of grass covered dikes, then a faster inspection process for this indicator is possible without limitations on accessibility.

The cover quality of grass covered dikes is assessed by evaluating the health of the vegetation and the presence of standing litter (dead plant material), flotsam (floating debris), bare soil and weeds. Multispectral, and more recently hyperspectral, remote sensing is widely used in vegetation studies (Blackburn, 2007; Lillesand et al., 2008; van der Meer et al., 2006). Vegetation health can be assessed by the amount of biomass and is influenced by water availability, 
the presence of diseases and nutrient availability. The multispectral based Normalized Difference Vegetation Index (NDVI) was developed and is still used for biomass estimation (Broge and Leblanc, 2000; Rouse et al., 1973). Hyperspectral remote sensing is also found to be useful for the estimation of biomass (Broge and Leblanc, 2000; Darvishzadeh et al., 2009; Haboudane et al., 2004). Remote sensing is researched extensively for assessing vegetation water content and plant stress induced by water deficit (Caccamo et al., 2011; Chen et al., 2005; Fensholt and Sandholt, 2003; Hunt and Rock, 1989; Kim et al., 2010).

Remote sensing has proven useful for estimating nutrient deficiencies in vegetation. Nitrogen, one of the key nutrients for plants, has been extensively researched (Ramoelo et al., 2012; Skidmore et al., 2010; Zhao et al., 2005), with some research being done on micronutrient deficiency (Adams et al., 2000). Additionally, it has been found that the spectral response of vegetation to soil-oxygen deficiency can be detected using hyperspectral remote sensing, regardless of whether the deficiency is the result of waterlogging or oxygen displacement by other gases (Smith et al., 2004). Thus remote sensing can be used for assessing overall vegetation health.

Plant types can be distinguished with the use of remote sensing since their spectral signatures differ (Bentivegna et al., 2012; de Castro et al., 2012; Kandwal et al., 2009). Remote sensing can therefore be used to discriminate between grass and weeds. The spectral signature of healthy vegetation is quite distinct especially when compared to those of bare soil, standing litter and water (Aguilar et al., 2012; Asner, 1998; Jensen, 2007; Lillesand et al., 2008). Therefore remote sensing should prove useful for evaluating the grass cover of dikes.

The objectives of the present chapter are to identify if there are significant relationships between 1) soil moisture content and 2) cover quality, and a) thermal, b) broadband visible, c) broadband multispectral and d) narrowband hyperspectral remote sensing measurements for grass covered dikes. The study makes use of ground-based, hand-held remote sensing sensors. Moreover, the findings are compared with the subsurface composition of the dike to assist in the understanding of processes that could be manifesting at the surface. 


\subsection{Materials and Methods}

\subsubsection{Study site}

A section of a grass covered dike in the Netherlands (from now on referred to as the dike, Figure 1.7) was selected as the study site since it is reported to have problems by the local authorities. The surface of the dike is uneven, showing signs of subsidence. In addition, the dike surface varies in firmness, with some areas feeling spongy when pressure is applied. Further, the bottom of the dike shows signs of extruding water. The dike is a 'peat dike', that is a water barrier of in situ material which has been left in place around an excavated area. In the 17th and 18th centuries, peat was excavated for fuel (Schuetze, 2008) and possibly salt production (Post, 2004). The resulting lowlands filled with water to create lakes. These lakes were later drained as the demand for land increased with population growth. Water is pumped out of ditches in the excavated areas to ditches above, which then drain into a system of canals to the nearest river and out to sea (Figure 1.8). The water level in the ditches is controlled and maintained at constant levels (Moria, 2008; Querner et al., 2008; Schuetze, 2008; ten Cate, 1982; van Baars, 2005). The study area has a ditch at the bottom and at the top of the dike (Figure 2.1).

The geology of the area consists of Holocene deposits (mainly clay and peat) on top of Pleistocene sandy deposits. After the last glaciation in the late Pleistocene, with the transgression in the west of the Netherlands, clay and sand layers were deposited over the Pleistocene deposits. Later in the Holocene, strand barriers developed, behind which extensive swamp areas formed

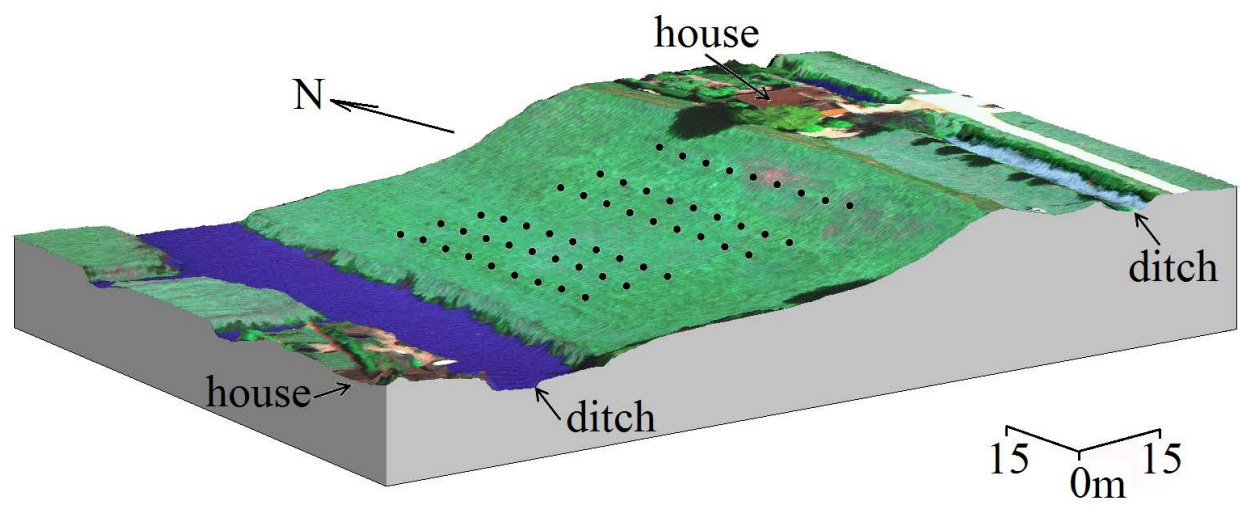

Figure 2.1: Section of dike showing the study area, with ditches at the top and the bottom of the dike. The black dots on the dike indicate the data location points. (C) 2014 IEEE. 
(resulting in peat development) (Bosch and Kok, 1994; de Mulder et al., 2003; ten Cate, 1982). Cundill et al. (2013) provide further information on the geology and landscape for the study location.

\subsubsection{Data collected}

A field campaign was conducted on 15 to 16 July 2010, when ground-based remote sensing and validation data sets were measured. Four types of remote sensing data were collected. These were thermal, visible, multispectral and hyperspectral remotes sensing data. Two sets of validation data, namely soil moisture data and quality assessment of the grass cover of the dike, were collected. The soil moisture and hyperspectral instruments limited the study to point based measurements. For every point location an image was recorded using each of the remaining remote sensing instruments (i.e., visible, multispectral and thermal). Since all measurements covered similar areal extents, each image was averaged to obtain a single value for each sensor for that location. Measurements were recorded at 54 point locations on the westfacing side of the dike (Figure 2.1). The measurement grid consisted of six lines along the dike, with nine points per line at $5 \mathrm{~m}$ spacing. The period April to July 2010 was extremely dry in the Netherlands, with the rainfall shortage (i.e., rainfall minus evaporation) being high enough that this period falls within the $5 \%$ driest years (Groen, 2010). The local weather conditions varied during the measurement period and included sunny, partly-cloudy and cloudy conditions (with the sunniest conditions being between $18 \mathrm{~h} 00$ and 21h00). A trace amount of rain occurred at about $16 \mathrm{~h} 00$ on 15 July 2010 . Solar noon was at $13 \mathrm{~h} 38$, with apparent sunset at $21 \mathrm{~h} 30$ on 15 July 2010 and apparent sunrise at $05 \mathrm{~h} 46$ on 16 July 2010 (Earth Systems Research Laboratory, n.d.).

\subsubsection{Validation data}

Soil moisture data and the quality of the grass cover of the dike were collected as validation data. Volumetric soil moisture for each location was measured using a ThetaProbe Soil Moisture Sensor-ML2x (by Delta-T Devices Ltd, Cambridge, UK). Nine sets of measurements were taken over a 24 hour period. Since the sensor pins slightly disturb the soil when removed after a measurement, the nine measurements for a location were not taken at exactly the same place because optimum soil-contact with the pins would not be attained, resulting in erroneous readings. However, the nine measurements were always taken within the areal extent of the remote sensing sensors. No diurnal trend was observed in the soil moisture measurements. Within-point variation was observed, which was probably the result of variations in soil composition within the measurement extent. For these reasons, the nine measurements per 
location were averaged and the mean soil moisture value was used for further analysis. The sensor was not calibrated for the site using gravimetric measurements and so the absolute values may not be completely correct. However, the spatial relations and statistics are still valid.

The quality of the dike cover was evaluated for each location for the areal extent of the remote sensing data. Evaluation criteria include grass density, canopy cover and the presence and quantity of standing litter (dead plant material), flotsam (floating debris), weeds and bare soil. The cover quality for each location was assessed and allocated to either a good, medium, poor or bad quality class (based on the current Dutch dike assessment classes) (Bakkenist et al., 2012a). The assessment criteria for the different classes are shown in Table 2.1.

Table 2.1: Cover quality classes and assessment criteria used for this study (modified after Bakkenist et al., 2012a). (C 2014 IEEE.

\begin{tabular}{|c|c|c|}
\hline Class & DESCRIPTION & EXAMPLE PHOTO \\
\hline Good & $\begin{array}{l}\text { More than } 90 \% \text { green grass cover; } \\
\text { little to no standing litter, weeds, etc.; } \\
\text { no bare soil }\end{array}$ & \\
\hline Medium & $\begin{array}{l}50 \% \text { to } 90 \% \text { green grass cover; } \\
\text { more than } 40 \% \text { dry grass or weeds; } \\
\text { less than } 5 \% \text { bare soil }\end{array}$ & \\
\hline Poor & $\begin{array}{l}\text { Less than } 50 \% \text { green grass cover; } \\
5 \% \text { to } 20 \% \text { bare soil }\end{array}$ & \\
\hline $\mathrm{Bad}$ & More than $20 \%$ bare soil & \\
\hline
\end{tabular}


A 3D electrical resistivity survey was completed in May 2008 for the study area. The resistivity of subsurface materials depends on their composition and structure and whether there is water present in the pore spaces (Price et al., 2009). Thus electrical resistivity can be used to map lateral and vertical changes in ground conditions (Nijland et al., 2010; Waltham, 2009). The survey was done using a Sting R1 resistance meter with a Swift control switching box (from Advanced Geosciences, Inc., Austin, Texas). Two multicore cables, each with 14 electrodes, were set out in a straight line, with $2 \mathrm{~m}$ spacing between electrodes. Twenty lines were measured, with $3 \mathrm{~m}$ spacing between lines (to enable 3D computation line spacing must be less than two times electrode spacing). Due to the position of a house and the location of possible seepage, the lines were shifted to a maximum of $20 \mathrm{~m}$ in the north-south direction. This has a limited effect on the inversion but limits interpretations along the edge of the model. The study area falls well within the edges of the model. Local elevations were measured and used for height correction in the resistivity inversion model. A Schlumberger array was used because it has a high signal to noise ratio, a good depth resolution (Dahlin and Zhou, 2004) and is moderately sensitive to both horizontal and vertical structures.

In August 2008, 17 Dutch cone penetration tests (CPT) were conducted on the study site (Hack et al., 2008). The test measures an index related to the strength of the ground that the cone passes through, thereby allowing for the boundaries of layers with different properties to be determined (Price et al., 2009). The CPTs, skin friction and pore water measurement were done to a depth of between $9 \mathrm{~m}$ and $15 \mathrm{~m}$ below surface. In December 2008, two boreholes were drilled with a $66 \mathrm{~mm}$ 'Delft Continuous Soil Sampler' (a type of triple-tube sampler) to a depth of $9 \mathrm{~m}$ below surface. The undisturbed cores were examined and the different geological layers and their boundaries were identified. The information from these geotechnical measurements were manually interpreted in a 3D GIS program so as to generate a 3D subsurface lithology model (Hack et al., 2008). The variation, both horizontally and vertically, is such that even over short distances correlation of lithological boundaries from one CPT to the next is not unambiguous. The accuracy of the $3 \mathrm{D}$ model in an environment with many (repeating) near similar layers and lenses, which may or may not be horizontally continuous, is always questionable. However, for the purpose of this research, the 3D model likely provides sufficient information. The trend of the layers and lenses is quite certain, and thicker layers with distinct differences in lithology can be followed throughout. The correlation of these is likely correct. 


\subsubsection{Remote sensing data}

Thermal, visible, multispectral and hyperspectral remotes sensing data were collected. A summary of data sets collected is shown in Table 2.2. Thermal images were taken for each location using the TH9100 Thermo Tracer camera (from NEC Avio Infrared Technologies Co., Ltd, Tokyo, Japan), which has a single broad band with the spectral range of 8 to $14 \mu \mathrm{m}$, measuring apparent temperature. Images were recorded over the 24 hour period, starting from $12 \mathrm{~h} 00$ on 15 July 2010. The main purpose of this data was to improve the understanding of the effects of time of observation and environmental conditions. According to Jensen (2007), there is an energy surplus around solar noon which results in maximum surface temperatures around the mid-point between solar noon and local sunset. Thermal cross-overs between water and other surfaces occur at sunset and about 1.5 hours after sunrise. From sunset until sunrise, temperatures tend toward convergence, with the exception of water due to its high thermal inertia. The maximum thermal difference between water and most other objects occurs just before sunrise. For these reasons thermal measurements were focused on the period from solar noon until sunset, and the hours preceding sunrise. Due to the collection of the other types of remote sensing data it was not possible to record thermal images at $13 \mathrm{~h} 00$ and 19h00. All thermal data sets were used for analysis. Since the peak surface temperature should have been around $17 \mathrm{~h} 30$ (based on Jensen, 2007: Fig. 8-22) and since the other types of remote sensing data were recorded for $19 \mathrm{~h} 00$, the $18 \mathrm{~h} 00$ and $20 \mathrm{~h} 00$ thermal measurements were averaged for an approximation of the $19 \mathrm{~h} 00$ temperatures for comparison with the other remote sensing data sets. The $16 \mathrm{~h} 00$ measurements were considered less suitable because the rain event occurred around this time and no visible imagery was recorded. Similarly, the $13 \mathrm{~h} 00$ measurements were also considered less suitable because there were more clouds at $13 \mathrm{~h} 00$, no visible imagery was recorded and $13 \mathrm{~h} 00$ falls outside the peak surface temperatures. As thermal remote sensing is based on emitted radiation, the remaining three types of remote sensing data will be collectively referred to as reflected remote sensing data.

Broadband multispectral images were taken for each location using the Agricultural Digital Camera 2004 model (from Tetracam, Inc., Chatsworth, California). The camera records images in the JPG format for overlapping broad bands in the green $(\mathrm{G})$, red (R) and near-infrared (NIR) wavelengths. Images were recorded at $13 \mathrm{~h} 00,16 \mathrm{~h} 00$ and $19 \mathrm{~h} 00$ on 15 July 2010 . Technical problems resulted in images not being recorded on 16 July 2010. For this chapter, the results for the $19 \mathrm{~h} 00$ measurements will be shown for the previously discussed reasons. 
Table 2.2: Summary of remote sensing measurements from 15 July $201012 \mathrm{~h} 00$ to 16 July 2010 $10 \mathrm{~h} 00$ (in local time). ( 2014 IEEE.

\begin{tabular}{|c|c|c|c|c|c|c|c|c|c|c|c|c|c|c|c|}
\hline \multirow[t]{2}{*}{ SENSOR } & \multicolumn{15}{|c|}{ TIME (in hours according to $24 \mathrm{~h} 00$ format, local time) } \\
\hline & 12 & 13 & 14 & 15 & 16 & 17 & 18 & 19 & 20 & 23 & 24 & 03 & 04 & 05 & 10 \\
\hline Thermal & $\mathrm{x}$ & & $\mathrm{x}$ & $\mathrm{x}$ & $\mathrm{x}$ & $\mathrm{x}$ & $\mathrm{x}$ & & $\mathrm{x}$ & $\mathrm{x}$ & $\mathrm{x}$ & $\mathrm{x}$ & $\mathrm{x}$ & $\mathrm{x}$ & $\mathrm{x}$ \\
\hline Multispectral & & $\mathrm{x}$ & & & $\mathrm{x}$ & & & $\mathrm{x}$ & & & & & & & \\
\hline Visible & & & & & & & & $\mathrm{x}$ & & & & & & & \\
\hline Hyperspectral & & $\mathrm{x}$ & & & $\mathrm{x}$ & & & $\mathrm{x}$ & & & & & & & $\mathrm{x}$ \\
\hline
\end{tabular}

It was decided to include measurements from a relatively cheap and easily available digital camera to test whether such an instrument could be used as a cost-effective and simple alternative to more expensive and complex sensors traditionally used in remote sensing applications. The camera used was a Canon EOS 400D (from Canon Inc., Tokyo, Japan). Visible light digital photographs were taken in raw CR2 format. The images have three layers with data recorded in broad bands in the red (R), green $(\mathrm{G})$ and blue (B) wavelengths. The blue band is sensitive from $\sim 410 \mathrm{~nm}$ to $\sim 540 \mathrm{~nm}$ with the band maxima at $\sim 450 \mathrm{~nm}$. The green band is sensitive from $\sim 460 \mathrm{~nm}$ to $\sim 600 \mathrm{~nm}$ with the band maxima at $\sim 540 \mathrm{~nm}$ and the red band is sensitive from $\sim 560 \mathrm{~nm}$ to $\sim 680 \mathrm{~nm}$ with the band maxima at $\sim 600 \mathrm{~nm}$ (Spigulis et al., 2010). The photographs were taken at $19 \mathrm{~h} 00$ on 15 July only and these were used for analysis (Table 2.2). Since these images also use broad bands, they will be included in the multispectral analysis and discussion.

Hyperspectral reflectance spectra for each location were measured using the ASD Fieldspec Pro spectrometer (from ASD, Inc., Boulder, Colorado), which has narrow bands of 2-3 nm (with a $1 \mathrm{~nm}$ sampling interval) over the spectral range of $350 \mathrm{~nm}-2500 \mathrm{~nm}$. An $8^{\circ}$ fore-optic was used at a height of about 75 $\mathrm{cm}$ with inclination so as to obtain data that covers about the same area as the image-based remote sensing instruments, which is about $30 \mathrm{~cm}$ by $40 \mathrm{~cm}$. Four sets of measurements were taken, namely $13 \mathrm{~h} 00,16 \mathrm{~h} 00$ and $19 \mathrm{~h} 00$ on 15 July 2010 and $10 \mathrm{~h} 00$ on 16 July 2010 (Table 2.2). For the reasons discussed above, the results for the $19 \mathrm{~h} 00$ measurements will be presented in this chapter.

\subsubsection{Analysis}

Pearson correlation coefficients were calculated in PASW Statistics v18 software (from IBM Corporation, Armonk, New York) to investigate the linear relationships between the data sets. For the ordinal data, namely the cover quality data set, the Spearman's rho correlation coefficient (Siegel and 
Castellan, 1988) was used. The strength of the relationships were qualified as strong when $r>0.7$, moderate when $0.4<r<0.7$ and weak when $r<0.4$. The same scale was used for the Spearman's rho. Using Moran's $I$ (Legendre and Legendre, 1998), the data was found to be spatially autocorrelated. This means that there is a systematic pattern in the spatial distribution of a data set. This is useful for the spatial interpretation of the data but it does mean that the data sets do not satisfy the correlation coefficients' assumptions of independence (Burt and Barber, 1996; Legendre and Legendre, 1998).

Dutilleul's modified $t$-test (Dutilleul, 1993) for the correlation coefficient corrects for spatial autocorrelation in the data by adjusting the degrees of freedom. Therefore the significance of the correlations were assessed with Dutilleul's modified $t$-test in the PASSaGE v2 software (Rosenberg and Anderson, 2011) for the Pearson correlation coefficient and in the modttest-5000 program (Legendre, 2000) for the Spearman's rho. The test requires the number of distance classes to be determined by the user, where more, narrower classes increase resolution but decrease the power of the test (since there are less pairs per distance class). The simple and often used Sturge's rule was used to determine the number of distance classes (Legendre and Legendre, 1998). Using the number of distances in the lower triangular matrix, Sturge's rule recommends eleven distance classes for this study. The classes were determined using the equal width setting.

Combinations of wavelength bands frequently provide more information than the bands on their own since the relative proportions of reflectance in different bands offer information on vegetation quality. For example, the NIR/R ratio provides information on overall vegetation quality and is sensitive to changes in chlorophyll concentration (Jensen, 2007) and the $\mathrm{G} / \mathrm{R}$ ratio provides information on the appearance of the vegetation including the presence of standing litter and bare soil (as observed in Asner, 1998: Fig. 2-4). Moreover, ratios reduce the effects of illumination differences between measurements (Lillesand et al., 2008), which allows for easier comparison between measurements. Simple ratios such as NIR/R, NIR/G and G/R were calculated as well a large number of indices (over 100 in total, see Table A.1) that were developed for assessing vegetation health and water content. These ratios and indices were used for analysis. The indices specifically mentioned in this chapter are shown in Table 2.3. To explore the spatial distribution and patterns of the data, the data were interpolated using the natural neighbour method and visualised using ArcGIS 10 (from ESRI, Redlands, California). 
Table 2.3: Hyperspectral indices specifically mentioned in the results and discussion of this chapter (C) 2014 IEEE.

\begin{tabular}{lll}
\hline INDEX NAME (ABBREV.) & EQUATION & REFERENCE \\
\hline $\begin{array}{l}\text { Carotenoid Reflectance Index } 1 \\
\left(\mathrm{CRI}_{550}\right)\end{array}$ & $\left(1 / \mathrm{R}_{510}\right)-\left(1 / \mathrm{R}_{550}\right)$ & (Gitelson et al., 2002b) \\
$\begin{array}{l}\text { Carotenoid Reflectance Index } 2 \\
\left(\mathrm{CRI}_{700}\right)\end{array}$ & $\left(1 / \mathrm{R}_{510}\right)-\left(1 / \mathrm{R}_{700}\right)$ & (Gitelson et al., 2002b) \\
Green/Red Ratio (GRR) & $\mathrm{R}_{554} / \mathrm{R}_{673}$ & (Kanemasu, 1974; Rodríguez- \\
& & Pérez et al., 2007) \\
Green/Red Ratio 2 (GRR $)$ & $\mathrm{R}_{550} / \mathrm{R}_{670}$ & This study \\
Greenness Index (GI) & $\mathrm{R}_{554} / \mathrm{R}_{677}$ & (Smith et al., 1995) \\
Near-infrared / Red Ratio (NIRRR) & $\mathrm{R}_{780} / \mathrm{R}_{670}$ & This study \\
Ratio Vegetation Index (RVI) ${ }^{\mathrm{a}}$ & $\mathrm{R}_{800} / \mathrm{R}_{673}$ & (Rodríguez-Pérez et al., 2007), \\
& & (Pearson and Miller, 1973) \\
Ratio Vegetation Index 1 (RVI $)$ & $\mathrm{R}_{810} / \mathrm{R}_{660}$ & (Zhu et al., 2008b) \\
Simple Ratio Water Index 2 (SRWI $)$ & $\mathrm{R}_{1350} / \mathrm{R}_{670}$ & (Rodríguez-Pérez et al., 2007) \\
Water Band Index (WBI) & $\mathrm{R}_{970} / \mathrm{R}_{900}$ & (Peñuelas et al., 1993)
\end{tabular}

R: Reflectance at specified wavelength in nanometres

${ }^{a}$ Original index was for a broadband sensor

\subsection{Results}

\subsubsection{Soil moisture and remote sensing data}

The mean volumetric soil moisture values measured for the dike for the 24 hour period ranged from 19.1 to $33.5 \%$ vol. with the average being $24.2 \%$ vol. Even accounting for calibration errors, these values are low for the soil type (Kabat and Beekma., 1994; Schlotzhauer and Price, 1999) which is predominantly clayey peat (obtained from the borehole and CPT data). It is not surprising that the measurements values were low considering that they were taken during one of the driest Julys on record. Most of the dike had low soil moisture values but the bottom part of the dike had higher values (boundary indicated by the dashed line in Figure 2.2a). Additionally, there are a number of locations over the dike which had higher values, noticeably the location near the top left of the dike.

There are significant negative correlations between the soil moisture values and the daytime thermal remote sensing, specifically the $15 \mathrm{~h} 00$ and $19 \mathrm{~h} 00$ data sets ( $r=-0.667$ and $r=-0.619$ respectively; see Table 2.4 for details). The 
correlations between the reflected remote sensing data and the soil moisture are less strong $(r<0.600)$, with about $68 \%$ of these having significant moderate correlations. The strongest of these are shown in Table 2.4 and are for the narrowband hyperspectral $\mathrm{RVI}_{1}, \mathrm{NIRRR}$ and RVI ratios as well as for the broadband visible $\mathrm{G} / \mathrm{R}$ ratio. All three of these hyperspectral narrowband indices are simple ratios using wavelengths in the range of $780 \mathrm{~nm}$ to $810 \mathrm{~nm}$ for the numerator and $660 \mathrm{~nm}$ to $673 \mathrm{~nm}$ for the denominator. The correlations between soil moisture and the multispectral remote sensing are mostly not significant, with only the ratios showing significant correlations. These were $r=0.447$ for NIR/R, $r=0.444$ for NIR/G and $r=0.354$ for $\mathrm{G} / \mathrm{R}$.

Table 2.4: Correlation coefficients for selected data sets. Resistivity (mean) refers to the mean resistivity value for the top $0.5 \mathrm{~m}$. See Table A.1 for definitions of hyperspectral indices. (C) 2014 IEEE.

\begin{tabular}{|c|c|c|c|}
\hline DATASET 1 & DATASET 2 & $\begin{array}{l}\text { CORRELATION } \\
\text { COEFFICIENT }\end{array}$ & $\begin{array}{l}\text { CORRELATION } \\
\text { TYPE }\end{array}$ \\
\hline Soil moisture & Thermal (15h00) & -0.667 & Pearson \\
\hline Soil moisture & Thermal (19h00) & -0.619 & Pearson \\
\hline Soil moisture & Hyperspec. $\mathrm{RVI}_{1}$ & 0.591 & Pearson \\
\hline Soil moisture & Hyperspec. NIRRR & 0.591 & Pearson \\
\hline Soil moisture & Thermal (20h00) & $-0.590 *$ & Pearson \\
\hline Soil moisture & Hyperspec. RVI & 0.590 & Pearson \\
\hline Soil moisture & Visible G/R & 0.589 & Pearson \\
\hline Cover quality & Multispec. NIR/R & -0.655 & Spearman \\
\hline Cover quality & Multispec. NIR/G & -0.632 & Spearman \\
\hline Cover quality & Hyperspec. WBI & -0.630 & Spearman \\
\hline Cover quality & Thermal (19h00) & 0.612 & Spearman \\
\hline Cover quality & Hyperspec. $\mathrm{CRI}_{700}$ & -0.611 & Spearman \\
\hline Cover quality & Hyperspec.CRI ${ }_{550}$ & -0.610 & Spearman \\
\hline Cover quality & Thermal (18h00) & 0.605 & Spearman \\
\hline Cover quality & Soil moisture & -0.460 & Spearman \\
\hline Resistivity (surface) & Hyperspec. GI & $0.611^{*}$ & Pearson \\
\hline Resistivity (surface) & Hyperspec. GRR & $0.610^{*}$ & Pearson \\
\hline Resistivity (surface) & Hyperspec. GRR 2 & $0.608 *$ & Pearson \\
\hline Resistivity (mean) & Hyperspec. GI & $0.633^{*}$ & Pearson \\
\hline Resistivity (mean) & Hyperspec. GRR & $0.632 *$ & Pearson \\
\hline Resistivity (mean) & Hyperspec. SRWI 2 & $0.603 *$ & Pearson \\
\hline
\end{tabular}

* Correlations are significant at $\mathrm{p}<0.05$ (two-tailed)

Remaining correlations are significant at $\mathrm{p}<0.01$ (two-tailed). 


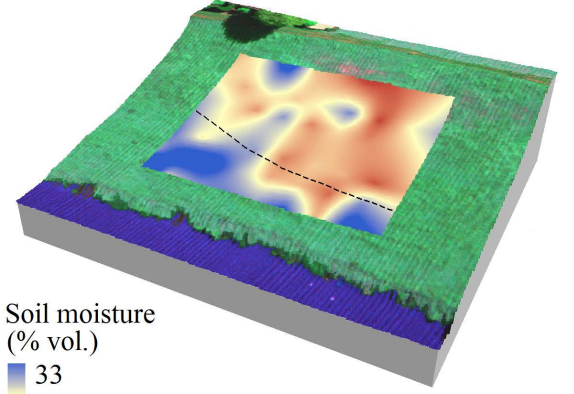

(a)

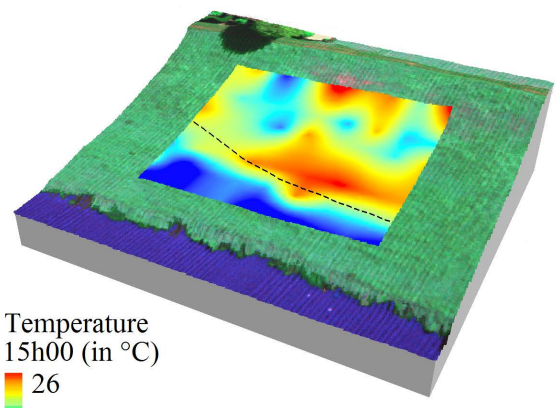

(c)

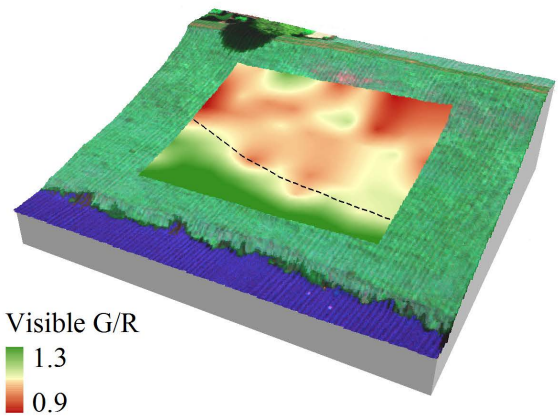

(e)

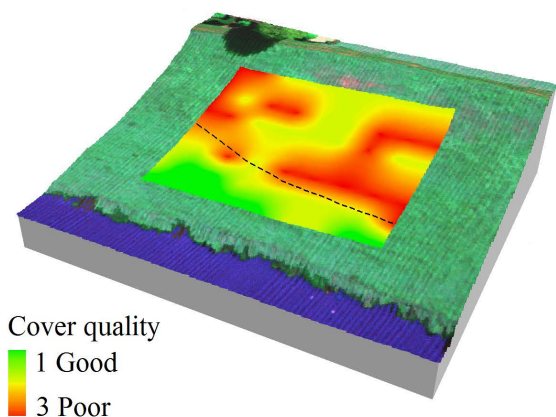

(b)

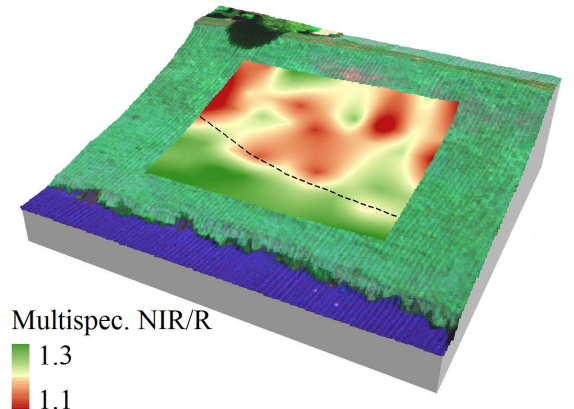

(d)

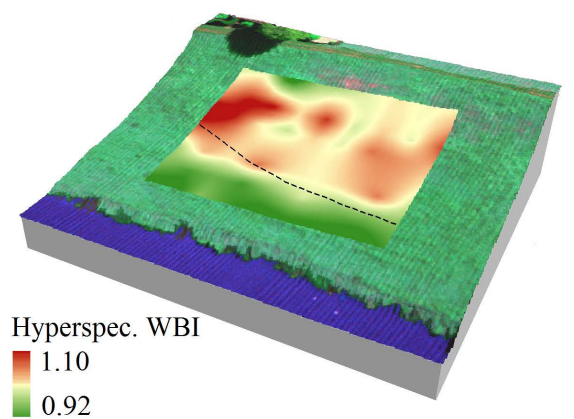

(f)

Figure 2.2: Maps showing spatial distribution of the two validation data sets, namely (a) soil moisture and (b) cover quality and four of the remote data sets from the four different types of sensors, namely (c) the thermal camera, (d) the multispectral camera, (e) the visible light digital camera and (f) the hyperspectral spectrometer. The dashed line indicates where the bottom part of the dike manifests differently from the rest of the dike. @ 2014 IEEE.

The spatial distributions for the thermal (15h00) data and the visible $\mathrm{G} / \mathrm{R}$ ratio are shown in Figure 2.2c and 2.2e respectively. The same overall spatial pattern, as found in the soil moisture map, is found in these maps, with the bottom part of the dike being different from the rest of the dike (as indicated by the dashed line) and with the smaller wetter locations also visibly different. There is a 
significant moderate correlation $(r=-0.460)$ between cover quality and soil moisture. The area at the bottom of the dike, which is different from the rest of the dike, is evident in both the soil moisture and cover quality maps (Figure 2.2a-b). This is not unexpected. Soil moisture has a considerable effect on vegetation health, on which the quality of the dike cover is largely dependent.

\subsubsection{Cover quality and remote sensing data}

The cover quality on the main dike body was medium to poor, with the bottom part of the dike having good quality cover. The spatial distribution of cover quality is shown by the cover quality map in Figure 2.2b, with the dashed line indicating the separation between the poorer quality cover on the top part of the dike from the good quality cover at the bottom. The line does not run parallel with the dike but moves up the dike towards the left of the study area. The cover quality has significant correlations with a number of the remote sensing data sets, with the strongest relationships shown in Table 2.4. About $75 \%$ of the reflected remote sensing data have significant moderate correlations to cover quality. The cover quality demonstrates stronger relationships with reflected remote sensing data compared to the emitted thermal remote sensing data. Noticeably, the correlations with the broadband multispectral NIR/R and NIR/G ratios and the narrowband hyperspectral Water Band Index (WBI) are moderate $(r=-0.655, r=-0.632$ and $r=-0.630$ respectively), with a less strong correlation to the $19 \mathrm{~h} 00$ thermal data $(r=0.612)$. Although there are other hyperspectral or thermal data sets that have higher correlations, the moderate -0.593 correlation for the simple visible $\mathrm{G} / \mathrm{R}$ ratio to cover quality is interesting because the data is from a standard digital camera. The NIR/R ratio, WBI and $\mathrm{G} / \mathrm{R}$ ratio spatial distributions are shown in Figure $2.2 \mathrm{~d}, 2.2 \mathrm{f}$ and $2.2 \mathrm{e}$ respectively. The same overall spatial pattern, as found in the cover quality map, with the bottom part of the dike being different from the rest of the dike (as indicated by the dashed line), is visible in all three data sets.

\subsubsection{Relationships between remote sensing data}

The remote sensing data sets have many strong significant correlations between different instruments and wavelengths (not shown). There are strong correlations between the afternoon thermal remote sensing data and many of the reflected remote sensing data, specifically vegetation indices. There are also strong correlations between the different types of reflected remote sensing data. The broadband visible $\mathrm{G} / \mathrm{R}$ ratio data shows correlations to many of the narrowband indices that make use of data in the NIR and R wavelengths. Water 
content indices show correlations to vegetation health indices. This, together with the correlation between soil moisture and cover quality, would indicate that the moisture and vegetation health are strongly linked for this dike.

Maps for four remote sensing data sets are shown in Figure 2.2c-f. These data sets were selected as they have strong correlations to soil moisture (Figure 2.2c and 2.2e) and to cover quality (Figure $2.2 \mathrm{~d}$ and $2.2 \mathrm{f}$ ) and so that the four types of remote sensing data are represented. The $15 \mathrm{~h} 00$ temperatures (Figure 2.2c) reveal that the dike was cooler along the bottom, with the temperatures warmer along the upper parts of the dike except for a cooler patch in the upper left corner of the study area. Similar patterns, with the large area along the bottom of the dike and the smaller area at the top left of the dike being different, are also apparent in the reflective data sets shown by the multispectral NIR/R, visible $\mathrm{G} / \mathrm{R}$ and hyperspectral WBI maps in Figure $2.2 \mathrm{~d}-\mathrm{f}$.

In order to explore the effect of time of observation on the thermal measurements, the values were plotted against time (Figure 2.3). For easier discernment, only six locations are presented, three for higher soil moisture content and three for lower soil moisture content. Two of the wetter locations were located at the bottom left of the dike and the third was located at the wetter spot in the upper left of the dike. The three drier locations were on the right hand side of the dike and distributed from top to middle. The maximal difference between the wetter and drier locations occurred in the afternoon after solar noon. Post sunset values converged with little to no difference between the locations. Heavy cloud accompanied by a few rain drops occurred at around $16 \mathrm{~h} 00$ and had a significant effect on the temperature values causing them to

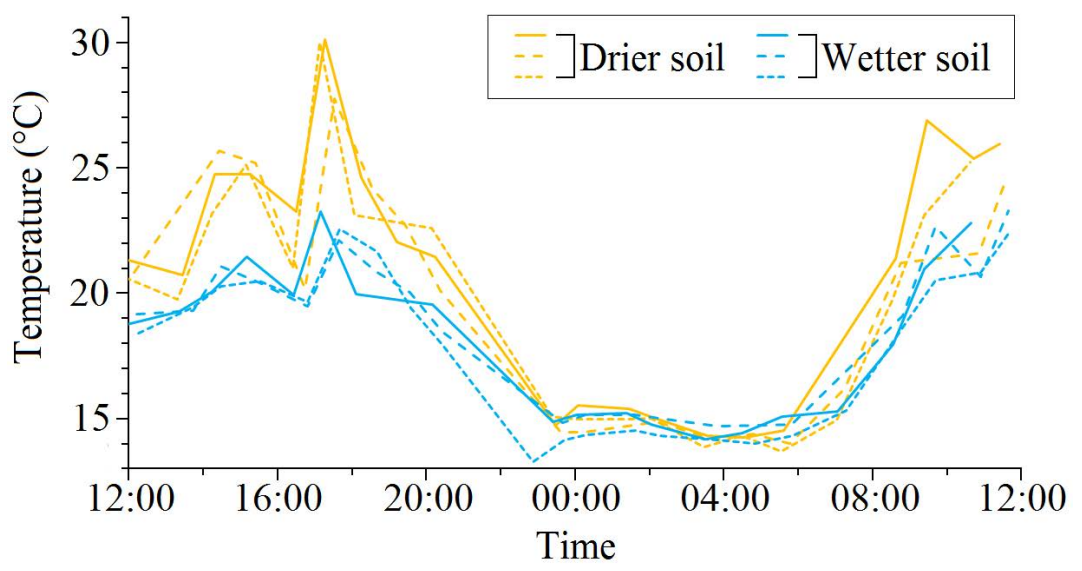

Figure 2.3: Thermal time series plot showing the diurnal variation in thermal measurements and the differences between wetter and drier soil locations. (C) 2014 IEEE. 
drop. The curves per location are not smooth and show fluctuations. Some of these fluctuations can be linked to the locations experiencing changes in illumination, either from changes in cloud cover density, shadowing from objects (such as trees) or due to the slope of the dike.

\subsubsection{Other data}

The resistivity values for the dike as a whole were relatively low (with a maximum of $39 \mathrm{Ohm}-\mathrm{m}$ ) which is in line with the geographical setting of the area in a former delta area with sea influences (Palacky, 1988). The electrical resistivity values at the surface layer and the mean resistivity values for the top $0.5 \mathrm{~m}$ show a moderate correlation to reflected remote sensing data sets, particularly in the green wavelengths and also a water index (Table 2.4). The correlation coefficients between these resistivity data sets and the soil moisture values and the cover quality are not significant. Figure $2.4 \mathrm{a}$ shows the spatial distribution of the surface resistivity values, where the bottom of the dike has higher resistivity values compared with the top. This basic spatial distribution, where the bottom of the dike is different from the rest of the dike, is also evident in the maps in Figure 2.2. Figure 2.4b shows the vertical spatial distribution of the electrical resistivity for a cross-section of the dike (the location of cross-section $\mathrm{A}-\mathrm{A}^{\prime}$ is indicated by the solid line in Figure 2.4a). The top part of the dike (on the right in Figure 2.4b) exhibits horizontal layering in the resistivity, with the resistivity decreasing from the surface to about -7.5 m NAP (Normaal Amsterdams Peil or Amsterdam Ordnance Datum), from where it starts to increase in value again. The bottom part of the dike (on the left in Figure 2.4b) exhibits higher resistivity values compared to the rest of the dike, with a slight decrease in resistivity at about $-8 \mathrm{~m}$ NAP, but without the horizontal layering found in the top part of the dike. When viewed in threedimensional space (not shown), this higher resistivity at the bottom of the dike manifests as a dome.

The 3D subsurface lithology model, which is based on the CPT and borehole data (Hack et al., 2008), shows that the dike is made up of horizontal layers of peat with slightly different compositions, which are interbedded with layers and lenses of clay and silt (Figure 2.4c). These lie above Pleistocene sands which occur at a depth of about -11 m NAP. The horizontal geological layers are apparent in the resistivity data for the top part of the dike (the right side of the cross-sections in Figure $2.4 \mathrm{~b}-\mathrm{c}$ ), where the decrease in resistivity at about -7 m NAP corresponds with thicker layers of silt and clay and where the increase in resistivity at about -11 m NAP corresponds with the sand layers. For the bottom part of the dike (the left side of the cross-sections in Figure $2.4 \mathrm{~b}-\mathrm{c}$ ), the horizontal geological layers are not reflected in the 


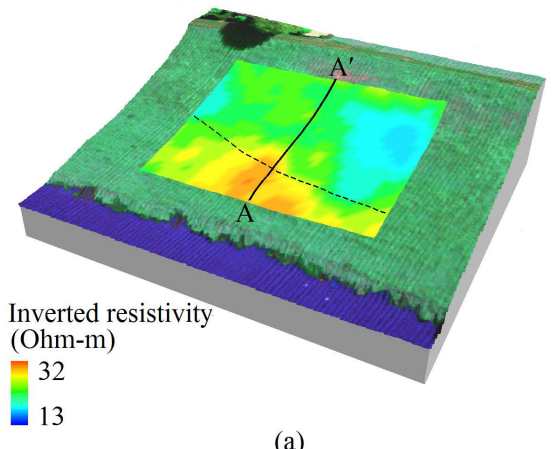

(a)
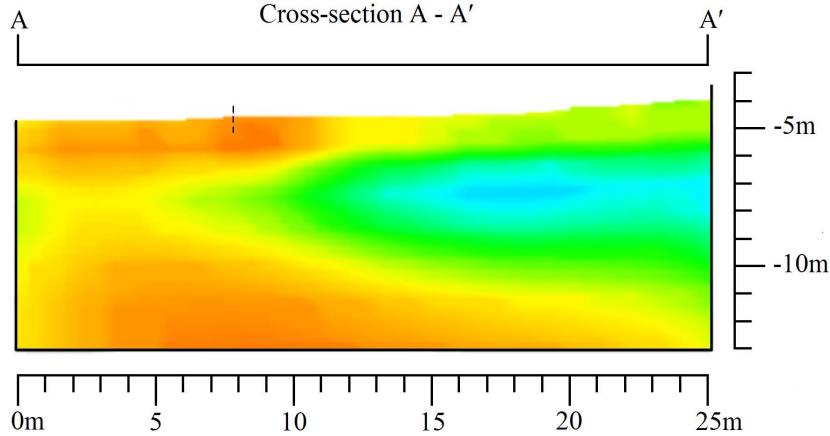

Inverted resistivity (Ohm-m)

(b)
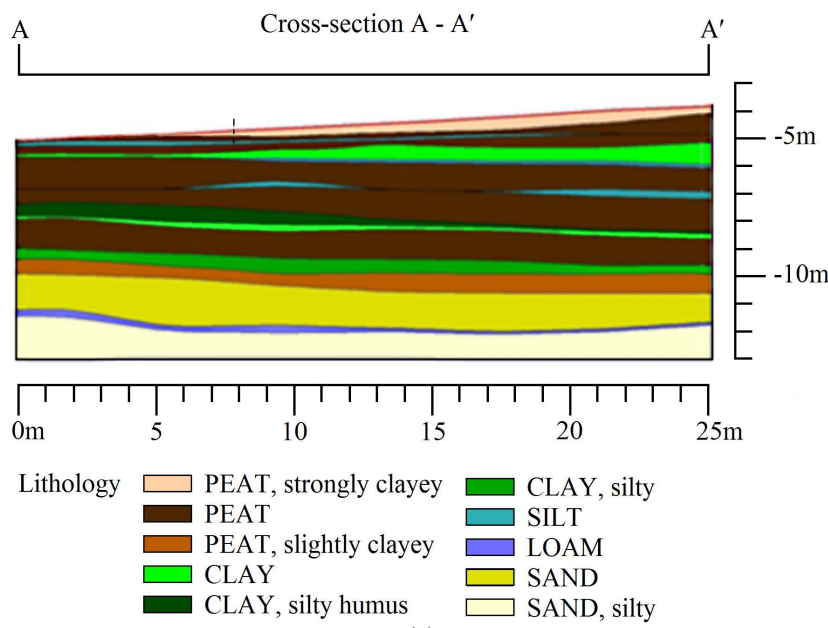

(c)

Figure 2.4: Resistivity and (simplified) lithology data: (a) map of resistivity at the surface, where the dashed line indicates where the bottom part of the $d$ ke manifests differently from the rest of the $d$ ke and with the location of cross-section A-A' indicated by the solid line; (b) resistivity cross-section $A-A^{\prime}$ showing horizontal layering on the right and higher resistivity values on the left (bottom of the dike) with horizontal layering absent; (c) lithology cross-section A-A' showing horizontal layering of peat, clay and silt, with sand layers starting at about -11 m NAP. (Note: the lithology descriptions are simplified, indicating the most important constituents for this research). ( 2014 IEEE. 
resistivity data. Rather the resistivity values are consistently higher than the rest of the dike and follow a plume shaped pattern originating from the bottom of the model and fanning out at the surface.

\subsection{Discussion}

\subsubsection{Soil moisture}

\subsubsection{Soil Moisture in Relation to Dike Condition}

The bottom of the dike was anomalously wet during the years that the dike has been investigated which may be indicative of processes, other than the dry season, which could be compromising the quality of the dike. The wetter area at the bottom of the dike could not be linked back to the lithology. As seen in the results, the lithological layering is predominantly horizontal. However, it could be linked to the resistivity measurements for the dike, where the occurrence of the plume shaped feature of higher resistivity is spatially correlated with the wetter portions in the area. There are two possible processes that can explain the higher resistivity values at the bottom of the dike while also accounting for the discrepancy between the lithographical and resistivity models. The first is that gases are present in the dike. Gases do not readily allow the flow of electric current and therefore their presence in the soil increases the electrical resistivity of the soil. These gases could originate from deeper layers below the dike or from other areas, transported via groundwater. The gases could also originate from decomposing peat (Estop-Aragonés and Blodau, 2012).

The second possible process is that fresh water is flowing upwards from the deeper sand layers. Fresh water has less free electrolytes, thereby increasing the overall resistivity of the medium. An up-rise of fresh water is remarkable in an area known for saline water seepages (de Louw et al., 2007; TNO, 2006). However, the saline effect is localized to boils and paleochannels (de Louw et al., 2007; de Louw et al., 2010). It is therefore possible that locally fresh water comes to the surface. Studies (de Louw et al., 2007; de Louw et al., 2010; Oude Essink et al., 2012) show that in environments such as the study site, upwelling of fresh water is not unlikely to occur (Figure 2.5). From the scale of the resistivity model it is not possible to explain if the water comes from the nearby ditch or the lakes further away (Figure 2.5). The small scale explanation with fresh water from the nearby channel is possibly more likely due to the size and shape of the plume but larger subsurface studies (both horizontally as well as vertically) would be required to provide more evidence to the source of this possible fresh water plume. 


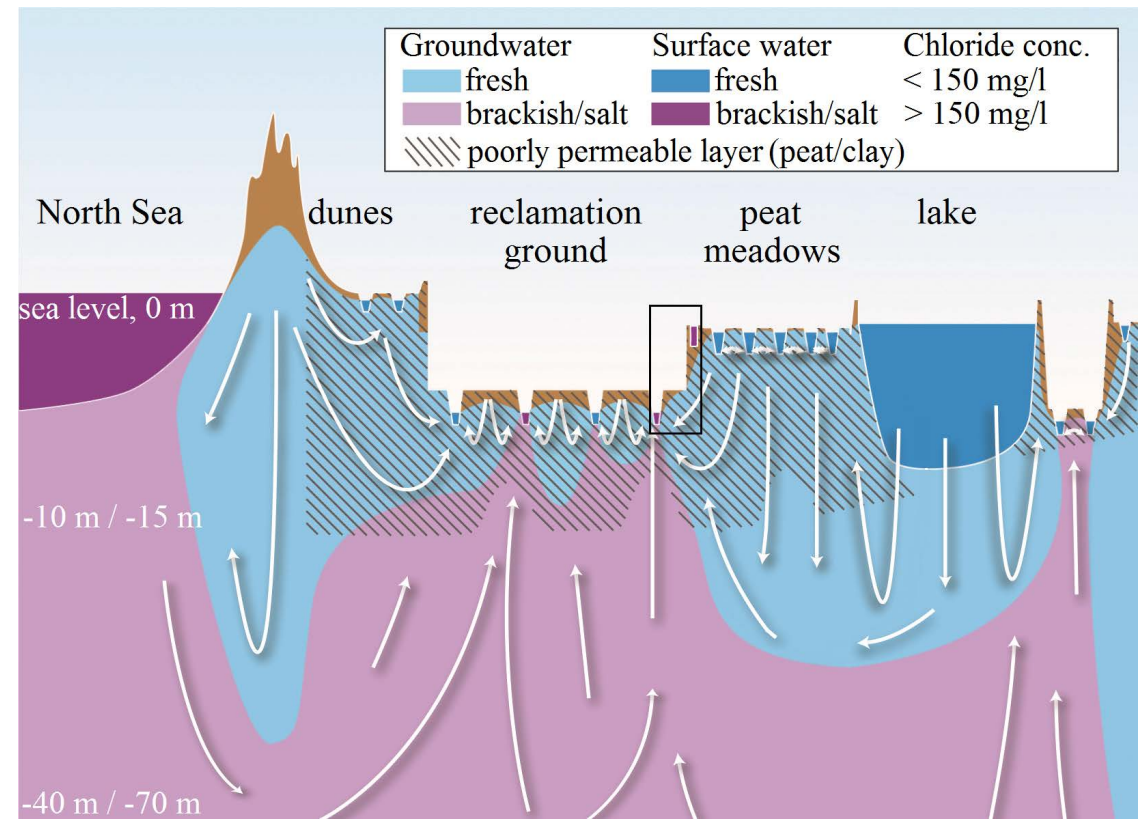

Figure 2.5: Schematic diagram of ground water flows in a peat excavation environment (modified after Oude Essink et al., 2012: Fig. by P. de Louw). The black rectangle indicates an area representative of the study site. (c) 2014 IEEE.

Due to the higher soil moisture levels measured at the bottom of the dike and the spreading of the higher resistivity plume along the surface, it seems unlikely that the higher resistivity values are due to gases in the subsurface, which would most likely not extend horizontally. The higher soil moisture values at the bottom of the dike would confirm the second process of upwelling water. Further, the healthier vegetation at the bottom of the dike during a time of extreme dryness would affirm a long-term process of upwelling water. In the long-term, the higher soil moisture values at the bottom of the dike indicate a process which needs to be investigated further to establish whether this process poses a problem to the dike quality.

\subsubsection{Soil moisture and thermal remote sensing}

Vegetation responds to available soil moisture. When a plant suffers from a shortage of water, the stomata close which reduces evapo-transpiration (Hopkins and Hüner, 2009; Medrano et al., 2003). This causes an increase in plant temperature (Jackson et al., 1986). Thus when a plant has sufficient water available, the plant is cooler than when suffering from water deficiency. Previous thermal remote sensing studies for dikes focused on seepage alone (Givehchi et al., 2002; Moser and Zomer, 2006; Swart, 2007; van Hemert, 
2004). These previous studies were only successful when there were large contrasts in temperature between the water and the dike surface. The results from this study show that thermal remote sensing can also be used to distinguish areas of varying soil moisture and not only where water itself is present at the surface.

Although there are correlations between soil moisture values and the thermal measurements, they are not strong, and their spatial distributions show some differences. This may be due to the fact that the cover was not a uniform green grass cover. The temperature of the dike cover recorded at the camera is affected by a number of factors. These include evapo-transpiration and the thermal properties of the cover, such as emissivity and specific heat capacity. Evapo-transpiration is an endothermic process which cools down green vegetation (Jayalakshmy and Philip, 2010). Green grass has a higher emissivity, which results in a lower apparent temperature, than dry grass or bare soil (Snyder et al., 1998). Vegetation, whether dry or green, has high values for the specific heat capacity (Jayalakshmy and Philip, 2010). This means that it requires more energy to raise the temperature of vegetation than for bare soil (which has a lower specific heat capacity). Therefore with the same amount of incoming solar radiation, vegetation will be cooler than bare soil. Additionally, some of the grass was long causing shadowing, which results in lower temperatures for the cover. Another reason for the moderate correlation could be the changing cloud cover during measurement, which caused fluctuations in temperatures, as shown in Figure 2.3.

\subsubsection{Soil moisture and multispectral remote sensing}

The simple $G / R$ ratio from the visible broadband camera has a moderate correlation to soil moisture, which is also evident in their spatial distribution. From these results, it would seem that the standard digital camera out-performs a specialised camera for this application. Thermal responses of vegetation are relatively rapid, whereas long-term exposure to abundant soil moisture results in lush, green vegetation. Long-term exposure to water deficiency results in plant senescence, with the leaves drying out and dying, and which may in turn result in the death of the plant itself. The $G / R$ ratio is used for estimating the greenness of the vegetation (Adamsen et al., 1999). Thus, this ratio could be used for identifying areas affected by long-term soil moisture regimes. Since there is a correlation between the G/R ratio and the soil moisture, it would appear that the study area is affected by a long-term water condition. This would confirm the explanation of the high resistivity values at the bottom of the dike, where it is proposed that water is being pushed up through the dike. Considering that the resistivity measurements are from 2008 and the remote 
sensing measurements from 2010, it would indeed seem that the process is a long-term one.

\subsubsection{Soil moisture and hyperspectral remote sensing}

The three strongest relationships found between the narrowband hyperspectral remote sensing data and the soil moisture values all make use of simple NIR/R ratios. These indices provide information about vegetation biomass (Jensen, 2007). Reflectance in these wavelengths is also affected by the presence of standing litter, the leaf area (as observed in Asner, 1998: Fig. 2 \& 4) and water stress (Jensen, 2007). Thus these indices provide information on overall vegetation health, which is strongly affected by soil moisture availability. Similarly to the G/R ratio discussed above, these NIR/R indices' correlations to soil moisture would seem to indicate that the dike is undergoing processes which affect the long-term water condition in the dike.

\subsubsection{Cover quality}

\subsubsection{Cover quality and thermal remote sensing}

A likely explanation for the only moderate correlations between the thermal remote sensing data and cover quality is that a single cover quality class is often comprised of several cover types, such as green vegetation, standing litter (dry vegetation) and bare soil, in varying proportions. As discussed in the soil moisture and thermal remote sensing section, these various cover types have different thermal responses. Thus the varying proportions of cover types within a single class could account for some of the differences between the thermal remote sensing data and the cover quality. A more detailed classification system could improve the strength of the relationships.

\subsubsection{Cover quality and multispectral remote sensing}

The multispectral remote sensing shows the strongest correlations to cover quality compared to the other remote sensing data sets. This is consistent with what Broge and Leblanc (2000) found, in that broadband indices performed better than hyperspectral narrowband indices for gauging green leaf area index and canopy chlorophyll density. Both the NIR/R and the NIR/G ratios have moderate correlations to cover quality. For these data sets, the NIR measurements are the main contributors, with measurements in the $\mathrm{R}$ and $\mathrm{G}$ being similar in magnitude. Energy in the NIR is strongly reflected from green vegetation (Jensen, 2007; Lillesand et al., 2008) and is affected by leaf area, bare soil and standing litter (Asner, 1998). Therefore, these ratios are suitable for cover quality evaluation. However, the cover quality data is ordinal and the 
ratio data is continuous which may account for the relationship being only moderate.

\subsubsection{Cover quality and hyperspectral remote sensing}

Significant relationships are found between the narrowband hyperspectral remote sensing data and the cover quality, and are also discernible in the spatial distribution of these data sets. The strongest relationship is between the WBI and cover quality. This index (see Table 2.3 for formula) was developed for use as an indicator for leaf and canopy water content (Peñuelas et al., 1993) based on a water absorption feature around $970 \mathrm{~nm}$, and the absence of it at $900 \mathrm{~nm}$. Reflection in the $970 \mathrm{~nm}$ and $900 \mathrm{~nm}$ wavelengths is also affected by low leaf area, standing litter and bare soil (as observed in Asner, 1998: Fig. 2-4), all of which increase the index value. Peñuelas et al. (1993) also state that the index does not perform well with changes in leaf area and if the vegetation does not completely cover the soil. The presence of standing litter and bare soil strongly affect values for this index and dominate over the subtler changes in absorption feature depth that result from water deficit stress in green vegetation. With the cover quality largely being medium to poor, there were substantial amounts of standing litter and bare soil. This would explain why, in this case, this index works well for cover quality but not for soil moisture. The next strongest correlations for hyperspectral data and cover quality are for the two carotenoid reflectance indices, $\mathrm{CRI}_{700}$ and $\mathrm{CRI}_{550}$. Although these indices were developed for assessing carotenoid content in plants, reflectance in the wavelengths $700 \mathrm{~nm}, 550 \mathrm{~nm}$ and $510 \mathrm{~nm}$ is strongly affected by the presence of standing litter and bare soil (as observed in Asner, 1998: Fig. 2-4). This supports that these indices are suitable for assessing cover quality, which is to a large degree determined by the presence of standing litter and bare soil.

For many of the remote sensing measurements, the signal collected was from a mixture of cover components. These components do not affect the signal linearly. In particular, a small amount of standing litter has an inordinate effect on the overall reflectance from the dike cover (Asner, 1998). This, together with the cover quality data being ordinal, could account for the correlations only being moderate between the remote sensing data and the cover quality data. Using a more detailed classification system for cover quality may improve these correlations. Further, for the hyperspectral data, the collection of end-member spectral signatures for the specific components of the dike cover and the use of these in spectral analysis could also be useful for determining proportions of the these components. This would further improve the characterisation of the dike cover. 


\subsubsection{Thermal remote sensing conditions}

From the results for both the soil moisture and the cover quality data sets, it is clear that the optimal time for thermal remote sensing data collection for these applications is between solar noon and apparent sunset, when temperature differences are at their maximum. Since no standing water was visible on the dike (e.g., from seepage), thermal cross-overs were not apparent in the thermal data and the pre-dawn measurements did not show separation between the wetter and drier locations. As has been discussed, the composition of the dike cover strongly affects the thermal response from the dike surface. This, together with the effect of moisture, makes the interpretation of thermal data complex. Additionally, as was shown in the thermal time series plot in Figure 2.3, local conditions have a substantial impact on temperatures. Heavy cloud cover and rain had a considerable cooling effect, reducing the difference between locations. The effect of illumination conditions, either from changing cloud cover, shadowing or slope, is seen in the fluctuations in temperature for individual locations.

\subsection{Conclusions}

This study, using ground-based measurements, found that there are relationships between remote sensing data and two inspection criteria for grass covered dikes, namely soil moisture and cover quality. Afternoon thermal remote sensing data have the strongest relationships to soil moisture. Weaker relationships are found between soil moisture and narrowband hyperspectral near-infrared and red indices and the broadband G/R ratio from the standard digital camera. These relationships to reflected remote sensing data appear to be based on long-term responses to a water regime induced by subsurface processes. A standard digital camera could be used to monitor long-term moisture conditions in dikes via vegetation responses. Nevertheless, relating soil moisture directly to dike quality is complex and requires contextual interpretation due to the peat dike quality being compromised by both excessive dryness and excessive wetness.

Broadband multispectral remote sensing data has the strongest relationships to cover quality, particularly those using NIR ratios. Weaker relationships are found between cover quality and afternoon thermal data and narrowband hyperspectral indices. Due to the complex nature of the spectral signature from mixed cover types, further research is required to establish if more information may be obtained from hyperspectral data with analysis of the whole spectra using specific end-members. 
It was found that the optimal time for thermal measurements for these applications is in the afternoon, after solar noon. However, it was shown that the thermal response of the dike is strongly affected by cover type, local weather conditions and illumination levels. Even fluctuations in thickness of cloud cover result in changes in measured temperatures. These factors can make the interpretation of the thermal data difficult and must be taken into consideration.

Remote sensing shows great potential for use as proxies for dike inspection criteria for grass covered dikes. From these results it is proposed that remote sensing can be used to facilitate dike inspection, particularly for identifying larger spatial features that require further geo-technical exploration. A large spatial feature at the bottom of the dike was consistently detected, with smaller features apparent only in certain data sets. Whether this is extendable to other dike situations requires further investigation. Future work will explore the scaling from ground-based measurements to airborne and satellite based imagery for dike inspection. 


\section{Adjusting Spectral Indices for Spectral Response Function Differences of Very High Spatial Resolution Sensors Simulated from Field Spectra ${ }^{2}$}

2 This chapter has been published as: Cundill, S. L., van der Werff, H. M. A. \& van der Meijde, M. (2015). Adjusting spectral indices for spectral response function differences of very high spatial resolution sensors simulated from field spectra. Sensors, 15 (3), 6221-6240. 


\subsection{Introduction}

Remote sensing data are widely used for vegetation, environmental, hazard and land process monitoring and assessment from local through to global scales. For monitoring, data from multiple sensors are often used in order to ensure coverage and continuity, particularly due to limitations of satellite revisit time (Steven et al., 2003), cloud cover (Soudani et al., 2006; Steven et al., 2003) as well as satellite design life (van Leeuwen et al., 2006). However, data obtained from different sensors are not directly comparable (Steven et al., 2003; Teillet et al., 1997). Differences in sensor specifications as well as scene-specific conditions (e.g., atmosphere, sun angle, etc.) affect measurements (Pandya et al., 2007; van Leeuwen et al., 2006). Cross-calibration between sensors is necessary for consistency and comparison of observations (Chander et al., 2013b; Steven et al., 2003; Teillet et al., 2007). One of the main causes of differences in remote sensing data is the difference in spectral response functions (SRF) between sensors (Chander et al., 2013b; D'Odorico et al., 2013; Gonsamo and Chen, 2013; Pandya et al., 2007; Trishchenko et al., 2002a). The effect may be such as to mask subtle natural variability that is of interest (D'Odorico et al., 2013; Trishchenko et al., 2002a).

It has been shown that SRF corrections are target (cover type) specific (Chander et al., 2013b; Du et al., 2007; Gallo et al., 2005; Teillet and Ren, 2008). The cover type of cultivated grasslands, which includes cultivated pastures (used for fodder production, grazing, erosion protection, etc.) and turf grasses (such as lawns, parks and golf courses), cover substantial proportions of land surface. For example turfgrass is estimated to cover some $1.9 \%$ (about $163800 \mathrm{~km}^{2}$ ) of the continental United States (Milesi et al., 2005) and permanent cultivated pastures cover about $18.4 \%$ (about $7664 \mathrm{~km}^{2}$ ) of the Netherlands (FAO, 2011), with thousands of kilometres of grass covered dikes (Knoeff et al., 2008; Verheij et al., 1997). Evaluation and monitoring of cultivated grasslands using remote sensing data are the subjects of numerous studies (e.g., Baghzouz et al., 2006; Dettman-Kruse et al., 2008; Metternicht, 2003), including for inspection and monitoring of grass covered dikes (Cundill et al., 2014; Hossain et al., 2006). Consequently investigation of SRF effects for the cross-calibration of sensors for the cultivated grasslands cover type is required.

While some investigations of SRF effects for cross-calibration focus on comparing sensors at reflectance band level (Chander et al., 2013b; Potts et al., 2013; Teillet et al., 2007), many include spectral indices that provide information on plant biophysical parameters. In fact, Miura et al. (2013) suggest that there may be an advantage to cross-calibrating at the index level rather than the reflectance band level, since indices generated from cross-calibrated 
reflectance bands may include bias errors that arise from not accounting for intra-sensor band to band correlations. Since the development of the attributed first vegetation index in 1969 (Jordan, 1969), over a hundred different indices have been developed (Cundill et al., 2014), addressing different aspects of improving vegetation characterization. Many aim at reducing the effects of extraneous influences (e.g., soil background, atmosphere) while others focus on specific chemical or structural components of vegetation (e.g., chlorophyll, water content). Various indices have been investigated for the evaluation and monitoring of turfgrass (Fitz-Rodriguez and Choi, 2002; Taghvaeian et al., 2013), pastures (Metternicht, 2003) and a large number of spectral indices have been tested for use in the inspection of grass covered dikes (Cundill et al., 2014). Only a few studies have addressed the SRF effects for cross-calibration of indices other than NDVI. These studies, for 2-8 indices across up to 17 sensors (Soudani et al., 2006; Steven et al., 2003; Teillet and Ren, 2008; Teillet et al., 1997; Xu and Zhang, 2011), show that variations in the SRFs of different sensors result in significant differences in index values which must be corrected to avoid bias in observations.

Most cross-calibration related studies focus on low to medium spatial resolution sensors, such as AVHRR, MODIS and Landsat (Chander et al., 2013b; Gonsamo and Chen, 2013; Miura et al., 2013; Teillet and Ren, 2008; Teillet et al., 1997; Trishchenko et al., 2002a; van Leeuwen et al., 2006). However, the small size of individual lawns and parks and the often long and narrow structure of dikes and golf courses dictate that remote sensing data of very high spatial resolution are required. A few studies have included higher spatial resolution instruments (e.g., IKONOS, QuickBird) amongst those studied (Forestier et al., 2013; Franke et al., 2006; Pandya et al., 2007; Soudani et al., 2006; Steven et al., 2003; Teillet et al., 2007), however SRF adjustment coefficients are dependent on the specific sensors studied and in particular, the sensor selected as reference. To the best of the authors' knowledge, none have focused on very high spatial resolution sensors.

This research is conducted as part of on-going studies that are investigating the use of remote sensing data for the inspection of grass covered dikes. The initial research (see Cundill et al., 2014) involved the testing of ground based remote sensing data for two dike inspection indicators. With the successful results of that research, a subsequent investigation is underway to test the use of imagery for the same application. However, since index values from different sensors are not directly comparable, this chapter aims to investigate the effects of differing SRFs of various very high spatial resolution sensors on the cross-calibration of numerous spectral indices in the context of cultivated grasslands, which are typically found on dikes that do not have a hardened cover. 


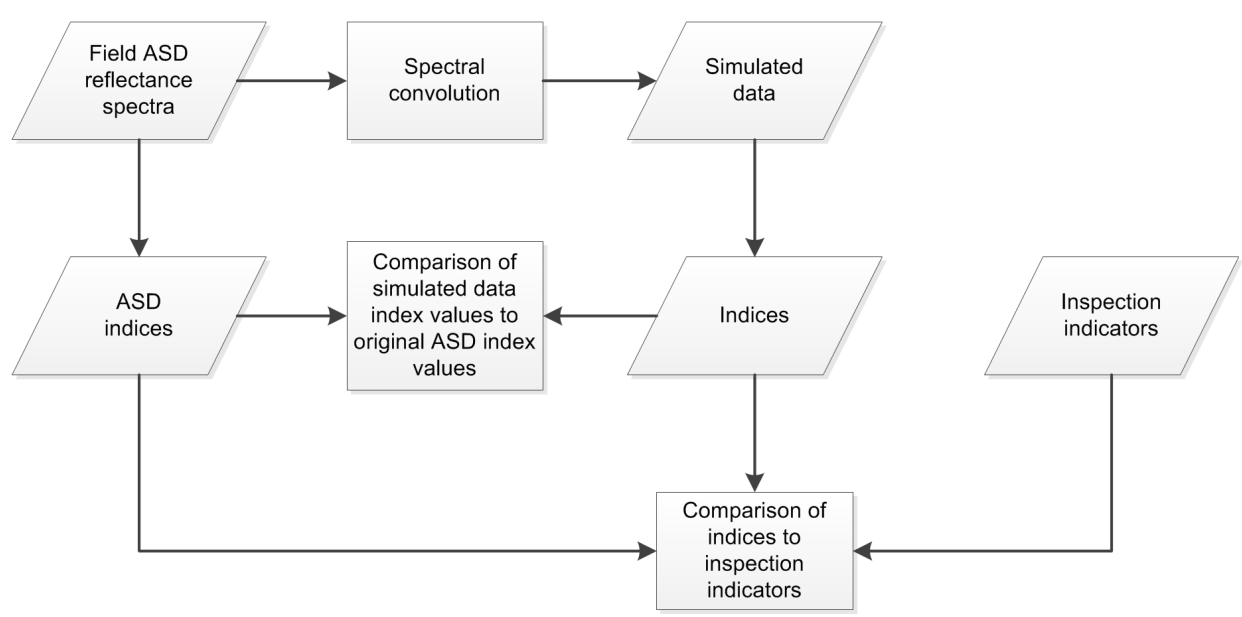

Figure 3.1: Summary workflow of the materials and methods used in this chapter.

\subsection{Materials and Methods}

A summary workflow of the materials and methods used in this chapter is given in Figure 3.1, with the details elaborated on in the remainder of this section.

\subsubsection{Data}

While some studies that address the effects of SRFs on cross-calibration between sensors make use of laboratory measurements (e.g., Trishchenko et al., 2002b), many make use data from airborne imagery (e.g., Franke et al., 2006; Teillet et al., 1997), satellite imagery (e.g., Chander et al., 2013b; Miura et al., 2013) or field measurements (e.g., Pandya et al., 2007; Steven et al., 2003). Data from field measurements provide reflectance spectra of the vegetation canopy, practically free from atmospheric affects, and allow for precise measurement of specific locations and a range of conditions. The data used for this chapter are field measurements that were collected as part of a study testing ground based remote sensing data for two dike inspection indicators (Cundill et al., 2014). The data were collected for 54 locations on a grass covered dike in the Netherlands on 15 July 2010. The measurement grid consisted of six lines running along the dike spread over the geometric profile, with nine points per line at $5 \mathrm{~m}$ spacing. The grass on the dike is cultivated pasture and used for hay production as well as directly for grazing. Although the measurements were recorded during one of the Netherlands' driest Julys on record, it should be noted that the soil moisture condition in part of the study area is thought to be 
influenced by long-term subsurface hydrological processes (Cundill et al., 2014). A wide range of grass conditions were thus present at the time of measurement, varying from extremely lush and green to substantial proportions of dry, dead grass and some bare soil, thereby making the data set representative of potential conditions for cultivated grasslands. The grass had not been recently mowed.

The data consists of three data sets: a set of reflectance spectra, a set of soil moisture measurements (referred to as the soil moisture indicator) and a set of grass cover assessments (referred to as the cover quality indicator). The groundbased reflectance spectra were obtained using an ASD FieldSpec Pro spectrometer (Analytical Spectral Devices, Boulder, CO, USA). The instrument has a wavelength range of $350 \mathrm{~nm}-2500 \mathrm{~nm}$, band widths of 2-3 nm, with a $1 \mathrm{~nm}$ sampling interval. An $8^{\circ}$ foreoptic was used to constrain the field of view to the areas of interest and aid in the accurate placement of measurement locations. Each spectrum per location was an average of three spectra with sample counts of 25 . A calibrated Spectralon ${ }^{\circledR}$ panel was used as a white reference to calculate reflectance. Soil moisture was directly measured using a ThetaProbe Soil Moisture Sensor-ML2× (by Delta-T Devices Ltd, Cambridge, U.K.), averaging nine measurements per location. The quality of the dike covering was evaluated and classified into four classes. The evaluation criteria include grass density, canopy cover and the presence and quantity of standing litter (dead plant material), flotsam (floating debris), weeds, and bare soil. A comprehensive description of the data are available in Cundill et al. (2014).

\subsubsection{Spectral convolution}

As cultivated grasslands are often relatively small or narrow, only sensors capable of a multispectral spatial resolution of $5 \mathrm{~m}$ or finer were considered. The selection includes both broad- and narrowband sensors, hyper- and multispectral sensors and sensors that are mounted on satellite, airplane and unmanned aerial vehicle (UAV) platforms. Simulated data were generated by convolving the field ASD reflectance spectra to the spectral resolution of each sensor (Table 3.1, Figure 3.2) by means of their respective SRFs using the built in resampling functions in the ENVI 5.0 software (Exelis Visual Information Solutions, Inc., Boulder, CO, USA). Since most of these sensors do not have a shortwave infrared (SWIR) band, only bands in the visible and near-infrared are considered. The WorldView-3, HyMap and two Tetracam Mini-MCA sensors were not available as pre-defined functions in ENVI. Therefore, for the two Tetracam Mini-MCA sensors, the ASD data were convolved in ENVI using sensor specific SRFs which were obtained from the supplier. However, to the best of the authors' knowledge, the SRFs for the HyMap and WorldView-3 
sensors had not yet been published. Thus for these two sensors, ASD spectra were convolved using Gaussian shaped response functions based on the position and width of each band. The only variation between these simulated data sets is thus due to the sensor specific SRFs (or approximate SRFs for the HyMap and WorldView-3 sensors). This allows for the investigation of only the effects of differing SRFs since all other parameters (e.g., atmospheric conditions, sun and viewing geometry, spatial resolution, etc.) are identical between the data sets.

Table 3.1: Details of sensors used in this chapter (in order of maximum band width from narrowest to broadest).

\begin{tabular}{|c|c|c|c|c|c|}
\hline $\begin{array}{l}\text { SENSOR } \\
\text { (ABBREV.) }\end{array}$ & $\begin{array}{l}\text { SPATIAL } \\
\text { RESOLUTION }\end{array}$ & $\begin{array}{l}\text { SPECTRAL } \\
\text { TYPE }\end{array}$ & $\begin{array}{l}\text { SPECTRAL } \\
\text { RESOLUTION }\end{array}$ & BANDS & PlatForm \\
\hline $\begin{array}{l}\text { ASD } \\
\text { Fieldspec Pro } \\
\text { spectrometer }\end{array}$ & $\begin{array}{l}\text { Dependent on } \\
\text { height of sensor } \\
\text { (non-imaging) }\end{array}$ & hyper & $\begin{array}{l}\text { narrow } \\
(2-3 \mathrm{~nm})\end{array}$ & $\begin{array}{l}2151 \text { contiguous } \\
\text { bands between } \\
350-2500 \mathrm{~nm}\end{array}$ & ground \\
\hline $\begin{array}{l}\text { Tetracam } \\
\text { Mini-MCA } \\
(\mathrm{TC} 10) *^{\mathrm{a}}\end{array}$ & $\begin{array}{l}10 \mathrm{~s} \text { to } 100 \mathrm{~s} \mathrm{~mm} \\
\text { (dependent on } \\
\text { height of } \\
\text { sensor) }\end{array}$ & multi & $\begin{array}{l}\text { narrow } \\
(10 \mathrm{~nm})\end{array}$ & $\begin{array}{l}6 \text { bands between } \\
520-910 \mathrm{~nm}\end{array}$ & $\begin{array}{l}\text { UAV, } \\
\text { airplane }\end{array}$ \\
\hline HyMap b & $\begin{array}{l}\text { Dependent on } \\
\text { height of sensor }\end{array}$ & hyper & $\begin{array}{l}\text { narrow } \\
(15-20 \mathrm{~nm})\end{array}$ & $\begin{array}{l}128 \text { contiguous } \\
\text { bands between } \\
450-2500 \mathrm{~nm}\end{array}$ & airplane \\
\hline $\begin{array}{l}\text { Tetracam } \\
\text { Mini-MCA } \\
(\mathrm{TC} 05)^{* a}\end{array}$ & $\begin{array}{l}10 \mathrm{~s} \text { to } 100 \mathrm{~s} \mathrm{~mm} \\
\text { (dependent on } \\
\text { height of } \\
\text { sensor) }\end{array}$ & multi & $\begin{array}{l}\text { narrow } \\
(10-20 \mathrm{~nm})\end{array}$ & $\begin{array}{l}6 \text { bands between } \\
430-790 \mathrm{~nm}\end{array}$ & $\begin{array}{l}\mathrm{UAV}, \\
\text { airplane }\end{array}$ \\
\hline RapidEye $^{c}$ & $5 \mathrm{~m}$ & multi & $\begin{array}{l}\text { broad } \\
(40-90 \mathrm{~nm})\end{array}$ & $\begin{array}{l}5 \text { bands between } \\
440-850 \mathrm{~nm}\end{array}$ & satellite \\
\hline IKONOS $^{d}$ & $3.2 \mathrm{~m}$ & multi & $\begin{array}{l}\text { broad } \\
(66-96 \mathrm{~nm})\end{array}$ & $\begin{array}{l}4 \text { bands between } \\
445-853 \mathrm{~nm}\end{array}$ & satellite \\
\hline GeoEye-1 ${ }^{d}$ & $1.65 \mathrm{~m}$ & multi & $\begin{array}{l}\text { broad } \\
(35-140 \mathrm{~nm})\end{array}$ & $\begin{array}{l}4 \text { bands between } \\
450-900 \mathrm{~nm}\end{array}$ & satellite \\
\hline $\begin{array}{l}\text { WorldView-3 } \\
\text { (WV3) }^{\mathrm{e}}\end{array}$ & $1.24 \mathrm{~m}$ & multi & $\begin{array}{l}\text { broad } \\
(40-180 \mathrm{~nm})\end{array}$ & $\begin{array}{l}8 \text { bands between } \\
400-1040 \mathrm{~nm}\end{array}$ & satellite \\
\hline $\begin{array}{l}\text { WorldView-2 } \\
\text { (WV2) }^{\mathrm{f}}\end{array}$ & $\begin{array}{l}2 \mathrm{~m} \\
\text { (resampled) }\end{array}$ & multi & $\begin{array}{l}\text { broad } \\
(40-180 \mathrm{~nm})\end{array}$ & $\begin{array}{l}8 \text { bands between } \\
400-1040 \mathrm{~nm}\end{array}$ & satellite \\
\hline Pléiades-1A ${ }^{g}$ & $2 \mathrm{~m}$ & multi & $\begin{array}{l}\text { broad } \\
(120-200 \mathrm{~nm})\end{array}$ & $\begin{array}{l}4 \text { bands between } \\
430-940 \mathrm{~nm}\end{array}$ & satellite \\
\hline $\begin{array}{l}\text { QuickBird } \\
\text { (QB) }\end{array}$ & $2.62 \mathrm{~m}$ & multi & $\begin{array}{l}\text { broad } \\
(115-203 \mathrm{~nm})\end{array}$ & $\begin{array}{l}4 \text { bands between } \\
430-918 \mathrm{~nm}\end{array}$ & satellite \\
\hline
\end{tabular}

*Note: the Tetracam Mini-MCA is a configurable spectroscope, using changeable filters which the user selects. ${ }^{a}$ (TetraCam Inc, n.d.); ${ }^{b}$ (HyVista Corporation, n.d.); ${ }^{c}$ (RapidEye, n.d.);

${ }^{\mathrm{d}}$ (GeoEye, 2010); ${ }^{\mathrm{e}}$ (DigitalGlobe, 2013b); ${ }^{\mathrm{f}}$ (DigitalGlobe, 2012b); ${ }^{\mathrm{g}}$ (Airbus Defence and Space, n.d.); ${ }^{\text {h }}$ (DigitalGlobe, 2012a). 


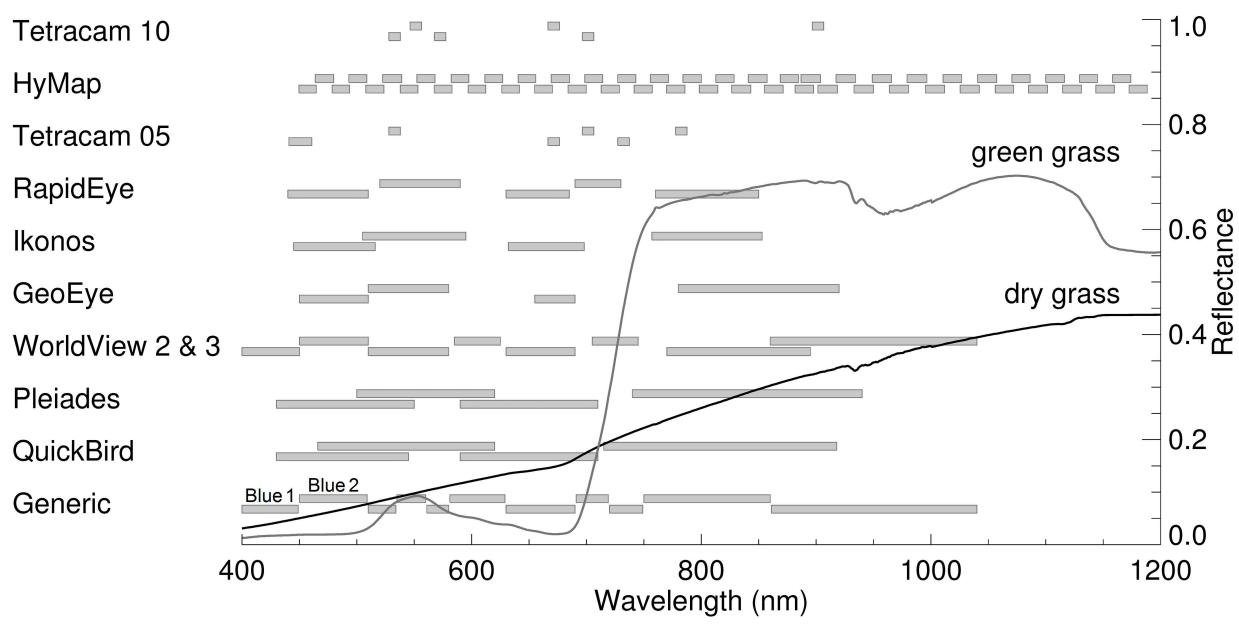

Figure 3.2: Band positions and widths for the sensors used in this chapter.

\subsubsection{Indices}

The selection of spectral indices tested in this chapter (see Table A.2) is based on over one hundred indices tested by Cundill et al. (2014), but limited to those that are applicable to at least three of the sensors being investigated (Table 3.1). The selected 48 indices cover general vegetation indices, moisture indices, as well as specific compositional or structural indices. Many were developed for narrowband data but those developed for broadband data (as indicated in Table A.2) have previously been applied in narrowband form in various publications (e.g., Haboudane et al., 2004; Kim et al., 2010; Rodríguez-Pérez et al., 2007). Likewise, narrowband indices have similarly been applied in broadband form (e.g., Kross et al., 2015; Waser et al., 2014). The current study includes both broad- and narrowband sensors, and thus indices are applied in both their broad- and narrowband form. Since the SRFs of broadband and narrowband sensors are considerably different, the index values calculated from these sensors are also expected to be different. However, it is sometimes necessary to compare data from these two extremes. In addition, a number of studies have investigated whether the broad- or narrowband form of an index performs better for a parameter. For example, Elvidge and Chen (1995) found that for seven indices investigated, the narrowband form performed better for percent green cover and leaf area index (LAI) than the broadband form of the same index. Similarly, Thenkabail et al. (2002) show that the narrowband form of various indices performed better for biomass and LAI. On the other hand, Broge and Leblanc (2000) demonstrate in their study that the broadband form of 
ten indices generally appear to be better at predicting LAI and canopy chlorophyll density. The results of the current study contribute to this discussion.

The equations for the indices in Table A.2 are in the form for narrowband hyperspectral data. If the specified wavelength was not available in the HyMap data set, then the band with the centre wavelength closest to this wavelength was used. For the other data sets, wavelengths were grouped into generic bands (Figure 3.2). For each sensor or index, a specific band or wavelength was allocated to a generic band based on whether the centre wavelength of the sensor band or index wavelength fell within the generic band's wavelength range. Exceptions were made when a sensor had only one band in a particular region of the electromagnetic spectrum (e.g., only generic Blue 2). In these cases, the same reflectance values were allocated to the remaining generic band/s for that region of the electromagnetic spectrum (e.g., Blue 1). This was done in order to limit the effect of the arbitrary allocation of wavelength range to the generic bands which may have resulted in the invalidity of an index for a particular sensor. An index was considered not valid (indicated by NA) for a particular sensor when either the required wavelengths were not available, or when the index became equivalent to another index as a result of using broader bands.

\subsubsection{Analysis}

The analysis to investigate the effects of SRFs and performance of the indices from different sensors took two main forms. The first was to evaluate index values generated from convolved narrow- and broadband data compared to the index values obtained from original narrowband ASD data. The original narrowband ASD data were selected as the reference data set for this study because the $2-3 \mathrm{~nm}$ band widths of the ASD sensor are an extreme case of narrowband sensors against which the indices calculated from broader-band sensors could be tested, thereby testing the robustness of the indices across a wide range of spectral resolutions. The band widths of the other sensors range between $10 \mathrm{~nm}$ and $203 \mathrm{~nm}$. In addition, narrowband multispectral sensors, such as the Tetracam Mini-MCA, are becoming increasingly popular, especially for use on UAVs. These narrowband sensors do not allow the averaging of wavelengths to simulate broad bands and so direct comparison of index values from narrow- and broadband sensors is useful. Further, Yao et al. (2013) point out a lack of cross-calibration studies that systematically compare narrowband indices with broadband indices. The other form of analysis was to compare the performance of indices from various sensors for an application, namely inspection and monitoring of grass covered dikes. The use of the original ASD 
data as the reference data set also allows for comparison with the results from Cundill et al. (2014).

\subsubsection{Comparison to original ASD index values}

To evaluate the effects of differing SRFs on indices between sensors, index values for simulated data were compared to those for original ASD data. Four measures were used to indicate the extent to which the simulated data deviate from the original ASD data, namely the slope and intercept of the linear trend line, and two variants of the coefficient of determination.

A perfect match between the index values for the original ASD data and those of the simulated data should render a linear trend line with a slope of 1 and intercept of 0 , the so-called 1:1 line. The linear trend was computed for each of the simulated index data sets, and the slope and intercept for these trend lines were compared to the 1:1 line. Since the value of the intercept is relative to the values for a particular index, the intercept was normalized via division by the mean of the ASD index values.

The two variants of the coefficient of determination used in this chapter have the same basic equation structure but their definitions differ in that they use different data sets. The first variant of the coefficient of determination, the square of the correlation coefficient (Eq. 3.1), is calculated to test how the data fits the linear trend. To avoid confusion with the second variant of the coefficient of determination (calculated for the 1:1 line), the square of the correlation coefficient is denoted in this chapter as $\mathrm{ccR}^{2}$. A perfect fit of the data to the trend line would render a $\mathrm{ccR}^{2}$ value of 1 . Values can range between 0 and 1.

$$
\operatorname{ccR}^{2}=1-\frac{\sum_{\mathrm{i}}\left(\mathrm{y}_{\mathrm{i}}-\hat{\mathrm{y}}_{\mathrm{i}}\right)^{2}}{\sum_{\mathrm{i}}\left(\mathrm{y}_{\mathrm{i}}-\overline{\mathrm{y}}\right)^{2}}
$$

where $y_{i}$ denotes index values for the simulated data, $\hat{y}_{i}$ denotes modelled index values, and $\bar{y}$ denotes the mean of the index values for the simulated data.

The second variant of the coefficient of determination (denoted as ${ }_{1: 1} \mathrm{R}^{2}$ in this chapter to avoid confusion with the first variant of the coefficient of determination) provides information on the overall deviation of simulated index values from original ASD index values, relative to the 1:1 line (Eq. 3.2), similar to the Nash-Sutcliffe efficiency (Nash and Sutcliffe, 1970). The simulated data have not been derived from a model fitting procedure, and thus values outside of the typical 0 to 1 range are possible since the test, in this case, is not using modelled values (Rooney, 2012). Ideally, ${ }_{1: 1} \mathrm{R}^{2}$ should be 1 , indicating that there is no difference between the simulated and original ASD index values. This is 
not expected, however, as the different SRFs of the various sensors will result in differing index values (as shown by the previous studies discussed in the Introduction).

$$
{ }_{1: 1} R^{2}=1-\frac{\sum_{i}\left(y_{A S D_{i}}-y_{S I M_{i}}\right)^{2}}{\sum_{i}\left(y_{A S D_{i}}-\bar{y}_{A S D}\right)^{2}}
$$

where $y_{A S D_{i}}$ denotes index values for the original ASD data, $y_{S I M_{i}}$ denotes index values for the simulated data, and $\bar{y}_{A S D}$ denotes the mean of the index values for the original ASD data.

For an objective overview of how an index performed across sensors, the mean for each measure per index was computed. This is straight-forward for the ${ }_{1: 1} \mathrm{R}^{2}$ and $\mathrm{ccR}^{2}$. However, for the other measures where the values vary around a central value ( 1 for the slope and 0 for the intercept), adjustments needed to be done before the mean could be calculated. In the case of the intercepts, the absolute values (|intercept|) were used for the calculation of the mean. For the slopes, since the values vary around 1 , the mean was computed from the absolute values of slope minus 1 (|slope $-1 \mid)$.

\subsubsection{Correlation to dike inspection indicators}

In a previous study (Cundill et al., 2014), the relationships between index values from the original ASD data and two inspection indicators for grass covered dikes were investigated. Now, to evaluate how the indices from the simulated data for various sensors perform for an application, the relationships between their index values and the two inspection indicators for grass covered dikes are explored. The two inspection indicators are soil moisture and cover quality. Although the inspection indicators are specifically defined here in the context of dikes, both soil moisture and condition of grass cover are the subject of many remote sensing studies relating to cultivated grasslands (e.g., DettmanKruse et al., 2008; Fitz-Rodriguez and Choi, 2002; Metternicht, 2003; Taghvaeian et al., 2013). The correlation coefficients between each index (for each sensor) and each quality indicator were computed, with the Pearson correlation coefficient used for the soil moisture quality indicator and the Spearman correlation coefficient used for the ordinal dike cover quality indicator. As for the previous measures, the mean for each correlation coefficient was computed per index, using their absolute values $(|\mathrm{r}|)$. 


\subsection{Results and Discussion}

\subsubsection{Comparison to original ASD index values}

The index values for the simulated data of the different sensors were tested against those of the original ASD data and, based on the mean statistical measures, can be grouped into three representative categories: overall performing well (i.e., similar to the original ASD index values), overall performing poorly (i.e., dissimilar to the original ASD index values) and mixed performance. Individual statistical measures for representative indices for these three groups are shown in Table 3.2, with DVI and GEMI representative of the first group, ARI and $\mathrm{CTR}_{1}$ of the second and $\mathrm{BGI}_{2}$ and $\mathrm{MSR}$ of the third. Mean statistical measures for all 48 indices are provided in Table B.1, with individual statistical measures for the 48 indices provided in Table B.2. For cultivated grasslands, indices that perform well for all measures for the simulated data from all selected sensors compared to the original ASD data are DVI and GEMI (Table 3.2 and Table B.1) as well as EVI, MCARI $1, \mathrm{MSAVI}_{2}, \mathrm{MTVI}_{1}, \mathrm{RDVI}$, SARVI and SAVI (Table B.1). This can be observed in the scatterplots for DVI and GEMI (Figure 3.3a-b), where the points fall close to the 1:1 line with very little scattering, and the slope and intercept are similar to the 1:1 line. All these indices make use of reflectance in the near-infrared and red wavelengths (see Table A.2 for index equations). Moreover, the indices all use the difference between the near-infrared and red bands. Most of these indices were originally designed for broadband sensors. Vegetation's broad spectral features in the red and near-infrared regions allow these indices to transfer well between sensors of differing band widths and positions. Despite the good performance of these indices, the relationships between the simulated data and the ASD data do not perfectly fit the 1:1 line (Table 3.2 and Table B.1). Thus for accurate comparisons between index output for data from different sensors, minor adjustments will need to be made using the modelled relationship between the data sets.

For cultivated grasslands, indices that perform the least for all measures for the simulated data compared to the original ASD data are ARI and $\mathrm{CTR}_{1}$ (Table 3.2 and Table B.1), as well as CARI, $\mathrm{CRI}_{700}$ and mARI (Table B.1). The scatterplots for ARI and $\mathrm{CTR}_{1}$ (Figure 3.3c-d) show general scattering of the points and their deviation from the 1:1 line. For ARI, the slope for some of the simulated data sets (e.g., WorldView-2) even reverses sign, with a resulting large shift in intercept. All these indices include the red-edge band, (Table A.2). For green vegetation, there is a sharp order-of-magnitude increase in reflectance in the region of the red-edge $(680 \mathrm{~nm}$ to $750 \mathrm{~nm})$ (Horler et al., 1983), over a 
Table 3.2: Individual statistical measures per sensor for representative indices.

\begin{tabular}{|c|c|c|c|c|c|c|c|c|c|c|}
\hline \multicolumn{11}{|c|}{${ }_{1: 1} \mathbf{R}^{2}$} \\
\hline $\begin{array}{l}\text { INDEX } \\
\end{array}$ & TC10 & HYMAP & TC05 & RAPID-EYE & IKONOS & GEOEYE & WV3 & WV2 & PLÉIADES & QB \\
\hline ARI & 0.576 & -3.853 & -0.624 & -14.216 & NA & NA & -34.998 & -28.234 & NA & NA \\
\hline $\mathrm{BGI}_{2}$ & NA & 0.944 & 0.646 & -0.260 & -8.800 & -1.320 & -3.378 & -0.670 & -10.000 & -7.200 \\
\hline $\mathrm{CTR}_{1}$ & NA & NA & 0.378 & -4.199 & NA & NA & -47.760 & -40.060 & $\mathrm{NA}$ & NA \\
\hline DVI & 0.966 & 0.999 & 0.983 & 0.993 & 0.877 & 1.000 & 0.986 & 1.000 & 0.995 & 0.958 \\
\hline GEMI & 0.972 & 1.000 & 0.986 & 0.994 & 0.887 & 1.000 & 0.988 & 1.000 & 0.995 & 0.962 \\
\hline MSR & 0.860 & 0.734 & 0.773 & 0.613 & -0.450 & 0.716 & 0.177 & 0.625 & 0.039 & 0.085 \\
\hline \multicolumn{11}{|c|}{ slope } \\
\hline INDEX & TC10 & HYMAP & TC05 & RAPIDEYE & IKONOS & GEOEYE & WV3 & WV2 & PLÉIADES & QB \\
\hline ARI & 0.616 & -0.176 & 0.486 & -1.135 & NA & NA & -2.000 & -1.715 & NA & NA \\
\hline $\mathrm{BGI}_{2}$ & NA & 1.019 & 1.012 & 0.953 & 0.594 & 0.967 & 0.848 & 0.984 & 0.544 & 0.693 \\
\hline $\mathrm{CTR}_{1}$ & NA & NA & 0.670 & 0.186 & NA & NA & 0.423 & 0.489 & NA & NA \\
\hline DVI & 1.058 & 1.012 & 0.959 & 0.971 & 0.859 & 1.009 & 0.953 & 0.999 & 0.974 & 0.920 \\
\hline GEMI & 1.004 & 1.005 & 1.001 & 0.994 & 0.909 & 0.998 & 0.961 & 0.998 & 0.965 & 0.956 \\
\hline MSR & 0.868 & 0.849 & 0.886 & 0.757 & 0.423 & 0.810 & 0.567 & 0.747 & 0.500 & 0.542 \\
\hline \multicolumn{11}{|c|}{ intercept } \\
\hline INDEX & TC10 & HYMAP & TC05 & RAPIDEYE & IKONOS & GEOEYE & WV3 & WV2 & PLÉIADES & QB \\
\hline ARI & 2.071 & 7.105 & 4.196 & 12.547 & NA & NA & 19.477 & 17.531 & NA & NA \\
\hline $\mathrm{BGI}_{2}$ & NA & 0.008 & 0.039 & 0.103 & 0.406 & 0.126 & 0.220 & 0.102 & 0.441 & 0.344 \\
\hline $\mathrm{CTR}_{1}$ & NA & NA & 1.312 & 3.520 & NA & NA & 6.547 & 5.983 & NA & NA \\
\hline DVI & 0.003 & -0.001 & -0.001 & -0.001 & -0.001 & 0.000 & 0.000 & -0.001 & -0.001 & -0.001 \\
\hline GEMI & 0.019 & -0.001 & -0.015 & -0.006 & 0.014 & 0.004 & 0.010 & 0.000 & 0.014 & 0.002 \\
\hline MSR & -0.064 & -0.179 & -0.238 & -0.038 & 0.251 & -0.087 & 0.183 & 0.003 & 0.301 & 0.199 \\
\hline
\end{tabular}

normalized intercept

\begin{tabular}{|l|cccrcccccc|}
\hline INDEX & TC10 & HYMAP & TC05 & RAPIDEYE & IKONOS & GEOEYE & WV3 & WV2 & PLÉIADES & QB \\
\hline ARI & 1.460 & 5.010 & 2.958 & 8.846 & NA & NA & 12.361 & 12.361 & NA & NA \\
BGI $_{2}$ & NA & 0.018 & 0.090 & 0.239 & 0.942 & 0.292 & 0.236 & 0.236 & 1.023 & 0.798 \\
CTR $_{1}$ & NA & NA & 0.532 & 1.426 & NA & NA & 2.425 & 2.425 & NA & NA \\
DVI & 0.012 & -0.003 & -0.004 & -0.004 & -0.004 & -0.001 & 2.425 & 2.425 & -0.004 & -0.004 \\
GEMI & 0.029 & -0.001 & -0.024 & -0.010 & 0.021 & 0.006 & 0.000 & 0.000 & 0.022 & 0.003 \\
MSR & -0.026 & -0.071 & -0.095 & -0.015 & 0.100 & -0.035 & 0.001 & 0.001 & 0.120 & 0.079 \\
\hline
\end{tabular}

$\mathbf{c c R}^{2}$

\begin{tabular}{|l|crrrrrrrrr|}
\hline INDEX & TC10 & HYMAP & TC05 & RAPIDEYE & IKONOS & GEOEYE & WV3 & WV2 & PLÉIADES & QB \\
\hline ARI & 0.910 & 0.067 & 0.654 & 0.489 & NA & NA & 0.556 & 0.528 & NA & NA \\
BGI $_{2}$ & NA & 0.991 & 0.997 & 0.984 & 0.978 & 0.946 & 0.990 & 0.962 & 0.972 & 0.989 \\
CTR $_{1}$ & NA & NA & 0.785 & 0.035 & NA & NA & 0.024 & 0.040 & NA & NA \\
DVI & 0.994 & 1.000 & 0.995 & 0.999 & 0.998 & 1.000 & 1.000 & 1.000 & 1.000 & 1.000 \\
GEMI & 0.995 & 1.000 & 0.997 & 0.999 & 0.998 & 1.000 & 1.000 & 1.000 & 1.000 & 1.000 \\
MSR & 0.998 & 0.999 & 0.999 & 0.999 & 0.989 & 0.999 & 0.996 & 0.999 & 0.992 & 0.995 \\
\hline
\end{tabular}



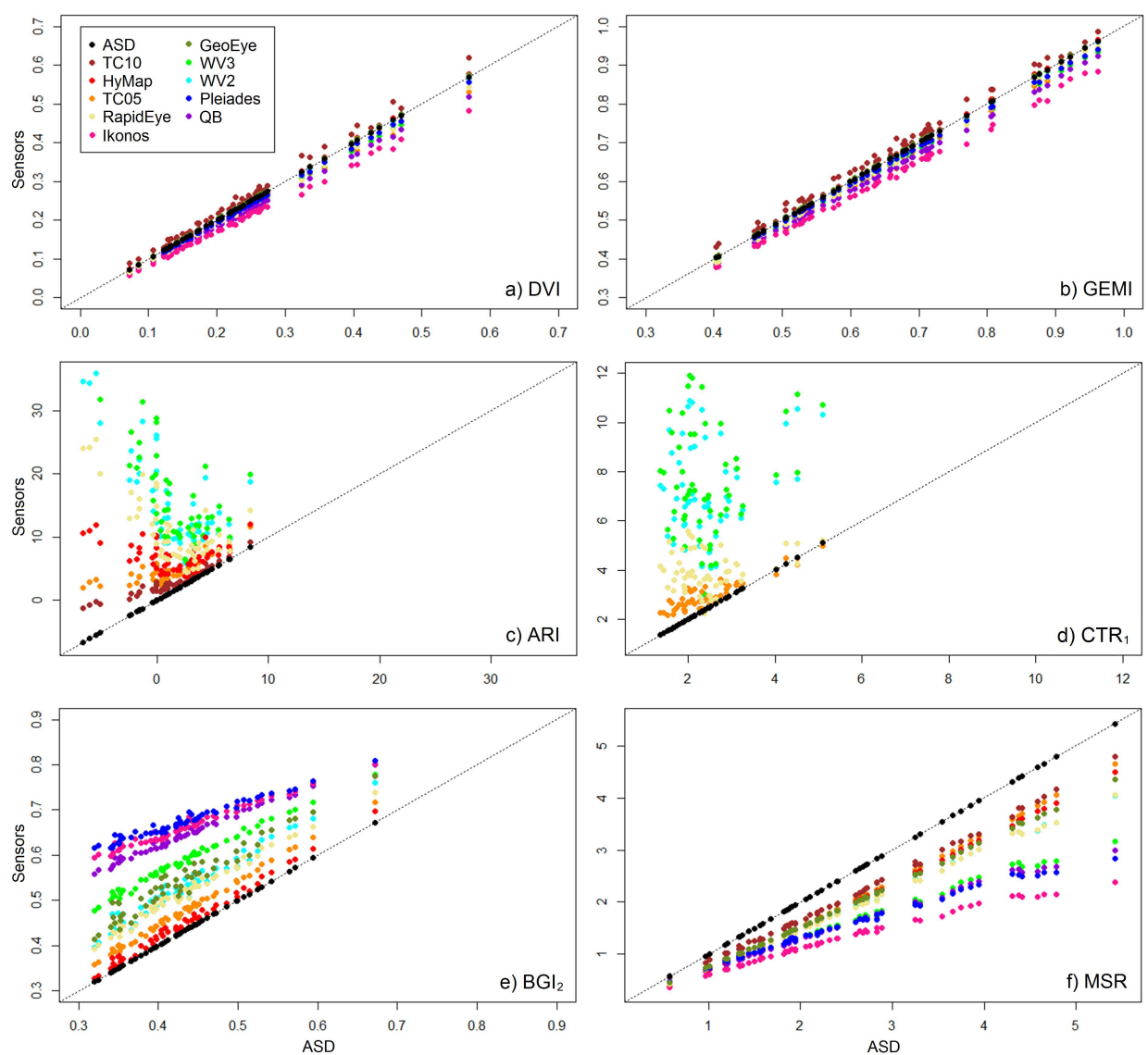

Figure 3.3: Scatterplots for representative indices, showing the relationships between the original ASD data and the spectrally simulated data of various sensors. (a) DVI, (b) GEMI, (c) ARI, (d) $\mathrm{CTR}_{1}$, (e) $B \mathrm{BG}_{2}$ and (f) MSR. The dashed line represents the 1:1 line.

relatively narrow wavelength range. Thus the position and width of the band in this transitional region will have a considerable effect on the reflectance measured by the sensor (Figure 3.2). A related and known problem for the cross-calibration of sensors is the spread of the SRFs for the red or near-infrared bands into the red-edge region (Gonsamo and Chen, 2013; Soudani et al., 2006; Trishchenko et al., 2002a).

For cultivated grasslands, indices with mixed behaviour for the statistical measures comparing the simulated data to the original ASD data are for example $\mathrm{BGI}_{2}$ and MSR. They perform well for some sensors and less well for others, while also showing differing performance for the individual measures (Table 3.2). They show little scatter but their trend lines can deviate quite far from the ideal 1:1 line. The scatterplot of $\mathrm{BGI}_{2}$ (Figure 3.3e) is an example of 
where both the ccR $\mathrm{R}^{2}$ and the slope are reasonable but the ${ }_{1: 1} \mathrm{R}^{2}$ and the intercept are poor (Table 3.2 and Table B.1). The scatterplot of MSR (Figure 3.3f), on the other hand, is an example of where the $c c \mathrm{R}^{2}$ and intercept are reasonable but the 1:1 $\mathrm{R}^{2}$ and slope are poor (Table 3.2 and Table B.1). Both these scatterplots show instances where the relationship between the simulated sensor data and the original ASD data can be modelled despite their deviation from the 1:1 line. Thus despite the apparent poor ${ }_{1: 1} \mathrm{R}^{2}$, slope and intercept values, many indices may still be transferable across sensors as long as the relationship between the two sensors (for an index) is defined and the $\mathrm{ccR}^{2}$ value is close to 1 . This is applicable regardless of the spatial resolution of the sensor and is in agreement with numerous studies that found that differences in SRFs cause systematic errors between data from different sensors (e.g., Chander et al., 2013b; Franke et al., 2006; Gonsamo and Chen, 2013; Trishchenko et al., 2002a). It should be noted that these relationships may not be linear. For example for the index MSR (Figure 3.3f), second order polynomial functions model the relationships between the ASD data set and the simulated data sets better than linear functions (with increases in the $\mathrm{ccR}^{2}$ values). The literature has examples of where linear translation functions are recommended (Gallo et al., 2005; Gonsamo and Chen, 2013; Steven et al., 2003; van Leeuwen et al., 2006) and where second order polynomial functions are recommended (D'Odorico et al., 2013; Pandya et al., 2007; Trishchenko, 2009; Trishchenko et al., 2002a). Additionally, D'Odorico et al. (2013) found that the choice of regression model is more important than the choice of calibration data source. Worth noting, is that the WorldView-2 and -3 data have the same band widths and positions with only their SRFs differing (WorldView-2 with actual SRFs and WorldView-3 with Gaussian curves), and yet their values for the various measures differ throughout this study (e.g., $\mathrm{BGI}_{2}$ in Figure 3.3e, Table 3.2). It is thus important that actual SRFs be used for spectral cross-calibration and not approximations such as Gaussian curves.

For some indices, no or only weak relationships are apparent (low $c \mathrm{R}^{2}$ values), with much scattering around the trend line (e.g., ARI, Figure 3.3c). In these cases, these indices are not suitable for cross-calibration between these sensors as there are non-systematic biases resulting from the different SRFs. It should however be noted that the relationships examined in this study are to the narrowband ASD data. It is possible that for these indices there may be strong relationships between two of the other sensors, particularly if they have similar band widths and positions. Several indices were excluded from this study as they are not appropriate for many sensors since they were designed for narrow spectral features and the bands in the sensors simply either do not cover that region of the electromagnetic spectrum or are too broad. Furthermore, certain 
indices (particularly those related to moisture) make use of reflectance in the short-wave infrared (SWIR) which is not covered by many sensors and were thus also excluded from the current study. Examples are the Photochemical Reflectance Index (PRI) which uses reflectance at 528nm and 567nm (Gamon et al., 1992) and the Normalized Difference Water Index (NDWI) which uses reflectance at $860 \mathrm{~nm}$ and $1240 \mathrm{~nm}(\mathrm{Gao}, 1996)$.

When applied to images, accounting for other parameters such as atmospheric variables, solar and observational geometries, spatial resolution, etc. (Teillet et al., 2007; Trishchenko et al., 2002a; van Leeuwen et al., 2006) is necessary to achieve high cross-calibration accuracy. The effect that different spatial resolutions of various sensors have on NDVI and other index values depends on the nature (and spatial extent) of the target (Teillet et al., 1997). A related, but often neglected, consideration is the effects of the change in support (scale effect) between sensors which affects items such as the variance (Dungan, 2001) and range (Wong, 2009) of values measured by various sensors. It has been recommended (Franke et al., 2006; Trishchenko et al., 2002a) that stepwise correction be applied for cross-calibration between sensors, with SRF effects being corrected first followed by correcting for residual factors such as atmospheric conditions, sun- and viewing angles and spatial resolution.

\subsubsection{Correlation to inspection indicators}

\subsubsection{Soil moisture}

Cundill et al. (2014) show that several spectral indices correlate with the soil moisture quality indicator for grass covered dikes, where they function as proxies for the vegetation's response to available soil moisture. In the current chapter, indices which have the highest correlations to soil moisture across all sensors are RVI, GRR, MSR, $\mathrm{GM}_{2}$, and $\mathrm{mSR}_{705}$ (mean $|r|>0.550$, Table C.1). These results are similar to what Cundill et al. (2014) found using only the original ASD data, where $\mathrm{RVI}_{1}$, NIRRR, RVI (which are all variants of nearinfrared:red ratio) and a broadband green:red ratio have the highest correlations to soil moisture. GRR is equivalent to the broadband green:red ratio and RVI and MSR are variants of the ratio near-infrared:red. Indices that were identified in the previous section as transferring particularly well between sensors (i.e., DVI, EVI, GEMI, MCARI ${ }_{1}, \mathrm{MSAVI}_{2}, \mathrm{MTVI}_{1}, \mathrm{RDVI}, \mathrm{SARVI}$ and SAVI, see Table B.1), but which all make use of the difference between the near-infrared and red bands, do not have high correlation coefficients for soil moisture (mean $|\mathrm{r}|<0.210$; Table C.1). $\mathrm{GM}_{2}$ and $\mathrm{mSR}_{705}$ make use of near-infrared:red-edge ratios. This appears contrary to what was discussed in the previous section, where the use of the transitional red-edge region indicated that an index would 
not transfer well. However, indices ARI, CARI, CRI ${ }_{700}, \mathrm{CTR}_{1}$ and mARI (which make use of the red-edge band and have low $c \mathrm{cR}^{2}$ values) primarily use a form of the difference between the red-edge band and the green band (Table A.2), with the exception of $\mathrm{CTR}_{1}$ (which uses a red-edge:blue ratio). It would thus seem that indices that ratio the near-infrared and red-edge bands can be used for correlation with soil moisture of grass covered surfaces. Further, it would also appear that for correlation to soil moisture, the proportional (ratio) reflectance of bands is important for adjusting for the effects of SRFs on indices rather than the difference in reflectance between bands.

This indeed would seem to be true. When examining vegetation spectra, there is an order-of-magnitude increase from red to near-infrared. Decreasing plant water content causes physiological changes that result in an increase in the nearinfrared reflectance and a lesser increase in the red reflectance (Jensen, 2007; Lee et al., 2007). However, proportionally the increase in the red reflectance is larger because of relatively low absolute reflectance values. This explains why the RVI and MSR indices, and also the $\mathrm{GM}_{2}$ and $\mathrm{mSR}_{705}$ indices, work well for soil moisture of grass covered surfaces while the DVI, EVI, GEMI, MCARI ${ }_{1}$, $\mathrm{MSAVI}_{2}, \mathrm{MTVI}_{1}, \mathrm{RDVI}, \mathrm{SARVI}$ and SAVI indices do not (Table C.1). For the GRR index, decreasing plant water content results in an overall increase in reflectance in the visible wavelengths $(400-700 \mathrm{~nm})$ due to leaf pigments' physiological dependence on water (Carter, 1993; Rodríguez-Pérez et al., 2007), with a greater proportional increase in red reflectance than in green (as observed in Carter, 1993: Fig. 2). Positive correlations were also found between GRR and water potential in a study by Rodríguez-Pérez et al. (2007) on grapevines. Further, with extreme water deficiencies, leaves turn yellow or brown (leaf firing) and ultimately result in an increase in standing litter (dead vegetation). Standing litter affects reflectance in that, similar to water deficit stress, there is an overall increase in reflectance in the visible spectrum, with a greater proportional increase in red than in green reflectance, although with much larger increases in magnitude (as observed in Asner, 1998: Fig. 8). Thus, for the current study, where there is also dead vegetation (most likely due to water deficit), the GRR index also correlates relatively well with soil moisture. Overall, the narrowband sensors appeared to perform better than the broadband sensors for the five indices with the highest correlations to the soil moisture indicator (Table C.1). However, the broadband RapidEye, GeoEye-1 and WorldView-2 sensors also performed relatively well.

\subsubsection{Cover quality}

Cundill et al. (2014) found that several spectral indices correlate with the cover quality indicator. In the current chapter, indices $\mathrm{NDVI}_{705}, \mathrm{mNDVI}_{705}, \mathrm{mSR}_{705}$, 
$\mathrm{GM}_{2}, \mathrm{CTR}_{2}$, RGI, GRR and NGRR have the highest correlations to cover quality across all the sensors (mean $|r|>0.580$, Table C.2). Indices $\mathrm{NDVI}_{705}$, $\mathrm{mNDVI}_{705}, \mathrm{mSR}_{705}, \mathrm{GM}_{2}$ and $\mathrm{CTR}_{2}$ use near-infrared and red-edge bands and the remaining three (RGI, GRR and NGRR) use green and red bands. These indices use either the ratio between the bands (i.e., $\mathrm{mSR}_{705}, \mathrm{GM}_{2}, \mathrm{CTR}_{2}$, RGI and GRR) or the difference between the bands (i.e., $\mathrm{NDVI}_{705}, \mathrm{mNDVI}_{705}$ and NGRR). Cover quality for the dike is determined by the presence and proportions of healthy grass, dry dead grass (standing litter) and bare soil. Dense green grass cover, with high LAI values, affect the reflectance spectra in that there is an order-of-magnitude increase in the near-infrared reflectance, an increase in the red-edge, a decrease in the red reflectance and little change in the green (as observed in Asner, 1998: Fig. 5). The presence of standing litter and bare soil affect the whole spectrum but non-linearly, with, for example, larger increases in reflectance in the red than the green (as observed in Asner, 1998: Fig. 2, 3, $8 \& 9$ ). The combined effects of the amount of lush green vegetation, standing litter and bare soil on reflectance are such that relationships to cover quality can be established using indices $\mathrm{NDVI}_{705}, \mathrm{mNDVI}_{705}, \mathrm{mSR}_{705}, \mathrm{GM}_{2}$, $\mathrm{CTR}_{2}$, RGI, GRR and NGRR.

Although these indices were not those found by Cundill et al. (2014) to have the highest correlations for the original ASD data (of which the highest is 0.630 for an index not valid for this study), their values still range between \pm 0.567 and \pm 0.580 for this data set (Table C.2). Indices that were identified in the previous section as transferring particularly well between sensors (i.e., DVI, EVI, GEMI, $\mathrm{MCARI}_{1}, \mathrm{MSAVI}_{2}, \mathrm{MTVI}_{1}, \mathrm{RDVI}, \mathrm{SARVI}$ and SAVI, see Table B.1), all make use of the difference between the near-infrared and red bands and do not have high correlation coefficients for cover quality (mean $|r|<0.205$, Table C.2). However, some indices that make use of the near-infrared and red bands (e.g., NDVI, RVI) have correlations for the original ASD data in the range of \pm 0.576 and \pm 0.583 , with mean $|r|$ values in the range of 0.578 and 0.580 across all sensors (Table C.2). These include indices that ratio the near-infrared bands as well as those that difference them. Thus correlation to cover quality depends not only on the bands used by the index but also the computation of the index, which cannot be simply separated based on ratio or difference.

Although the indices that performed well for cover quality were designed for narrowband sensors, the spectral features for cover quality in the green, red and near-infrared are broad. Thus for an application such as grass cover quality assessment, broadband sensors can perform as well and sometimes better than narrowband sensors. This is in agreement with other studies which found that for some applications broadband indices perform almost as well or better than the equivalent narrowband indices (Broge and Leblanc, 2000; Elvidge and 
Chen, 1995), particularly if attention is paid to the position of the bands (Zhao et al., 2007) and the parameter which is being estimated (Yoder and Waring, 1994). This is favourable for the implementation of operational systems for monitoring and assessing cultivated grasslands, including dike inspection and monitoring, because broadband satellite data are cheaper and more easily available than airborne and narrowband data.

\subsection{Conclusions}

This chapter examined the effects of differing spectral response functions (SRFs) on the cross-calibration of a large number of indices across various very high spatial resolution sensors for cultivated grasslands. The data for the various sensors were simulated by convolving field reflectance spectra using sensor specific SRFs, which enabled the investigation of the SRF effects alone without being affected by other factors such as atmospheric condition or spatial resolution. Index values calculated from data of sensors with differing spectral response functions are not directly comparable. Broadband indices DVI, GEMI, EVI, $\mathrm{MSAVI}_{2}$ and SAVI render the most similar values per index across all sensors tested (1:1 line mean ${ }_{1: 1} \mathrm{R}^{2}>0.960$ and linear trend mean $\left.c c \mathrm{R}^{2}>0.997\right)$, but despite their similarity, there are differences which should be adjusted for when comparing absolute index values between sensors. For many indices, the index values altered significantly with the changing spectral resolution of the sensors. However, in most cases, relationships could be established between the index values for different sensors and the narrowband ASD data. The width and position of bands that fall within transitional regions of the spectrum (e.g., rededge) adversely affect the relationships for indices that use these bands. The correct definition of the relationship is necessary for accurate adjustment of SRF effects and is often linear or second order polynomial. Thus adjusting for the effects of SRFs on indices between sensors of different spectral resolutions is possible as long as the relationship of the index values between these sensors can be modelled and the square of the correlation coefficient $\left(\mathrm{ccR}^{2}\right)$ is close to 1. It is crucial that the full definition of the SRFs be used and not only the band widths and positions. It is recommended that when applied to indices obtained from images of different sensors, not only SRF effects should be considered but also the effects of items such as atmospheric conditions, solar and observational geometries, spatial resolution and change in support.

The performance of indices across sensors was tested for an application. Correlations to two indicators were tested in the context of inspection and monitoring of grass covered dikes, although the results could be more generally applied to cultivated grasslands. For the soil moisture indicator, indices that 
ratio bands performed better across sensors than those that difference bands, with ratios using the near-infrared and red bands out-performing others. Although the index values were different between sensors, the correlation coefficients were similar because the relationships between the sensors could be defined. Similarly, various indices had similar correlation coefficients across different sensors to the indicator of cover quality. However, for this indicator, the bands used by the index affect the performance as well as how they are applied. The results show that for certain indices, sensors with broad spectral bands can perform almost as well or better than narrowband sensors for the estimation of these parameters and that for many indices it is not necessary to have narrowband data if the appropriate bands are defined in the broadband system. 


\section{Comparison of Indices from Field Spectral Measurements and Satellite Imagery as Proxies for Dike Inspection Indicators}

3 This chapter has been submitted for publication as: Cundill, S.L., van der Werff, H.M.A., van der Meijde, M., van der Meer, F.D. \& Hack, H.R.G.K. (in review). Comparison of indices from field spectral measurements and satellite imagery as proxies for dike inspection indicators. 


\subsection{Introduction}

Remote sensing data are widely used as proxies for various parameters, notably relating to vegetated surfaces (e.g., Daughtry et al., 2000; Gitelson et al., 2014; Hall et al., 1992; Houborg et al., 2013). Recently, various ground-based field remote sensing data were researched as proxies for two indicators, cover quality and soil moisture, used for inspection of grass covered dikes (Cundill et al., 2014). Grass cover is one of the most common forms of surface cover on dikes (CIRIA et al., 2013). The grass cover protects against external erosion, inhibits infiltration and the roots help prevent sliding (CIRIA et al., 2013). Although dike inspection procedures and regulations vary between (and even within) countries, inspections are most often done by visual examination, ideally on foot (CIRIA et al., 2013). Inspectors evaluate the quality of the grass cover taking into account such items as the cover density, grass health, absence of grass and presence of weeds, dead vegetation or debris (Bakkenist et al., 2012a; CIRIA et al., 2013; USACE, 2006). Additionally, discontinuous grass cover may be indicative of other issues (e.g., erosion, slumps, slides, burrowing animals) (CIRIA et al., 2013). A further indicator that inspectors consider for grass covered dikes is soil moisture content. Excess soil moisture may soften soils, weaken shear strength and decrease stability, while also being indicative of other possible issues such as internal erosion (CIRIA et al., 2013). Desiccation of dike soils may lead to the loss of weight, soil shrinkage and the formations of cracks, which in turn can decrease stability, reduce crown height and increase the risk of seepage. Cracks may also cause increased infiltration resulting in further instability (CIRIA et al., 2013). Inspectors look for standing or pooling water, increased vegetation growth due to increased water availability, yellowing or dead vegetation due to water deficiency and the presence of cracks (Bakkenist et al., 2012b; CIRIA et al., 2013; USACE, 2006).

The dike inspection process could be facilitated by the use of remote sensing data since large areas can be covered in a relatively short space of time. In a proof-of-concept study, Cundill et al. (2014) investigated the potential use of remote sensing data as proxies for the two indicators of cover quality and soil moisture for grass covered dikes. They used ground-based point field measurements from narrowband hyperspectral, and broadband multispectral, visible and thermal instruments as well as measuring soil moisture and assessing cover quality. Cundill et al. (2014) found relationships and similar spatial patterns between the two indicators and various remote sensing data. The use of field measurements is a commonly used approach to investigate the relationships between the parameter of interest and remote sensing data (e.g., Peñuelas et al., 1995a; Gitelson et al., 2005; Zhang et al., 2012a). However, field measurements, although useful, do not provide contiguous data coverage 
and are also time-consuming and labour-intensive to collect. Imagery provides contiguous coverage over large areas and thus a subsequent step is to evaluate remote sensing image data against field measurements for the parameter of interest, as the change in spatial scale is a recognized problem (Moreno and Melia, 1992; Fisher et al., 2006; Baccini et al., 2007). Further, at an operational level, the use of airborne or satellite imagery is required in order to obtain data with the necessary coverage. An important question is how the data from imagery compare to what is measured in the field and to the parameters of interest.

The aim of this chapter is to compare and evaluate the remote sensing measurements obtained from satellite imagery to those obtained in the field for assessing soil moisture and cover quality indicators for the inspection of grass covered dikes. Index values obtained from satellite image data and those obtained from field data for a section of grass covered in situ peat dike are examined and possible reasons for discrepancies are discussed. As with all sensor cross-calibration, a number of factors could contribute to measurements not being directly comparable. These include sensor specific and scene specific differences. The relationships of both the image and field data to the indicators are studied and findings are discussed.

\subsection{Materials and Methods}

The study site is a section of a dike located near Gouda in the Netherlands (Figure 4.1). It is an in situ peak dike, covered with a thin mixed layer of peat and clay and a grass cover. It is reported by the local authorities to have problems, notably due to seepage and possibly subsidence. It is thought that parts of the dike are influenced by a long-term subsurface process with upwelling water (Cundill et al., 2014). Measurements were made during one of the driest summers on record, which allowed for a range of soil moisture and cover quality conditions to be represented. The dike section is about $60 \mathrm{~m}$ wide and westerly-facing with a gentle slope over about $45 \mathrm{~m}$. The soils are predominately strongly-clayey peat. The dike has a grass cover which is mowed regularly for hay production, as well as used directly for grazing. The condition of the grass at the time of measurement varied from extremely lush and green to substantial proportions of dry, dead grass (standing litter) and some bare soil. It had not been recently mowed. 


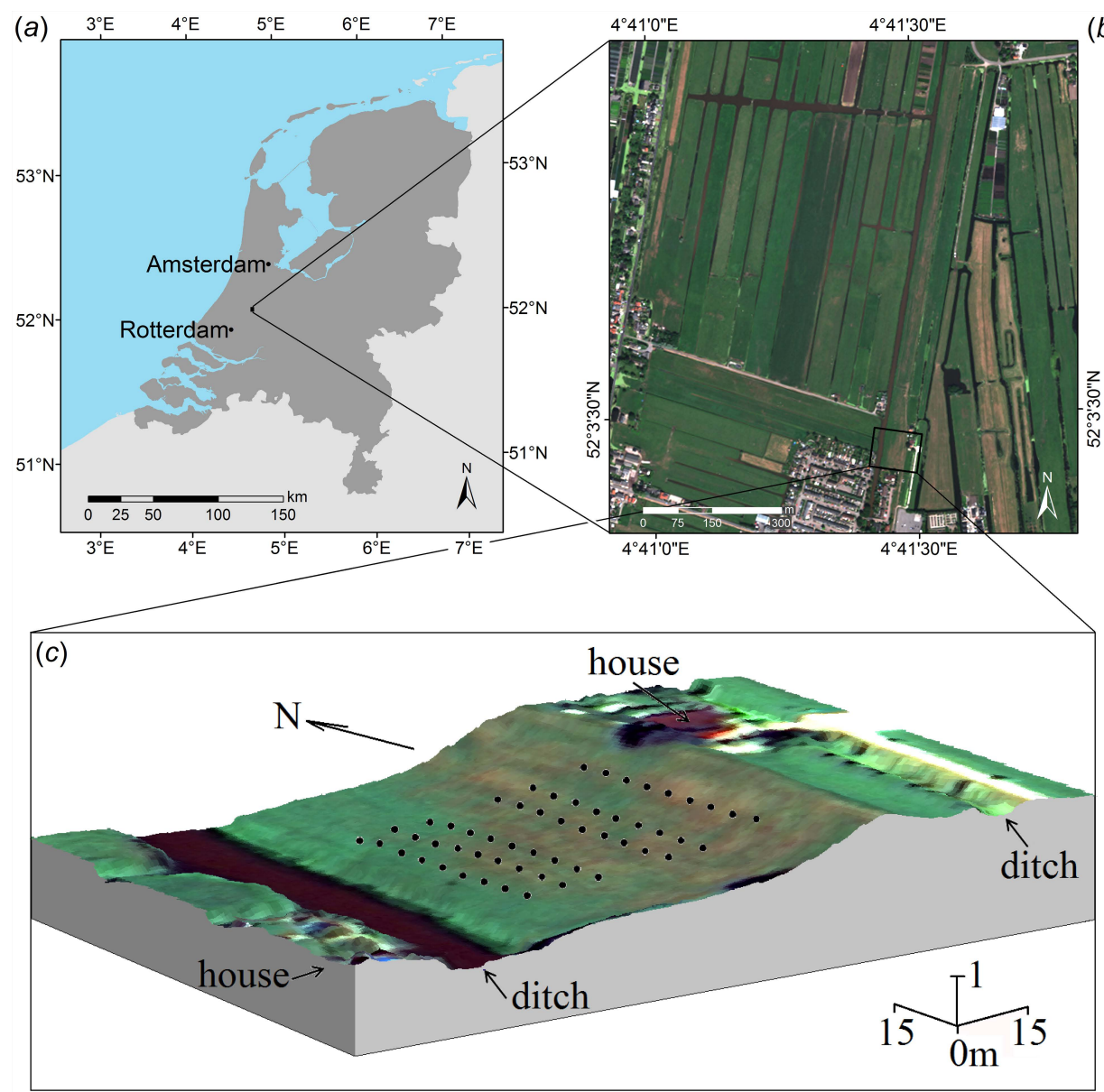

(b)

Figure 4.1: Maps of (a) the Netherlands showing the location of the study site and (b) the $d$ ke and surrounding area, with (c) the section of dike (vertical scale exaggerated). WorldView-2 panmerge image (๑ DigitalGlobe, Inc. All Rights Reserved) draped over the Actueel Hoogtebestand Nederland AHN2 digital elevation model data. The black dots represent the locations for which field measurements were recorded.

\subsubsection{Data}

The ground-based field measurements for this study were recorded on 15 July 2010 at 54 point locations within the $35 \mathrm{~m}$ (width) by $45 \mathrm{~m}$ (length) study area (Figure 4.1) which covers both the supposed seepage region, which is several metres in diameter, and a broad region around it which represents natural conditions of the dike system. The experiment setup is described in detail in Cundill et al. (2014) and the most relevant parts are summarized below. The measurement grid consisted of six lines along the dike, with nine points per line 
at $5 \mathrm{~m}$ spacing. The ground-based field remote sensing data set are hyperspectral reflectance spectra recorded using an ASD FieldSpec Pro spectrometer (Analytical Spectral Devices, Boulder, CO, USA) with an $8^{\circ}$ foreoptic (Table 4.1) and a calibrated Spectralon ${ }^{\circledR}$ panel was used to calculate reflectance. This data set and products (i.e., indices) are referred to as the ASD data sets in the remainder of the chapter (Table 4.2). As a result of the used foreoptic, each point location covered an area of about $30 \mathrm{~cm}$ by $40 \mathrm{~cm}$, for which both indicators and remote sensing data sets were recorded. Volumetric soil moisture for each location was measured using a ThetaProbe Soil Moisture Sensor-ML2x (by Delta-T Devices Ltd, Cambridge, UK). Nine sets of measurements were taken over a 24 hour period and since no diurnal trend was observed, the mean values were used for the soil moisture indicator. For the cover quality indicator, the dike cover was assessed for each location and allocated to either a good, medium, poor or bad quality class. The evaluation criteria include grass density, canopy cover and health as well as the presence and quantity of standing litter (dead plant material), debris, weeds and bare soil. The spatial patterns of the two indicators for dike inspection are shown by the maps in Figure 4.2.

The satellite image used in this chapter is a WorldView-2 image (Table 4.1; DigitalGlobe, Longmont, CO, USA). It was selected since it has the very high spatial resolution required to provide sufficient pixels to cover the narrow structure of the dike, it has eight spectral bands (more than most other very high spatial resolution satellite sensors) and it was recorded on 14 July 2010, a day before the ASD reflectance spectra. In addition, WorldView-2 data are shown to exhibit high spectral compatibility with ASD data (as observed in Cundill et al., 2015; see ccR ${ }^{2}$ in Table B.2). The processing level of the WorldView-2 image is $2 \mathrm{~A}$ and digital numbers were converted to radiance using the ENVI 5.0

Table 4.1: Sensor characteristics of the ASD FieldSpec Pro spectrometer and WorldView-2 sensor.

\begin{tabular}{|c|c|c|}
\hline CHARACTERISTIC & ASD FIELDSPEC PRO & WORLDVIEW-2* \\
\hline Nominal spatial resolution & $\begin{array}{l}30-40 \mathrm{~cm} \\
\text { (for this study) }\end{array}$ & $2 \mathrm{~m}$ \\
\hline Spectral resolution & $\begin{array}{l}\text { Continuous: } \\
350 \mathrm{~nm}-2500 \mathrm{~nm} \text { range } \\
1 \mathrm{~nm} \text { sampling interval } \\
2-3 \mathrm{~nm} \text { band width }\end{array}$ & $\begin{array}{l}8 \text { bands: } \\
396-458 \mathrm{~nm} \text { (coastal) } \\
442-515 \mathrm{~nm} \text { (blue) } \\
506-586 \mathrm{~nm} \text { (green) } \\
584-632 \mathrm{~nm} \text { (yellow) } \\
624-694 \mathrm{~nm} \text { (red) } \\
699-749 \mathrm{~nm} \text { (RE) } \\
765-901 \mathrm{~nm} \text { (NIR1) } \\
856-1043 \mathrm{~nm} \text { (NIR2) }\end{array}$ \\
\hline & & * (DigitalGlobe, 2013a) \\
\hline
\end{tabular}


Table 4.2: Summary of data sets, and their abbreviations, used in this chapter.

\begin{tabular}{|c|c|}
\hline DATA SET & DESCRIPTION OF DATA SETS \\
\hline $\begin{array}{l}\text { Soil } \\
\text { moisture }\end{array}$ & $\begin{array}{l}\text { Data set for the soil moisture indicator for inspection of grass covered dikes, } \\
\text { consisting of mean volumetric soil moisture measurements for } 54 \text { point locations on } \\
\text { a grass covered dike obtained using a ThetaProbe Soil Moisture Sensor. }\end{array}$ \\
\hline $\begin{array}{l}\text { Cover } \\
\text { quality }\end{array}$ & $\begin{array}{l}\text { Data set for the cover quality indicator for inspection of grass covered dikes, where } \\
\text { the quality of the grass cover was assessed for } 54 \text { point location on a grass covered } \\
\text { dike and allocated to one of four classes. }\end{array}$ \\
\hline ASD & $\begin{array}{l}\text { Reference data set of narrowband hyperspectral ground-based field reflectance } \\
\text { spectra obtained using an ASD FieldSpec Pro spectrometer, consisting of spectra } \\
\text { for } 54 \text { point locations on a grass covered dike. Includes product data sets (i.e., data } \\
\text { sets for various indices). }\end{array}$ \\
\hline Sim & $\begin{array}{l}\text { Simulated data set convolved from the ASD data set using the spectral response } \\
\text { functions (SRFs) of the WorldView-2 sensor. Includes product data sets (i.e., data } \\
\text { sets for various indices). }\end{array}$ \\
\hline SimAdj & $\begin{array}{l}\text { The simulated data set that has been adjusted to correct for the spectral differences } \\
\text { between the ASD FieldSpec Pro sensor and the WorldView- } 2 \text { sensor using a } \\
\text { translation function. Includes product data sets (i.e., data sets for various indices). }\end{array}$ \\
\hline Img54 & $\begin{array}{l}\text { The data set obtained from the WorldView- } 2 \text { image, where the pixel values were } \\
\text { extracted from the reflectance image for the } 54 \text { point locations. Includes product } \\
\text { data sets (i.e., data sets for various indices). }\end{array}$ \\
\hline Img54Adj & $\begin{array}{l}\text { The image data set (for the } 54 \text { point locations) that has been adjusted to correct for } \\
\text { the spectral differences between the ASD FieldSpec Pro sensor and the WorldView- } \\
2 \text { sensor using a translation function. Includes product data sets (i.e., data sets for } \\
\text { various indices). }\end{array}$ \\
\hline ImgAdj & $\begin{array}{l}\text { The image clipped to the study area boundary and where the index values have been } \\
\text { adjusted to correct for the spectral differences between the ASD FieldSpec Pro } \\
\text { sensor and the WorldView- } 2 \text { sensor using a translation function. The data set } \\
\text { includes all the WorldView- } 2 \text { image pixels within the study area. Includes product } \\
\text { data sets (i.e., data sets for various indices). }\end{array}$ \\
\hline
\end{tabular}

software (Exelis Visual Information Solutions, Inc., Boulder, CO, USA). Reflectance values were then calculated using ENVI's FLAASH atmospheric correction module (Adler-Golden et al., 1998; Adler-Golden et al., 1999), which incorporates the MODTRAN4 radiation transfer code (Berk et al., 1998). FLAASH supports the WorldView-2 sensor, correcting for scene specific sun and viewing angles. The atmospheric model applied was Mid-Latitude Summer, with the Rural aerosol model and initial visibility set to $35 \mathrm{~km}$ (from nearest weather station) (KNMI, 2011). Pixel values were extracted from the WorldView-2 reflectance image for each of the eight bands for the 54 locations for which the ASD reflectance data were collected. This point data set and products are referred to as the Img54 data sets (Table 4.2). 

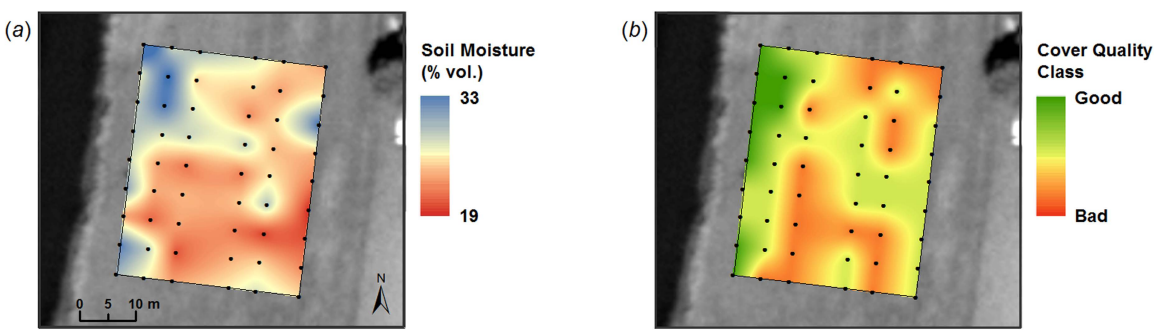

Figure 4.2: Maps showing the spatial distr bution and values for the two indicators used in this study, namely (a) soil moisture indicator and (b) cover quality indicator. The values are interpolated from the point data for the 54 locations (black dots) using natural neighbour algorithm. The study area is outlined by the black rectangle and the background image is the panchromatic WorldView-2 image (๑ DigitalGlobe, Inc. All Rights Reserved).

\subsubsection{Translation functions}

Variations in spectral response functions (SRFs) between sensors are considered one of the main causes of differences in reflectance data and derived products (Chander et al., 2013b; Trishchenko et al., 2002a). Since the SRFs of the WorldView-2 sensor are known, it was decided to correct for the differences in SRFs between the WorldView-2 sensor and ASD FieldSpec Pro sensor before continuing with further analysis. A common approach is to use translation functions (Gonsamo and Chen, 2013; Steven et al., 2003; Trishchenko et al., 2002a), which convert the reflectance or product values of one sensor to equivalent values of another by adjusting for differences in SRFs. These translation functions are usually defined by modelling the relationships between simulated data sets from two different sensors, where the differences in reflectance or product values are due to the differences in sensor SRFs.

Following the method described in Cundill et al. (2015), the ASD reflectance spectra were convolved using the SRFs of the WorldView-2 sensor. The only differences between these simulated data and the ASD data are due to differences in the SRFs. These simulated data (and products) are referred to as the Sim data sets in this chapter (Table 4.2). Translation functions were defined based on relationships between ASD and Sim data sets. Although Cundill et al. (2015) used linear regression in their study (which included the WorldView-2 and ASD FieldSpec Pro sensors), D'Odorico et al. (2013) found that the choice of regression model is more important than the choice of calibration data source. It was therefore decided to also test second degree polynomial functions for this chapter, since in the literature there are examples of where linear translation functions are recommended (Gallo et al., 2005; Gonsamo and Chen, 2013; Steven et al., 2003; van Leeuwen et al., 2006) and where second degree 
polynomial functions are recommended (D'Odorico et al., 2013; Pandya et al., 2007; Trishchenko, 2009; Trishchenko et al., 2002a). Best-fit translation functions were selected based on highest coefficients of determination $\left(R^{2}\right)$. However, since similar wavelengths are used, bands and products are not independent and so no statistical confidence should be inferred from the $R^{2}$ value. The best-fit translation functions (see Table 4.4 in the Results section) were applied to the Sim and Img54 data sets to create ASD-equivalent values and are referred to as SimAdj and Img54Adj data sets respectively (Table 4.2). Likewise, the translation functions were applied to the index values for the WorldView-2 image, which was clipped to the study area boundary (thereby including all pixels within the study area). This spectral resolution adjusted image and product data sets are referred to as the ImgAdj data sets (Table 4.2).

\subsubsection{Indices}

Cundill et al. (2015) explored relationships between numerous spectral indices from simulated data of ten very high spatial resolution sensors to two indicators for the same study site. They found that ten indices (Table 4.3) have the strongest mean correlations across all ten sensors, indices RVI, GRR, MSR, $\mathrm{GM}_{2}$, and $\mathrm{mSR}_{705}$ for the soil moisture indicator and indices $\mathrm{NDVI}_{705}$, $\mathrm{mNDVI}_{705}, \mathrm{mSR}_{705}, \mathrm{GM}_{2}, \mathrm{CTR}_{2}$, RGI, GRR and NGRR for the cover quality indicator. There is some overlap in indices between the indicators (i.e., GRR, $\mathrm{GM}_{2}$ and $\mathrm{mSR}_{705}$ ) due to the long-term subsurface process that affects both the cover quality and soil moisture of the dike. Many of these indices are of the same types that Cundill et al. (2014) found to perform well for the soil moisture and cover quality indicators. It was thus decided to use these ten indices for the current study. The index values for the ten indices were calculated for the ASD, Sim and Img54 data sets according to the equations in Table 4.3.

\subsubsection{Analysis methods}

Univariate statistical measures and boxplots were generated to explore and compare data sets. To further compare the data sets to the field ASD data sets, three bivariate measures were calculated for the Sim, SimAdj, Img54 and Img54Adj data sets.

The first of the bivariate measures is a variant of the coefficient of determination (denoted as $\mathrm{r}_{1: 1}^{2}$ ) and is calculated as a function of the 1:1 line (Eq. 4.1) similar to the Nash-Sutcliffe efficiency (Nash and Sutcliffe, 1970), and not as a function of the trend line. It therefore provides information on the overall deviation of the index values for a data set from the index values for the field ASD data set. The ideal value of 1 is not expected since the translation 
Table 4.3: Indices used in this chapter.

\begin{tabular}{|c|c|c|c|}
\hline INDEX NAME (ABBREV.) & $\begin{array}{l}\text { EQUATION FOR } \\
\text { ASD DATA }\end{array}$ & $\begin{array}{l}\text { EQUATION FOR } \\
\text { WORLDVIEW-2 } \\
\text { DATA } \\
\text { (i.e., Sim, Img54) }\end{array}$ & REFERENCE \\
\hline Carter Index $2\left(\mathrm{CTR}_{2}\right)$ & $\mathrm{R}_{695} / \mathrm{R}_{760}$ & $\mathrm{R}_{\mathrm{RE}} / \mathrm{R}_{\mathrm{NIR} 1}$ & (Carter, 1994) \\
\hline $\begin{array}{l}\text { Gitelson and Merzlyak } 2 \\
\left(\mathrm{GM}_{2}\right)\end{array}$ & $\mathrm{R}_{750} / \mathrm{R}_{700}$ & $\mathrm{R}_{\mathrm{NIR} 1} / \mathrm{R}_{\mathrm{RE}}$ & $\begin{array}{l}\text { (Gitelson and } \\
\text { Merzlyak, 1997) }\end{array}$ \\
\hline Green/Red Ratio (GRR) & $\mathrm{R}_{554} / \mathrm{R}_{673}$ & $\mathrm{R}_{\text {green }} / \mathrm{R}_{\text {red }}$ & $\begin{array}{l}\text { (Kanemasu, 1974; } \\
\text { Rodríguez-Pérez et } \\
\text { al., 2007) }\end{array}$ \\
\hline $\begin{array}{l}\text { Modified Red Edge } \\
\text { Normalized Difference } \\
\text { Vegetation Index } \\
\left(\mathrm{mNDVI}_{705}\right)\end{array}$ & $\begin{array}{l}\left(\mathrm{R}_{750}-\mathrm{R}_{705}\right) / \\
\left(\mathrm{R}_{750}+\mathrm{R}_{705}-2 *\right. \\
\left.\mathrm{R}_{445}\right)\end{array}$ & $\begin{array}{l}\left(\mathrm{R}_{\mathrm{NIR} 1}-\mathrm{R}_{\mathrm{RE}}\right) / \\
\left(\mathrm{R}_{\mathrm{NIR} 1}+\mathrm{R}_{\mathrm{RE}}-2 *\right. \\
\left.\mathrm{R}_{\text {coastal }}\right)\end{array}$ & $\begin{array}{l}\text { (Sims and Gamon, } \\
\text { 2002) }\end{array}$ \\
\hline $\begin{array}{l}\text { Modified Simple Ratio } \\
\text { (MSR) }^{\mathrm{a}}\end{array}$ & $\begin{array}{l}\left(\mathrm{R}_{800} / \mathrm{R}_{670}-1\right) / \\
{\left[\left(\mathrm{R}_{800} / \mathrm{R}_{670}\right)^{05}+1\right]}\end{array}$ & $\begin{array}{l}\left(\mathrm{R}_{\mathrm{NIR} 1} / \mathrm{R}_{\mathrm{red}}-1\right) / \\
{\left[\left(\mathrm{R}_{\mathrm{NIR} 1} / \mathrm{R}_{\mathrm{red}}\right)^{05}+1\right]}\end{array}$ & (Chen, 1996) \\
\hline $\begin{array}{l}\text { Modified Simple Red Edge } \\
\text { Ratio Index }\left(\mathrm{mSR}_{705}\right)\end{array}$ & $\begin{array}{l}\left(\mathrm{R}_{750}-\mathrm{R}_{445}\right) / \\
\left(\mathrm{R}_{705}-\mathrm{R}_{445}\right)\end{array}$ & $\begin{array}{l}\left(\mathrm{R}_{\mathrm{NIR1}}-\mathrm{R}_{\text {coastal }}\right) / \\
\left(\mathrm{R}_{\mathrm{RE}}-\mathrm{R}_{\text {coastal }}\right)\end{array}$ & $\begin{array}{l}\text { (Sims and Gamon, } \\
2002 \text { ) }\end{array}$ \\
\hline $\begin{array}{l}\text { Normalized Green/Red Ratio } \\
\text { (NGRR) }\end{array}$ & $\begin{array}{l}\left(\mathrm{R}_{673}-\mathrm{R}_{554}\right) / \\
\left(\mathrm{R}_{673}+\mathrm{R}_{554}\right)\end{array}$ & $\begin{array}{l}\left(\mathrm{R}_{\text {red }}-\mathrm{R}_{\text {green }}\right) / \\
\left(\mathrm{R}_{\text {red }}+\mathrm{R}_{\text {green }}\right)\end{array}$ & $\begin{array}{l}\text { (Rodríguez-Pérez et } \\
\text { al., 2007) }\end{array}$ \\
\hline $\begin{array}{l}\text { Ratio Vegetation Index } \\
(\mathrm{RVI})^{\text {a }}\end{array}$ & $\mathrm{R}_{800} / \mathrm{R}_{673}$ & $\mathrm{R}_{\mathrm{NIR} 1} / \mathrm{R}_{\mathrm{red}}$ & $\begin{array}{l}\text { (Jordan, 1969; } \\
\text { Rodríguez-Pérez et } \\
\text { al., 2007), }\end{array}$ \\
\hline $\begin{array}{l}\text { Red Edge Normalized } \\
\text { Difference Vegetation Index } \\
\left(\mathrm{NDVI}_{705}\right)\end{array}$ & $\begin{array}{l}\left(\mathrm{R}_{750}-\mathrm{R}_{705}\right) / \\
\left(\mathrm{R}_{750}+\mathrm{R}_{705}\right)\end{array}$ & $\begin{array}{l}\left(\mathrm{R}_{\mathrm{NIR} 1}-\mathrm{R}_{\mathrm{RE}}\right) / \\
\left(\mathrm{R}_{\mathrm{NIR} 1}+\mathrm{R}_{\mathrm{RE}}\right)\end{array}$ & $\begin{array}{l}\text { (Sims and Gamon, } \\
\text { 2002) }\end{array}$ \\
\hline Red/Green Index (RGI) & $\mathrm{R}_{690} / \mathrm{R}_{550}$ & $\mathrm{R}_{\text {red }} / \mathrm{R}_{\text {green }}$ & $\begin{array}{l}\text { (Zarco-Tejada et al., } \\
\text { 2005) }\end{array}$ \\
\hline
\end{tabular}

R: Reflectance at specified wavelength (in nanometres) or band

${ }^{a}$ Original index was for a broadband sensor

functions already have $R^{2}$ values below 1 (see Table 4.4 in the Results section). Further, for the WorldView-2 image data sets, it is anticipated that the increase in spatial resolution and other sensor and scene specific differences will increase the deviation from the 1:1 line. Values outside of the typical 0 to 1 range are possible since the test, in this case, is not using modelled values.

$$
r_{1: 1}^{2}=1-\frac{\sum_{i}\left(y_{i}-\hat{y}_{i}\right)^{2}}{\sum_{i}\left(y_{i}-\bar{y}\right)^{2}}
$$


where $y_{i}$ denotes index values for the field ASD data set, $\hat{y}_{i}$ denotes index values for the simulated or image data set, and $\bar{y}$ denotes the mean of the index values for the field ASD data set.

The second bivariate measure, the mean percentage difference (Eq. 4.2), is used to evaluate the differences between the field ASD data sets and the other data sets. This measure is useful for comparing data sets for the same index but not across indices since the measure is not standardized. Ideally, the mean percentage difference should be 0 indicating that there is no difference between the data sets. As for the $\mathrm{r}_{1: 1}^{2}$, the ideal is not expected.

$$
\text { mean } \% \text { diff. }=\frac{1}{n} \sum_{i}\left(\left|\frac{\hat{y}_{i}-y_{i}}{\left(\hat{y}_{i}+y_{i}\right) / 2}\right| \times 100\right)
$$

where $y_{i}$ denotes index values for the field ASD data set, and $\hat{y}_{i}$ denotes index values for the simulated or image data set.

The third bivariate measure is Hedges's $g$ (Eq. 4.3), which is one estimate of effect size. Effect size is a generic term referring to the magnitude and direction of the relationship of interest (other examples include correlation coefficient and coefficient of determination). Hedges's $g$ is a standardized measure of the difference between two means, used to assess the difference between two groups (Ellis, 2010). Ideally, Hedges's $g$ should be 0 indicating that there is no difference between the data sets. Hedges's $g$ can be grouped into effect size classes (Ellis, 2009) based on the Cohen's (1988, as cited in Ellis, 2009) and Rosenthal's (1996, as cited in Ellis, 2009) thresholds of 0.20 for small, 0.50 for medium, 0.80 for large and 1.30 for very large effect size and where an effect size of less than 0.20 is considered trivial. Effect size should be preferably interpreted in context of the problem under study (Ellis, 2010).

$$
\begin{gathered}
\text { Hedges's } g=\frac{\bar{x}_{1}-\bar{x}_{2}}{s^{*}} \\
s^{*}=\sqrt{\frac{\left(n_{1}-1\right) s_{1}^{2}+\left(n_{2}-1\right) s_{2}^{2}}{n_{1}+n_{2}-2}}
\end{gathered}
$$

where $\bar{x}_{1}$ denotes the mean of the index values for the field ASD data set, $\bar{x}_{2}$ denotes the mean of the index values for the simulated or image data set, $n_{1}$ denotes the number of cases for the field ASD data set, $n_{2}$ denotes the number of cases for the simulated or image data set, $s_{1}$ denotes the standard deviation for the field ASD data set and $s_{2}$ denotes the standard deviation or the simulated or image data set. 
Correlations of the ASD, Img54 and Img54Adj product data sets to the indicators were calculated. The Pearson correlation coefficient was used for the soil moisture indicator and the Spearman correlation coefficient was used for the ordinal cover quality indicator. Spatial patterns were visualized either using the image itself or by interpolating the data for the 54 locations using the natural neighbour algorithm of ArcGIS 10.2 (from ESRI, Redlands, CA, USA).

\subsection{Results and Discussion}

\subsubsection{Translation functions}

Translation functions, to correct for spectral resolution differences between sensors, were defined based on relationships between ASD and Sim data sets, where for all ten indices second degree polynomial functions rendered higher coefficients of determination $\left(R^{2}\right)$ than for linear functions. Since the $R^{2}$ values are less than 1, not all biases caused by differing SRFs could be modelled and adjusted. Translation functions with $R^{2}$ values less than 0.995 are for indices that include the red-edge band. Cundill et al. (2015) note that reflectance measured for bands in transitional regions of the spectrum (i.e., where the slope of the spectrum changes such as in the red-edge region for vegetation) are noticeably influenced by the position and width of these bands and that relationships between sensors for indices that use these bands are thus adversely affected. The second degree polynomial functions (Table 4.4) were applied to the Sim, Img54 and image data sets to render the respective spectral resolution adjusted (i.e., ASD-equivalent) SimAdj, Img54Adj and ImgAdj data sets.

\subsubsection{Comparison of field and image data}

Based on the bands used, the ten indices (Table 4.3) can be divided into three groups, namely those that use green and red bands, those that use red and nearinfrared bands and those that use red-edge and near-infrared bands. For each group, indices RGI, MSR and $\mathrm{GM}_{2}$ were respectively selected as representative based on the $R^{2}$ values presented in Table 4.4. While indices MSR and RGI have the highest $R^{2}$ values, index mNDVI $\mathrm{I}_{705}$ has the lowest $R^{2}$ value and thus was also added to the selection of representative indices. Boxplots (Figure 4.3), bar graphs of the bivariate statistics (Figure 4.4) and maps showing spatial patterns (Figure 4.5) are presented for representative indices. Bivariate statistics for all ten indices are given in Table D.1. 
Table 4.4: Best-fit translation functions for correcting differences in spectral resolution between the ASD FieldSpec Pro and WorldView-2 sensors for grass cover of varying conditions, where $\mathrm{x}$ is the WorldView-2 value and y the ASD-equivalent value.

\begin{tabular}{llc}
\hline INDEX & TRANSLATION FUNCTION & $R^{2}$ \\
\hline CTR $_{2}$ & $\mathrm{y}=10.543 \mathrm{x}^{2}-10.312 \mathrm{x}+2.6175$ & 0.917 \\
$\mathrm{GM}_{2}$ & $\mathrm{y}=-0.7182 \mathrm{x}^{2}+10.978 \mathrm{x}-12.902$ & 0.965 \\
GRR $_{\text {mNDVI }}$ & $\mathrm{y}=0.2016 \mathrm{x}^{2}+0.9764 \mathrm{x}-0.0532$ & 0.997 \\
MSR $_{\text {mSR }}$ & $\mathrm{y}=-11.474 \mathrm{x}^{2}+9.6459 \mathrm{x}-1.272$ & 0.882 \\
NGRR $_{\text {RVI }}$ & $\mathrm{y}=-0.0153 \mathrm{x}^{2}+1.4023 \mathrm{x}-0.0598$ & 0.999 \\
NDVI $_{705}$ & $\mathrm{y}=-1.0929 \mathrm{x}^{2}+11.548 \mathrm{x}-13.737$ & 0.944 \\
RGI & $\mathrm{y}=0.1677 \mathrm{x}^{2}+1.2639 \mathrm{x}-0.0575$ & 0.998 \\
\hline
\end{tabular}

Comparing the results for the Sim and SimAdj data sets (Figures 4.3 and 4.4), it can be seen that the translation functions reduced the differences between the simulated data sets and the field ASD data sets. The $\mathrm{r}^{2}{ }_{1: 1}$ values improved closer to 1 , the mean percentage differences improved to less than $13 \%$ and the Hedges's $g$ values reduced to 0.00 for all indices. As previously mentioned, not all the differences caused by spectral resolution could be modelled (Table 4.4, $R^{2}<1$ ) and thus corrected, and so some uncertainty remains (especially for lower $R^{2}$ values). This is particularly evident for $\mathrm{GM}_{2}\left(R^{2}=0.965\right)$ and $\mathrm{mNDVI}_{705}\left(R^{2}=0.882\right)$, where the bivariate statistical measures (Figure 4.4) have higher values than for MSR $\left(R^{2}=0.999\right)$ and RGI $\left(R^{2}=0.999\right)$. Comparing the results for the Img54 and Img54Adj data sets (Figures 4.3 and 4.4), it can likewise be seen that the translation functions reduced the differences between the image data sets and the field ASD data sets. For all indices except RGI, $r_{1: 1}^{2}$ values improved and both the mean percentage difference and Hedges's $g$ reduced in value. As expected, the Img54Adj data sets are less similar to the field ASD data sets than the SimAdj data sets, as are the Img54 data sets than the Sim data sets (Figures 4.3 and 4.4). Since these data sets have the same spectral resolution, the differences undoubtedly arise from some other source. Possible sources for these differences are discussed in the following paragraph.

There are a number of possible causes for differences between data sets. Atmospheric influences are a challenge for the comparison of data (Teillet et al., 2007; van Leeuwen et al., 2006), though their effects are sometimes considered negligible or small (Teillet et al., 2007; Trishchenko et al., 2002a). 


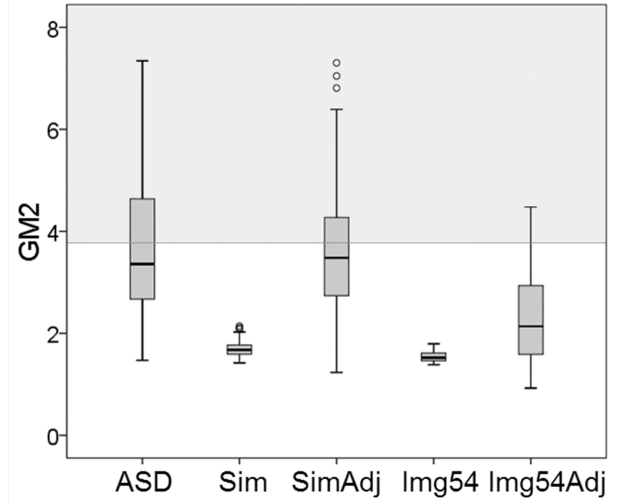

(a)

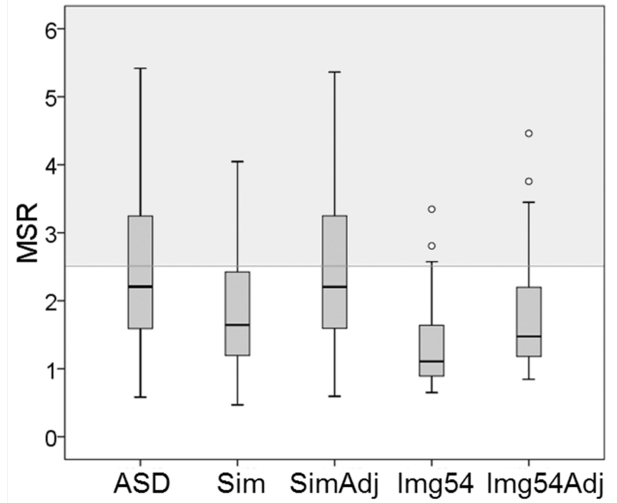

(c)

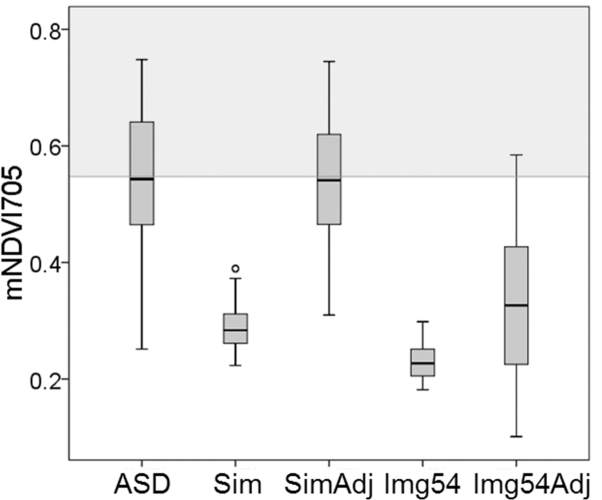

(b)

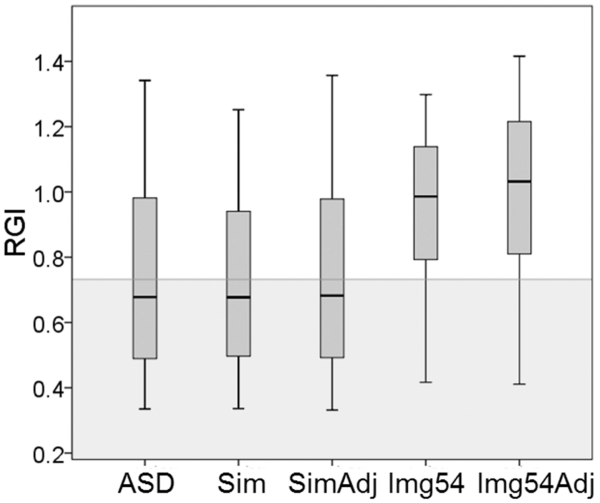

(d)

Figure 4.3: Boxplots for selected indices (selection based on $R^{2}$ values in Table 4.4). The grey line is at the position of the mean for the ASD data sets. The shaded area indicates the area above or below the mean (depending on the direction of the correlation to the indicators). For example, the $\mathrm{GM}_{2}$ index values tend to increase with increasing soil moisture, while the RGI index values tend to decrease with increasing soil moisture.

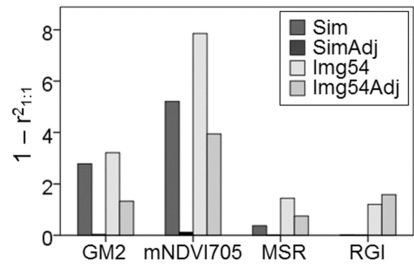

(a)

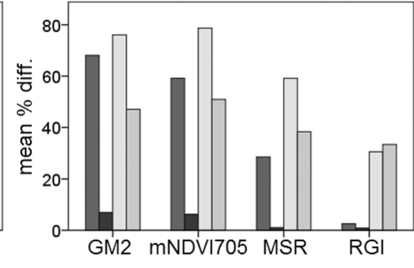

(b)

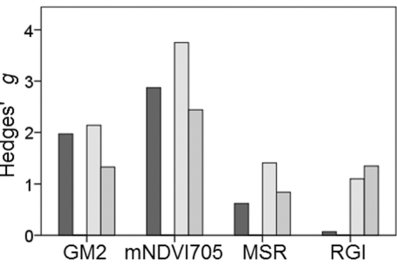

(c)

Figure 4.4: Bar graphs for the three bivariate measures for selected indices (selection based on $R^{2}$ values in Table 4.4). The coefficient of determination to the 1:1 line (denoted as $r^{2}{ }_{1: 1}$ ) has been subtracted from 1 in order that the graph may be more easily interpreted with the value 0 representative of no difference from the field ASD data sets. 
Both the ASD spectra and image data were corrected to reflectance before processing and analysis. It is therefore likely that atmospheric conditions (including sun and viewing geometry) do not contribute significantly to the differences between the data sets and that any remaining uncertainties in the atmospheric corrections will be negligible. Differences between the data sets due to geometric misregistration are foreseen to be small since the RMS error is less than $0.6 \mathrm{~m}$, which is less than half the WorldView-2 image pixel size. This study did not address the effects of directional reflectance (affected by anisotropy, topography and sun and viewing angles). Their correction is complex, dependent on land cover, terrain model resolution, sensor spectral resolution and confounded by mixed pixels (Feingersh et al., 2010). Disparity between the data sets as a result of directional effects could account for some of the differences between the data sets. Interestingly, Verrelst et al. (2008) in their study of angular sensitivity of vegetation indices found that RVI and $\mathrm{NDVI}_{705}$ are sensitive to changing viewing angles while $\mathrm{mSR}_{705}$ and $\mathrm{mNDVI}_{705}$ are insensitive. In the current study, the RVI image data sets were among the most similar to the ASD data sets (see Table D.1) and that $\mathrm{mSR}_{705}, \mathrm{mNDVI}_{705}$ and $\mathrm{NDVI}_{705}$ were among the least similar (e.g., $\mathrm{mNDVI}_{705}$ in Figures 4.3 and 4.4). The fact that that $\mathrm{mSR}_{705}, \mathrm{mNDVI}_{705}$ and $\mathrm{NDVI}_{705}$ were among the least similar is most likely strongly influenced by the inclusion of the red-edge band in these indices (and consequently the lower $R^{2}$ value for translation functions). Therefore, when the $\mathrm{NDVI}_{705}$ (Table D.1) and $\mathrm{mNDVI}_{705}$ are compared, $\mathrm{NDVI}_{705}$ is found to be more similar to the ASD data sets. This would seem to indicate that the differences observed in the current study were not due to viewing angle variations.

Differences in spatial scale and resolution are known problems for data comparison (Chander et al., 2013a; Steven et al., 2003; Teillet et al., 1997), especially for heterogeneous surfaces (Jiang et al., 2006) where the relative size of land cover elements to spatial resolution is important (Teillet et al., 1997; van der Meer et al., 2001). Already at the spatial scale of the ASD FieldSpec Pro sensor, many of the measurements contained a mixture of cover types, i.e., green grass, standing litter and bare soil. It is expected that the proportions of cover types will alter and become more complex as the measured area increases in size, such as with the spatial resolution of the WorldView-2 sensor. Indeed, Weber et al. (2013) illustrate that as the pixel size increases over a heterogeneous surface so it becomes more mixed, and Moreno and Melia (1992) found that within-pixel variance increases with increasing pixel size. Further, Teillet et al. (1997) showed that, for various vegetation indices, index values change considerably when the spatial resolution varies with respect to the size of the land cover elements, and Jiang et al. (2006) state that the 
Normalized Difference Vegetation Index (NDVI) may not be comparable at different spatial resolutions over heterogeneous surfaces. In addition, the effect of standing litter is complex, and can cause the response of vegetation indices to be either higher or lower than for a pure green canopy (van Leeuwen and Huete, 1996). Since the cover of the dike was heterogeneous, with small element sizes, and contained standing litter, it is reasonable that the increase in spatial resolution is largely responsible for differences in the index values between the WorldView-2 image data sets and the ASD and simulated data sets. It is anticipated that when comparing imagery of similar spatial resolution that the effects of spatial scale and resolution differences will be reduced.

Despite the differences in index values between the ASD data sets and the Img54Adj data sets, the main spatial patterns observed in the field ASD data sets can still be observed in the Img54Adj and ImgAdj data sets (Figure 4.5) even while being represented with the same colour scale. As expected from the statistics (Figures 4.3 and 4.4), the actual MSR index values between the ASD and image (Img54Adj and ImgAdj) data sets are more similar compared to those of the mNDVI705 (as seen in the similar shading intensity in Figure 4.5). The spatial patterns can be observed in that the toe of the dike (western part of study area) is different from the rest of the dike, although to a lesser extent in the interpolated Img54Adj data sets. The small feature along the eastern boundary of the study area, while not evident in the interpolated Img54Adj data sets, can be seen in the ImgAdj data sets. Thus similar spatial information can be deduced from both the field and image data.

\subsubsection{Indicators}

The spatial patterns of the indices presented in Figure 4.5 show similarities to those of the two indicators (Figure 4.2). For both indicators (Figure 4.2), the toe of the dike (western part of study area) is different from the rest of the dike, with the cover quality indicator having a more continuous feature. The small feature along the eastern boundary of the study area is visible in the map for the soil moisture indicator. The correlations (Table 4.5) of the ASD and image data sets to the indicators are moderate $(0.4<|r|<0.7)$. The strongest correlations to the soil moisture indicator are for indices RVI, MSR and GRR, while for the cover quality indicator, indices RGI, GRR and NGRR have the strongest correlations. The correlations to soil moisture indicator are stronger for the Img54 and Img54Adj data sets compared to the ASD data sets. This increase in the soil moisture correlation coefficients could be due to the long-term subsurface process thought to be affecting the dike. The correlations to the cover quality indicator are weaker for the Img54 and Img54Adj data sets. This decrease is probably due to the heterogeneity of the cover being generalized. 

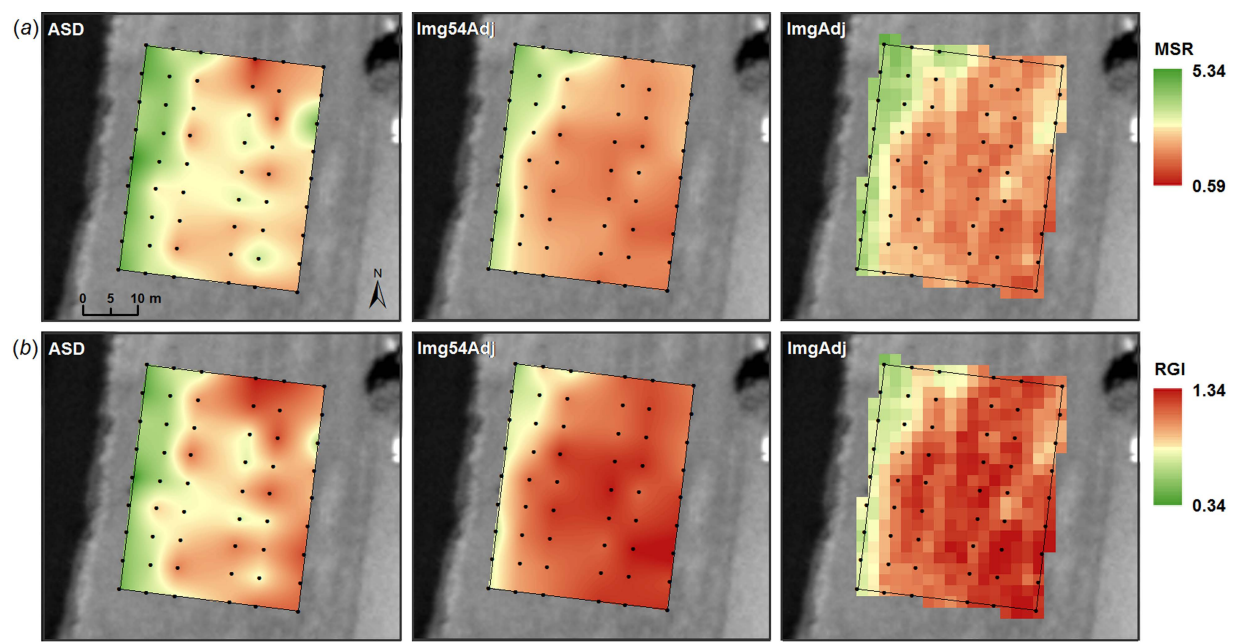

RGI
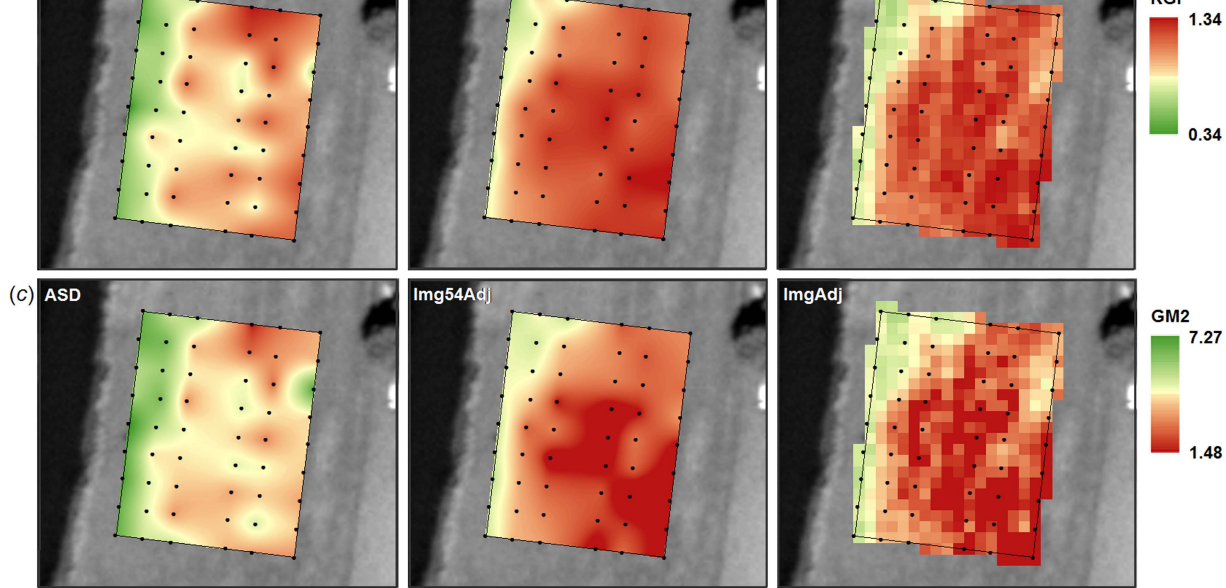

GM2

(d) ASD
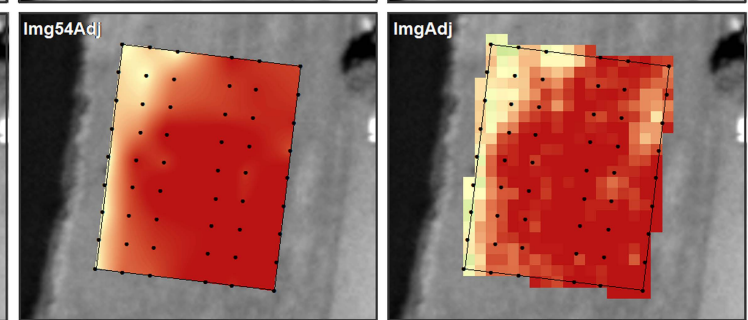

Figure 4.5: Maps showing the spatial distribution and values for selected indices (selection based on $R^{2}$ values in Table 4.4) for (left) the interpolated ASD point data (ASD data sets); (centre) the interpolated WorldView-2 spectrally-translated image point data (Img54Adj data sets) and (right) the actual WorldView-2 spectrally-translated pixel data (ImgAdj data sets). The study area for the 54 locations is outlined by the black rectangle and the 54 locations are indicated by the black dots. The background image is the panchromatic WorldView-2 image (๑ DigitalGlobe, Inc. All Rights Reserved).

For data to be useful for the inspection of dikes, index values need to consistently have the same meaning (i.e., the same or similar values) across different sensors. The statistics (Figures 4.3 and 4.4) indicate that the Img54 and Img54Adj data sets are dissimilar to the field ASD data sets, although correcting the image data for differences in spectral resolution (by means of translation equations) reduced the dissimilarity of the Img54Adj data sets. Nevertheless, the maps (Figure 4.5) show that for some of the indices 
(e.g., MSR) the index values for the Img54Adj data sets were sufficiently similar to the ASD data sets (observed in the similar shading) for the toe of the dike to be consistently identified as different from the rest of the dike based on index value. This is also apparent in the ImgAdj data sets (Figure 4.5). This would allow for the use of thresholds (whether absolute or fuzzy boundary) and the potential for implementation at an operational level using data from more than one sensor. The maps (Figure 4.5) for the RGI and $\mathrm{GM}_{2}$ indices show that, based on index values, a smaller proportion of the dike toe would be identified as different while for the $\mathrm{mNDVI}_{705}$ index virtually none of the dike toe would be considered as different. The normalized measures of $r_{1: 1}^{2}$ and Hedges's $g$ indicate the extent to which the image data sets are similar to the field ASD data sets. For the Img54Adj data sets, indices RVI (Table D.1) and MSR (Figure 4.4) were the most similar to their respective field ASD data sets, with $\mathrm{r}_{1: 1}^{2} \geq 0.250$ and Hedges's $g<0.85$, followed by index GRR with $\mathrm{r}_{1: 1}^{2}=0.066$ and Hedges's $g=1.03$, while indices $\mathrm{CTR}_{2}$ (Table D.1) and $\mathrm{mNDVI}_{705}$ (Figure 4.4) were the least similar, with $\mathrm{r}_{1: 1}^{2}<-2.200$ and Hedges's $g \geq 1.90$. Based on the two normalized measures of $r_{1: 1}^{2}$ and Hedges's $g$, the observations from the maps and the correlations to the indicators, it would appear that indices MSR (Figures 4.4 and 4.5), RVI and GRR (Table D.1) could be used for the inspection of dikes between the ASD FieldSpec Pro and WorldView-2 sensors. Since the differences between the Img54Adj and ASD data sets are mostly attributed to the change in spatial resolution, it is expected that for sensors with similar spatial resolutions that the similarity would improve between the index values for the different sensors.

Table 4.5: Correlation coefficients to the indicators, with the Pearson correlation coefficient for the soil moisture indicator and the Spearman correlation coefficient for the ordinal cover quality indicator.

\begin{tabular}{lccc}
\hline \multicolumn{4}{l}{ SoIL MoISTURE INDICATOR } \\
INDEX & ASD & IMG54 & IMG54ADJ \\
\hline $\mathrm{GM}_{2}$ & 0.575 & 0.634 & 0.633 \\
$\mathrm{GRR}$ & 0.585 & 0.653 & 0.651 \\
$\mathrm{MSR}$ & 0.573 & 0.662 & 0.661 \\
$\mathrm{mSR}_{705}$ & 0.555 & 0.627 & 0.626 \\
$\mathrm{RVI}$ & 0.590 & 0.661 & 0.660 \\
\hline
\end{tabular}

\begin{tabular}{lccc}
\hline \multicolumn{4}{l}{ COVER QUALITY INDICATOR } \\
INDEX & ASD & IMG54 & IMG54ADJ \\
\hline $\mathrm{CTR}_{2}$ & 0.570 & 0.416 & 0.416 \\
$\mathrm{GM}_{2}$ & -0.567 & -0.416 & -0.416 \\
$\mathrm{GRR}$ & -0.579 & -0.464 & -0.464 \\
$\mathrm{mNDVI}_{705}$ & -0.579 & -0.406 & -0.406 \\
$\mathrm{mSR}_{705}$ & -0.579 & -0.406 & -0.406 \\
NGRR & 0.579 & 0.464 & 0.464 \\
NDVI $_{705}$ & -0.573 & -0.416 & -0.416 \\
RGI & 0.580 & 0.464 & 0.464 \\
\hline
\end{tabular}




\subsection{Conclusion}

This chapter compares and evaluates indices for image remote sensing data to spectral point data obtained in the field for assessing soil moisture and cover quality indicators for dike inspection. Index values obtained from the imagery are different to those of the field data. Index value differences due to spectral resolution were predominately corrected using translation functions but some residual errors remained. The more than fourfold increase in spatial resolution is believed to be the main cause of the differences in index values between the image and field data sets owing to the heterogeneity of the cover. Of the ten indices studied, the values for indices RVI and MSR, followed by GRR, were the most similar and thus appear to be the least affected by changes in spectral and spatial resolution for this cover type. The values for indices $\mathrm{CTR}_{2}$ and $\mathrm{mNDVI}_{705}$ were found to be the least similar between the image and field data sets. It is expected that the spatial resolution effects should be considerably reduced when comparing sensors of similar spatial resolution, such as imagery of other very high spatial resolution satellite sensors to that of the WorldView-2 sensor. This is promising for the inspection of dikes, as imagery from multiple sensors should provide the necessary coverage while still being comparable. The strongest correlations to the soil moisture indicator for the two sensors were for indices RVI, MSR and GRR, while for the cover quality indicator, indices RGI, GRR and NGRR had the strongest correlations. The indices MSR, RVI and GRR were the most similar between the field and image data sets while still having the strongest correlations to the two indicators. To facilitate the inspection of grass covered dikes, indices RVI, MSR and GRR could be used as proxies for the soil moisture indicator while index GRR could be used as a proxy for the cover quality indicator. 


\section{Usability of Multi-Date Image Data for Dike Inspection}




\subsection{Introduction}

In the previous chapter (Chapter 4), index values for various indices computed from field spectral data and from satellite image data (recorded a day apart in July 2010) were compared for assessing soil moisture and cover quality indicators for the inspection of grass covered dikes. Translation functions, for adjusting for spectral response function (SRF) variations between sensors, reduced the differences (i.e. improved relationships) between the image data sets and the field spectral data sets. However, differences remained between the data sets. A wide range of factors could contribute towards these differences, including remaining biases from SRF differences, atmospheric influences, geometric misregistration, and spatial scale and resolution differences. The remaining biases due to SRF differences and the effects of atmospheric influences, geometric misregistration and directional reflectance for the field spectral and image data are considered negligible or small in this case (see Section 4.3.2). Spatial scale and resolution differences are known issues for data comparison (Chander et al., 2013a; Steven et al., 2003; Teillet et al., 1997), particularly for heterogeneous surfaces (Jiang et al., 2006; Teillet et al., 1997; van der Meer et al., 2001). Even at the fine spatial scale of the field spectral data, many of the measurements from July 2010 contained a mixture of cover types, i.e., green grass, standing litter (dead plant material) and bare soil. As a result of the heterogeneity of the cover, the more than fourfold increase in spatial resolution between the field spectral data and image data is considered to be the main contributor towards the differences in index values between the image and field data sets.

Despite the differences in index values between the field spectral data sets and the adjusted image data sets, the main spatial patterns observed in the field spectral data sets can still be observed in the adjusted image data sets (see Figure 4.5). It was found that the Ratio Vegetation Index (RVI), Modified Simple Ratio (MSR) and Green/Red Ratio (GRR) could potentially be used as proxies for the soil moisture indicator while index GRR could potentially be used as a proxy for the cover quality indicator.

The current chapter aims at addressing whether the spatial patterns observed in both the field spectral data and the adjusted image data are still observed in other image data sets and thus whether multi-date imagery from different sensors can be used to identify and monitor spatial patterns associated with an anomalous subsurface process. The hypothesis for this chapter is: considering the long-term process of upwelling water that affects parts of the dike, it is expected that similarities in spatial patterns will still be observed in imagery from different dates and different sensors. 


\subsection{Materials and Methods}

\subsubsection{Study site}

The study site is a section of a grass covered dike located near Gouda in the Netherlands $\left(52^{\circ} 03^{\prime} \mathrm{N}, 4^{\circ} 41^{\prime} \mathrm{E}\right)$. It was selected as the study site since it is reported by the local authorities to have problems, notably due to seepage and possibly subsidence. Evidence of these phenomena was observed during field campaigns in 2008 and 2010. It is thought that parts of the dike are influenced by a long-term subsurface process with upwelling water (Cundill et al., 2014). Spatial patterns associated with this long-term upwelling process were apparent in field data (Cundill et al., 2014) and very high spatial resolution imagery (Chapter 4) recorded in July 2010, where the toe of the dike section (western part) is different from the rest of the dike section. The dike is an in situ peat dike, covered with a thin mixed layer of peat and clay and a grass cover. The soils are predominately strongly-clayey peat. The dike section is westerlyfacing with a gentle slope (about $5^{\circ}$ ) over about $45 \mathrm{~m}$. An extended dike segment is examined in this chapter, with a length of about $170 \mathrm{~m}$. The dike has a grass cover which is mowed regularly for hay production, as well as used directly for grazing. According to the Köppen-Geiger climate classification, the Netherlands has a warm temperate, fully humid with warm summer climate (Kottek et al., 2006). The temperate maritime climate is associated with cool summers (mean temperature of $16^{\circ} \mathrm{C}$ ) and mild winters (mean temperature of $3^{\circ}$ ) with rainfall throughout the year (annual average $770 \mathrm{~mm}$ ) (KNMI, n.d.) Specific weather information is presented in Figure 5.1 for and preceding image acquisition dates.

\subsubsection{Image acquisition}

In the previous chapter (Chapter 4), a WorldView-2 image dated 14 July 2010 (recorded one day before the field campaign) was introduced. For this chapter, a further five satellite images from five very high spatial resolution sensors were acquired (Figure 5.1), namely GeoEye-1, IKONOS, QuickBird, WorldView-2 (DigitalGlobe, Longmont, CO, USA) and Pléiades-1B (CNES, Paris, France). In total, the six images were recorded between April 2008 and September 2013, for the months of March, April, May (two different years), July and September. No sufficiently cloud-free images were available for the study site for the months October to February (autumn and winter) from satellite imaging sensors with a multispectral spatial resolution of less than $5 \mathrm{~m}$. No images were 

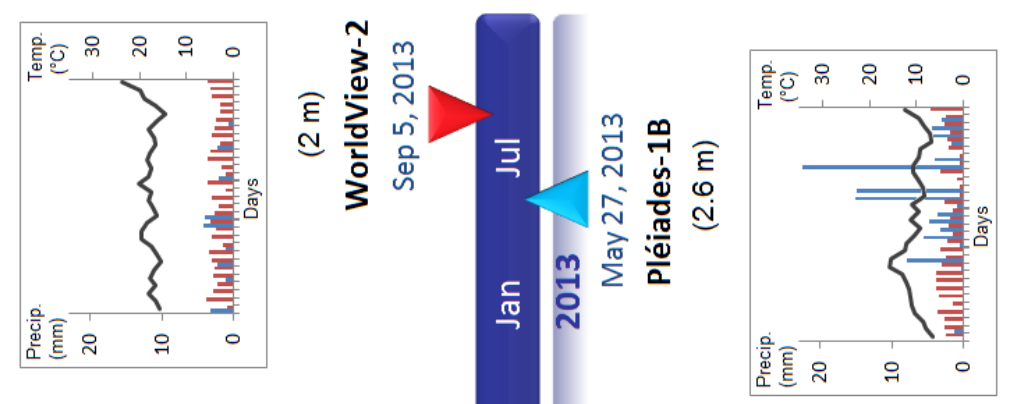

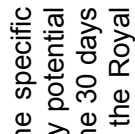

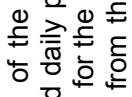

을 응 일

긍 은 ⿱ㅠㄴ 흉

즌 흔 흥

윤든

त्त

구

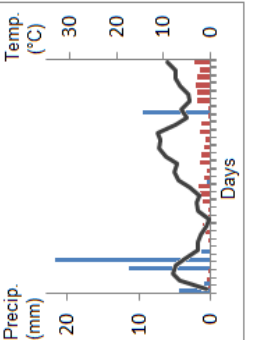

독

ํํㅇ

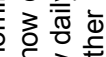

的令贾

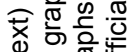

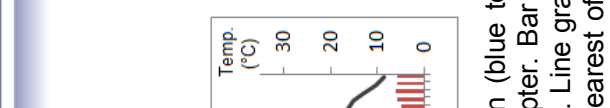

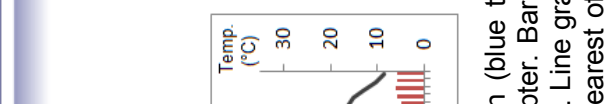

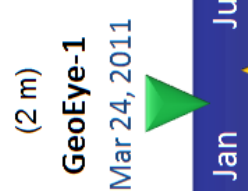

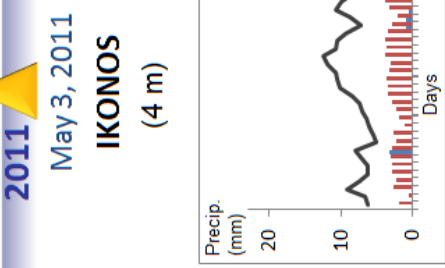

은 원휴웜

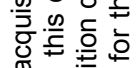

능 $\cong \frac{5}{5}$

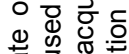

壱

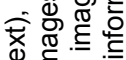

$\Phi$.

弟 $\frac{x}{\omega}$

을 웡

응휴웡

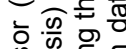

득

울

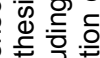

인

응 인

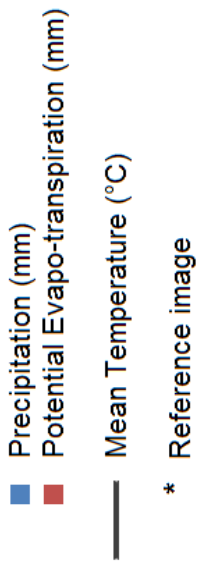

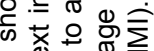

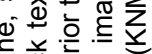

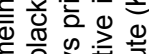

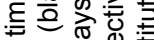

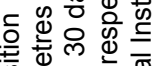

D.

可

넌은 응

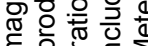

$\because$ 뜬 क응

듁

ம)

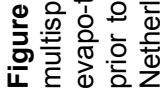


available from these sensors for July 2010 other than the single WorldView-2 image dated 14 July 2010. The 3 May 2011 IKONOS image suffers from sun glint off most water surfaces.

The multispectral bands have nominal spatial resolutions of between $2 \mathrm{~m}$ and $4 \mathrm{~m}$ (Figure 5.1). Four of the sensors have four multispectral bands with WorldView-2 having eight. The sensors have differing band positions and numbers, so for ease of reference the bands will be referred to by their general position in the electromagnetic spectrum instead of their specific wavelength or band number. Thus for the four band sensors, bands 1 to 4 will be referred to as blue, green, red and near-infrared (NIR) respectively. For the eight band WorldView-2 sensor, bands 2, 3, 5 and 7 will be referred to as blue, green, red and NIR respectively. Images were acquired for a minimal orderable area of $25 \mathrm{~km}^{2}$. Due to scene boundaries, not all images were able to cover exactly the same area, thus the overlapping image area is about $11 \mathrm{~km}^{2}$ with the study site located about $750 \mathrm{~m}$ north-east of the centre. The processing level of the GeoEye-1, IKONOS, QuickBird and WorldView-2 images is Standard 2A (radiometrically corrected, sensor corrected, and projected to a plane with the application of a coarse DEM, uniform ground sample distance (GSD) throughout the entire product). The processing level of the Pléiades image is Primary (radiometrically corrected, sensor corrected, and sensor level geometric correction).

\subsubsection{Pre-processing}

A number of corrections and procedures are necessary for direct comparison between the data of the images. A workflow of these pre-processing steps is given in Figure 5.2, with specific details for each step explained in the sections that follow. Radiometric correction was performed before geometric registration in order to avoid alteration of pixel values due to spatial resampling. Geometric correction was applied before the radiometric normalization (between images) and the verification steps so as to facilitate the selection of invariant targets for these processes. The image selected as reference for this chapter is the WorldView-2 image dated 14 July 2010. It was selected because it was recorded a day before the field measurements and it has one of the finer spatial resolutions. The other five images used in this chapter are referred to as the subject images. 


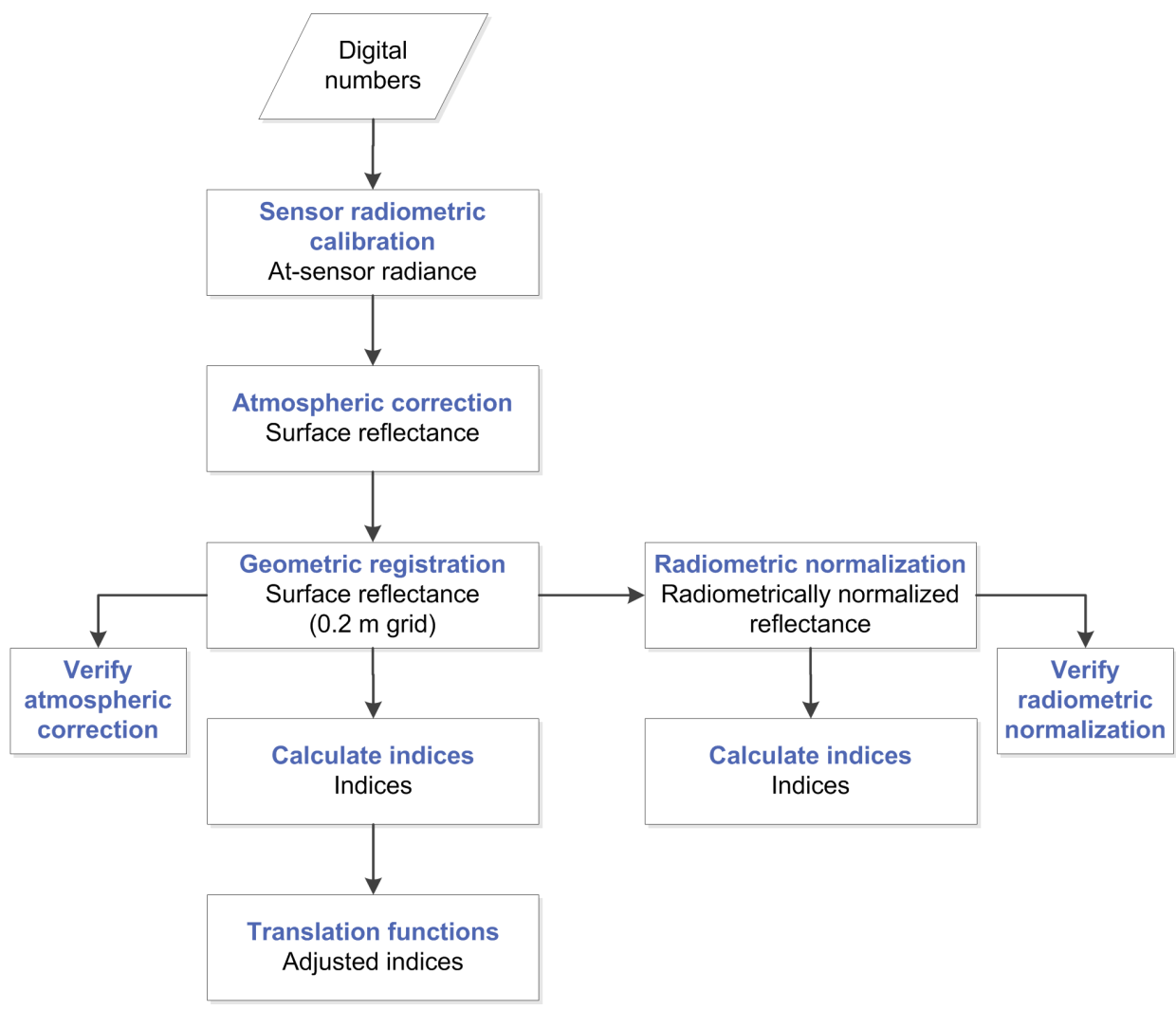

Figure 5.2: Summary workflow of the image pre-processing and processing steps applied in this chapter. Data are indicated as black text and processes as bold blue text.

\subsubsection{Radiometric calibration}

Image digital numbers (DN) were converted to at-sensor radiances (in $\mathrm{W} \mathrm{m}^{-2} \mathrm{sr}^{-1} \mu \mathrm{m}^{-1}$ ) in ENVI 5.0 software (Exelis Visual Information Solutions, Inc., Boulder, CO, USA), using the calibration coefficients provided in the image metadata or by the image supplier.

\subsubsection{Atmospheric correction}

Atmospheric correction was performed using ENVI's FLAASH (Fast Line-ofsight Atmospheric Analysis of Hypercubes) atmospheric correction tool (AdlerGolden et al., 1998; Adler-Golden et al., 1999), which incorporates the MODTRAN4 radiation transfer code (Berk et al., 1998), to convert radiance to surface reflectance. FLAASH requires input radiance data in $\mu \mathrm{W} \mathrm{cm}{ }^{-2} \mathrm{sr}^{-1} \mu \mathrm{m}^{-1}$ and thus the necessary scale factors were applied. FLAASH supports the 
Table 5.1: ENVI FLAASH atmospheric correction module settings for images used in this chapter.

\begin{tabular}{|c|c|c|c|c|}
\hline IMAGE DATE & SENSOR & $\begin{array}{l}\text { ATMOSPHERIC MODEL } \\
\text { based on temperature at } \\
\text { nearest weather station; } \\
\text { (KNMI, 2011; KNMI, } \\
\text { 2013) }\end{array}$ & $\begin{array}{l}\text { AEROSOL } \\
\text { MODEL }\end{array}$ & $\begin{array}{l}\text { INITIAL } \\
\text { VISIBILITY } \\
\text { at nearest } \\
\text { weather station; } \\
\text { (KNMI, 2011; } \\
\text { KNMI, 2013) }\end{array}$ \\
\hline 09 Apr 2008 & QuickBird & Sub-Artic Summer & Rural & $21 \mathrm{~km}$ \\
\hline $14 \mathrm{Jul} 2010$ & WorldView-2 & Mid-Latitude Summer & Rural & $35 \mathrm{~km}$ \\
\hline $24 \operatorname{Mar} 2011$ & GeoEye-1 & Sub-Artic Summer & Rural & $60 \mathrm{~km} *$ \\
\hline 03 May 2011 & IKONOS & Sub-Artic Summer & Rural & $35 \mathrm{~km}$ \\
\hline 27 May 2013 & Pléiades-1B & Sub-Artic Summer & Rural & $22 \mathrm{~km}$ \\
\hline 05 Sep 2013 & WorldView-2 & Mid-Latitude Summer * & Rural & $30 \mathrm{~km}$ \\
\hline
\end{tabular}

* Exceptions (see Section 5.2.3.2 for details)

GeoEye-1, IKONOS, Pléiades-1, QuickBird and WorldView-2 sensors, as well as correcting for scene specific sun and viewing angles. FLAASH does not correct for terrain but the imaged area is relatively flat (see Section 5.2.3.3). Image specific FLAASH settings (Table 5.1) were determined according to the ENVI Atmospheric Correction Module User's Guide (ITT Visual Information Solutions, 2009) using weather information from the nearest weather station (KNMI, 2011; KNMI, 2013), with two exceptions. Based on the surface temperature for 05 September 2013, the ENVI User's Guide proposes a Tropical atmospheric model but due to the latitude of the image location, MidLatitude Summer was preferred. The second exception was that the Initial Visibility for the 24 March 2011 GeoEye-1 image was increased to avoid excessive negative reflectance values.

\subsubsection{Geometric registration}

The five subject surface reflectance images were orthorectified to the reference WorldView-2 image (dated 14 July 2010) in Erdas Imagine 2014 (Intergraph Corporation, Madison, AL, USA). The geometric models were created using image specific rational polynomial coefficient (RPC) files, a digital elevation model (DEM) and refined using a first order polynomial based on ground control points (GCPs). The digital elevation model used was AHN1 (Actueel Hoogtebestand Nederland or Actual Height model of the Netherlands) with a spatial resolution of $5 \mathrm{~m}$. The ground surface for the area under the images is mostly $(>80 \%$ ) between $-6.0 \mathrm{~m}$ and $-1.5 \mathrm{~m}$ NAP (Normaal Amsterdams Peil or Amsterdam Ordnance Datum). Between 68 and 272 GCPs were defined between the subject images and the reference image. The total root mean square (RMS) errors for the geometric models were between $0.16 \mathrm{~m}$ and $0.64 \mathrm{~m}$. The 
output projection was Universal Transverse Mercator (UTM), zone 31, Northern Hemisphere, with the WGS84 datum and spheroid. A nearest neighbour resampling kernel was applied and the original image pixel sizes (Figure 5.1) were retained in order to limit the effects of resampling on pixel values. Since the sensors have different spatial resolutions, the image pixels were divided into grids with a cell size of $0.2 \mathrm{~m}$ (which is divisible into the spatial resolutions of the all images used in this study). This was done so as to facilitate the extraction of data for invariant targets and field locations.

\subsubsection{Radiometric normalization}

Although atmospheric correction will remove most of the atmospheric influences, the algorithms necessarily assume simplifications of reality and thus some degree of bias remains. To address these remaining biases, relative radiometric normalization was applied to the atmospherically corrected images. Relative radiometric normalization is often applied to improve homogeneity between images (Vicente-Serrano et al., 2008) since it reduces differences between images that are the result of disparities in acquisition conditions (e.g., atmospheric effects, illumination conditions, sensor properties) rather than changes in surface reflectance (Caselles and López García, 1989; Eckhardt et al., 1990; Hall et al., 1991; Schott et al., 1988; Yang and Lo, 2000; Yuan and Elvidge, 1996) by using one image as a reference to which the subject image(s) are adjusted, with separate corrections derived for each spectral band. Relative radiometric normalization can be applied to DNs, radiance, top-of-atmosphere reflectance or surface reflectance values although Vicente-Serrano et al. (2008) recommend that it be applied after other corrections.

The most widely used method of radiometric normalization is linear regression. Confirmation of the validity of the assumption of a linear relationship can be found in Caselles and López García (1989), Schott et al. (1988), and Hall et al. (1991). An empirical linear scene-to-scene radiometric normalization technique was applied using the analyst selection of invariant targets approach (after Eckhardt et al., 1990) in ENVI software. This approach was preferred as the sun glint off most water bodies in the 3 May 2011 IKONOS image as well as the seasonal differences in vegetation cover and general land cover change amongst all images would likely adversely influence most automated relative radiometric normalization target selection approaches. In addition, invariant targets are also required for verification of the atmospheric correction and radiometric normalization steps. 


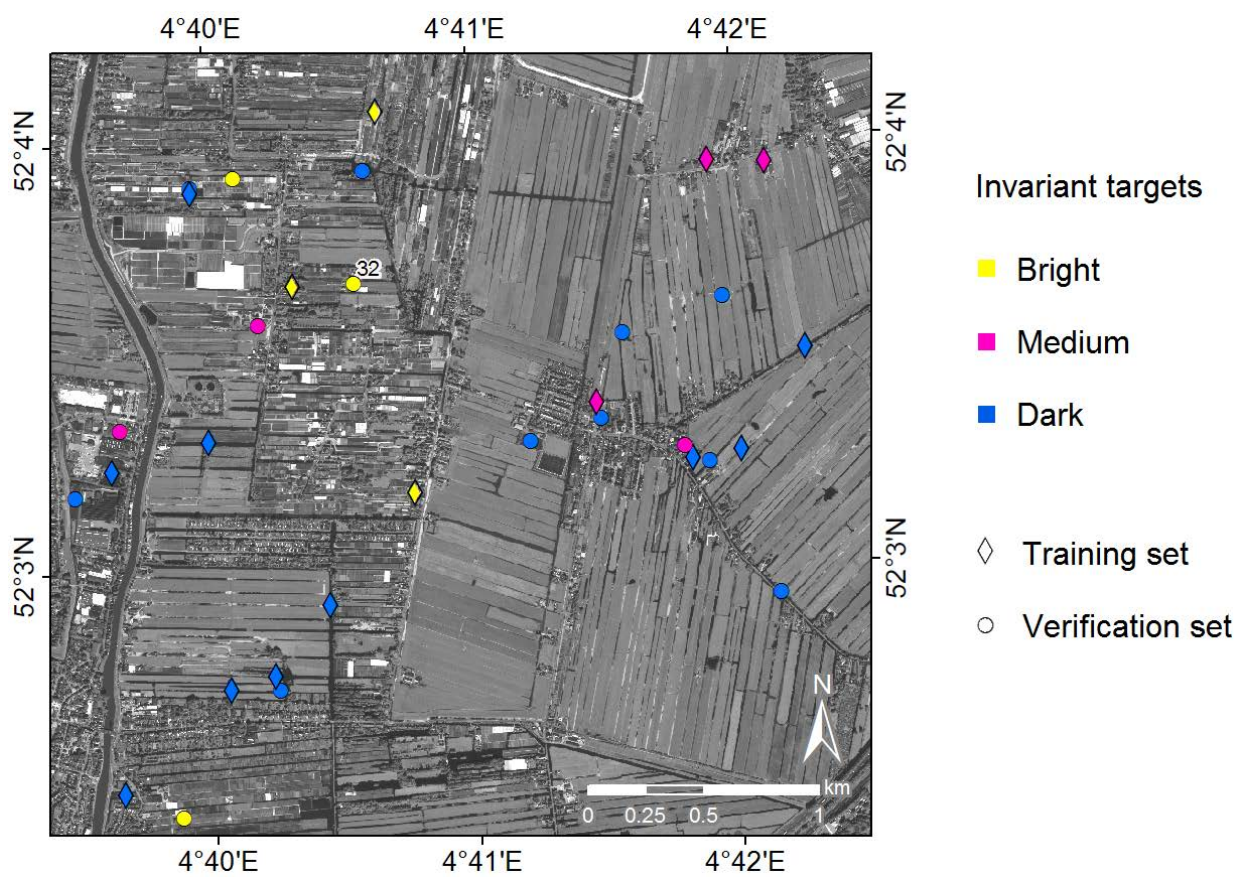

Figure 5.3: Location of the training and verification invariant targets on the background of the panchromatic WorldView-2 image dated 5 September 2013 (๑ DigitalGlobe, Inc. All Rights Reserved). Data from invariant target 32 (as indicated on the map) are included in the results shown in Figures 5.12 and 5.13

At least two points of constant reflectance are required for relative radiometric normalization (Caselles and López García, 1989). Following the criteria suggested by Eckhardt et al. (1990) for manual invariant target selection, the same 32 targets were selected for all images over a wide range of brightness values (Figure 5.3). The targets covered areas of dark water, roofs, asphalt and sand and were distributed throughout the image overlap area. These can broadly be grouped into bright, dark and medium brightness targets. Each group was randomly divided into two independent sets: one for training the radiometric normalization regression and one for the verification of this as well as the atmospheric correction products. This resulted in 16 invariant targets per set consisting of 3 bright, 3 medium and 10 dark invariant targets each.

Unlike in Eckhardt et al. (1990), the mean pixel values for the invariant target were used. This is because the sensors have different spatial resolutions and so, for example, the IKONOS image $(4 \mathrm{~m}$ resolution) already has average reflectance values over the same area covered by more than one pixel of the WorldView-2 or GeoEye-1 images. To ensure that, as precisely as possible, the same target area is averaged and averaged over the same number of cells, the 
images with the $0.2 \mathrm{~m}$ gridded cell size (see Section 5.2.3.3) were used for this and subsequent steps, thus averaging over multiple $0.2 \mathrm{~m}$ grid cells.

\subsubsection{Verification}

Verification of the atmospheric correction and radiometric normalization products were evaluated using the 16 invariant targets selected randomly for this purpose (see Section 5.2.3.4 for description). Two widely used statistical measures are employed to assess the robustness and error of the corrections, namely the root mean square error (RMSE, Eq. 5.1) and mean absolute error (MAE, Eq. 5.2), which are calculated between the reference image and corrected subject images (per spectral band). The RMSE and MAE are calculated as:

$$
\begin{aligned}
R M S E & =\sqrt{\frac{1}{n} \sum_{i=1}^{n}\left(\hat{y}_{i}-y_{i}\right)^{2}} \\
M A E & =\frac{1}{n} \sum_{i=1}^{n}\left|\hat{y}_{i}-y_{i}\right|
\end{aligned}
$$

where $y_{i}$ is the reference image value and $\hat{y}_{i}$ is the corrected subject image value for $n$ invariant targets. The results are given in Section 5.3.1.2.

\subsubsection{Processing}

A workflow showing the processing steps is given in Figure 5.2, with specific details for each step explained in the sections that follow.

\subsubsection{Indices}

Indices are widely used as proxies for parameters relating to vegetated surfaces (e.g., Houborg et al., 2013; Kross et al., 2015; Peñuelas et al., 1995a; Rouse et al., 1973). In the previous chapters, various indices (calculated from groundbased field spectra and 14 July 2010 WorldView-2 image data) were researched as proxies for two indicators, cover quality and soil moisture, used for inspection of grass covered dikes. Chapter 3 showed that of the numerous indices tested, ten had the strongest mean correlations to the two dike inspection indicators despite the spectral differences between the sensors investigated (Cundill et al., 2015). Of these ten indices, the values of three indices were the most similar between field spectra and 14 July 2010WorldView- 2 image data (Chapter 4), while also maintaining the strongest correlations to the two dike 
inspection indicators. Based on these results, the three indices Ratio Vegetation Index (RVI), Modified Simple Ratio (MSR) and Green/Red Ratio (GRR) will be examined in this chapter and are defined as:

$$
\begin{array}{cc}
R V I=\frac{R_{N I R}}{R_{\text {red }}} & \text { (Jordan, 1969) } \\
M S R=\frac{\frac{R_{N I R}}{R_{\text {red }}}-1}{\sqrt{\frac{R_{N I R}}{R_{\text {red }}}+1}} & \text { (Chen, 1996) } \\
G R R=\frac{R_{\text {green }}}{R_{\text {red }}} & \text { (Kanemasu, 1974) }
\end{array}
$$

where $R$ is reflectance of the specified band. Indices were calculated for the atmospherically corrected images as well as for the radiometric normalized images.

\subsubsection{Translation functions}

Although the image data from the different sensors have been corrected to atmospherically corrected reflectance products, data obtained from different sensors are not directly comparable due to differences in sensor characteristics (Steven et al., 2003; Teillet et al., 1997), with variations in SRFs between sensors considered one of the main causes of differences in reflectance data and derived products (Chander et al., 2013b; Trishchenko et al., 2002a). The five sensors used in this chapter have different SRFs, which are shown in Figure 5.4. Since the SRFs of the image sensors used in this study are known, corrections for the differences in SRFs between the WorldView-2 sensor and the GeoEye-1, IKONOS, Pléiades-1B and QuickBird sensors were made before analysis. A common approach in correcting for SRF differences is to use translation functions (Gonsamo and Chen, 2013; Steven et al., 2003; Trishchenko et al., 2002a), which convert the reflectance or product values of one sensor to equivalent values of another sensor by adjusting for the differences in SRFs. These translation functions are usually defined by modelling the relationships between simulated data sets from two different sensors, where the differences in reflectance or product values are due only to differences in sensor SRFs. 

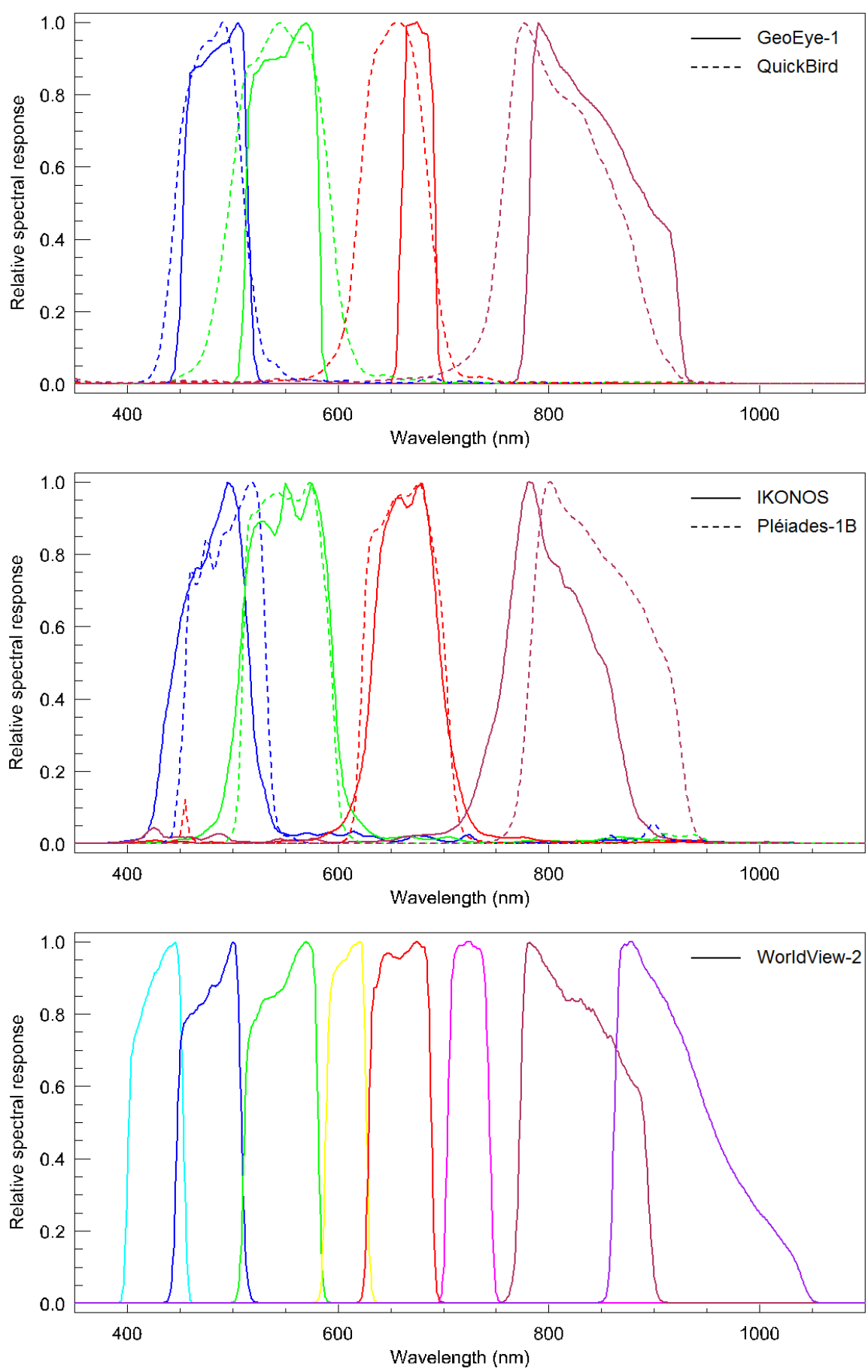

Figure 5.4: Spectral response functions (SRFs) for the sensors used in this chapter. The sensor is indicated by a solid or dashed line while colours are used to differentiate bands. 
Following the method described in Cundill et al. (2015), field reflectance spectra (described in Cundill et al., 2014; Cundill et al., 2015) were convolved using the SRFs of the five image sensors. The differences between these simulated data sets are thus due only to differences in the SRFs of the sensors. Translation functions were defined based on relationships between the simulated WorldView-2 and the other simulated sensor data sets. These translation functions are specific for grass covered surfaces. The literature has examples of both linear translation functions (Gallo et al., 2005; Gonsamo and Chen, 2013; Steven et al., 2003; van Leeuwen et al., 2006) and second degree polynomial functions (D'Odorico et al., 2013; Pandya et al., 2007; Trishchenko, 2009; Trishchenko et al., 2002a). Since D'Odorico et al. (2013) found that the choice of regression model is more important than the choice of calibration data source, best-fit translation functions were selected based on highest coefficients of determination $\left(R^{2}\right)$. It should be noted however that since similar wavelengths are used, bands and products are not independent and so no statistical confidence should be inferred from the $R^{2}$ value. The best-fit translation functions (see Table 5.4) were applied to the index values calculated from the atmospherically corrected reflectance images of GeoEye-1, IKONOS, Pléiades1B and QuickBird to create WorldView-2-equivalent index values.

\subsubsection{Analysis methods}

Visual comparison of the index image products is used to qualitatively analyse spatial patterns over time. Scatterplots and Pearson correlation coefficients are used to statistically assess relationships between the image index products. To assess spectral behaviour, mean index values were extracted for four locations on the dike and plotted over time. The four locations were selected over the width of the dike (Figure 5.5) with varying soil moisture and cover quality values (as measured on 15 July 2010, values given in Figure 5.5). For all the 54 locations measured on 15 July 2010, the volumetric soil moisture measurements ranged between 19.1 and $33.5 \%$ vol. and the cover quality was classified as good, medium, poor or bad. In order to reduce differences due to image spatial resolution, the mean index values per location were calculated (using the images with the $0.2 \mathrm{~m}$ gridded cell size, see Section 5.2.3.3) for an area of $4 \mathrm{~m}$ by $4 \mathrm{~m}$, which corresponds to the coarsest spatial resolution of the images used in this study (i.e., IKONOS). In addition, the index values for one of the verification invariant targets (see Figure 5.3) were also included in the graphs to illustrate the variation that remains between the images after corrections. 


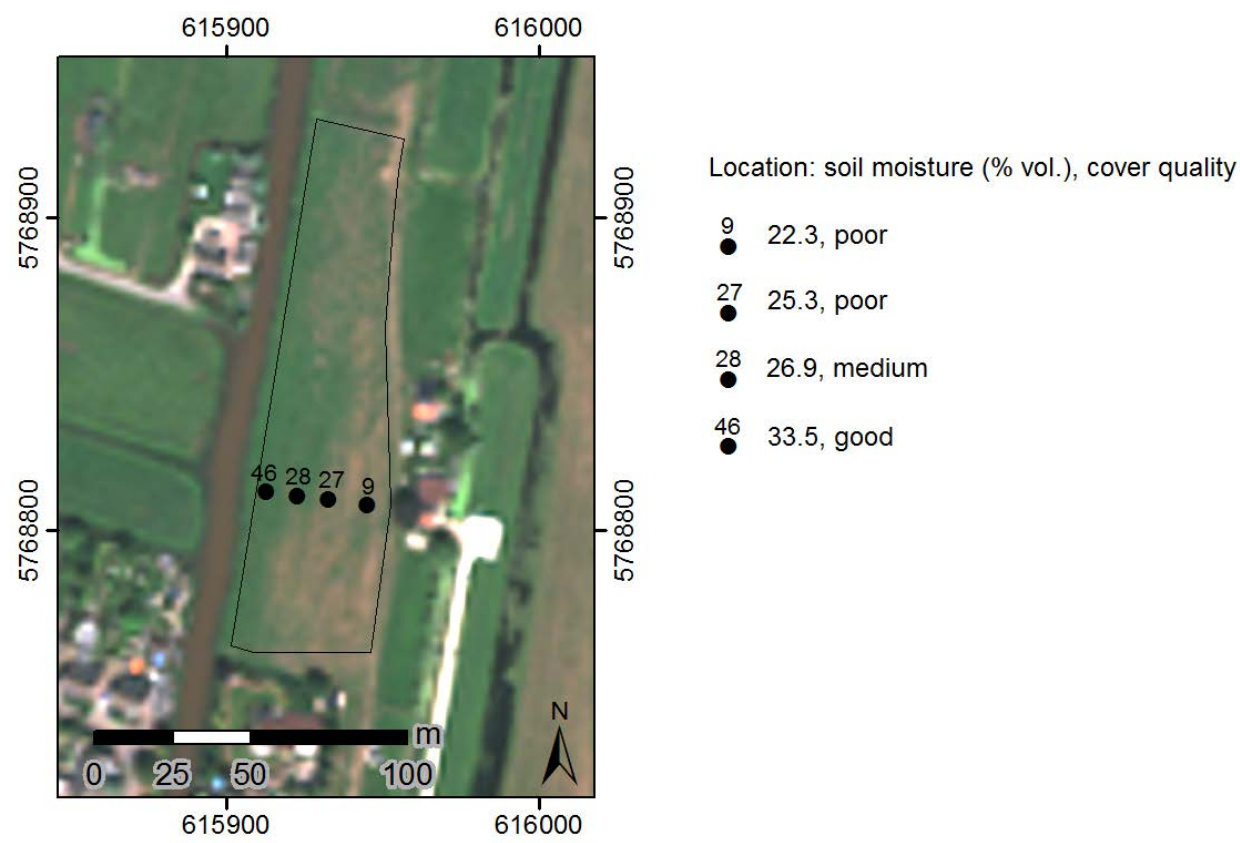

Figure 5.5: Map showing the four locations used for spectral behaviour analysis. The location identification numbers correspond to those defined in Chapter 2. The volumetric soil moisture and cover quality values are those measured on 15 July 2010 in the field, with cover quality assessed using the classification described in Table 2.1. The dike segment is outlined in black on the background of the 14 July 2010 WorldView-2 image (RGB:532; ( ) DigitalGlobe, Inc. All Rights Reserved).

\subsection{Results and discussion}

\subsubsection{Pre-processing}

\subsubsection{Radiometric normalization}

Based on the 16 invariant targets of the training data set (see Section 5.2.3.4), empirical line functions for relative radiometric normalization were defined per band for each subject reflectance image to the reference reflectance image using ENVI's Empirical Line Compute Factors function. Coefficients for the linear regression equations are given in Table 5.2, along with their coefficients of determination $\left(R^{2}\right)$. The $R^{2}$ values are above 0.978 for all bands with the exceptions of Pléiades-1B red and near infra-red bands (0.977 and 0.963 respectively). These $R^{2}$ values are in alignment with those reported by Caselles and López García (1989), who reported $R^{2}$ values equal to or above 0.978 for paired Landsat-5 TM images. 
Table 5.2: Coefficients for linear relative radiometric normalization of the five subject images to the reference WorldView-2 image (dated 14 July 2010) obtained from 16 training invariant targets; $\hat{y}=a+b x$ where $a$ is the intercept, $b$ is the slope, $x$ is the input subject image reflectance value and $\hat{y}$ is the normalized reflectance value.

\begin{tabular}{llccc}
\hline IMAGE & BAND & $a$ & $b$ & $R^{2}$ \\
\hline QuickBird & Blue & -0.029 & 0.750 & 0.992 \\
9 Apr 2008 & Green & -0.017 & 0.764 & 0.992 \\
& Red & -0.007 & 0.830 & 0.993 \\
& Near-infrared & -0.015 & 0.951 & 0.990 \\
\hline GeoEye-1 & Blue & -0.047 & 0.702 & 0.991 \\
24 Mar 2011 & Green & -0.020 & 0.715 & 0.987 \\
& Red & -0.003 & 0.752 & 0.988 \\
& Near-infrared & 0.010 & 0.771 & 0.979 \\
\hline IKONOS & Blue & -0.028 & 0.899 & 0.980 \\
3 May 2011 & Green & -0.010 & 0.977 & 0.982 \\
& Red & -0.001 & 1.076 & 0.988 \\
& Near-infrared & -0.011 & 1.039 & 0.994 \\
\hline Pléiades-1B & Blue & -0.017 & 0.762 & 0.987 \\
27 May 2013 & Green & -0.011 & 0.807 & 0.982 \\
& Red & -0.003 & 0.846 & 0.977 \\
& Near-infrared & 0.004 & 0.875 & 0.963 \\
\hline WorldView-2 & Blue & -0.044 & 1.084 & 0.997 \\
5 Sep 2013 & Green & -0.028 & 1.101 & 0.997 \\
& Red & -0.017 & 1.088 & 0.996 \\
& Near-infrared & -0.015 & 1.040 & 0.992 \\
\hline
\end{tabular}

\subsubsection{Verification}

RMSE and MAE values calculated from the 16 verification invariant targets for the atmospheric correction and radiometric normalization products of the subject images are presented in Table 5.3. The RMSE values for the atmospheric correction products range between 0.017 and 0.099 , while for the radiometric normalization products they range between 0.016 and 0.044 . The MAE values for the atmospheric correction products range between 0.011 and 0.081 , while for the radiometric normalization products they range between 0.012 and 0.027 .

While many related previous studies focus on methods to train and fit relative radiometric normalization functions, only a few report verification results in terms of comparable statistical measures or in reflectance units (many are in digital numbers which cannot be compared when dynamic ranges between sensing systems differ, e.g., 8 bit versus 11 bit). The MAE values reported in 
Table 5.3: Root mean square error (RMSE) and mean absolute error (MAE) for each band per image relative to the reference WorldView-2 image (dated 14 July 2010) obtained from 16 verification invariant targets for both the atmospherically corrected images and the radiometrically normalized images (expressed in reflectance).

\begin{tabular}{|c|c|c|c|c|c|c|c|c|c|}
\hline \multirow[b]{2}{*}{ IMAGE } & \multirow[b]{2}{*}{ CORRECTION } & \multicolumn{2}{|c|}{ Blue } & \multicolumn{2}{|c|}{ GREEN } & \multicolumn{2}{|c|}{ RED } & \multicolumn{2}{|c|}{ NIR } \\
\hline & & RMSE & MAE & RMSE & MAE & RMSE & MAE & RMSE & MAE \\
\hline \multirow[t]{2}{*}{ QB } & Atm. Cor. & 0.065 & 0.055 & 0.059 & 0.046 & 0.036 & 0.026 & 0.029 & 0.025 \\
\hline & Rad. Nor. & 0.034 & 0.021 & 0.031 & 0.021 & 0.030 & 0.020 & 0.034 & 0.024 \\
\hline \multirow[t]{2}{*}{ GE } & Atm. Cor. & 0.099 & 0.081 & 0.081 & 0.054 & 0.066 & 0.035 & 0.050 & 0.027 \\
\hline & Rad. Nor. & 0.035 & 0.020 & 0.036 & 0.020 & 0.038 & 0.023 & 0.039 & 0.026 \\
\hline \multirow[t]{2}{*}{ IK } & Atm. Cor. & 0.053 & 0.047 & 0.029 & 0.023 & 0.017 & 0.011 & 0.030 & 0.023 \\
\hline & Rad. Nor. & 0.016 & 0.012 & 0.019 & 0.012 & 0.023 & 0.013 & 0.028 & 0.020 \\
\hline \multirow[t]{2}{*}{ PL } & Atm. Cor. & 0.052 & 0.040 & 0.048 & 0.032 & 0.041 & 0.022 & 0.028 & 0.022 \\
\hline & Rad. Nor. & 0.044 & 0.022 & 0.038 & 0.021 & 0.036 & 0.020 & 0.036 & 0.027 \\
\hline \multirow[t]{2}{*}{ WV2 } & Atm. Cor. & 0.051 & 0.046 & 0.037 & 0.030 & 0.033 & 0.023 & 0.036 & 0.029 \\
\hline & Rad. Nor. & 0.030 & 0.018 & 0.033 & 0.020 & 0.035 & 0.019 & 0.030 & 0.021 \\
\hline
\end{tabular}

QB: 9 April 2008 QuickBird, GE: 24 March 2011 GeoEye-1, IK: 3 May 2011 IKONOS, PL: 27 May 2013 Pléiades-1B, WV2: 5 September 2013 WorldView-2.

Table 5.3 for the atmospheric correction products are well within the range $(\leq 0.160)$ reported by Vicente-Serrano et al. (2008) for across-sensor comparisons (in their case, Landsat-5 TM and MODIS). Half the RMSE values for the atmospheric correction products (Table 5.3) are within the range $(<0.050)$ reported by Schroeder et al. (2006), with the other half higher. However they reported averaged RMSE values using only Landsat-5 TM and Landsat-7 ETM+ images, where the differences in sensing systems are comparatively small and where averaging suppresses extreme values. Thus, from these verification results (Table 5.3), the atmospheric correction products are considered acceptable.

The RMSE values for the radiometric normalization products (Table 5.3) are generally higher than the averaged RMSE values $(\leq 0.025)$ reported by Schroeder et al. (2006) using only Landsat-5 TM and Landsat-7 ETM+ images. Schott et al. (1988) report adjusted RMSE values of 0.016 and less for radiometrically normalized Landsat-5 TM image pairs and values of less than 0.022 for aerial photos paired to Landsat-5 TM images. Their adjusted RMSE values have been corrected for sampling error and thus are smaller than regular RMSE values. Vicente-Serrano et al. (2008) report averaged MAE values for only radiometrically normalized Landsat image pairs (i.e., not including MODIS), with values less than 0.013 . While the values presented in Table 5.3 
for radiometric normalization are generally larger than those presented in the literature, most of these studies compare images from the same sensor or sensor series. The differences in the sensing systems (including band positions and widths, spatial resolution and viewing geometry) of the various images used in the current study may account for these higher values as well as the actual values being reported (i.e., not averaged values). Radiometric normalization generally reduced the RMSE and MAE values compared to those of the atmospheric correction products, thereby improving homogeneity between the images. The exceptions were IKONOS red band and the near-infrared bands of Pléiades-1B and QuickBird. These bands already had the lowest RMSE and MAE values for the atmospherically corrected products, with those for the radiometrically normalized products comparable to the other bands.

\subsubsection{Translation functions}

Translation functions, to correct for SRF differences between sensors, were defined based on relationships between simulated WorldView-2 and simulated GeoEye-1, IKONOS, Pléiades-1B and QuickBird data sets, where for all cases second degree polynomial functions rendered higher coefficients of determination $\left(R^{2}\right)$ than for linear functions. The $R^{2}$ values of the second degree polynomial functions (Table 5.4) are all greater than 0.995 with the exception of IKONOS GRR which has a $R^{2}$ value of 0.984 . The lower $R^{2}$ value for IKONOS GRR is likely attributable to the SRF of the IKONOS red band, where the tails extend into the neighbouring portions of the electromagnetic spectrum, specifically into the near-infrared portion. Based on the simulated data, the IKONOS red reflectance is $32 \%$ higher than that of the WorldView-2 (other sensors to WorldView- 2 : $-3 \%$ to $+21 \%$ ) while the IKONOS green reflectance is $4 \%$ higher (other sensors to WorldView- 2 : $-6 \%$ to $+8 \%$ ) and IKONOS NIR reflectance is $8 \%$ lower (other sensors to WorldView-2: $-5 \%$ to $+1 \%$ ). This is agreement with the findings of Soudani et al. (2006) where IKONOS red reflectance is $53 \%$ higher and NIR reflectance $5 \%$ lower than those of Landsat-7 ETM+ and SPOT-4 HRVIR and where the edge distortion of the IKONOS red SRF was found to be the main explanatory factor for reflectance product differences between IKONOS and both Landsat-7 ETM+ and SPOT-4 HRVIR. The second degree polynomial functions defined for the current study (Table 5.4) were applied to the index values obtained from atmospherically corrected reflectance images of GeoEye-1, IKONOS, Pléiades-1B and QuickBird to create WorldView-2-equivalent index values. 
Table 5.4: Best-fit translation functions for correcting differences in spectral response functions between WorldView-2 and GeoEye-1, IKONOS, Pléiades-1B and QuickBird sensors for grass cover of varying conditions, where $y$ the WorldView-2-equivalent index value and $x$ is the subject sensor index value.

\begin{tabular}{lclc}
\hline SENSOR & INDEX & TRANSLATION FUNCTION & $R^{2}$ \\
\hline QuickBird & RVI & $y=0.0377 x^{2}+0.9709 x+0.0387$ & 0.999 \\
& MSR & $y=0.1199 x^{2}+0.9615 x+0.0426$ & 0.999 \\
& GRR & $y=0.9205 x^{2}-0.3512 x+0.5603$ & 0.995 \\
\hline GeoEye-1 & RVI & $y=-0.0031 x^{2}+0.9725 x+0.1435$ & 0.999 \\
& MSR & $y=-0.0125 x^{2}+0.9795 x+0.0303$ & 0.999 \\
& GRR & $y=-0.0393 x^{2}+1.0035 x+0.0479$ & 0.999 \\
\hline IKONOS & RVI & $y=0.1327 x^{2}+0.6037 x+0.7733$ & 0.998 \\
& MSR & $y=0.3359 x^{2}+0.8036 x+0.1659$ & 0.999 \\
& GRR & $y=2.4907 x^{2}-3.144 x+1.8183$ & 0.984 \\
\hline Pléiades-1B & RVI & $y=0.0358 x^{2}+0.9899 x-0.1442$ & 0.999 \\
& MSR & $y=0.1111 x^{2}+0.9955 x-0.0149$ & 0.999 \\
& GRR & $y=0.5152 x^{2}+0.2417 x+0.3009$ & 0.998 \\
\hline
\end{tabular}

\subsubsection{Comparison of multi-temporal and multi-sensor image index data}

Maps of the dike segment showing the values and spatial patterns of the RVI, MSR and GRR indices for the adjusted atmospherically corrected image products are presented in Figures 5.6, 5.7 and 5.8 and for the radiometrically normalized image products in Figures 5.9, 5.10 and 5.11. The previously mentioned anomaly-related spatial patterns (Section 5.2.1) can be observed in the reference 14 July 2010 WorldView-2 index products (e.g., Figure 5.6b), where the toe of the dike segment (western part) is different from the rest of the dike segment. Furthermore, in the extended study area, the anomalous spatial patterns expand into the central part of the dike segment (central western part), which was already signalled by the spread of the anomaly in the north-western corner of the original study section (see Figure 2.4).

Dot graphs showing the spectral behaviour of four locations on the dike segment (see Figure 5.5 for locations) for the three indices are presented in Figure 5.12 for the adjusted atmospherically corrected image products and in Figure 5.13 for the radiometrically normalized image products. The inclusion of the verification invariant target (IT 32, see Figure 5.3 for location) illustrates the remaining variability of the index values after image corrections. 


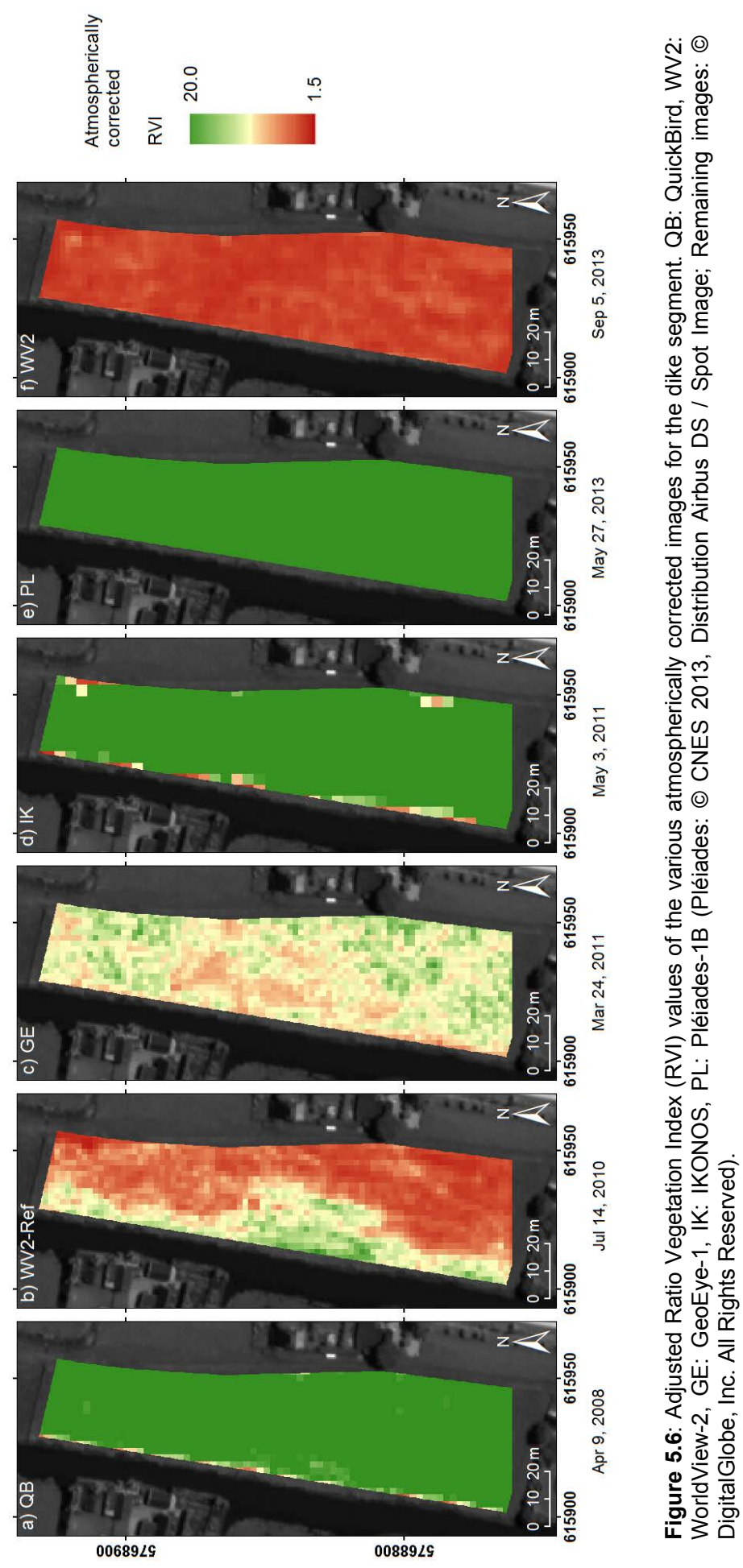




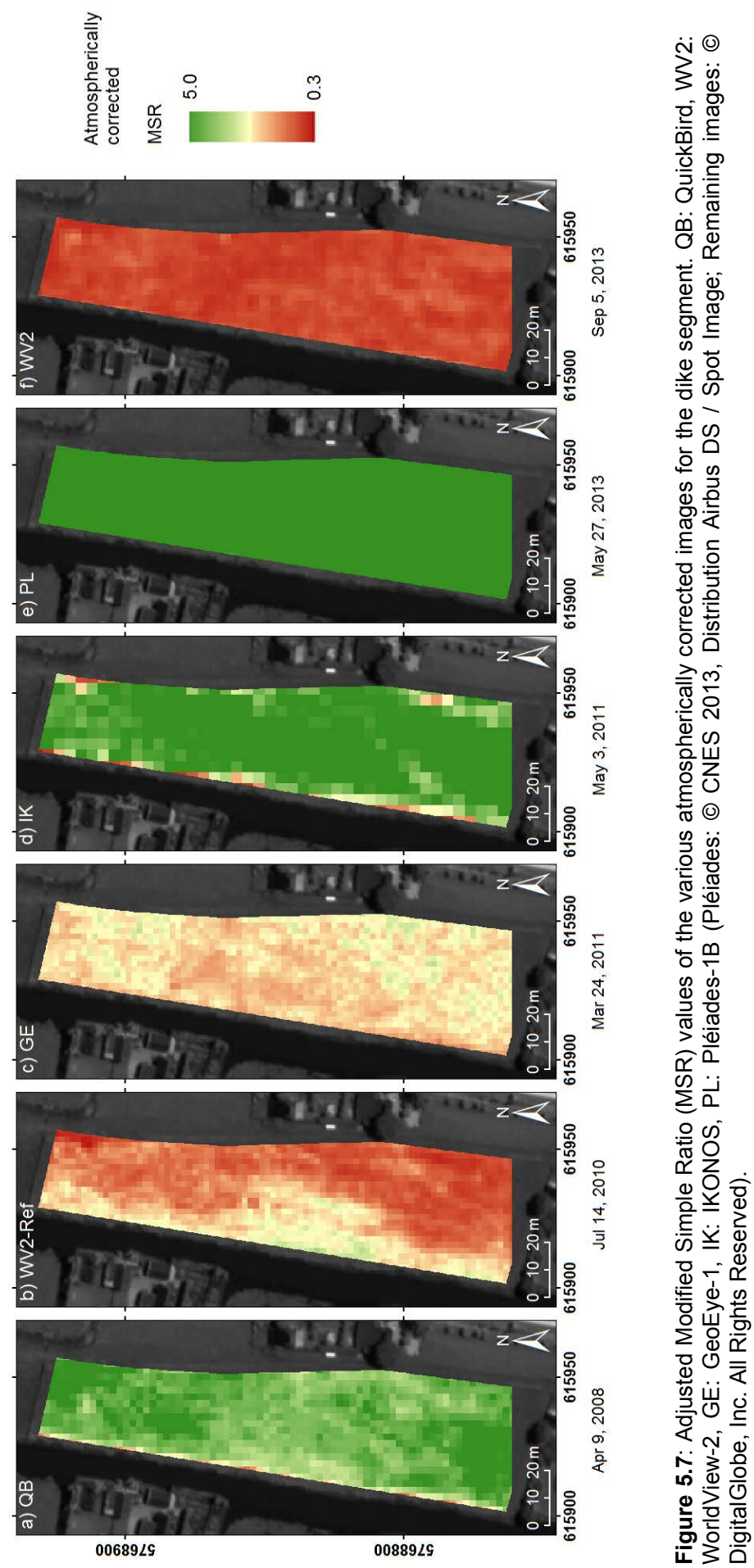




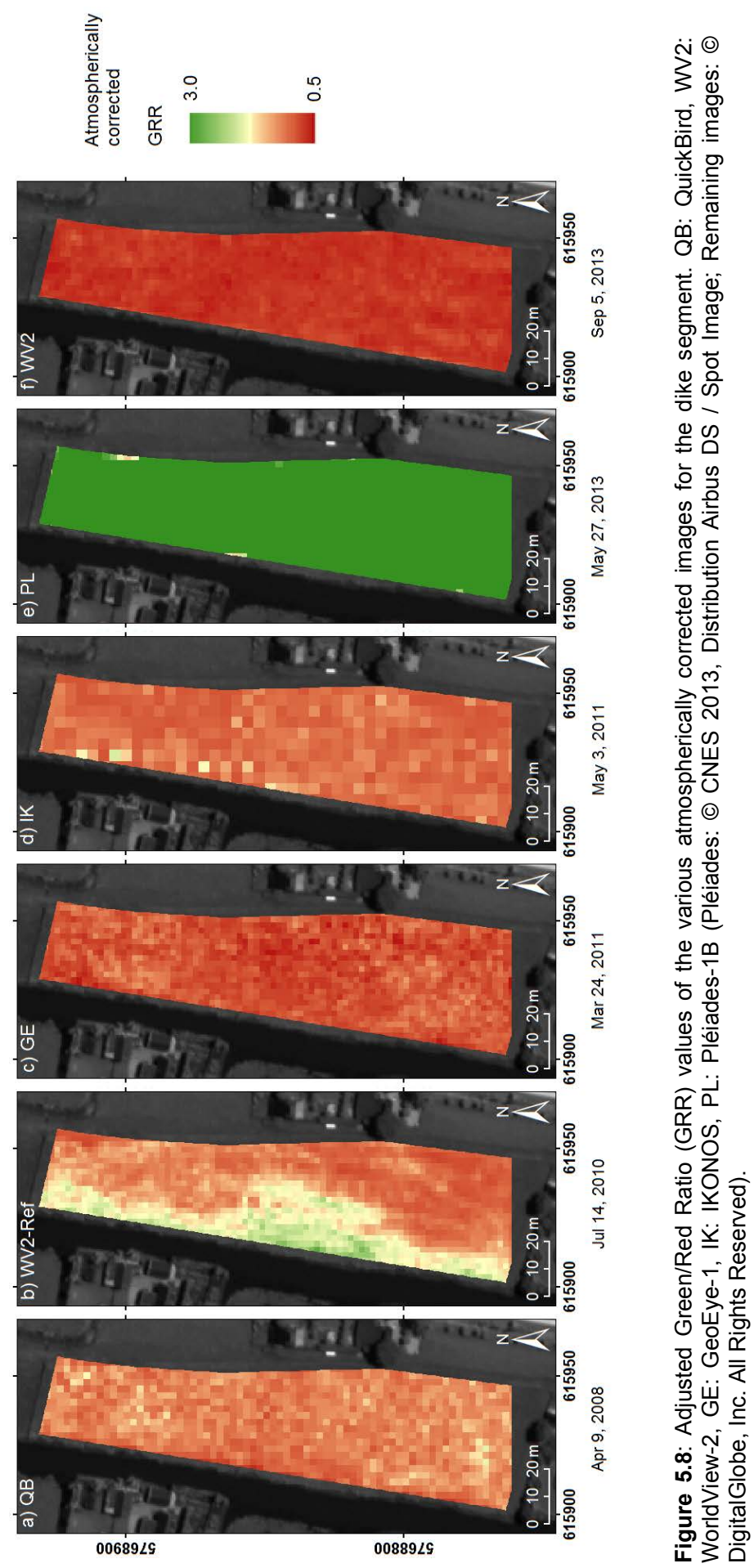



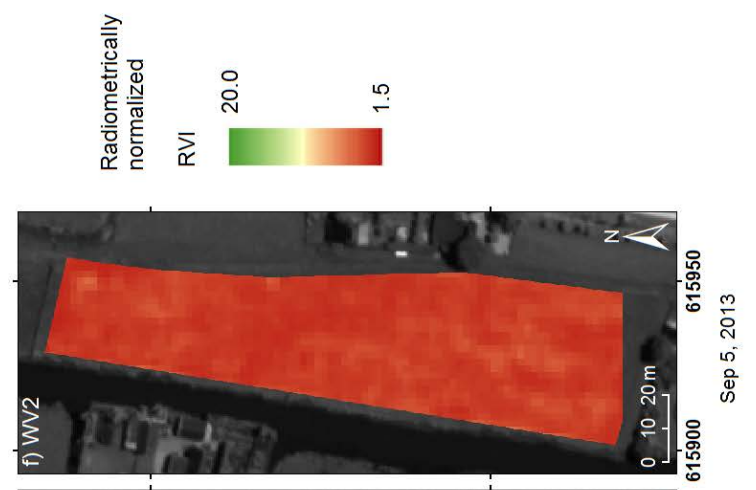

$\stackrel{\square}{\varpi}$
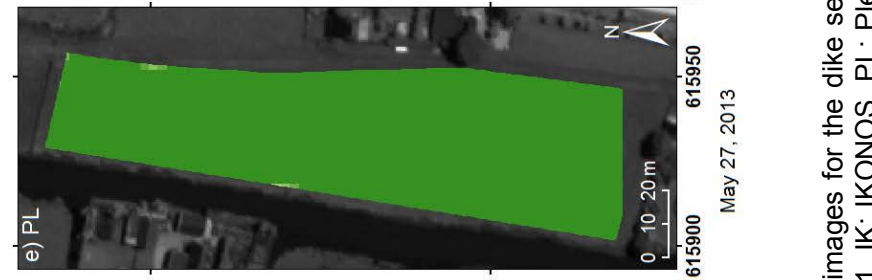

要这

$\stackrel{\oplus \infty}{=}$

흐는

电

ه्ष

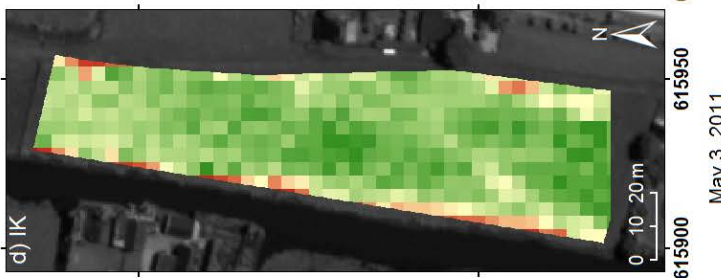

更

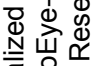

क्ष

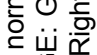

정

늘

응 흔 용

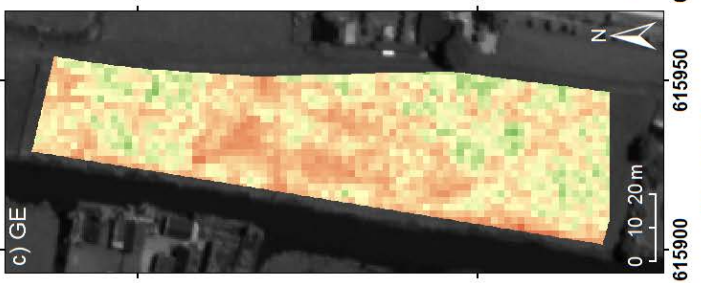

$\frac{\pi}{3} \frac{\pi}{0}$

表守

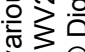

o

$\mp$

㗝

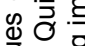

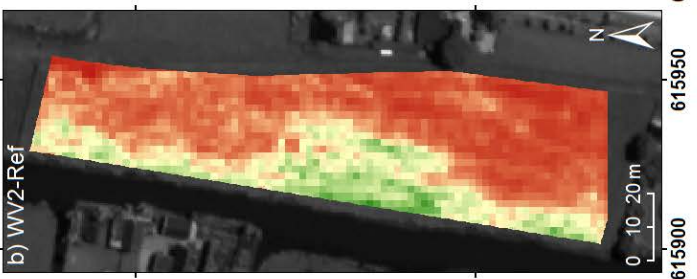

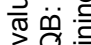

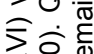

또음 뜸

정

등 을

든

तٓ क्ष

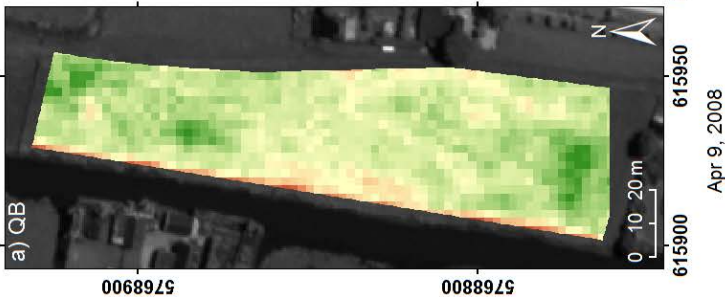

ब্

$>00$

윰요

준

के

言 등

00889LS

年曹 


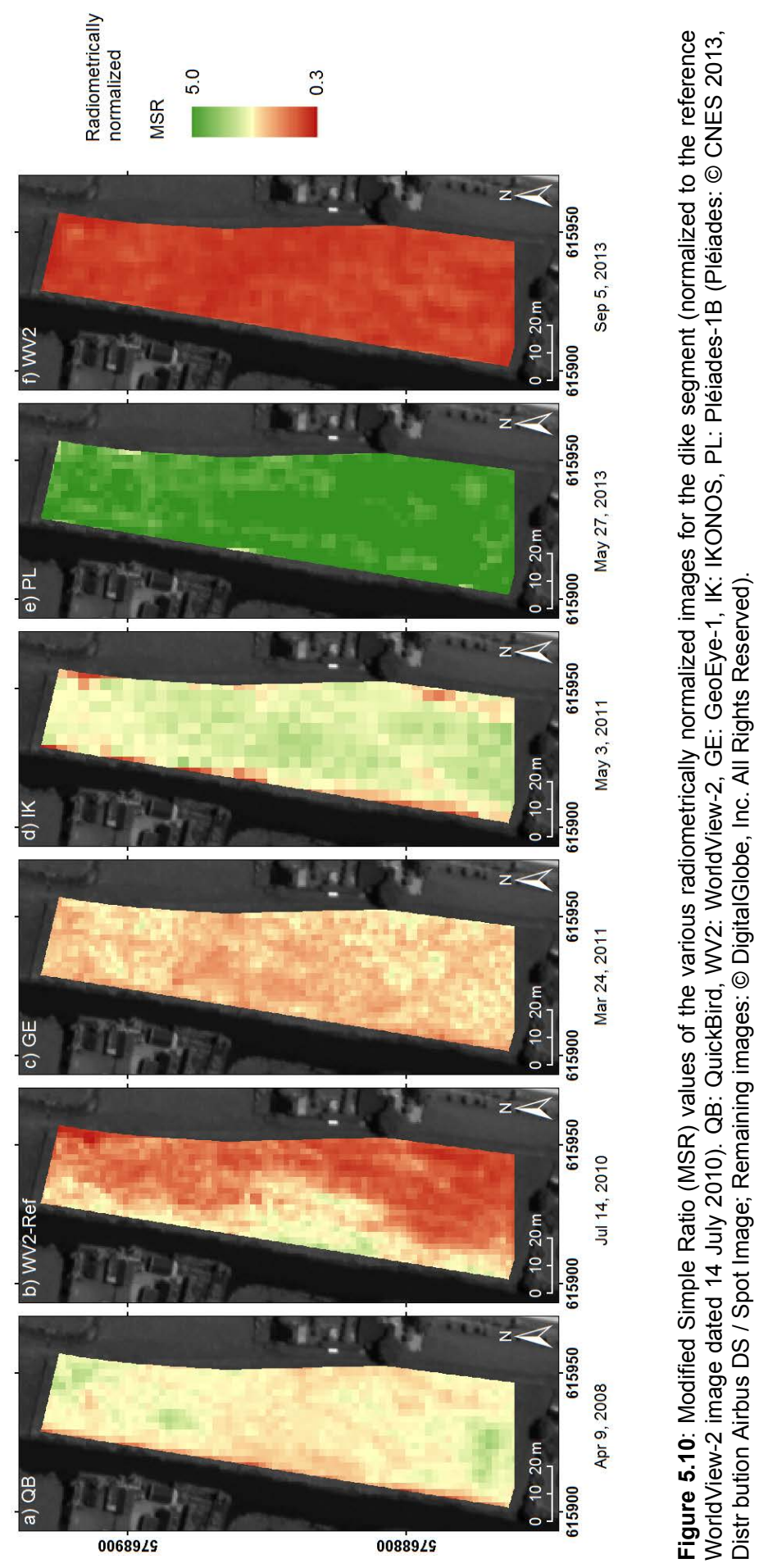




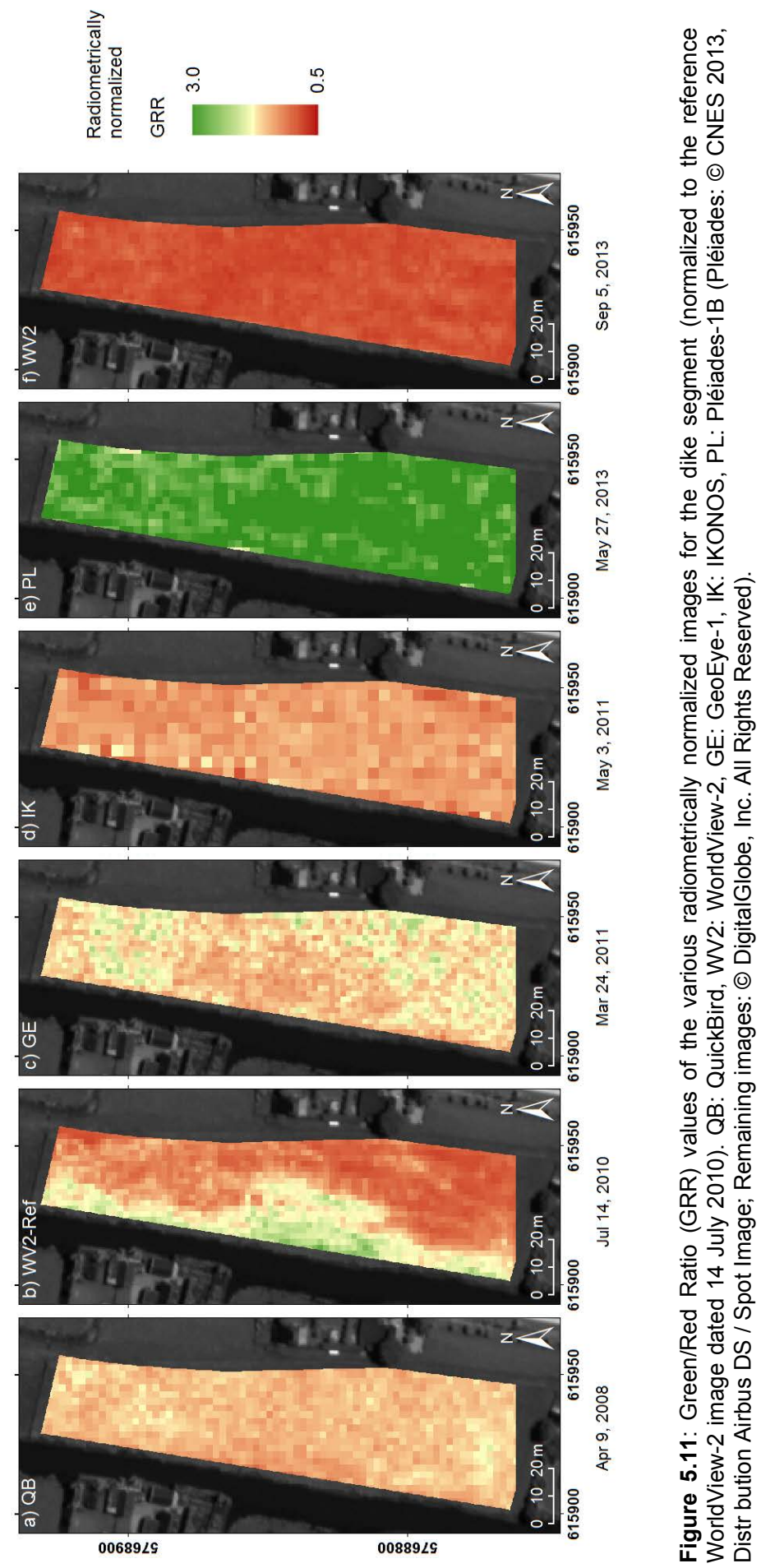




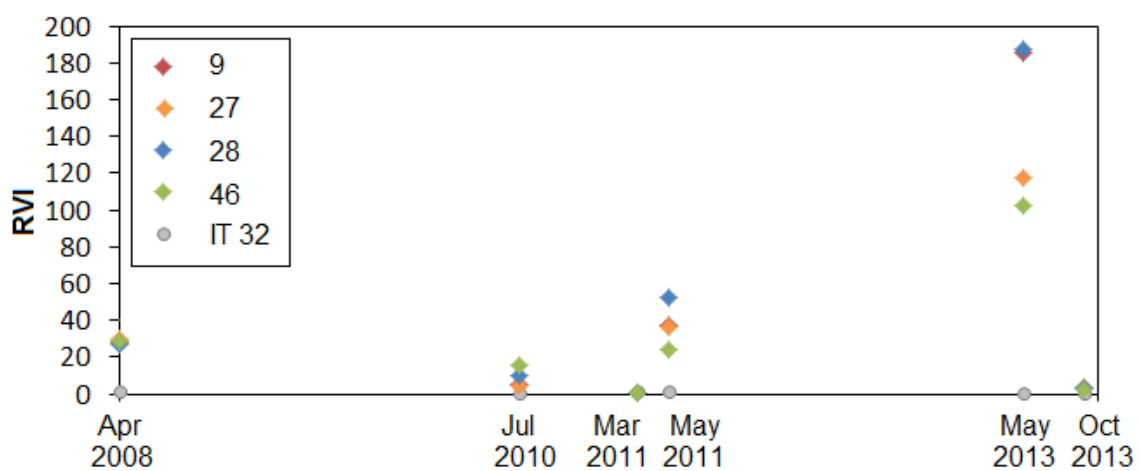

(a)

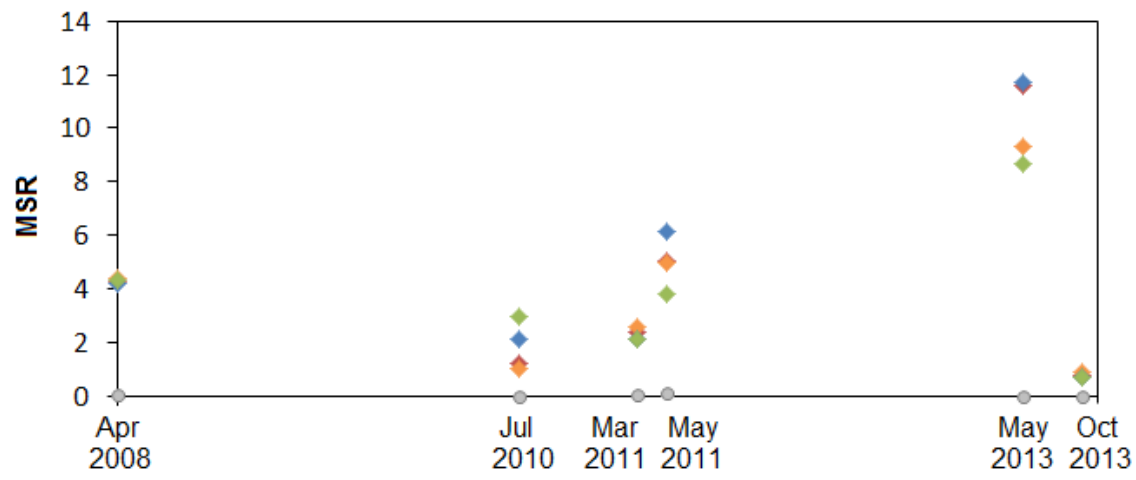

(b)

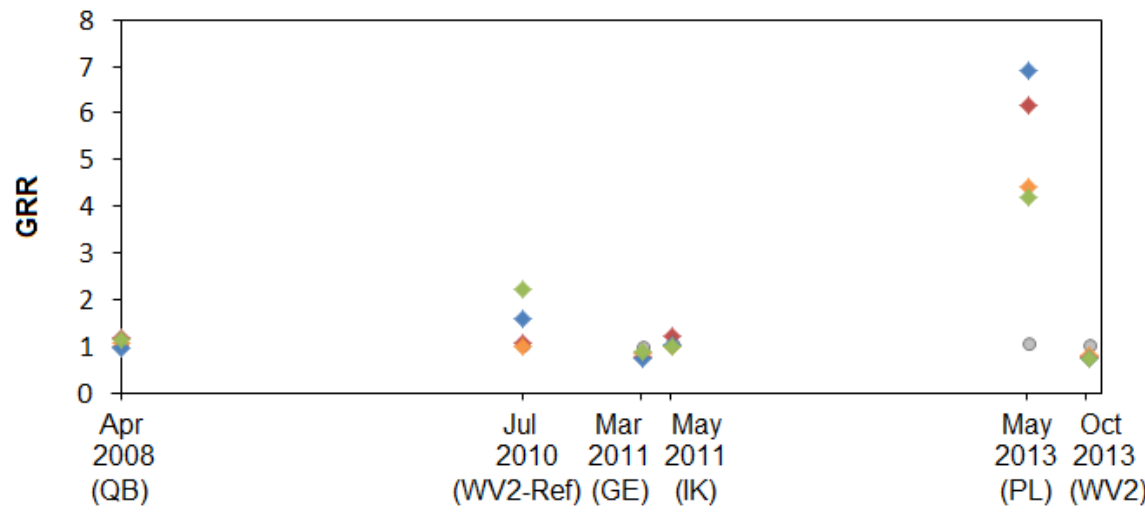

Date

Figure 5.12: Dot graphs showing the spectral behaviour of the adjusted RVI, MSR and GRR atmospherically corrected image products for four locations on the dike segment (Figure 5.5) and one verification invariant target (IT 32, Figure 5.3) for the six image time series. 


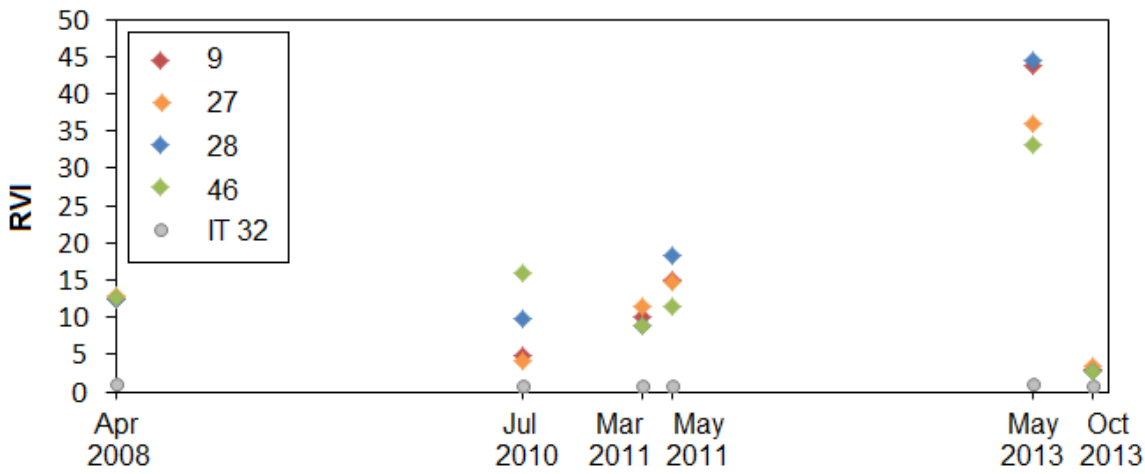

(a)

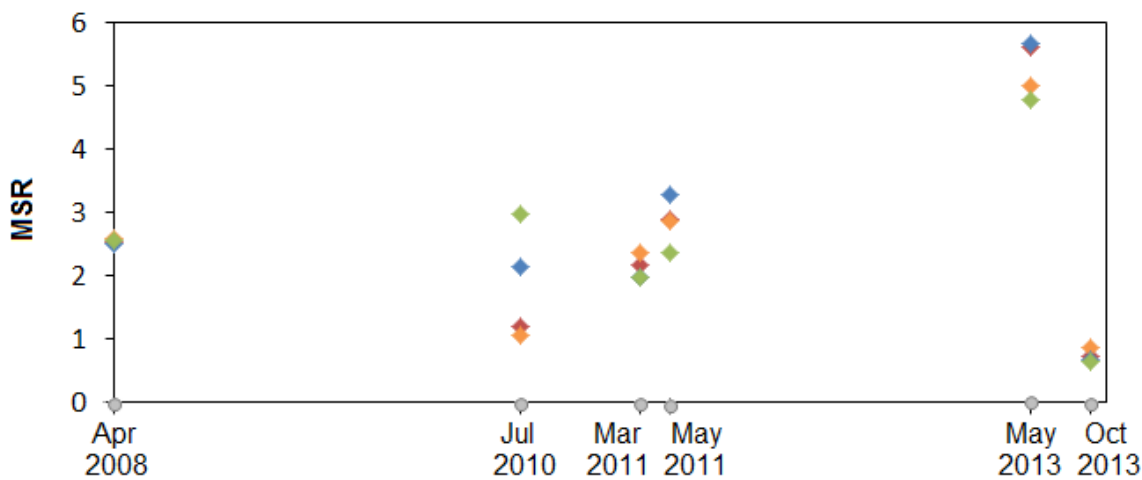

(b)

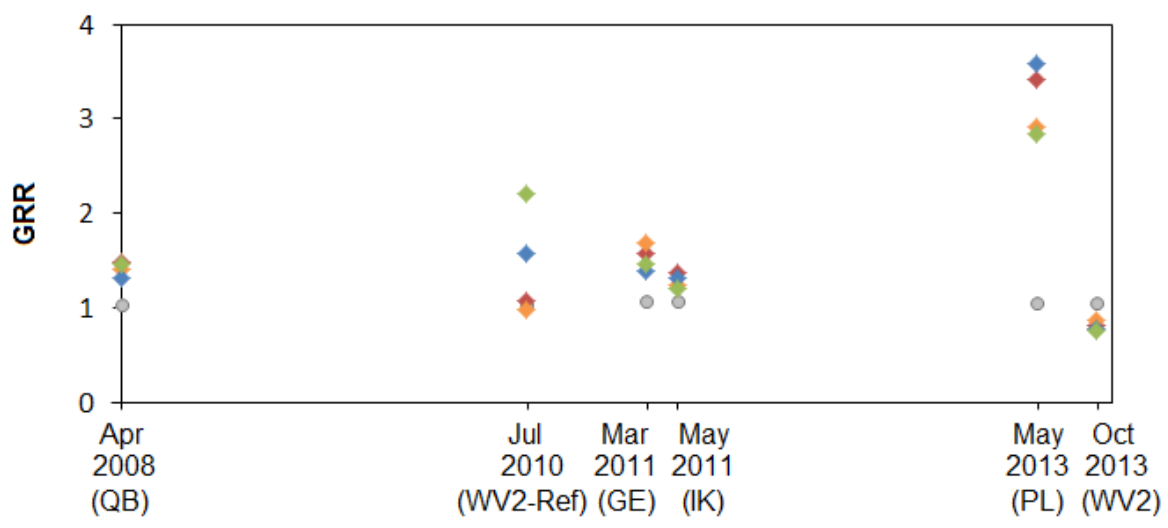

(c)

Figure 5.13: Dot graphs showing the spectral behaviour of the RVI, MSR and GRR radiometrically normalized image products for four locations on the dike segment (Figure 5.5) and one verification invariant target (IT 32, Figure 5.3) for the six image time series. 
The maps (Figures 5.6 to 5.11) show that for the dike segment, the 5 September 2013 WorldView-2 index products (Figures 5.6f to 5.11f) have the lowest mean index values and the 27 May 2013 Pléiades-1B (Figures 5.6e to 5.11e) the highest mean index values. RVI and MSR image products for the 3 May 2011 IKONOS (Figures 5.6d, 5.7d, 5.9d and 5.10d) and 9 April 2008 QuickBird (Figures 5.6a, 5.7a, 5.9a and 5.10a) images have the next highest overall values after 27 May 2013 Pléiades-1B. For the atmospherically corrected GRR image products, the next highest overall values after 27 May 2013 Pléiades-1B are for 14 July 2010 WorldView-2 (Figure 5.8b), while the 24 March 2011 GeoEye-1 (Figure 5.11c) index values are the next highest for the radiometrically normalized GRR image products. Similar to the maps, the dot graphs (Figures 5.12 and 5.13) of four locations show that the 27 May 2013 Pléiades-1B index products have the highest index values and the 5 September 2013 WorldView-2 index products have the lowest (with the exception of atmospherically corrected RVI where the 24 March 2011 GeoEye-1 index values are the lowest). The indicated general weather conditions preceding each image acquisition (see Figure 5.1) are hot and very dry for 14 July 2010 WorldView-2, warm and very dry for 3 May 2011 IKONOS, hot and dry for 5 September 2013 WorldView-2, cool and wet for 24 March 2011 GeoEye-1, warm and wet for 27 May 2013 Pléiades-1B and cool and very wet for 9 April 2008 QuickBird. These weather conditions preceding each image acquisition do not explain the overall index values observed in the maps and dot graphs.

The outputs of the two correction methods (i.e., atmospheric correction and radiometric normalization) have different accuracies when compared to the reference image (see Table 5.3), and thus the expected differences in actual index values are evident in the maps (Figures 5.6 to 5.11) and dot graphs (Figures 5.12 and 5.13). Despite this, the spatial patterns observed for an imagedate's atmospherically corrected index product appear almost identical for the same image-date's radiometrically normalized index product (e.g., compare Figures 5.6c and 5.9c). Similarly, in the dot graphs (Figures 5.12 and 5.13) the relative distributions of index values per date do not alter between the two correction methods. This is confirmed by strong Pearson correlation coefficients of above 0.957 between an image-date's atmospherically corrected and radiometrically normalized index products for the dike segment, with two exceptions. The first exception is for the 3 May 2011 IKONOS GRR products where the Pearson correlation coefficient is 0.862 and the second is for the 24 March 2011 GeoEye-1 GRR products where the Pearson correlation coefficient is 0.833 . Nevertheless, these correlation coefficients are still strong. It would thus appear that in this study the correction method does not substantially influence spatial patterns. The differences in actual index values 
(due to correction methods) do however alter the trends in spectral behaviour across the image series (Figures 5.12 and 5.13). The most noticeable changes can be observed in the GRR dot graphs (compare Figures 5.12c and 5.13c), where the 9 April 2008 QuickBird, 24 March 2011 GeoEye-1 and 3 May 2011 IKONOS index values change noticeably in relation to the other image dates. This is problematic for direct comparison of index values over time.

Scatterplots between image-dates (of the same index and correction method) reveal weak negative relationships between the 14 July 2010 WorldView-2 image products and those of the 9 April 2008 QuickBird and 24 March 2011 GeoEye-1 image products (Figure 5.14 shows examples). The Pearson correlation coefficients between the respective reference 14 July 2010 WorldView-2 index products and those of the 9 April 2008 QuickBird are weaker than -0.438 for the dike segment, and weaker than -0.373 for those of the 24 March 2011 GeoEye-1 index products. The weak negative relationships can also be observed as weak inverse spatial patterns (where the central part and western edge of the dike segment is different from the rest of the dike segment) in both the 9 April 2008 QuickBird (e.g. Figure 5.9a) and 24 March 2011 GeoEye-1 (e.g. Figure 5.9c) index products compared to the 14 July 2010 WorldView-2 (e.g. Figure 5.9b) index products, although the boundaries of the patterns do not consistently coincide. The dot graphs of four locations also show an inverse distribution for the 24 March 2011 GeoEye-1 index products (e.g., Figure 5.13b) compared to the 14 July 2010 WorldView-2 index products. However, this inverse distribution does not persist when examining other sets of locations across the slope of the dike (not shown). Unlike in the scatterplots and maps, the dot graphs do not show an inverse distribution for 9 April 2008 QuickBird index products (e.g., Figure 5.13c) compared to the reference 14 July 2010 WorldView-2 index products, but rather the 5 September 2013 WorldView-2 index products show an inverse distribution. The Pearson correlation coefficients between the 5 September 2013 WorldView-2 and 14 July 2010 WorldView-2 index products however only range between -0.006 and 0.093 (i.e., there is practically no relationship).

The indicated general weather conditions (see Figure 5.1) preceding the image acquisitions are cool and wet for both 9 April 2008 QuickBird and 24 March 2011 GeoEye-1 but hot and dry for 14 July 2010 WorldView-2. The weak negative relationships and inverse spatial patterns and distributions between these two subject images and the reference image could thus be related to the preceding weather conditions. Vegetation is highly responsive to changes in soil moisture (Hopkins and Hüner, 2009) but increases in soil moisture (due to wetter and cooler weather) were expected to rather increase than decrease index values because of water being more readily available. However, the soil may 


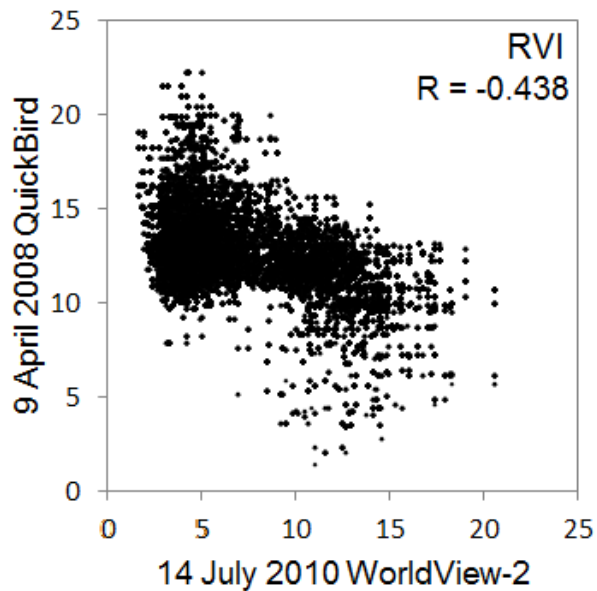

(a)

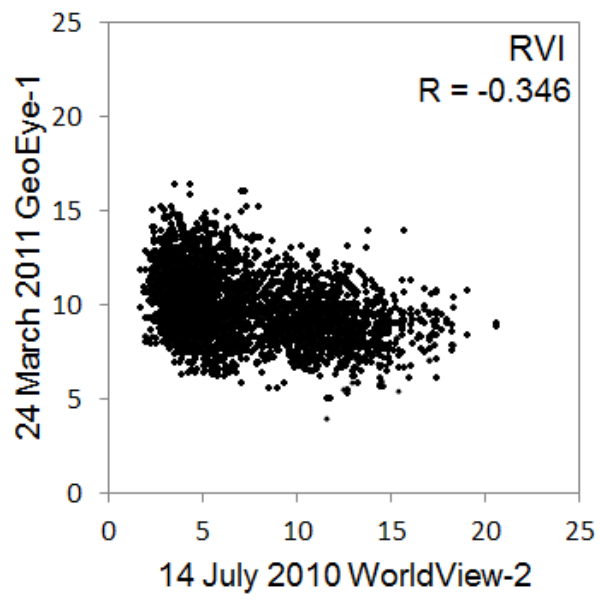

(b)

Figure 5.14: Scatterplots of the radiometrically normalized RVI image products for (a) 9 April 2008 QuickBird versus 14 July 2010 WorldView-2 and (b) 24 March 2011 GeoEye-1 versus 14 July 2010 WorldView-2.

have become waterlogged due to the high precipitation, low evaporation (as a result of low temperatures) and long-term subsurface process of upwelling water. Waterlogging results in plant stress primarily owing to anaerobic soil conditions caused by displacement of oxygen by water (Anderson and Perry, 1996; Smith et al., 2004). Waterlogging has been shown to result in the chlorosis (yellowing due to lack of chlorophyll) of leaves in red maples (Anderson and Perry, 1996) and stunted, yellowed and sparse vegetation in wheat (Pickerill and Malthus, 1998). Furthermore, waterlogging results in increased reflectance particularly in the visible wavelengths (Anderson and Perry, 1996; Pickerill and Malthus, 1998; Smith et al., 2004). If the soil were waterlogged for extended periods of time, then the vegetative grass cover could be stressed, chlorotic or even dying off, resulting in lower index values in these areas compared to the rest of the dike segment.

Since both the 9 April 2008 QuickBird and 24 March 2011 GeoEye-1 index products show negative relationships to the 14 July 2010 WorldView-2 index products, and the preceding weather conditions were cool and wet as opposed to the hot and dry conditions preceding the 14 July 2010 WorldView-2 image, strong positive correlations are expected between the 9 April 2008 QuickBird and 24 March 2011 GeoEye-1 index products. However, the Pearson correlation coefficients between the respective 9 April 2008 QuickBird and 24 March 2011 GeoEye-1 index products are weaker than 0.268 . Although these relationships are positive, they are weak. Furthermore, the relationships and spatial patterns 
of the other subject images' products do not correspond to preceding weather conditions. Namely, the 27 May 2013 Pléiades-1B index products, which had warm and wet weather preceding acquisition, have almost no relationships (weaker than 0.039 ) to 14 July 2010 WorldView-2 index products and no to very weak relationships $( \pm 0.007$ to \pm 0.148$)$ to the other subject images. As stated earlier, the 5 September 2013 WorldView-2 index products have almost no relationships to the 14 July 2010 WorldView-2 index products despite the preceding weather conditions being hot and dry for both image acquisitions. The 3 May 2011 IKONOS atmospherically corrected GRR product, with its preceding weather conditions of warm and dry, show a weak positive relationship (0.301) to the atmospherically corrected GRR product of 14 July 2010 WorldView-2. However this relationship weakens to only 0.181 for the radiometrically normalized GRR products. The Pearson correlation coefficients for the RVI and MSR index products show very weak negative relationships (weaker than -0.166) for these two image-dates. It would thus seem that although preceding weather conditions may contribute in some instances to manifestation of the anomalous spatial patterns associated with the upwelling process, the spectral measurements of the dike grass cover are clearly influenced by other factors.

Sensor and pre-processing factors that may influence the manifestation of spatial patterns are remaining bias due to SRF differences, atmospheric influences, geometric misregistration, and spatial scale and resolution differences. The remaining bias after adjusting for SRF differences using translation functions are expected to be trivial, where the $R^{2}$ values are greater than 0.995 with the exception of IKONOS GRR. In addition, two of the images are from the same sensor (i.e., WorldView-2) and thus have exactly the same SRFs and yet do not manifest the same spatial patterns. Although differences remain in reflectance values between images (Table 5.3), the pre-processing correction methods do not appear to be responsible for the lack of consistent spatial patterns visible in the index products between image dates, since the same spatial patterns can be observed in both the atmospheric correction and radiometric normalization products. This would also imply that atmospheric influences are not responsible for the lack of consistent spatial patterns between image acquisitions. For geometric registration, the total RMS errors for the geometric models are less than a third of the reference WorldView-2 image pixel size and are thus small. Two of the subject images have the same nominal spatial resolution as the reference image (i.e., 24 March 2011 GeoEye-1 and 5 September 2013 WorldView-2). Consequently, for these two images, spatial resolution should not be a significant factor. In addition, when the reference WorldView-2 image (dated 14 July 2010) is aggregated to coarser spatial 

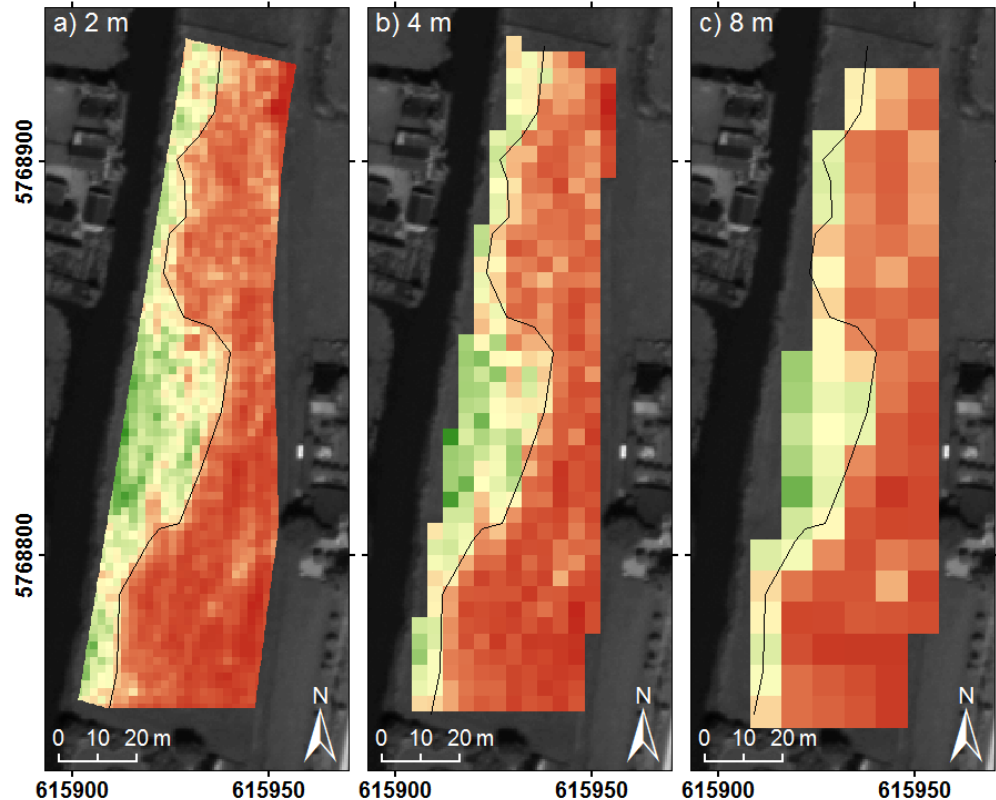

Atmospherically corrected

RVI

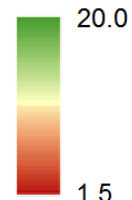

Figure 5.15: The effects of spatial aggregation on spatial patterns in the reference 14 July 2010 WorldView-2 RVI image products, with a) original atmospherically corrected RVI image product at $2 \mathrm{~m}$ spatial resolution; b) RVI image product using atmospherically corrected image aggregated to $4 \mathrm{~m}$ spatial resolution using bilinear resampling and c) RVI image product using atmospherically corrected image aggregated to $8 \mathrm{~m}$ spatial resolution using cubic convolution resampling. Black line indicates general spatial pattern of the bottom of the $\mathrm{d}$ ke segment being different from the rest of the dike segment. (C DigitalGlobe, Inc. All Rights Reserved).

resolutions (Figure 5.15), the general spatial patterns are still discernible in the data. Similarly, the spatial patterns observed in the reference image are evident in the interpolated field spectral point data (see Figure 4.5). It is thus unlikely that geometric misregistration or spatial resolution are major contributors towards the lack in consistent spatial patterns between the reference and subject images.

Management is another factor that may impact on the manifestation of spatial patterns. Pasture management for the dike usually involves mowing every six to eight weeks during the growing season of April through to September. Although the pasture management is unknown for the times of the subject images, it is known that the dike had not been recently mown at the time of the reference image acquisition due to the extreme dry conditions that prevailed at the time. It is thus possible that in July 2010, the natural variation of vegetation in response to the long-term upwelling process was able to become apparent due to the lack of human interference. For the same reason, the inverse spatial patterns observed in the 9 April 2008 QuickBird and 24 March 2011 GeoEye-1 
index products (compared to the 14 July 2010 WorldView-2) may have been apparent since they were both recorded at the beginning of the growing season, possibly before any mowing had occurred. It has been suggested (see above) that these inverse patterns could be the result of waterlogging. These inverse spatial patterns may be less obvious than the original spatial patterns observed in the 14 July 2010 WorldView-2 products because waterlogging during the wet season may influence vegetation less strongly than upwelling water in times of drought. Many dikes are multi-purposed for both flood protection and pasture. Standard dike maintenance practice requires the regular trimming of grass to promote a healthy cover as well as good visibility along the dike (CIRIA et al., 2013; Mériaux and Royet, 2007). It would thus seem that pasture and dike management (specifically mowing) could override the natural variation of vegetation in response to the long-term upwelling process that may otherwise have been apparent in other subject images.

\subsection{Conclusion}

This chapter investigated whether multi-date and multi-sensor imagery can be used to identify and monitor spatial patterns associated with an anomalous subsurface process affecting a dike. Index products of a reference satellite image were compared to those of five subject images obtained from various very high spatial resolution satellite sensors. The RMSE and MAE values for the atmospheric correction and radiometric normalization pre-processing steps are, while generally higher, compatible with what has been reported in the literature. Radiometric normalization improved homogeneity between the images, as evidenced by lower RMSE and MAE values. The correction methods (i.e., atmospheric correction and radiometric normalization) have been shown in this study to not substantially influence spatial patterns. However, the correction method does affect direct comparison of index values across an image series, as shown by the trends in the dot graphs.

The weather conditions preceding each image acquisition do not clearly explain the overall index values observed in data. Nevertheless, anomalous spatial patterns associated with a long-term upwelling process are apparent in the index products of the reference image which was acquired after a period of hot and dry weather conditions. Weak negative relationships and inverse spatial patterns are observed between index products of two images acquired after cool and wet periods and those of the reference image acquired after a hot and dry period. These are perhaps thought to be related to waterlogging as a result of high precipitation, low evaporation (as a result of low temperatures) and the longterm subsurface process of upwelling water. However, the index products of the 
two images acquired after cool and wet periods are only weakly correlated and the other images do not correlate with images acquired after periods of similar weather conditions. Although preceding weather conditions may contribute in some instances to the manifestation of the anomalous spatial patterns associated with the upwelling process, other factors also influence the spectral responses of the dike grass cover. Atmospheric influences, geometric misregistration and spatial resolution were eliminated as major contributors to the lack of spatial patterns associated with the upwelling process. It is thought that pasture and dike management (specifically mowing) could override the natural variation of vegetation in response to the long-term upwelling process that may otherwise be apparent. The findings of this study do not conclusively support the hypothesis, i.e., that considering the long-term process of upwelling water that affects parts of the dike, it is expected that similarities in spatial patterns will still be observed in imagery from different dates and different sensors. It is recommended that the research be expanded to include the non-growing season (i.e., winter period) as well as examine dikes undergoing little or no pasture management, where mowing may only occur once a year or less. 


\section{Synthesis}




\subsection{Introduction}

The purpose of dikes is flood protection and the goal of dike inspection is to ensure that dikes maintain their functional capability. Since dike inspection is typically done on foot and thus slow, tools to expedite the inspection process would be of value. Remote sensing is one such possible tool. Previous work has focused on the use of remote sensing for deformation, slides and seepage. The aim of this research is to evaluate optical remote sensing as proxies for two inspection indicators for grass covered dikes that have not previously been investigated. The soil moisture indicator encompasses not only seepage but also dryness. In this study, the vegetation response to available soil moisture is investigated. The cover quality indicator is used to evaluate the quality of the grass cover taking into account the cover density, grass health, the presence of weeds, standing litter (dead plant material) or debris as well as the absence of vegetation. Absence of vegetation can be indicative of other issues, such as slides, animal activity, etc. The results in this thesis are specifically for in situ peat dikes (see Section 1.1.2 for descriptions of in situ dikes and Section 1.4 for in situ peat dikes specifically). It is possible that results can be extrapolated to other forms of dikes with a grass cover but that has not been tested in this thesis.

This chapter summarises the results and achievements of previous chapters (Chapters 2 to 5) and discusses the findings in relation to the original research objectives, which were defined as:

- to identify if, when using field measurements, there are significant relationships between 1) soil moisture indicator and 2) cover quality indicator, and a) broadband thermal, b) broadband visible, c) broadband multispectral and d) narrowband hyperspectral remote sensing data for grass covered dikes (Section 6.2),

- to investigate the effects of differing spectral response functions (SRFs) of various very high spatial resolution sensors on the cross-calibration of numerous spectral indices for cultivated grasslands that are typically found on dikes that do not have a hardened cover (Section 6.3),

- to compare and evaluate remote sensing measurements obtained from imagery to those obtained in the field for assessing soil moisture and cover quality indicators for the inspection of grass covered dikes (Section 6.4.1),

- to compare and evaluate remote sensing image data obtained from different very high spatial resolution satellite imaging sensors for a section of dike in the context of facilitating the inspection of dikes (Section 6.4.2). 
The following sections are structured around the research objectives, under the themes of proof of concept, technical issues relating to the comparison of data from different sensors and evaluating remote sensing imagery for use in dike inspections. The final two sections specifically relate the findings to use in dike inspection and give recommendations for future research.

\subsection{Proof of concept}

The first objective of this thesis pertains to the proof of concept as to whether relationships exist between optical remote sensing and two inspection indicators. In Chapter 2, significant relationships were found between four types of ground-based remote sensing data (i.e., broadband thermal, broadband visible, broadband multispectral and narrowband hyperspectral) and both inspection indicators. For the reflected remote sensing data sets, indices were specifically investigated.

For the soil moisture indicator, the strongest relationships were to the afternoon thermal data sets. Since there was no very high spatial resolution thermal imagery available (see Section 6.4), these relationships have not been further tested and developed for airborne or space-borne implementation. From the reflected data sets, the strongest correlations to the soil moisture indicator were narrowband ratios using near-infrared and red bands and the broadband ratio of green to red (see Sections 2.4.1.3, 2.4.1.4 and 3.3.2.1). Interestingly, in the case of the green to red ratio, a standard digital camera out-performed a specialised camera. In addition to the correlation coefficients as evidence of relationships, spatial patterns from the various remote sensing data were linked to those of the soil moisture indicator. A large spatial feature was consistently identified at the bottom of the dike section. This was associated to a possible subsurface process of upwelling water. In Chapter 3 it was shown that for the top five indices for the soil moisture indicator, indices from narrowband sensors appeared to perform better than those from broadband sensors. Nonetheless, the differences in correlation coefficients to soil moisture were small $(<0.050)$ and indices for certain broadband sensors performed as well or better. In Chapter 4 , the indices recommended for potential use by dike inspectors as proxies for the soil moisture indicator were narrowed down to RVI, MSR and GRR, in either their broad- or narrowband form.

For the cover quality indicator, the strongest relationships were to broadband multispectral data, particularly ratios using the near-infrared band, followed by afternoon thermal data and narrowband hyperspectral indices. The list was narrowed down in Chapter 3 to eight indices (i.e., $\mathrm{NDVI}_{705}, \mathrm{mNDVI}_{705}, \mathrm{mSR}_{705}$, $\mathrm{GM}_{2}, \mathrm{CTR}_{2}$, RGI, GRR and NGRR) based on their correlation coefficients to 
cover quality across all sensors investigated. These include indices that use near-infrared and red-edge bands and those that use green and red bands (see Sections 2.4.2.2 and 3.3.2.2). However, it was found that the choice of index for the cover quality indicator could not be so easily generalized according to the bands used but also their specific formulation should be considered. It was further shown in Chapter 3 that for these eight indices, those from broadband sensors appeared to perform better overall than those from narrowband sensors but that the differences in correlation coefficients were small $(<0.040)$. As for the soil moisture indicator, spatial patterns from various remote sensing data were linked to those of the cover quality indicator, with a large spatial feature consistently identified at the bottom of the dike section. In Chapter 4, indices RGI, GRR and NGRR are recommended as proxies for the cover quality indicator, with a preference (based on similarity between field and actual image data) for GRR. These indices could be used by dike inspectors as proxies for the cover quality indicator to identify potentially problematic areas on grass covered dikes, but that may require further investigation.

An additional aim of Chapter 2 was to investigate time of observation and environmental influences on thermal measurements. Temperatures measured for vegetated surfaces are a complex combination of actual temperature, evapotranspiration (related to available soil moisture), illumination and thermal properties of the specific cover type (e.g., emissivity, specific heat capacity). Pre-dawn thermal crossovers were not evident, seemingly due to lack of standing water (not tested) and vegetation effect. For soil moisture, as well as cover quality, the optimal time for thermal measurements of grass covered dikes was found to be between solar noon and apparent sunset when temperature differences were at their maximum. Thermal response is strongly affected by cover type (e.g., bare soil, standing litter, green vegetation), local weather conditions (e.g., rain) and illumination (e.g., cloud, shadowing). Whereas nonuniform cover is of interest for cover quality, it distorts the measured thermal response of green vegetation to available soil moisture. For both indicators, illumination and weather conditions are problematic. This study contributed to knowledge regarding optimal time of observation as well as effects of environmental conditions for thermal measurements.

\subsection{Data processing}

There are a number of factors that can affect the comparison of data from different sensors. SRF differences are one of the main causes of differences in data sets between sensors. SRFs are usually known which makes it sensible to address this source of differences. While much research has tried to address the 
effects of different SRFs, this research fills the knowledge gap regarding SRFs of very high spatial resolution sensors specifically for the cover type of cultivated grasslands. This is the subject of the second research objective of this thesis.

This research confirmed that the change in SRFs between sensors noticeably altered index values (Chapter 3). Indices DVI, GEMI, EVI, MCARI ${ }_{1}, \mathrm{MSAVI}_{2}$, $\mathrm{MTVI}_{1}, \mathrm{RDVI}$, SARVI and SAVI were found to be the least affected by SRF differences across a range of band widths. Nonetheless there are still differences in their index values that should be corrected. In most cases, relationships could be modelled between the index values for the reference narrowband ASD FieldSpec Pro spectrometer and those of the ten different sensors (both narrowand broadband). The coefficients of determination $\left(R^{2}\right)$ for the modelled translation function should be as close to perfect (i.e., 1) as possible in order to reduce biases. Caution should be exercised when using indices that use bands which fall within transitional regions of the spectrum (e.g., red-edge), since the relationships for these indices between sensors are particularly adversely affected by the widths and positions of these bands (as evidenced by the often lower $R^{2}$ values). The importance of using actual SRFs and not approximations such as Gaussian curves was illustrated by differences in statistical measures between WorldView-2 and WorldView-3 in Chapter 3 (where the SRFs for WorldView-3 were not yet available and so were approximated using Gaussian curves based on band width and positions, identical to those of WorldView-2). In Chapter 4, translation functions were proven to reduce differences (i.e., improve similarity) in index values between the reference narrowband ASD FieldSpec Pro spectrometer data and both simulated and image data for the broadband WorldView-2 sensor. Since, for many studies, data from multiple sensors are often required to ensure coverage and continuity, it is essential that translation functions be used to correct for differences in sensor SRFs before comparing data across sensors.

Linear translation function coefficients for 48 indices are provided in Table B.2 in order to adjust data from ten very high spatial resolution sensors to ASD FieldSpec Pro spectrometer-equivalent index values for cultivated grasslands. Although linear coefficients are presented, correct definition of the relationship is necessary for accurate adjustment of SRF effects and the best-fit translation function may not necessarily be linear but rather second order polynomial. This is the case for translation functions between ASD FieldSpec Pro spectrometer and WorldView-2 for specific indices (coefficients are provided in Table 4.4 for 10 indices) and between WorldView-2 and GeoEye-1, IKONOS, Pléiades-1B and QuickBird sensors (coefficients are provided in Table 5.4 for three indices). Although care was taken to include a range of grass cover conditions and 
multiple grassland species, a limitation of the data set is that it lacks the possible worldwide variability of cultivated grassland species and underlying soil types. The translation function coefficients are thus considered transferable to environments similar to the study site but may not be applicable to vastly different environments, particularly with paler underlying soils.

Further considerations for comparing data are atmospheric and radiometric corrections. In Chapter 5, whether an image was only atmospherically corrected or also radiometrically normalized did not substantially influence spatial patterns, which is encouraging for geospatial studies. In this study, as in literature, radiometric normalization generally improved homogeneity between images. However the corrections did alter the actual index values per image and thus altered trends over time. This is problematic for comparison of index values between dates and sensors where choice and level of correction may result in larger variability in the data values than the subtle natural differences that are of interest. A challenge remains for the remote sensing researcher in determining what level of processing is adequate and what errors are considered acceptable for the application at hand. For dike inspection purposes, specific rectifications could be proposed, which is done in detail in Section 6.5.

\subsection{Imagery}

A challenge to achieving the third and fourth objectives was obtaining suitable imagery. Due to the narrowness of the dike, very high spatial resolution imagery is required to avoid contamination of pixels from other surfaces such as ditches, buildings, roads and trees. Very high spatial resolution imagery is also preferred when comparing image data to those obtained from field measurements so as to limit spatial scale and resolution effects. Various traditional as well as unconventional methods were explored in order to obtain the required very high spatial resolution imagery. Due to the nature of thermal electromagnetic energy, the spatial resolutions of thermal imaging systems are typically coarser than those of reflected. At the time of the study, the available thermal imaging systems were too coarse, prohibitively expensive, not practical or not yet operational. However, continual technological advancements should overcome most of these issues in the near future. Traditional hyper- and multispectral airborne imaging campaigns (using manned-aircraft) were considered financially unjustified for this comparatively small research area and so more cost-effective alternatives were favoured. Very high spatial resolution images were obtained for the study site using a multispectral sensor mounted on a UAV platform. The images suffered from extensive random noise and striping (thought to be a result of electronic interference), as well as non-systematic 
geometric distortions from the rolling shutter and UAV motion. These rendered the images unsuitable for use due to the high levels of uncertainty in the data. There are a number of satellite sensors with the necessary very high spatial resolution, although all are multispectral. Availability of these images is limited by revisit times and cloud cover. Six suitable multispectral images were found for the study site. One was recorded a day before the field campaign. None of the other images were recorded close to this date and nor did any of the other images have overlapping dates.

\subsubsection{Single image}

In order to achieve the third objective, WorldView-2 image data from a day before the field campaign were compared to the ASD FieldSpec Pro spectrometer data (Chapter 4). After atmospheric correction, index values obtained from the WorldView-2 image are different to those of the ASD FieldSpec Pro spectrometer field data. Differences due to SRFs were predominately corrected using translation functions with some residual biases remaining (as seen in the adjusted simulated data sets in Figures 4.3 and 4.4) since the relationships are not perfect (Table 4.4, $R^{2}$ ). However, after adjustment for SRFs, the image index values (although improved) are still different from the ASD FieldSpec Pro spectrometer field data. These differences arise from biases remaining after the SRF adjustments as well as other factors. Through a process of reasoning and elimination, the more than fourfold increase in spatial resolution is considered to be the main cause of these differences in index values owing to the heterogeneity of the cover (although this could not be tested due to the lack of suitable imagery).

Despite the differences in index values between the field and adjusted image data, the index values for certain indices (e.g., MSR) were sufficiently similar to allow similar spatial patterns to be identified even when represented with the same colour scale. The spatial patterns could also be related back to those of the inspection indicators, where the correlations between the soil moisture indictor and certain indices for the adjusted image data even improved compared to the field data. These comparable index values between the field and adjusted image data were achieved without any operator interference or "tweaking". This allows for the use of thresholds (whether absolute or fuzzy boundary) and shows potential for implementation at an operational level using data from more than one sensor. 


\subsubsection{Multiple images}

The last research objective involved comparing images from different satellite imaging sensors. When evaluating six satellite images, weather conditions preceding each image acquisition do not explain the overall index values observed in the data. The relationships and spatial patterns between image-dates (of the same index and correction method) are mostly weak or practically nonexistent. Although in some instances, weather conditions may contribute to the manifestation of the anomalous spatial patterns associated with the upwelling process, they could not conclusively be linked to the observed spatial patterns and index values. Factors other than weather conditions clearly affect the spectral response of the dike cover. In this case, atmospheric influences, geometric misregistration and remaining biases due to SRF differences were ruled out as major contributors to the absence of spatial patterns associated with the upwelling process. Since similar date imagery from different sensors of similar spatial resolution were not available, it was not possible to test if similar spatial resolution reduces differences between data sets (i.e., that differences are in fact a result of spatial resolution effects). Nevertheless, as when comparing the ASD FieldSpec Pro spectrometer data to the similar date WorldView-2 data, similar spatial patterns were still evident when the reference image was resampled to coarser resolutions. Thus spatial scale and resolution effects were also ruled out as major contributors to the absence of spatial patterns associated with the upwelling process. The findings of this study do not conclusively support the use of optical remote sensing data as proxies for the soil moisture and cover quality indicators so as to facilitate the inspection of grass covered dikes. Pasture and dike management (especially mowing) are thought to override the natural expression of vegetation response to the long-term upwelling process that may otherwise be apparent.

\subsection{Remote sensing for dike inspection}

Remote sensing for dike inspection is a relatively new application with literature only starting about a decade ago. The current research is the first to systematically investigate optical remote sensing data as proxies for the inspection indicators of cover quality and soil moisture so as to facilitate the inspection of grass covered dikes. All four specific research objectives (Section 1.3) have been achieved, with the latter three achieved for reflected but not thermal remote sensing data. 
The current research was conducted for an in situ peat dike but it is expected that the dike inspector could use indices RVI, MSR and GRR as proxies for the soil moisture indicator for long-term moisture processes (e.g., weeks to months) for grass covered dikes, where vegetation growth and health have sufficient time to respond to available soil moisture. It should be remembered that vegetation responds to available soil moisture that is in reach of its roots and thus soil moisture variations in the subsurface may not be evident in the remote sensing data. The vegetation response to available soil moisture is most likely season dependent and thus relationships between the indices and the soil moisture indicator may be either negative or positive and thus both conditions should be considered. Similarly, indices RGI, NGRR and especially GRR could be used as proxies for the cover quality indicator, signifying the state of the grass cover at the time of imaging. While the relationships between the indices and the two indicators are not strong, the observed spatial patterns were sufficiently clear to identify and delineate a comparable area that is affected by a possible upwelling process. Smaller features observed in the field data were not always identified in imagery (Chapter 4). Although the internal structure and composition of the dike may influence soil moisture and cover quality, no definitive link could be established between the subsurface lithography of the dike and either the inspection indicators or the remote sensing data (Chapter 2). As was shown in Chapter 5, evidence of the upwelling process was not always evident in the remote sensing data and may be masked (e.g., by management practices). The remote sensing information is thus not definitive but rather indicative. Dike inspectors can use information obtained from the remotely sensed index data to identify potential problem areas for further investigation. It should be noted that not all potential problem areas may be identified using the remote sensing data and that the absolute values of the indicators might not be retrieved from the remote sensing proxies. Traditional inspections should be continued but remote sensing may help as a screening tool by identifying potentially problematic areas that may have been over looked in the field or manifest between traditional inspections.

Following are suggestions for operational implementation of optical remote sensing for dike inspection, in the context of the specific indices as proxies for soil moisture and cover quality indicators. It is suggested that imagery be recorded on a regular basis (e.g., every 1-3 months) throughout the year and that extra campaigns be scheduled during times of drought or high water. Images can then not only be assessed for a moment in time but also evaluated for changes over time. Very high spatial resolution imagery is required for dike inspection due to the narrowness of dike structures and the small size of features of interest. Although a large spatial feature could be still be identified in 
resampled $8 \mathrm{~m}$ imagery (Figure 5.15), it is suggested that imagery for dike inspections should have a spatial resolution of $2 \mathrm{~m}$ or less, with a preference for sub-metre imagery (optimal spatial resolution remains to be tested). Satellite image data are limited by revisit times, cloud cover and multispectral spatial resolution. Aerial surveys may overcome these problems as well as reducing atmospheric effects due to a reduction in the atmospheric path (although aerial images are more prone to geometric distortions associated with aircraft attitude). Images need to be adequately corrected, taking into account, for example, atmospheric, spatial and spectral characteristics. Ideally, multi-date images should be recorded using the same or at least similar sensors (where SRFs and spatial resolutions are similar) so as to reduce possible biases. It is recommended to perform full atmospheric corrections and adjust for SRF differences when comparing imagery. Radiometric normalization improves homogeneity between images and is additionally recommended for data comparison across image series despite invariant target selection being potentially labour-intensive or computationally complicated.

\subsection{The way forward}

In general, the results from this and previous studies on remote sensing for dike inspection (Table 1.2) appear promising. Nonetheless, there is still much that needs to be addressed and clarified, with ample interesting and challenging work to be done. Sensor and system technologies are constantly improving, with instruments getting smaller, lighter, more diverse (greater assortment), more specialised, cheaper and more ubiquitous. This is encouraging for future research, as it makes obtaining the required measurements and images more probable. Future research opportunities which arise out of the current research, as well as in the context of previous studies, are:

- For the cover quality indicator, it is suggested to test whether a more detailed classification improves the relationships between the indicator and remote sensing indices. It is also suggested to test whether endmembers can be used to produce proportions for the various cover types present within a pixel, thereby improving the classification of a pixel into a specific cover quality class. This will however require hyperspectral remote sensing data.

- For the soil moisture indicator, it is recommended to pursue the use of thermal remote sensing images. Technological improvements have improved the spatial resolution of thermal sensors and thermal imaging systems are even designed for use on UAV platforms. Since the type of cover (with its particular thermal properties) can significantly influence 
thermal response, it is suggested to investigate the use of reflected remote sensing for stratifying the thermal data according to cover type. This may prove particularly useful in identifying recent increases or decreases in soil moisture since the thermal response of vegetation to changes in available soil moisture is relatively rapid compared to the vegetation's growth response. It is also suggested to investigate the combination or fusion of thermal with microwave remote sensing data (e.g., PMR, PolSAR), as it may assist with their interpretation and issues related to spatial resolution. This could also be extended (or limited) to include reflected remote sensing data to overcome complications related with vegetated surfaces.

- Management practices are thought to override otherwise observable spatial patterns associated with either the soil moisture or cover quality indicators. To confirm this, it is advised to expand the research to include the non-growing season (i.e., winter period) as well as dikes undergoing little or no pasture management (where mowing may only occur once a year or less). If management practices are proven to override these spatial patterns, then it may be interesting to explore if these techniques can be used in specific extreme events, such as drought when there is little or no mowing or during high water in the nongrowing season.

- Although the research for this thesis was conducted using data from an in situ peat dike, the findings should be transferrable to other dikes with a grass cover since it focused on the quality of the grass cover and the vegetation response to available soil moisture. However, internal structure and composition of the dike may affect how the soil moisture is made available to the vegetation and different substrates may affect general vegetation health. The findings should thus be tested for other types of dikes.

- This and other research (Table 1.2) have investigated the use of remote sensing for various inspection indictors (i.e., deformation, seepage, slides, soil moisture and grass cover quality). There are however other inspection indicators that still require investigation as to whether remote sensing could facilitate with their inspection (e.g., riprap and other revetments, woody vegetation, encroachments, cracking and animal burrows). 
- Geophysics is concerned (amongst other things) with measuring and mapping physical properties of the subsurface from the surface, including lithological layers, water content, intrusions and voids. Traditionally, measurements are ground-based but geophysical instruments are increasingly developed and modified for airborne use, including electromagnetic, magnetic, gravimetric, ground penetrating radar (GPR) and radiometric (gamma-ray spectrometry) methods. Although these airborne systems often have coarser resolutions than ground-based systems, sensor and system technologies are constantly improving, allowing higher subsurface resolutions to be achieved. It is recommended that airborne geophysical methods be explored not only for dike inspection indicators (e.g., soil moisture, cracking and animal burrows) but also to facilitate the characterisation of the dike earthfill and foundations themselves.

- On the technical side, translation functions for many indices presented in this research were often (for simplicity) in their linear form. These need to be reviewed as to whether these are in fact the best fitting functions. In addition, for the purpose of the research, only two reference sensors were selected. It would be useful to expand the definition of translation functions to incorporate, as reference, the other sensors. The translation functions are based on data encompassing a wide range of grass cover conditions on a background of clayey peat soil. For completeness, translation functions for cultivated grasslands should be defined for other soil types.

- At the time of this study, imagery available for the study site was limited and thus spatial scale and resolution effects could not be completely tested. Using actual image data (not simulated data), it would be interesting to explore index value differences between images recorded on the same date with a similar spatial resolution but differing spectral resolutions, as well as those recorded on the same date with similar spectral resolutions but differing spatial resolutions. This should contribute to the understanding of factors affecting image data comparisons, specifically for indices and for cultivated grasslands. 


\section{References}

Aanstoos, J. V., Hasan, K., O'Hara, C. G., Dabbiru, L., Mahrooghy, M., Nobrega, R. \& Lee, M. A. (2012). Detection of slump slides on earthen levees using polarimetric SAR imagery. In: Applied Imagery Pattern Recognition Workshop (AIPR), 2012 IEEE, 9-11 October 2012: IEEE, $7 \mathrm{pp}$.

Aanstoos, J. V., Hasan, K., O'Hara, C. G., Prasad, S., Dabbiru, L., Mahrooghy, M., Gokaraju, B. \& Nobrega, R. (2011). Earthen levee monitoring with Synthetic Aperture Radar. In: Applied Imagery Pattern Recognition Workshop (AIPR), 2011 IEEE, 11-13 October 2011: IEEE, 6 pp.

Aanstoos, J. V., Hasan, K., O'Hara, C. G., Prasad, S., Dabbiru, L., Mahrooghy, M., Nobrega, R., Lee, M. \& Shrestha, B. (2010). Use of remote sensing to screen earthen levees. In: Applied Imagery Pattern Recognition Workshop (AIPR), 2010 IEEE 39th, 13-15 October 2010: IEEE, 6 pp.

Abakarov, A. R., Idarmachev, S. G. \& Kornienko, S. G. (2000). A remote IR sensing study on the turbine inlet at Chirkey HES dam. Hydrotechnical Construction, 34 (5), 216-220.

Adams, M. L., Norvell, W. A., Philpot, W. D. \& Peverly, J. H. (2000). Toward the discrimination of manganese, zinc, copper, and iron deficiency in 'Bragg' soybean using spectral detection methods. Agronomy Journal, 92 (2), 268-274.

Adamsen, F. J., Pinter, P. J., Barnes, E. M., LaMorte, R. L., Wall, G. W., Leavitt, S. W. \& Kimball, B. A. (1999). Measuring wheat senescence with a digital camera. Crop Science, 39 (3), 719-724.

Adler-Golden, S. M., Berk, A., Bernstein, L. S., Richtsmeier, S., Acharya, P. K., Matthew, M. W., Anderson, G. P., Allred, C., Jeong, L. S. \& Chetwynd, J. H. (1998). FLAASH, a MODTRAN4 atmospheric correction package for hyperspectral data retrievals and simulations. In: Proc. 7th Ann. JPL Airborne Earth Science Workshop, Pasadena, California, USA. JPL, 9-14.

Adler-Golden, S. M., Matthew, M. W., Bernstein, L. S., Levine, R. Y., Berk, A., Richtsmeier, S. C., Acharya, P. K., Anderson, G. P., Felde, J. W., Gardner, J. A., Hoke, M. L., Jeong, L. S., Pukall, B., Ratkowski, A. J. \& Burke, H.-H. K. (1999). Atmospheric correction for shortwave spectral imagery based on MODTRAN4. In: SPIE Conference on lmaqing Spectrometry V, July 1999 Denver, Colorado. 61-69.

Aguilar, J., Evans, R., Vigil, M. \& Daughtry, C. S. T. (2012). Spectral estimates of crop residue cover and density for standing and flat wheat stubble. Agronomy Journal, 104 (2), 271-279.

Airbus Defence and Space. (n.d.). Pléiades Products [Online]. Airbus Defence and Space. Available: http://www.astrium-geo.com/en/3027-pleiades50-cm-resolution-products [Accessed 25 May 2013]. 
Algaze, G. (2001). Initial social complexity in southwestern Asia - The Mesopotamian advantage. Current Anthropology, 42 (2), 199-233.

Allsop, W., Kortenhaus, A. \& Morris, M. (2007). Failure Mechanisms for Flood Defence Structures. T04-06-01, 4_1_P01. FLOODsite Consortium.

Anderson, J. E. \& Perry, J. E. (1996). Characterization of wetland plant stress using leaf spectral reflectance: Implications for wetland remote sensing. Wetlands, 16 (4), 477-487.

Asner, G. P. (1998). Biophysical and biochemical sources of variability in canopy reflectance. Remote Sensing of Environment, 64 (3), 234-253.

Baccini, A., Friedl, M. A., Woodcock, C. E. \& Zhu, Z. (2007). Scaling field data to calibrate and validate moderate spatial resolution remote sensing models. Photogrammetric Engineering and Remote Sensing, 73 (8), 945-954.

Baghzouz, M., Devitt, D. A. \& Morris, R. L. (2006). Evaluating temporal variability in the spectral reflectance response of annual ryegrass to changes in nitrogen applications and leaching fractions. International Journal of Remote Sensing, 27 (19), 4137-4157.

Bagus, P. (2006). Wresting land from the sea: an argument against public goods theory. Journal of Libertarian Studies, 20 (4), 21-40.

Bakkenist, S., van Dam, O., van der Nat, A., Thijs, F. \& de Vries, W. (2012a). Bouwstenen professionele inspecties: Handreiking voor het organiseren van inspecties [Building blocks for professional inspections: Guide for the organization of inspections], PIW 2012-13. Amersfoort, The Netherlands: STOWA. (In Dutch).

Bakkenist, S., van Dam, O., van der Nat, A., Thijs, F. \& de Vries, W. (2012b). Inspectiewijzers [Inspection indicators], PIW 2012-14. Amersfoort, The Netherlands: STOWA. (In Dutch).

Barnes, J. D., Balaguer, L., Manrique, E., Elvira, S. \& Davison, A. W. (1992). A reappraisal of the use of DMSO for the extraction and determination of chlorophylls $a$ and $b$ in lichens and higher plants. Environmental and Experimental Botany, 32 (2), 85-100.

Bentivegna, D. J., Smeda, R. J. \& Wang, C. (2012). Detecting cutleaf teasel (Dipsacus laciniatus) along a Missouri highway with hyperspectral imagery. Invasive Plant Science and Management, 5 (2), 155-163.

Berk, A., Bernstein, L. S., Anderson, G. P., Acharya, P. K., Robertson, D. C., Chetwynd, J. H. \& Adler-Golden, S. M. (1998). MODTRAN cloud and multiple scattering upgrades with application to AVIRIS. Remote Sensing of Environment, 65 (3), 367-375.

Bersan, S. \& Koelewijn, A. R. (2015). Temperature monitoring in piping-prone hydraulic structures. In: Lollino, G., Giordan, D., Crosta, G. B., Corominas, J., Azzam, R., Wasowski, J. \& Sciarra, N. (Eds.) Engineering Geology for Society and Territory - Volume 2. Switzerland: Springer International Publishing. 1409-1413. 
Bersan, S., Schenato, L., Rajendran, A., Palmieri, L., Cola, S., Pasuto, A. \& Simonini, P. (2014). Application of a high resolution Distributed Temperature Sensor in a physical model reproducing subsurface water flow. In: 20th IMEKO TC4 Symposium and 18th International Workshop on ADC Modelling and Testing (IWADC). Research on Electrical and Electronic Measurement for the Economic Upturn, 1517 September 2014 Benevento, Italy. International Measurement Confederation IMEKO, 216-220.

Bezuijen, A., Kruse, G. \& Van, M. (2011). Failure of peat dikes in the Netherlands. In: Van, M., den Haan, E. \& van Deen, J. (Eds.) A feeling for soil and water. Delft, The Netherlands: Stichting Deltares. 119-128.

Bishop, M. J., Dunbar, J. B. \& Peyman-Dove, L. P. (2003). Integration of remote sensing (LiDAR, electromagnetic conductivity) and geologic data toward the condition assessment of levee systems. In: Ehlers, M., Ed. Proceedings SPIE 4886, Remote Sensing for Environmental Monitoring, GIS Applications, and Geology II, 23 September 2002 Crete, Greece. SPIE, 400-407.

Blackburn, G. A. (2007). Hyperspectral remote sensing of plant pigments. Journal of Experimental Botany, 58 (4), 855-867.

Blacus, V. (2012). The electromagnetic spectrum [Online]. ElectromagneticSpectrum.svg is licensed under CC BY-SA 3.0. Available: http://upload.wikimedia.org/wikipedia/commons/2/25/ElectromagneticSpectrum.svg [Accessed 3 February 2015].

Bosch, J. H. A. \& Kok, H. (1994). Toelichtingen bij de geologische kaart van Nederland [Explanatory notes on the geological map of Netherlands] 1:50.000 $(38 \mathrm{~W})$. Haarlem, The Netherlands: Rijks Geologische Dienst. (In Dutch).

Boukalová, Z., Benes, V., Koran, P. \& Vesely, L. (2009). Application of geophysical monitoring system and GIH 01 tool at the river basin scale as a part of integrated water resources management in the Czech Republic. In: Brebbia, C. A. (Ed.) River Basin Management $V$. Southampton: Wit Press. 361-372.

Broge, N. H. \& Leblanc, E. (2000). Comparing prediction power and stability of broadband and hyperspectral vegetation indices for estimation of green leaf area index and canopy chlorophyll density. Remote Sensing of Environment, 76 (2), 156-172.

Burt, J. E. \& Barber, G. M. (1996). Elementary statistics for geographers, 2nd ed. New York: Guilford Press.

Caccamo, G., Chisholm, L. A., Bradstock, R. A. \& Puotinen, M. L. (2011). Assessing the sensitivity of MODIS to monitor drought in high biomass ecosystems. Remote Sensing of Environment, 115 (10), 2626-2639.

Campbell, J. B. (2002). Introduction to Remote Sensing. New York: The Guilford Press. 
Canada Centre for Remote Sensing (2007). Fundamentals of Remote Sensing: A Canada Center for Remote Sensing Remote Sensing Tutorial. Natural Resources Canada. Available: http://www.nrcan.gc.ca/sites /www.nrcan.gc.ca/files/earthsciences/pdf/resource/tutor/fundam/pdf/fun damentals e.pdf [Accessed 29 January 2015].

Carter, G. A. (1993). Responses of leaf spectral reflectance to plant stress. American Journal of Botany, 80 (3), 239-243.

Carter, G. A. (1994). Ratios of leaf reflectances in narrow wavebands as indicators of plant stress. International Journal of Remote Sensing, 15 (3), 697-703.

Caselles, V. \& López García, M. J. (1989). An alternative simple approach to estimate atmospheric correction in multitemporal studies. International Journal of Remote Sensing, 10 (6), 1127-1134.

Chander, G., Helder, D. L., Aaron, D., Mishra, N. \& Shrestha, A. K. (2013a). Assessment of spectral, misregistration, and spatial uncertainties inherent in the cross-calibration study. IEEE Transactions on Geoscience and Remote Sensing, 51 (3), 1282-1296.

Chander, G., Mishra, N., Helder, D. L., Aaron, D. B., Angal, A., Taeyoung, C., Xiaoxiong, X. \& Doelling, D. R. (2013b). Applications of spectral band adjustment factors (SBAF) for cross-calibration. IEEE Transactions on Geoscience and Remote Sensing, 51 (3), 1267-1281.

Chen, D., Huang, J. \& Jackson, T. J. (2005). Vegetation water content estimation for corn and soybeans using spectral indices derived from MODIS near- and short-wave infrared bands. Remote Sensing of Environment, 98 (2-3), 225-236.

Chen, J. M. (1996). Evaluation of vegetation indices and a modified simple ratio for boreal applications. Canadian Journal of Remote Sensing, 22 (3), 229-242.

Chen, P. F., Haboudane, D., Tremblay, N., Wang, J. H., Vigneault, P. \& Li, B. G. (2010). New spectral indicator assessing the efficiency of crop nitrogen treatment in corn and wheat. Remote Sensing of Environment, 114 (9), 1987-1997.

CIRIA, (Construction Industry Research and Information Association), MEDDE (Ministère de l'Écologie du Développement durable et de l'Énergie - French Mininstry of Ecology) \& USACE (US Army Corps of Engineers) (2013). The International Levee Handbook. London: CIRIA.

Closson, D., Karaki, N. A., Hansen, H., Derauw, D., Barbier, C. \& Ozer, A. (2003). Space-borne radar interferometric mapping of precursory deformations of a dyke collapse, Dead Sea area, Jordan. International Journal of Remote Sensing, 24 (4), 843-849.

Cohen, J. (1988). [cited in Ellis, 2009] Statistical Power Analysis for the Behavioral Sciences, 2nd ed. Hillsdale, NJ, USA: Lawrence Erlbaum. 
Cole, S. W. \& Gasche, H. (1998). Second- and first-millennium BC rivers in northern Babylonia. In: Gasche, H. \& Tanret, M. (Eds.) Changing Watercourses in Babylonia: Towards a Reconstruction of the Ancient Environment in Lower Mesopotamia. Chigago \& Ghent: The Oriental Institute \& The University of Ghent. 1-64.

Crippen, R. E. (1990). Calculating the vegetation index faster. Remote Sensing of Environment, 34 (1), 71-73.

Cundill, S. L., Hack, H. R. G. K., van der Meijde, M., van der Schrier, J. S. \& Ngan-Tillard, D. J. M. (2013). Quality of peat dykes evaluated by remote sensing. In: Klijn, F. \& Schweckediek, T. (Eds.) Comprehensive Flood Risk Management: Research for policy and practice. Leiden: CRC Press (Taylor \& Francis).

Cundill, S. L., van der Meijde, M. \& Hack, H. R. G. K. (2014). Investigation of remote sensing for potential use in dike inspection. Selected Topics in Applied Earth Observations and Remote Sensing, IEEE Journal of, 7 (2), 733-746.

Cundill, S. L., van der Werff, H. M. A. \& van der Meijde, M. (2015). Adjusting spectral indices for spectral response function differences of very high spatial resolution sensors simulated from field spectra. Sensors, 15 (3), 6221-6240.

D'Odorico, P., Gonsamo, A., Damm, A. \& Schaepman, M. E. (2013). Experimental evaluation of Sentinel-2 spectral response functions for NDVI time-series continuity. IEEE Transactions on Geoscience and Remote Sensing, 51 (3), 1336-1348.

Dabbiru, L., Aanstoos, J. V., Mahrooghy, M., Li, W., Shanker, A. \& Younan, N. H. (2012). Levee anomaly detection using polarimetric synthetic aperture radar data. In: IGARSS 2012 IEEE International Geoscience and Remote Sensing Symposium, 22-27 July 2012 Munich, Germany. IEEE, 5113-5116.

Dabbiru, L., Aanstoos, J. V. \& Younan, N. H. (2014). Comparison of L-band and X-band polarimetric SAR data classification for screening earthen levees. In: Geoscience and Remote Sensing Symposium (IGARSS), 2014 IEEE International, 13-18 July 2014 Quebec City, Canada. IEEE, $2723-2726$.

Dahlin, T. \& Zhou, B. (2004). A numerical comparison of 2D resistivity imaging with 10 electrode arrays. Geophysical Prospecting, 52, 379398.

Darvishzadeh, R., Atzberger, C., Skidmore, A. K. \& Abkar, A. A. (2009). Leaf Area Index derivation from hyperspectral vegetation indices and the red edge position. International Journal of Remote Sensing, 30 (23), 6199 6218.

Daughtry, C. S. T., Walthall, C. L., Kim, M. S., de Colstoun, E. B. \& McMurtrey, J. E. (2000). Estimating corn leaf chlorophyll 
concentration from leaf and canopy reflectance. Remote Sensing of Environment, 74 (2), 229-239.

de Castro, A. I., Jurado-Exposito, M., Pena-Barragan, J. M. \& Lopez-Granados, F. (2012). Airborne multi-spectral imagery for mapping cruciferous weeds in cereal and legume crops. Precision Agriculture, 13 (3), 302 321.

de Louw, P. G. B., Oude Essink, G. H. P. \& Maljaars, P. (2007). Achtergrondstudie kwelreductietechnieken [Background study on seepage-reduction techniques]. 2007-U-R0357/B. Utrecht: TNO Bouw en Ondergrond, Geological Survey of the Netherlands. (In Dutch).

de Louw, P. G. B., Oude Essink, G. H. P., Stuyfzand, P. J. \& van der Zee, S. E. A. T. M. (2010). Upward groundwater flow in boils as the dominant mechanism of salinization in deep polders, The Netherlands. Journal of Hydrology, 394 (3-4), 494-506.

de Mulder, E. F. J., Geluk, M. C., Ritsema, I., Westerhoff, W. E. \& Wong, T. E. (2003). De ondergrond van Nederland [The subsurface of the Netherlands]. Utrecht, The Netherlands: Nederlands Instituut voor Toegepaste Geowetenschappen TNO. (In Dutch).

Dettman-Kruse, J. K., Christians, N. E. \& Chaplin, M. H. (2008). Predicting soil water content through remote sensing of vegetative characteristics in a turfgrass system. Crop Science, 48 (2), 763-770.

Di Prinzio, M., Bittelli, M., Castellarin, A. \& Pisa, P. R. (2010). Application of GPR to the monitoring of river embankments. Journal of Applied Geophysics, 71 (2-3), 53-61.

DigitalGlobe. (2012a). QuickBird Datasheet [Online]. DigitalGlobe. Available: https://www.digitalglobe.com/downloads/QuickBird-DS-QB-Web.pdf [Accessed 25 May 2013].

DigitalGlobe. (2012b). WorldView-2 Datasheet [Online]. DigitalGlobe. Available: https://www.digitalglobe.com/downloads/WorldView2-DSWV2-Web.pdf [Accessed 25 May 2013].

DigitalGlobe. (2013a). Basic Imagery Datasheet [Online]. DigitalGlobe. Available: $\quad$ https://www.digitalglobe.com/sites/default/files /BasicImagery-DS-BASIC-PROD.pdf [Accessed 17 February 2014].

DigitalGlobe. (2013b). WorldView-3 Datasheet [Online]. DigitalGlobe. Available: http://www.digitalglobe.com/downloads/WorldView3-DSWV3-Web.pdf [Accessed 17 July 2013].

Du, P. J., Zhang, H. P., Yuan, L. S., Liu, P. \& Zhang, H. R. (2007). Comparison of vegetation index from ASTER, CBERS and Landsat ETM. In: IGARSS: 2007 IEEE International Geoscience and Remote Sensing Symposium, Vols 1-12: Sensing and Understanding Our Planet, 23-28 July 2007 Barcelona, Spain. IEEE, 3341-3344.

Dungan, J. L. (2001). Scaling up and scaling down: The relevance of the support effect on remote sensing of vegetation. In: Tate, N. J. \& 
Atkinson, P. M. (Eds.) Modelling Scale in Geographical Information Science. Chichester, England: John Wiley and Sons. 221-236.

Dupray, S., Tourment, R., Pohl, R., Schelfhout, H., Gamst, K., Williamson, T. \& Sharp, M. (2010). International Levee Handbook - Scoping Report. London: CIRIA. Available: http://www.leveehandbook.net/index.asp [Accessed 14 July 2011].

Dutilleul, P. (1993). Modifying the $t$ test for assessing the correlation between two spatial processes. Biometrics, 49 (1), 305-314.

Earth Systems Research Laboratory. (n.d.). NOAA Solar Calulator [Online]. NOAA. Available: http://www.esrl.noaa.gov/gmd/grad/solcalc/ [Accessed 15 September 2011].

Eckhardt, D. W., Verdin, J. P. \& Lyford, G. R. (1990). Automated update of an irrigated lands GIS using SPOT HRV imagery. Photogrammetric Engineering and Remote Sensing, 56 (11), 1515-1522.

Ellis, P. D. (2009). Thresholds for interpreting effect sizes [Online]. Available: http://www.polyu.edu.hk/mm/effectsizefaqs/thresholds_for_interpreting effect_sizes2.html [Accessed 26 October 2013].

Ellis, P. D. (2010). The Essential Guide to Effect Sizes. Cambridge, UK: Cambridge University Press.

Elvidge, C. D. \& Chen, Z. K. (1995). Comparison of broad-band and narrowband red and near-infrared vegetation indexes. Remote Sensing of Environment, 54 (1), 38-48.

Environment Agency (2006). Condition Assessment Manual. 166-03-SD01. Bristol, UK: Environment Agency.

Estop-Aragonés, C. \& Blodau, C. (2012). Effects of experimental drying intensity and duration on respiration and methane production recovery in fen peat incubations. Soil Biology \& Biochemistry, 47, 1-9.

Ey, J. (2005). Früher Deichbau und Entwässerung im nordwestdeutschen Küstengebiet. [Early dike construction and water management in the North-West German coastal area.]. In: KLÁPŠTE, J. (Ed.) Water management in medieval rural economy. Památky archeologické Supplementum 17, Ruralia V. Prague. 146-151. (In German).

FAO. (2011). FAOSTAT - Resources - Land [Online]. FAO - Food and Agriculture Organization of the United Nations. Available: http://faostat3.fao.org/faostat-gateway/go/to/home/E [Accessed 14 May 2014].

Fargier, Y., Fauchard, C., Mériaux, P., Royet, P., Palma-Lopes, S., François, D., Côte, P. \& Bretar, F. (2012). Methodology applied to the diagnosis and monitoring of dikes and dams. In: Luo, Y. (Ed.) Novel Approaches and Their Applications in Risk Assessment. Rijeka, Croatia: InTech. Available: http://www.intechopen.com/books/ [Accessed 15 July 2013].

Feingersh, T., Ben-Dor, E. \& Filin, S. (2010). Correction of reflectance anisotropy: a multi-sensor approach. International Journal of Remote Sensing, 31 (1), 49-74. 
FEMA (2012). History of Levees. Federal Emergency Management Agency (FEMA). Available: http://www.fema.gov/media-library-data /20130726-1807-25045-3487/history_of_levees.pdf [Accessed 22 November 2012].

Fensholt, R. \& Sandholt, I. (2003). Derivation of a shortwave infrared water stress index from MODIS near- and shortwave infrared data in a semiarid environment. Remote Sensing of Environment, 87 (1), 111121.

Fisher, J. I., Mustard, J. F. \& Vadeboncoeur, M. A. (2006). Green leaf phenology at Landsat resolution: Scaling from the field to the satellite. Remote Sensing of Environment, 100 (2), 265-279.

Fitz-Rodriguez, E. \& Choi, C. Y. (2002). Monitoring turfgrass quality using multispectral radiometry. Transactions of the ASAE, 45 (3), 865-871.

Fitzgerald, G. J., Rodriguez, D., Christensen, L. K., Belford, R., Sadras, V. O. $\&$ Clarke, T. R. (2006). Spectral and thermal sensing for nitrogen and water status in rainfed and irrigated wheat environments. Precision Agriculture, 7 (4), 233-248.

Forestier, G., Inglada, J., Wemmert, C. \& Gancarski, P. (2013). Comparison of optical sensors discrimination ability using spectral libraries. International Journal of Remote Sensing, 34 (7), 2327-2349.

Franke, J., Heinzel, V. \& Menz, G. (2006). Assessment of NDVI-differences caused by sensor-specific relative spectral response functions. In: 2006 IEEE International Geoscience and Remote Sensing Symposium, Vols 1-8, 31 July - 04 August 2006 Denver, Colorado, USA. New York, NY: IEEE, 1138-1141.

Frazee, C. A. (1997). The First Indian Civilization. World History the easy way. Hauppauge, New York: Barron's Educational Series. 67-74.

Gallo, K., Li, L., Reed, B., Eidenshink, J. \& Dwyer, J. (2005). Multi-platform comparisons of MODIS and AVHRR normalized difference vegetation index data. Remote Sensing of Environment, 99 (3), 221-231.

Gamon, J. A., Peñuelas, J. \& Field, C. B. (1992). A narrow-waveband spectral index that tracks diurnal changes in photosynthetic efficiency Remote Sensing of Environment, 41 (1), 35-44.

Gamon, J. A. \& Surfus, J. S. (1999). Assessing leaf pigment content and activity with a reflectometer. New Phytologist, 143 (1), 105-117.

Gao, B. C. (1996). NDWI - A normalized difference water index for remote sensing of vegetation liquid water from space. Remote Sensing of Environment, 58 (3), 257-266.

GeoEye. (2010). GeoEye Constallation [Online]. Available: http://www.geoeye.com/CorpSite/assets/docs/brochures/GeoEye Constellation.pdf [Accessed 25 May 2013].

Gitelson, A. A. (2013). Remote estimation of crop fractional vegetation cover: the use of noise equivalent as an indicator of performance of vegetation indices. International Journal of Remote Sensing, 34 (17), 6054-6066. 
Gitelson, A. A., Chivkunova, O. B. \& Merzlyak, M. N. (2009). Nondestructive estimation of anthocyanons and chlorophylls in anthocyanic leaves. American Journal of Botany, 96 (10), 1861-1868.

Gitelson, A. A., Kaufman, Y. J., Stark, R. \& Rundquist, D. (2002a). Novel algorithms for remote estimation of vegetation fraction. Remote Sensing of Environment, 80, 76-87.

Gitelson, A. A. \& Merzlyak, M. N. (1997). Remote estimation of chlorophyll content in higher plant leaves. International Journal of Remote Sensing, 18 (12), 2691-2697.

Gitelson, A. A. \& Merzlyak, M. N. (1998). Remote sensing of chlorophyll concentration in higher plant leaves. Advances in Space Research, 22 (5), 689-692.

Gitelson, A. A., Merzlyak, M. N. \& Chivkunova, O. B. (2001). Optical properties and nondestructive estimation of anthocyanin content in plant leaves. Photochemistry and Photobiology, 74 (1), 38-45.

Gitelson, A. A., Peng, Y., Arkebauer, T. J. \& Schepers, J. (2014). Relationships between gross primary production, green LAI, and canopy chlorophyll content in maize: Implications for remote sensing of primary production. Remote Sensing of Environment, 144, 65-72.

Gitelson, A. A., Vina, A., Ciganda, V., Rundquist, D. C. \& Arkebauer, T. J. (2005). Remote estimation of canopy chlorophyll content in crops. Geophysical Research Letters, 32 (8), L08403 (4 pp.).

Gitelson, A. A., Zur, Y., Chivkunova, O. B. \& Merzlyak, M. N. (2002b). Assessing carotenoid content in plant leaves with reflectance spectroscopy. Photochemistry and Photobiology, 75 (3), 272-281.

Givehchi, M., Vrijling, J. K., Hartmann, A., Van Gelder, P. H. A. J. M. \& Van Baars, S. (2002). Application of remotely sensed data for detection of seepage in dikes. In: Navalgund, R. R., Nayak, S. R., Sudarshana, R., Nagaraja, R. \& Ravindran, S., Eds. Proceedings of the ISPRS Commission VII Symposium: Resource and Environmental Monitoring, 3-6 December 2002 Hyderabad, India.

Gonsamo, A. \& Chen, J. M. (2013). Spectral response function comparability among 21 satellite sensors for vegetation monitoring. IEEE Transactions on Geoscience and Remote Sensing, 51 (3), 1319-1335.

Govender, M., Dye, P. J., Weiersbye, I. M., Witkowski, E. T. F. \& Ahmed, F. (2009). Review of commonly used remote sensing and ground-based technologies to measure plant water stress. Water $S A$, 35 (5), 741-752.

Grant, O. M., Tronina, L., Jones, H. G. \& Chaves, M. M. (2007). Exploring thermal imaging variables for the detection of stress responses in grapevine under different irrigation regimes. Journal of Experimental Botany, 58 (4), 815-825.

Groen, G. (2010). Klimaatdata en -advies: Juli 2010: zeer warm, zeer zonnig en de normale hoeveelheid neerslag [Climate data and advice: July 2010: very warm, very sunny and normal rainfall] [Online]. De Bilt: 
Koninklijk Nederlands Meteorologisch Instituut (KNMI). Available: www.knmi.nl/klimatologie/maand_en_seizoensoverzichten/maand /jul10.html [Accessed 16 October 2012]. (In Dutch).

Guyot, G. \& Baret, F. (1988). Utilisation de la haute resolution spectrale pour suivre l'etat des couverts vegetaux [Utilisation of high spectral resolution for monitoring the status of plant cover]. In: Guyenne, T. D. \& Hunt, J. J., Eds. Proceedings 4th International Colloquium on Spectral Signatures of Objects in Remote Sensing, 18-22 January 1988 Aussois, France. European Space Agency, 279-286. (In French).

Haarbrink, R. B. \& Shutko, A. M. (2006). New airborne sensor for soil moisture mapping. In: Everaerts, J., Ed. ISPRS Second International Workshop 'The Future of Remote Sensing', 17-18 October 2006 Antwerp, Belgium.

Haarbrink, R. B. \& Shutko, A. M. (2008). Simultaneous multi-sensor data for global information management system. In: 2008 Microwave Radiometry and Remote Sensing of the Environment, 11-14 March 2008 Firenze, Italy. IEEE, 17-20.

Haboudane, D., Miller, J. R., Pattey, E., Zarco-Tejada, P. J. \& Strachan, I. B. (2004). Hyperspectral vegetation indices and novel algorithms for predicting green LAI of crop canopies: Modeling and validation in the context of precision agriculture. Remote Sensing of Environment, 90 (3), 337-352.

Haboudane, D., Miller, J. R., Tremblay, N., Zarco-Tejada, P. J. \& Dextraze, L. (2002). Integrated narrow-band vegetation indices for prediction of crop chlorophyll content for application to precision agriculture. Remote Sensing of Environment, 81 (2-3), 416-426.

Hack, H. R. G. K., van der Meijde, M., van der Schrier, J. S., Awaju, Y. H., Rupke, J., Barritt, S., van 'T Hof, J., Maccabiani, J., Maresch, S., Calero, D. P., Reymer, A. P. S., Schweckendiek, T., Stoop, J., Wilbrink, H. J. \& Zomer, W. (2008). Strength of peat dykes evaluated by remote sensing (Gebiedsdekkende dijksterkte bepaling met remote sensing): Pilot project: RSDYK2008, Program Flood Control 2015. Delft: Flood Control 2015. Available: http://www.itc.nl/library/papers_2008/scie /hack_strength_2008.pdf.

Hall, F. G., Huemmrich, K. F., Goetz, S. J., Sellers, P. J. \& Nickeson, J. E. (1992). Satellite remote sensing of surface energy balance: success, failures, and unresolved issues in FIFE. Journal of Geophysical Research-Atmospheres, 97 (D17), 19061-19089.

Hall, F. G., Strebel, D. E., Nickeson, J. E. \& Goetz, S. J. (1991). Radiometric rectification: Toward a common radiometric response among multidate, multisensor images. Remote Sensing of Environment, 35 (1), 11-27.

Hansen, P. M. \& Schjoerring, J. K. (2003). Reflectance measurement of canopy biomass and nitrogen status in wheat crops using normalized difference 
vegetation indices and partial least squares regression. Remote Sensing of Environment, 86 (4), 542-553.

Hanssen, R. F. \& van Leijen, F. J. (2008). Monitoring water defense structures using radar interferometry. In: IEEE Radar Conference 2008, 26-30 May 2008 Rome, Italy. IEEE, 1594-1597.

Hardisky, M. A., Klemas, V. \& Smart, R. M. (1983). The influence of soil salinity, growth form, and leaf moisture on the spectral radiance of Spartina alterniflora canopies. Photogrammetric Engineering \& Remote Sensing, 49 (1), 77-83.

Harper, R. F. (1904). The Code of Hammurabi King of Babylon about 2250 B.C., 2nd ed. Chigago: The University of Chigago Press.

Harris, A., Bryant, R. G. \& Baird, A. J. (2005). Detecting near-surface moisture stress in Sphagnum spp. Remote Sensing of Environment, 97 (3), 371381.

Haubrock, S. N., Chabrillat, S., Kuhnert, M., Hostert, P. \& Kaufmann, H. (2008). Surface soil moisture quantification and validation based on hyperspectral data and field measurements. Journal of Applied Remote Sensing, 2 (1), 023552 (26 pp.).

Henault, J.-M., Moreau, G., Blairon, S., Salin, J., Courivaud, J.-R., Taillade, F., Merliot, E., Dubois, J.-P., Bertrand, J., Buschaert, S., Mayer, S. \& Delepine-Lesoille, S. (2010). Truly distributed optical fiber sensors for structural health monitoring: From the telecommunication optical fiber drawling tower to water leakage detection in dikes and concrete structure strain monitoring. Advances in Civil Engineering, 2010, 930796 (13 pp.).

Hillen, M. M., Jonkman, S. N., Kanning, W., Kok, M., Geldenhuys, M. A. \& Stive, M. J. F. (2010). Coastal defence cost estimates: Case study of the Netherlands, New Orleans and Vietnam. Communications on Hydraulic and Geotechnical Engineering. 2010-01. Delft, the Netherlands: Delft University of Technology.

Hopkins, W. G. \& Hüner, N. P. A. (2009). Introduction to plant physiology, 4th ed. New York: Wiley \& Sons.

Horler, D. N. H., Dockray, M. \& Barber, J. (1983). The red edge of plant leaf reflectance. International Journal of Remote Sensing, 4 (2), 273-288.

Hossain, A. \& Easson, G. (2012). Predicting shallow surficial failures in the Mississippi River levee system using airborne hyperspectral imagery. Geomatics Natural Hazards \& Risk, 3 (1), 55-78.

Hossain, A., Easson, G. \& Hasan, K. (2006). Detection of levee slides using commercially available remotely sensed data. Environmental \& Engineering Geoscience, 12 (3), 235-246.

Houborg, R., Cescatti, A., Migliavacca, M. \& Kustas, W. P. (2013). Satellite retrievals of leaf chlorophyll and photosynthetic capacity for improved modeling of GPP. Agricultural and Forest Meteorology, 177, 10-23. 
Huang, Y. B., Fipps, G., Maas, S. J. \& Fletcher, R. S. (2010). Airborne remote sensing for detection of irrigation canal leakage. Irrigation and Drainage, 59 (5), 524-534.

Huete, A., Justice, C. \& Liu, H. (1994). Development of vegetation and soil indices for MODIS-EOS. Remote Sensing of Environment, 49 (3), 224 234.

Huete, A. R. (1988). A Soil-Adjusted Vegetation Index (SAVI). Remote Sensing of Environment, 25 (3), 295-309.

Huete, A. R., HuiQing, L. \& van Leeuwen, W. J. D. (1997). The use of vegetation indices in forested regions: issues of linearity and saturation. In: Stein, T. I., Ed. IEEE International Geoscience and Remote Sensing, 1997. IGARSS '97. Remote Sensing - A Scientific Vision for Sustainable Development, 3-8 August 1997 Singapore. New York, New York: IEEE, 1966-1968.

Hunt, E. R. \& Rock, B. N. (1989). Detection of changes in leaf water content using near- and middle-infrared reflectances. Remote Sensing of Environment, 30 (1), 43-54.

HyVista Corporation. (n.d.). HyMap [Online]. HyVista Corporation. Available: http://www.hyvista.com/?page_id=440 [Accessed 25 May 2013].

ITT Visual Information Solutions (2009). ENVI Atmospheric Correction Module Version 4.7. ITT Visual Information Solutions. Available: https://www.exelisvis.com/portals/0/pdfs/envi/Flaash_Module.pdf [Accessed 24 February 2014].

Jackson, R. D., Pinter, P. J., Reginato, R. J. \& Idso, S. B. (1986). Detection and evaluation of plant stresses for crop management decisions. IEEE Transactions on Geoscience and Remote Sensing, GE-24 (1), 99-106.

Jayalakshmy, M. S. \& Philip, J. (2010). Thermophysical properties of plant leaves and their influence on the environment temperature. International Journal of Thermophysics, 31 (11-12), 2295-2304.

Jensen, J. R. (2007). Remote sensing of the environment : an earth resource perspective, 2nd ed. Upper Saddle River, New Jersey: Prentice Hall.

Jiang, Z., Huete, A. R., Chen, J., Chen, Y., Li, J., Yan, G. \& Zhang, X. (2006). Analysis of NDVI and scaled difference vegetation index retrievals of vegetation fraction. Remote Sensing of Environment, 101 (3), 366-378.

Jimenez-Bello, M. A., Ballester, C., Castel, J. R. \& Intrigliolo, D. S. (2011). Development and validation of an automatic thermal imaging process for assessing plant water status. Agricultural Water Management, 98 (10), 1497-1504.

Jones, C., Bawden, G., Deverel, S., Dudas, J. \& Hensley, S. (2011). Characterizing land surface change and levee stability in the Sacramento-San Joaquin Delta using UAVSAR RADAR imagery. In: 2011 IEEE International Geoscience and Remote Sensing Symposium, Vancouver, Canada. IEEE, 1638-1641. 
Jones, C. E., Bawden, G., Deverel, S., Dudas, J., Hensley, S. \& Yun, S. H. (2012). Study of movement and seepage along levees using DINSAR and the airborne UAVSAR instrument. In: Notarnicola, C., Paloscia, S. \& Pierdicca, N. (Eds.) SAR Image Analysis, Modeling, and Techniques XII. SPIE. 85360E (8 pp.).

Jones, H. G., Serraj, R., Loveys, B. R., Xiong, L. Z., Wheaton, A. \& Price, A. H. (2009). Thermal infrared imaging of crop canopies for the remote diagnosis and quantification of plant responses to water stress in the field. Functional Plant Biology, 36 (10-11), 978-989.

Jordan, C. F. (1969). Derivation of leaf-area index from quality of light on the forest floor. Ecology, 50 (4), 663-666.

Ju, C. H., Tian, Y. C., Yao, X., Cao, W. X., Zhu, Y. \& Hannaway, D. (2010). Estimating leaf chlorophyll content using red edge parameters. Pedosphere, 20 (5), 633-644.

Kabat, P. \& Beekma., J. (1994). Water in the unsaturated zone. In: Ritzema, H. P. (Ed.) Drainage principles and applications. Rev. 2nd ed. Wageningen, The Netherlands: International Institute for Land Reclamation and Improvement (ILRI). 383-434.

Kandwal, R., Jeganathan, C., Tolpekin, V. \& Kushwaha, S. P. S. (2009). Discriminating the invasive species, 'Lantana' using vegetation indices. Journal of the Indian Society of Remote Sensing, 37 (2), 275-290.

Kanemasu, E. T. (1974). Seasonal canopy reflectance patterns of wheat, sorghum, and soybean. Remote Sensing of Environment, 3 (1), 43-47.

Kaufman, Y. J. \& Tanré, D. (1992). Atmospherically resistant vegetation index (ARVI) for EOS-MODIS. IEEE Transactions on Geoscience and Remote Sensing, 30 (2), 261-270.

Khan, A. A., Vrabie, V., d'Urso, G. \& Mars, J. I. (2008). SVD based automated dike monitoring system using DTS data. In: Industrial Electronics, 2008. IECON 2008. 34th Annual Conference of IEEE, 10-13 November 2008, 1931-1936.

Kim, M. S., Daughtry, C. S. T., Chappelle, E. W., McMurtrey III, J. E. \& Walthall, C. L. (1994). The use of high spectral resolution bands for estimating absorbed photosynthetically active radiation (APAR). In: Proceedings of the ISPRS 6th Symposium on Physical Measurements and Signatures in Remote Sensing, Val D'Isere, France. Toulouse, France: CNES, 299-306.

Kim, Y., Glenn, D. M., Park, J., Ngugi, H. K. \& Lehman, B. L. (2010). Hyperspectral image analysis for plant stress detection. In: American Society of Agricultural and Biological Engineers Annual International Meeting 2010, 20-23 June 2010 Pittsburgh, Pennsylvania. American Society of Agricultural \& Biological Engineers, 3512-3524.

KNMI. (2011). Klimatologie Uurgegevens van het weer in Nederland Download [Climatology Hourly data of weather in the Netherlands Download] [Online]. KNMI - Koninklijk Nederlands Meteorologisch 
Instituut (The Royal Netherlands Meteorological Institute). Available: http://www.knmi.nl/klimatologie/uurgegevens/ [Accessed 19 October 2011]. (In Dutch).

KNMI. (2013). Klimatologie Uurgegevens van het weer in Nederland Download [Climatology Hourly data of weather in the Netherlands Download] [Online]. KNMI - Koninklijk Nederlands Meteorologisch Instituut (The Royal Netherlands Meteorological Institute). Available: http://www.knmi.nl/klimatologie/uurgegevens/ [Accessed 30 November 2013]. (In Dutch).

KNMI. (n.d.). Langjarige gemiddelden en extremen, tijdvak 1971 - 2000, landelijk 15 stations [Long-term averages and extremes, period 1971 2000, nationwide 15 stations] [Online]. KNMI - Koninklijk Nederlands Meteorologisch Instituut (The Royal Netherlands Meteorological Institute). Available: http://www.knmi.n1/klimatologie/normalen19712000/per_station/LH15/4-normalen/LH15_landelijk15stns.pdf [Accessed 26 June 2014]. (In Dutch).

Knoeff, J. G., Vastenburg, E. W. \& Tromp, E. (2008). Rational risk assessment of dikes by using a stochastic subsurface model. In: Simonovic, S. P., Bourget, P. G. \& Blanchard, S. F., Eds. 4th International Symposium on Flood Defence: Managing Flood Risk, Reliability and Vulnerability, 68 May 2008 Toronto, Canada. Toronto, Canada: Institute for Catastrophic Loss Reduction.

Knol, E. (1991). [cited in Nienhuis, 2008] Het Noord-Nederlandse kustgebied: kwelders en terpen. [The northern-Dutch coastal area: salt marshes and mounds]. In: Bloemers, J. H. F. \& van Dorp, T. (Eds.) Pre- en protohistorie van de lage landen [Pre- and protohistory of the low countries]. Houten: De Haan/Unieboek/Open Universiteit. 395-406. (In Dutch).

Kottek, M., Grieser, J., Beck, C., Rudolf, B. \& Rubel, F. (2006). World Map of the Köppen-Geiger climate classification updated. Meteorologische Zeitschrif, 15 (3), 259-263.

Kross, A., McNairn, H., Lapen, D., Sunohara, M. \& Champagne, C. (2015). Assessment of RapidEye vegetation indices for estimation of leaf area index and biomass in corn and soybean crops. International Journal of Applied Earth Observation and Geoinformation, 34, 235-248.

Kühn, F. \& Brose, F. (1998). Die Auswertung von Fernerkundungsdaten zur Deichzustandseinschätzung [The analysis of remote sensing data for dike condition assessment]. Brandenburgische Geowissenschaftliche Beiträge, Kleinmachnow, Germany: Landesamt für Bergbau, Geologie und Rohstoffe Brandenburg. 5, (1), 59-63. (In German).

Lee, K.-S., Kook, M.-J., Shin, J.-I., Kim, S.-H. \& Kim, T.-G. (2007). Spectral characteristics of forest vegetation in moderate drought condition observed by laboratory measurements and spaceborne hyperspectral 
data. Photogrammetric Engineering \& Remote Sensing, 73 (10), 11211127.

Lee, M. A., Aanstoos, J. V., Bruce, L. M. \& Prasad, S. (2012). Application of omni-directional texture analysis to SAR images for levee landslide detection. In: IGARSS 2012 IEEE International Geoscience and Remote Sensing Symposium, New York. IEEE, 1805-1808.

Legendre, P. (2000). Modified t-test modttest-5000 program. Software available online at http://www.bio.umontreal.ca/casgrain/en/labo/mod_t_test.html [Accessed 24 September 2012].

Legendre, P. \& Legendre, L. (1998). Numerical ecology, 2nd ed. Amsterdam: Elsevier Science.

Lichtenthaler, H. K. (1996). Vegetation stress: an introduction to the stress concept in plants. Journal of Plant Physiology, 148 (1-2), 4-14.

Lichtenthaler, H. K., Gitelson, A. \& Lang, M. (1996). Non-destructive determination of chlorophyll content of leaves of a green and an aurea mutant of tobacco by reflectance measurements. Journal of Plant Physiology, 148 (3-4), 483-493.

Lillesand, T. M., Kiefer, R. W. \& Chipman, J. W. (2008). Remote sensing and image interpretation, 6th ed. New York: Wiley \& Sons.

Lorenzo, J. M., Hicks, J. \& Vera, E. E. (2014). Integrated seismic and cone penetration test observations at a distressed earthen levee: Marrero, Louisiana, U.S.A. Engineering Geology, 168, 59-68.

Lv, X., Yazici, B., Bennett, V., Zeghal, M. \& Abdoun, T. (2013). Joint pixels InSAR for health assessment of levees in New Orleans. In: Meehan, C., Pradel, D., Pando, M. A. \& Labuz, J. F., Eds. Geo-Congress 2013: Stability and Performance of Slopes and Embankments III, 3-7 March 2013 San Diego, California, United States. American Society of Civil Engineers (ASCE), 279-288.

Mahrooghy, M., Aanstoos, J., Hasan, K., Prasad, S. \& Younan, N. H. (2011). Effect of vegetation height and volume scattering on soil moisture classification using synthetic aperture radar (SAR) images. In: Applied Imagery Pattern Recognition Workshop (AIPR), 2011 IEEE, 11-13 October 2011, 5 pp.

Margueron, J.-C. (2003). Mari and the Syro-Mesopotamian World. In: Aruz, J. \& Wallenfels, R. (Eds.) Art of the First Cities. New York: The Metropolitan Museum of Art. 135-138.

Mayer, R. (2012). Urban Levee Design Criteria. May 2012. Sacramento, CA, USA: Department of Water Resources, The California Natural Resources Agency, State of California.

McFeeters, S. K. (1996). The use of the normalized difference water index (NDWI) in the delineation of open water features. International Journal of Remote Sensing, 17 (7), 1425-1432. 
McGranahan, G., Balk, D. \& Anderson, B. (2007). The rising tide: assessing the risks of climate change and human settlements in low elevation coastal zones. Environment and Urbanization, 19 (1), 17-37.

McInerney, G. P., O'Kelly, B. C. \& M., J. P. (2007). Geotechnical stability of peat dams and embankments. In: Soft Ground Engineering Seminar, 15-16 February 2007 Portlaoise, Ireland. Engineers Ireland, 2.6 (5 pp.).

Medrano, H., Escalona, J. M., Cifre, J., Bota, J. \& Flexas, J. (2003). A ten-year study on the physiology of two Spanish grapevine cultivars under field conditions: effects of water availability from leaf photosynthesis to grape yield and quality. Functional Plant Biology, 30 (6), 607-619.

Melnikova, N. B., Krzhizhanovskaya, V. V. \& Sloot, P. M. A. (2013). Modeling earthen dikes using real-time sensor data. Journal of Hydrology, 496, 154-165.

Mériaux, P. \& Royet, P. M. P. (2007). Surveillance, Maintenance and Diagnosis of Flood Protection Dikes. Versailles: Editions Quae.

Merzlyak, M. N., Gitelson, A. A., Chivkunova, O. B. \& Rakitin, V. Y. (1999). Non-destructive optical detection of pigment changes during leaf senescence and fruit ripening. Physiologia Plantarum, 106 (1), 135141.

Metternicht, G. (2003). Vegetation indices derived from high-resolution airborne videography for precision crop management. International Journal of Remote Sensing, 24 (14), 2855-2877.

Milesi, C., Running, S. W., Elvidge, C. D., Dietz, J. B., Tuttle, B. T. \& Nemani, R. R. (2005). Mapping and modeling the biogeochemical cycling of turf grasses in the United States. Environmental Management, 36 (3), 426438.

Miura, T., Turner, J. P. \& Huete, A. R. (2013). Spectral compatibility of the NDVI across VIIRS, MODIS, and AVHRR: An analysis of atmospheric effects using EO-1 Hyperion. IEEE Transactions on Geoscience and Remote Sensing, 51 (3), 1349-1359.

Moller, M., Alchanatis, V., Cohen, Y., Meron, M., Tsipris, J., Naor, A., Ostrovsky, V., Sprintsin, M. \& Cohen, S. (2007). Use of thermal and visible imagery for estimating crop water status of irrigated grapevine. Journal of Experimental Botany, 58 (4), 827-838.

Mooney, M., Parekh, M., Lowry, B., Rittgers, J., Grasmick, J., Koelewijn, A., Revil, A. \& Zhou, W. (2014). Design and implementation of geophysical monitoring and remote sensing during a full-scale embankment internal erosion test. In: Abu-Farsakh, M., Yu, X. \& Hoyos, L., Eds. Geo-Congress 2014 Technical Papers, 23-26 February 2014 Atlanta, Georgia, USA. American Society of Civil Engineers (ASCE), 202-211.

Moreno, J. \& Melia, J. (1992). About the problem of scaling from ground measurements to low resolution satellite data. In: Geoscience and 
Remote Sensing Symposium, 1992. IGARSS '92. International, 26-29 May 1992 Houston, TX, USA. 1640-1642.

Moria, L. (2008). Fish Friendly Pumping Stations: Principles, Practices \& Outcomes in Dutch Water Management., 2008-W-04. Utrecht: STOWA

Moser, G. M., Kok, J. W. \& Thijs, F. J. J. (2008a). Basisinformatie dijken [Dikes general information]. Utrecht, The Netherlands: STOWA. (In Dutch).

Moser, G. M., Kok, J. W. \& Thijs, F. J. J. (2008b). Handreiking Inspectie Waterkeringen - Strategisch, tactisch deel [Water Barrier Inspection Guide - Strategic, tactical section]. Utecht, The Netherlands: STOWA. (In Dutch).

Moser, G. M. \& Zomer, W. S. (2006). Inspectie van Waterkeringen, een Overzicht van Meettechnieken [Inspection of water barriers, an overview of measurement techniques]. 90.5773.319.6. Utrecht, The Netherlands: STOWA. (In Dutch).

Muijs, J. A. (1999). Grasmat als dijkbekleding [Grass turf as dike cover]. TR13. Delft, The Netherlands: TAW (Technische Adviescommissie voor de Waterkeringen). (In Dutch).

Mukhlisin, M., Baidillah, M. R., R., T. M. \& El-Shafie, A. (2011). Effect of soil water retention model on slope stability analysis. International Journal of Physical Sciences, 6 (19), 4629-4635.

Nagler, P. L., Inoue, Y., Glenn, E. P., Russ, A. L. \& Daughtry, C. S. T. (2003). Cellulose absorption index (CAI) to quantify mixed soil-plant litter scenes. Remote Sensing of Environment, 87 (2-3), 310-325.

Naruse, H. (2001). Applications of distributed fiber strain sensing for smart structures. In: Lasers and Electro-Optics, 2001. CLEO/Pacific Rim 2001. The 4th Pacific Rim Conference on, 15-19 July 2001 Chiba, Japan. IEEE, I488-I489.

Nash, J. E. \& Sutcliffe, J. V. (1970). River flow forecasting through conceptual models part I - A discussion of principles. Journal of Hydrology, 10 (3), 282-290.

Nellis, M. D. (1982). Application of thermal infrared imagery to canal leakage detection. Remote Sensing of Environment, 12 (3), 229-234.

Ng, G. \& Oswalt, K. (2010). Levee Monitoring System. Better management through better information. CEE 180: Engineering Systems [Online]. Available: http://www.alertsolutions.nl/publicationdocs/pdf_article berkeley_oswalt.pdf or http://www.floodcontrol2015.com/xmlpages /tan/files?p_file_id=13668 [Accessed 23 January 2015].

Niederleithinger, E., Weller, A. \& Lewis, R. (2012). Evaluation of geophysical techniques for dike inspection. Journal of Environmental and Engineering Geophysics, 17 (4), 185-195.

Nienhuis, P. H. (2008). Environmental History of the Rhine-Meuse Delta. Netherlands: Springer. 
Nijland, W., van der Meijde, M., Addink, E. A. \& de Jong, S. M. (2010). Detection of soil moisture and vegetation water abstraction in a Mediterranean natural area using electrical resistivity tomography. Catena, 81 (3), 209-216.

Oude Essink, G. H. P., de Louw, P. G. B. \& van Vliet, L. (2012). Brakke kwel [Brakish seepage]. Deltafact. Amersfoort: Stichting Toegepast Onderzoek Waterbeheer (STOWA). Available: http://deltaproof .stowa.nl/pdf/Brakke_kwel?rId=21 [Accessed 7 February 2013]. (In Dutch).

Palacky, G. V. (1988). Resistivity characteristics of geologic targets. In: Nabighian, M. N. (Ed.) Electromagnetic Methods in Applied Geophysics. Society of Exploration Geophysicists. 52-129.

Pandya, M. R., Singh, R. P., Chaudhari, K. N., Murali, K. R., Kirankumar, A. S., Dadhwal, V. K. \& Parihar, J. S. (2007). Spectral characteristics of sensors onboard IRS-1D and P6 satellites: Estimation and their influence on surface reflectance and NDVI. Photonirvachak-Journal of the Indian Society of Remote Sensing, 35 (4), 333-350.

Pearson, R. L. \& Miller, L. D. (1973). Remote mapping of standing crop biomass for estimation of the productivity of the shortgrass prairie, Pawnee National Grasslands, Colorado. In: Proceedings for the Eighth International Symposium on Remote Sensing of Environment (ERIM International), 2-6 October 1972 Ann Arbor, Maryland. 1357-1381.

Pengel, B. E., Krzhizhanovskaya, V. V., Melnikova, N. B., Shirshov, G. S., Koelewijn, A. R., Pyayt, A. L. \& Mokhov, I. I. (2013). Flood early warning system: sensors and internet. In: Chavoshian, A. \& Takeuchi, K. (Eds.) Floods: From Risk to Opportunity. Wallingford, England: International Association of Hydrological Sciences. 445-453.

Peñuelas, J., Baret, F. \& Filella, I. (1995a). Semi-empirical indices to assess carotenoids/chlorophyll a ratio from leaf spectral reflectance. Photosynthetica, 31 (2), 221-230.

Peñuelas, J., Filella, I., Biel, C., Serrano, L. \& Savé, R. (1993). The reflectance at the 950-970 $\mathrm{nm}$ region as an indicator of plant water status. International Journal of Remote Sensing, 14 (10), 1887-1905.

Peñuelas, J., Filella, I., Lloret, P., Muñoz, F. \& Vilajeliu, M. (1995b). Reflectance assessment of mite effects on apple trees. International Journal of Remote Sensing, 16 (14), 2727-2733.

Peñuelas, J., Gamon, J. A., Fredeen, A. L., Merino, J. \& Field, C. B. (1994). Reflectance indices associated with physiological changes in nitrogenand water-limited sunflower leaves. Remote Sensing of Environment, 48 (2), 135-146.

Perri, M. T., Boaga, J., Bersan, S., Cassiani, G., Cola, S., Deiana, R., Simonini, P. \& Patti, S. (2014). River embankment characterization: The joint use of geophysical and geotechnical techniques. Journal of Applied Geophysics, 110, 5-22. 
Pickerill, J. M. \& Malthus, T. J. (1998). Leak detection from rural aqueducts using airborne remote sensing techniques. International Journal of Remote Sensing, 19 (12), 2427-2433.

Pinty, B. \& Verstraete, M. M. (1992). GEMI: a non-linear index to monitor global vegetation from satellites. Vegetatio, 101 (1), 15-20.

Post, V. E. A. (2004). De oorsprong van het brakke en zoute grondwater in het Nederlandse kustgebied [The origin of the brackish and saline groundwater in the Dutch coastal area]. Stromingen, 10 (2), 51-61. (In Dutch).

Potts, D. R., Mackin, S., Muller, J. P. \& Fox, N. (2013). Sensor intercalibration over Dome $\mathrm{C}$ for the ESA GlobAlbedo project. IEEE Transactions on Geoscience and Remote Sensing, 51 (3), 1139-1146.

Price, D. G., de Freitas, M. H., Hack, H. R. G. K., Higginbottom, I. E., Knill, J. L. \& Maurenbrecher, M. (2009). Engineering geology : principles and practice. Berlin: Springer.

Pyayt, A., Kozionov, A., Mokhov, I., Lang, B., Meijer, R., Krzhizhanovskaya, V. \& Sloot, P. (2014). Time-frequency methods for structural health monitoring. Sensors, 14 (3), 5147-5173.

Qi, J., Chehbouni, A., Huete, A. R., Kerr, Y. H. \& Sorooshian, S. (1994). A Modified Soil Adjusted Vegetation Index. Remote Sensing of Environment, 48 (2), 119-126.

Querner, E. P., Jansen, P. C. \& Kwakernaak, C. (2008). Effects of water level strategies in Dutch peatlands: a scenario study for the polder Zegveld. In: Farrell, C. \& Feehan, J., Eds. Proceedings of the 13th International Peat Congress: After Wise Use - The future of Peatlands, 8 - 13 June 2008 Tullamore, Ireland. 620-623

Radzicki, K. (2014). The important issues of levees monitoring with special attention to thermal-monitoring method application. In: South Baltic Conference on New Technologies and Recent Developments in Flood Protection, 5-6 June 2014 Gdańsk, Poland. 10 pp.

Ramoelo, A., Skidmore, A. K., Cho, M. A., Schlerf, M., Mathieu, R. \& Heitkönig, I. M. A. (2012). Regional estimation of savanna grass nitrogen using the red-edge band of the spaceborne RapidEye sensor. International Journal of Applied Earth Observation and Geoinformation, 19, 151-162.

RapidEye. (n.d.). RapidEye Products [Online]. Available: http://www.rapideye .com/products/index.htm [Accessed 25 May 2013].

Richardson, A. J. \& Everitt, J. H. (1992). Using spectral vegetation indices to estimate rangeland productivity. Geocarto International, 7 (1), 63-69.

Rittgers, J. B., Revil, A., Planes, T., Mooney, M. A. \& Koelewijn, A. R. (2015). 4-D imaging of seepage in earthen embankments with time-lapse inversion of self-potential data constrained by acoustic emissions localization. Geophysical Journal International, 200 (2), 756-770. 
Rock, B. N., Vogelmann, J. E., Williams, D. L., Vogelmann, A. F. \& Hoshizaki, T. (1986). Remote detection of forest damage. BioScience, 36 (7), 439 445.

Rodríguez-Pérez, J. R., Riaño, D., Carlisle, E., Ustin, S. L. \& Smart, D. R. (2007). Evaluation of hyperspectral reflectance indexes to detect grapevine water status in vineyards. American Journal of Enology and Viticulture, 58 (3), 302-317.

Rondeaux, G., Steven, M. \& Baret, F. (1996). Optimization of soil-adjusted vegetation indices. Remote Sensing of Environment, 55 (2), 95-107.

Rooney, N. (2012). Least Squares and their Applications. Delhi, India: Library Press.

Rosenberg, M. S. \& Anderson, C. D. (2011). PASSaGE: Pattern Analysis, Spatial Statistics and Geographic Exegesis. Version 2. Methods in Ecology and Evolution, 2 (3), 229-232.

Rosenthal, J. A. (1996). [cited in Ellis, 2009] Qualitative descriptors of strength of association and effect size. Journal of Social Service Research, 21 (4), 37-59.

Roujean, J. L. \& Breon, F. M. (1995). Estimating PAR absorbed by vegetation from bidirectional reflectance measurements. Remote Sensing of Environment, 51 (3), 375-384.

Rouse, J., J. W., Haas, R. H., Deering, D. W., Schell, J. A. \& Harlan, J. C. (1974). Monitoring the vernal advancement and retrogradation (Green wave effect) of natural vegetation. RSC 1978-4. College Station, Texas: Remote Sensing Center, Texas A\&M University.

Rouse, J., J. W., Haas, R. H., Schell, J. A. \& Deering, D. W. (1973). Monitoring vegetation systems in the Great Plains with ERTS. In: Freden, S. C., Mercanti, E. P. \& Becker, M. A., Eds. Third Earth Resources Technology Satellite-1 Symposium. Volume I: Technical Presentations. Section A, 10-14 December 1973 Washington, D.C.: Goddard Space Flight Center, NASA, 309-317.

Royet, P., Palma-Lopes, S., Fauchard, C., Mériaux, P. \& Auriau, L. (2013). Rapid and cost-effective dike condition assessment methods: geophysics and remote sensing. WP3-01-12-20. FloodProBE project. Available: http://www.floodprobe.eu/partner/assets/documents/Floodprobe-D3.2 _V1_4_April_2013.pdf [Accessed 8 July 2014].

Schelfhout, H. (2011). Understanding dike safety. In: Van, M., den Haan, E. \& van Deen, J. (Eds.) A feeling for soil and water. Delft, The Netherlands: Stichting Deltares.

Schlotzhauer, S. M. \& Price, J. S. (1999). Soil water flow dynamics in a managed cutover peat field, Quebec: Field and laboratory investigations. Water Resources Research, 35 (12), 3675-3683.

Schott, J. R., Salvaggio, C. \& Volchok, W. J. (1988). Radiometric scene normalization using pseudoinvariant features. Remote Sensing of Environment, 26 (1), 1-16. 
Schroeder, T. A., Cohen, W. B., Song, C. H., Canty, M. J. \& Yang, Z. Q. (2006). Radiometric correction of multi-temporal Landsat data for characterization of early successional forest patterns in western Oregon. Remote Sensing of Environment, 103 (1), 16-26.

Schuetze, T. (2008). Climate adaptive urban design with water in Dutch polders. In: Proceedings IWA World Water Conference: Rainwater Harvesting Task Force, "Rainwater Harvesting and Management", 7 11 September 2008 Vienna, Austria.

Sehat, S., Vahedifard, F., Aanstoos, J. V., Dabbiru, L. \& Hasan, K. (2014a). Using in situ soil measurements for analysis of a polarimetric SARbased classification of levee slump slides in the Lower Mississippi River. Engineering Geology, 181, 157-168.

Sehat, S., Vahedifard, F., Aanstoos, J. V., Dabbiru, L., Hasan, K. \& Mooney, M. A. (2014b). Analysis of the output from a radar-based levee monitoring system using in-situ soil data. In: Abu-Farsakh, M. \& Hoyos, L. R., Eds. Geo-Congress 2014, 23-26 February 2014 Atlanta, Georgia, USA. Reston, Virgina, USA: American Society of Civil Engineers (ASCE), 943-952.

Sepulcre-Canto, G., Zarco-Tejada, P. J., Jimenez-Munoz, J. C., Sobrino, J. A., de Miguel, E. \& Villalobos, F. J. (2006). Detection of water stress in an olive orchard with thermal remote sensing imagery. Agricultural and Forest Meteorology, 136 (1-2), 31-44.

Serrano, L., Peñuelas, J. \& Ustin, S. L. (2002). Remote sensing of nitrogen and lignin in Mediterranean vegetation from AVIRIS data: Decomposing biochemical from structural signals. Remote Sensing of Environment, 81 (2-3), 355-364.

Shutko, A. M., Golovachev, S. P., Novichikhin, E. P., Haldin, A. A., Krapivin, V. F., Sidorov, I. A., Coleman, T. L., Dachev, T., Haarbrink, R., Krissilov, A. D., Archer, F. \& Tadesse, W. (2006). Teaching and conducting scientific research: An experience in joint USA-RussiaBulgaria-Holland-Ukraine international collaboration between the universities and academic institutions in GIS and microwave and optical remote sensing from spacecraft, piloting and unmanned aircraft platforms and rovers. In: 2006 IEEE MicroRad, New York. IEEE, 8286.

Siegel, S. \& Castellan, N. J. (1988). Nonparametric statistics for the behavioral sciences, 2nd ed. New York etc.: McGraw-Hill.

Sims, D. A. \& Gamon, J. A. (2002). Relationships between leaf pigment content and spectral reflectance across a wide range of species, leaf structures and developmental stages. Remote Sensing of Environment, 81 (2-3), 337-354.

Skidmore, A. K., Ferwerda, J. G., Mutanga, O., van Wieren, S. E., Peel, M., Grant, R. C., Prins, H. H. T., Balcik, F. B. \& Venus, V. (2010). Forage quality of savannas - Simultaneously mapping foliar protein and 
polyphenols for trees and grass using hyperspectral imagery. Remote Sensing of Environment, 114 (1), 64-72.

Smith, K. L., Steven, M. D. \& Colls, J. J. (2004). Spectral responses of potgrown plants to displacement of soil oxygen. International Journal of Remote Sensing, 25 (20), 4395-4410.

Smith, R. C. G., Adams, J., Stephens, D. J. \& Hick, P. T. (1995). Forecasting wheat yield in a Mediterranean-type environment from the NOAA satellite. Australian Journal of Agricultural Research, 46 (1), 113-125.

Snyder, W. C., Wan, Z., Zhang, Y. \& Feng, Y. Z. (1998). Classification-based emissivity for land surface temperature measurement from space. International Journal of Remote Sensing, 19 (14), 2753-2774.

Soudani, K., Francois, C., le Maire, G., Le Dantec, V. \& Dufrene, E. (2006). Comparative analysis of IKONOS, SPOT, and ETM+ data for leaf area index estimation in temperate coniferous and deciduous forest stands. Remote Sensing of Environment, 102 (1-2), 161-175.

Spigulis, J., Jakovels, D. \& Rubins, U. (2010). Multi-spectral skin imaging by a consumer photo-camera. In: Azar, F. S. \& Intes, X., Eds. Multimodal Biomedical Imaging V, Proceedings of SPIE Vol. 7557, 23-25 January 2010 San Francisco, California, USA. Bellingham, WA: SPIE, 75570M (9 pp.).

Steven, M. D., Malthus, T. J., Baret, F., Xu, H. \& Chopping, M. J. (2003). Intercalibration of vegetation indices from different sensor systems. Remote Sensing of Environment, 88 (4), 412-422.

Strachan, I. B., Pattey, E. \& Boisvert, J. B. (2002). Impact of nitrogen and environmental conditions on corn as detected by hyperspectral reflectance. Remote Sensing of Environment, 80 (2), 213-224.

$\mathrm{Su}$, H. \& Kang, Y. (2013). Design of system for monitoring seepage of levee engineering based on distributed optical fiber sensing technology. International Journal of Distributed Sensor Networks, 2013, 10 pp.

Swart, L. M. Th. (2007). Remote sensing voor inspectie van waterkeringen [Remote sensing for inspection of flood defences]. Nieuw-Vennep, The Netherlands: Swartvast. (In Dutch).

Taghvaeian, S., Chávez, J., Hattendorf, M. \& Crookston, M. (2013). Optical and thermal remote sensing of turfgrass quality, water stress, and water use under different soil and irrigation treatments. Remote Sensing, 5 (5), 2327-2347.

Teillet, P. M., Fedosejevs, G., Thome, K. J. \& Barker, J. L. (2007). Impacts of spectral band difference effects on radiometric cross-calibration between satellite sensors in the solar-reflective spectral domain. Remote Sensing of Environment, 110 (3), 393-409.

Teillet, P. M. \& Ren, X. M. (2008). Spectral band difference effects on vegetation indices derived from multiple satellite sensor data. Canadian Journal of Remote Sensing, 34 (3), 159-173. 
Teillet, P. M., Staenz, K. \& Williams, D. J. (1997). Effects of spectral, spatial, and radiometric characteristics on remote sensing vegetation indices of forested regions. Remote Sensing of Environment, 61 (1), 139-149.

ten Cate, J. A. M. (1982). The river and coastal plains of the Netherlands. In: ten Cate, J. A. M. (Ed.) Report of the working group from September 13, 1981 till May 31, 1982 - IGU working Group on Geomorphology of River and Coastal Plains. Wageningen, The Netherlands. 4-11.

TetraCam Inc. (n.d.). Mini-MCA: Tetracam's Miniature Multiple Camera Array [Online]. TetraCam Inc. Available: http://www.tetracam.com/ProductsMini_MCA.htm [Accessed 25 May 2013].

Thenkabail, P. S., Lyon, J. G. \& Huete, A. (Eds.) (2012). Hyperspectral remote sensing of vegetation. Boca Raton, FL: CRC Press.

Thenkabail, P. S., Smith, R. B. \& De Pauw, E. (2002). Evaluation of narrowband and broadband vegetation indices for determining optimal hyperspectral wavebands for agricultural crop characterization. Photogrammetric Engineering and Remote Sensing, 68 (6), 607-621.

Thiele, E., Helbig, R., Erth, H., Krebber, K., Nöther, N. \& Wosniok, A. (2008). Dike monitoring. In: 4th International Symposium on Flood Defence: Managing Flood Risk, Reliability and Vulnerability, 6-8 May 2008 Toronto, Ontario, Canada. Institute for Catastrophic Loss Reduction, 19 (7 pp.).

TNO (2006). Waterberging in Middelburg-Tempelpolder: Oplossing of overlast? [Water storage in Middelburg-Tempel polder: solution or problem?]. TNO Kennis voor zaken: Waterbeheer en ruimtelijke inrichting. Utrecht: TNO Bouw en Ondergrond, Geological Survey of the Netherlands. (In Dutch).

Trishchenko, A. P. (2009). Effects of spectral response function on surface reflectance and NDVI measured with moderate resolution satellite sensors: Extension to AVHRR NOAA-17,18 and METOP-A. Remote Sensing of Environment, 113 (2), 335-341.

Trishchenko, A. P., Cihlar, J. \& Li, Z. Q. (2002a). Effects of spectral response function on surface reflectance and NDVI measured with moderate resolution satellite sensors. Remote Sensing of Environment, 81 (1), 118.

Trishchenko, A. P., Cihlar, J., Li, Z. Q. \& Hwang, B. (2002b). Long-term monitoring of surface reflectance, NDVI and clouds from space: What contribution we can expect due to effect of instrument spectral response variations? In: Shaw, J. A. (Ed.) Atmospheric Radiation Measurements and Applications in Climate. Bellingham: SPIE-Int Soc Optical Engineering. 108-119.

USACE (2006). Levee Owner's Manual for Non-Federal Flood Control Works. Washington DC, USA: US Army Corps of Engineers. Available: http://www.nfrmp.us/docs/USACE_NonFed Levee Owner's Manual _Mar06.pdf [Accessed 4 June 2014]. 
USACE (2008). USACE Levee Inspection Checklist. Available: http://www.usace.army.mil/Portals/2/docs/civilworks/levee/Levee InspectionChecklist.pdf [Accessed 4 June 2014].

van Baars, S. (2004). Peat dike failure in the Netherlands. E-WAter [Online], 2004/03. Available: http://www.ewaonline.de/portale/ewa/ewa.nsf /home?readform\&objectid=0AB6528C5177A8B7C12572B1004EF1C7 \&editor $=$ no\&\&submenu $=$ _1_6_2\&\&treeid $=$ _1_6_2\& [Accessed 18 May 2010].

van Baars, S. (2005). The horizontal failure mechanism of the Wilnis peat dyke. Geotechnique, 55 (4), 319-323.

van Baars, S. \& van Kempen, I. M. (2009). The causes and mechanisms of historical dike failures in the Netherlands. E-WAter [Online], 2009/06. Available: http://www.dwa.de/portale/ewa/ewa.nsf/home?readform \&submenu=_1_6_2\&objectid=0AB6528C5177A8B7C12572B1004 EF1C7 [Accessed 18 May 2010].

van der Meer, F., Bakker, W., Scholte, K., Skidmore, A., De Jong, S. M., Clevers, J., Addink, E. \& Epema, G. (2001). Spatial scale variations in vegetation indices and above-ground biomass estimates: implications for MERIS. International Journal of Remote Sensing, 22 (17), 33813396.

van der Meer, F. D., van der Meijde, M., Kooistra, J. F., van der Werff, H. M. A. \& Noomen, M. F. (2006). Detection of hazardous gas leakage from pipelines using anomalous spectral reflectance features of vegetation. In: Marçal, A., Ed. Global developments in environmental earth observation from space: proceedings of the 25th symposium of the European Association of Remote Sensing Laboratories (EARSeL), 6-11 June, 2005 Porto, Portugal. Rotterdam: Millpress, 191-198.

van der Schrier, J. S., Slob, S., Straeter, J., Hack, H. R. G. K. \& Rupke, J. (2004). Slim kijken naar dijken: patroon en anomalie herkenning door combinatie van verschillende air-borne remote sensing technieken [Looking intelligently at dikes: pattern and anomaly detection by combining various air-borne remote sensing techniques]. Presented at Kennisdag Waterkeringsbeheer en Remote Sensing - STOWA, Lelystad, The Netherlands, 9 March 2004. Available: http://intranet.itc.nl/papers/2004/pres/hack_sli.pdf [Accessed 12 December 2010]. (In Dutch).

van Geel, B., Hallewas, D. P. \& Pals, J. P. (1983). A late holocene deposit under the Westfriese Zeedijk near Enkhuizen (Prov. of Noord-Holland, the Netherlands): Palaeoecological and archaeological aspects. Review of Palaeobotany and Palynology, 38, 269-335.

van Hemert, H. (Ed.) (2004). Inspectietechnieken voor droge veenkaden [Inspection techniques for dry peat embankments]. Utrecht, The Netherlands: STOWA. (In Dutch). 
van Leeuwen, W. A., Slob, E. C. \& de Vries, G. (2007). Peat dike stability monitoring with a semi-permanent electrical resistivity set-up. In: 13th European Meeting of Environmental and Engineering Geophysics, 3-5 September 2007 Istanbul, Turkey. B24, 1-5.

van Leeuwen, W. J. D. \& Huete, A. R. (1996). Effects of standing litter on the biophysical interpretation of plant canopies with spectral indices. Remote Sensing of Environment, 55 (2), 123-138.

van Leeuwen, W. J. D., Orr, B. J., Marsh, S. E. \& Herrmann, S. M. (2006). Multi-sensor NDVI data continuity: Uncertainties and implications for vegetation monitoring applications. Remote Sensing of Environment, $100(1), 67-81$.

van Westen, C. J. (2005). Flood Risks and Safety in the Netherlands (Floris): Floris study - Full report. DWW-2006-014; ISBN 90-369-5604-9. The Hague, The Netherlands: Ministerie van Verkeer en Waterstaat.

Verheij, H. J., Kruse, G. A. M., Niemeijer, J. H., Sprangers, J. T. C. M., De Smidt, J. T. \& Wondergem, P. J. M. (1997). Erosion Resistance of Grassland as Dike Covering. Delft, The Netherlands: TAW (Technical Advisory Committee for Flood Defence in The Netherlands).

Verrelst, J., Schaepman, M. E., Koetz, B. \& Kneubuhler, M. (2008). Angular sensitivity analysis of vegetation indices derived from CHRIS/PROBA data. Remote Sensing of Environment, 112 (5), 2341-2353.

Vicente-Serrano, S. M., Pérez-Cabello, F. \& Lasanta, T. (2008). Assessment of radiometric correction techniques in analyzing vegetation variability and change using time series of Landsat images. Remote Sensing of Environment, 112 (10), 3916-3934.

Viganotti, M., Jackson, R., Krahn, H. \& Dyer, M. (2013). Geometric and frequency EMI sounding of estuarine earthen flood defence embankments in Ireland using 1D inversion models. Journal of Applied Geophysics, 92, 110-120.

Viollet, P.-L. (2007). Water Engineering in Ancient Civilizations: 5000 Years of History. Boca Raton, Florida, USA: CRC Press.

Vogelmann, J. E., Rock, B. N. \& Moss, D. M. (1993). Red edge spectral measurements from sugar maple leaves. International Journal of Remote Sensing, 14 (8), 1563-1575.

Waltham, A. C. (2009). Foundations of engineering geology, 3rd ed. London: Spon.

Wang, L. \& Qu, J. J. (2007). NMDI: A normalized multi-band drought index for monitoring soil and vegetation moisture with satellite remote sensing. Geophysical Research Letters, 34 (20), L20405 (5 pp.).

Waser, L. T., Kuchler, M., Jutte, K. \& Stampfer, T. (2014). Evaluating the potential of WorldView-2 data to classify tree species and different levels of ash mortality. Remote Sensing, 6 (5), 4515-4545. 
Weber, K. T., Chen, F., Booth, D. T., Raza, M., Serr, K. \& Gokhale, B. (2013). Comparing two ground-cover measurement methodologies for semiarid rangelands. Rangeland Ecology \& Management, 66 (1), 82-87.

Weijers, J., Elbersen, G. T., Koelewijn, A. R. \& Pals, N., (Eds.) (2009). Macrostabiliteit IJkdijk: Sensor-en meettechnologie [Macro-stability IJkdijk: Sensor- and measurement technology]. 978.90.5773.432.8; VIW: 2009-19. Rijkswaterstaat. Available: http://www.stowa.nl/Upload /publicaties/RWS\%20IJKDIJK\%20EINDRAPPORT\%20deel\%201\%20 (p.\%201-104).pdf [Accessed 14 September 2015]. (In Dutch).

Weller, A., Lewis, R., Canh, T., Moller, M. \& Scholz, B. (2014). Geotechnical and geophysical long-term monitoring at a levee of Red River in Vietnam. Journal of Environmental and Engineering Geophysics, 19 (3), 183-192.

White, L. P. (1977). Aerial photography and remote sensing for soil survey. Oxford: Clarendon Press.

Wong, D. (2009). The Modifiable Areal Unit Problem (MAUP). In: Fotheringham, A. S. \& Rogerson, P. A. (Eds.) The SAGE Handbook of Spatial Analysis. London: SAGE Publications. 105-124.

Xiao, H. L. \& Huang, J. (2013). Experimental study of the applications of fiber optic distributed temperature sensors in detecting seepage in soils. Geotechnical Testing Journal, 36 (3), 360-368.

$\mathrm{Xu}, \mathrm{H}$. Q. \& Zhang, T. J. (2011). Cross comparison of ASTER and Landsat ETM plus multispectral measurements for NDVI and SAVI vegetation indices [Abstract]. Spectroscopy and Spectral Analysis, 31 (7), 19021907. (In Chinese).

Xue, L. H., Cao, W. X., Luo, W. H., Dai, T. B. \& Zhu, Y. (2004). Monitoring leaf nitrogen status in rice with canopy spectral reflectance. Agronomy Journal, 96 (1), 135-142.

Yang, X. J. \& Lo, C. P. (2000). Relative radiometric normalization performance for change detection from multi-date satellite images. Photogrammetric Engineering and Remote Sensing, 66 (8), 967-980.

Yao, X., Yao, X., Jia, W., Tian, Y., Ni, J., Cao, W. \& Zhu, Y. (2013). Comparison and intercalibration of vegetation indices from different sensors for monitoring above-ground plant nitrogen uptake in winter wheat. Sensors, 13 (3), 3109-3130.

Yoder, B. J. \& Waring, R. H. (1994). The Normalized Difference Vegetation Index of small Douglas-fir canopies with varying chlorophyll concentrations. Remote Sensing of Environment, 49 (1), 81-91.

Yuan, D. \& Elvidge, C. D. (1996). Comparison of relative radiometric normalization techniques. ISPRS Journal of Photogrammetry and Remote Sensing, 51 (3), 117-126.

Zarco-Tejada, P. J., Berjón, A., López-Lozano, R., Miller, J. R., Martín, P., Cachorro, V., González, M. R. \& de Frutos, A. (2005). Assessing vineyard condition with hyperspectral indices: Leaf and canopy 
reflectance simulation in a row-structured discontinuous canopy. Remote Sensing of Environment, 99 (3), 271-287.

Zarco-Tejada, P. J., Miller, J. R., Mohammed, G. H. \& Noland, T. L. (2000). Chlorophyll fluorescence effects on vegetation apparent reflectance: I. Leaf-level measurements and model simulation. Remote Sensing of Environment, 74 (3), 582-595.

Zarco-Tejada, P. J., Miller, J. R., Noland, T. L., Mohammed, G. H. \& Sampson, P. H. (2001). Scaling-up and model inversion methods with narrowband optical indices for chlorophyll content estimation in closed forest canopies with hyperspectral data. IEEE Transactions on Geoscience and Remote Sensing, 39 (7), 1491-1507.

Zarco-Tejada, P. J. \& Ustin, S. L. (2001). Modeling canopy water content for carbon estimates from MODIS data at land EOS validation sites. In: International Geoscience and Remote Sensing Symposium, 2001. IGARSS '01. IEEE 2001 Sydney, NSW, Australia. IEEE, 342 - 344.

Zeghal, M., Abdoun, T., Exton, M., Mercado, V., Lv, X., Bennett, V., Yazici, B. \& Marr, A. (2013). Development of a multiscale monitoring and health assessment framework for effective management of levee infrastructure. In: Meehan, C., Pradel, D., Pando, M. A. \& Labuz, J. F., Eds. Geo-Congress 2013: Stability and Performance of Slopes and Embankments III, 3-7 March 2013 San Diego, California, USA. American Society of Civil Engineers (ASCE), 1605-1614.

Zeghal, M., Abdoun, T., Yazici, B., Lv, X., Bennett, V., Mercado, V. \& Marr, A. (2011). Health assessment of levees using remote sensing and field monitoring. In: Ninth International Workshop on Remote Sensing for Disaster Response, 15-16 September 2011 Stanford, California, USA. $7 \mathrm{pp}$.

Zhang, J.-C., Pu, R.-1., Wang, J.-h., Huang, W.-j., Yuan, L. \& Luo, J.-h. (2012a). Detecting powdery mildew of winter wheat using leaf level hyperspectral measurements. Computers and Electronics in Agriculture, 85, 13-23.

Zhang, J. (2001). RE: Comments on WCD's Final Report. Addressed to The World Commission on Dams. [Response of the vice-president of the Chinese National Commission on Large Dams (CHINCOLD) to the report by the World Commission on Dams (WCD) entitled "Dams and Development - A New Frame Work for Decision-Making" ]. Available: http://www.unep.org/dams/documents/default.asp?documentid=464 [Accessed 3 December 2014].

Zhang, Q. X., Li, Q. B. \& Zhang, G. J. (2012b). Rapid determination of leaf water content using VIS/NIR spectroscopy analysis with wavelength selection. Spectroscopy: An International Journal, 27 (2), 93-105.

Zhao, D. H., Huang, L. M., Li, J. L. \& Qi, J. G. (2007). A comparative analysis of broadband and narrowband derived vegetation indices in predicting 
LAI and CCD of a cotton canopy. ISPRS Journal of Photogrammetry and Remote Sensing, 62 (1), 25-33.

Zhao, D. H., Li, J. L. \& Qi, J. G. (2005). Identification of red and NIR spectral regions and vegetative indices for discrimination of cotton nitrogen stress and growth stage. Computers and Electronics in Agriculture, 48 (2), 155-169.

Zhu, P., Leng, Y., Dhillon, B. S. \& Bin, G. (2008a). Reliability analysis of a seepage monitoring system based on distributed optical fiber sensing. In: Intelligent Computation Technology and Automation (ICICTA), 2008 International Conference on, 20-22 October 2008, 1116-1120.

Zhu, P., Leng, Y. B., Y.Zhou \& Jiang, G. L. (2011). Safety inspection strategy for earth embankment dams using fully distributed sensing. Procedia Engineering, 8, 520-526.

Zhu, P. Y., Zeng, H. Y., Yuan, B. L. \& Ma, J. M. (2010). Signal processing in settlement and seepage monitoring for earth levee using fully distributed sensing along optical fibers. In: Fuji, Y. \& Maru, K. (Eds.) Precision Instrumentation and Measurement. Zurich, Switzerland: Trans Tech Publications. 75-79.

Zhu, Y., Yao, X., Tian, Y., Liu, X. \& Cao, W. (2008b). Analysis of common canopy vegetation indices for indicating leaf nitrogen accumulations in wheat and rice. International Journal of Applied Earth Observation and Geoinformation, 10 (1), 1-10. 
Appendix A:

Indices used in this study 
Table A.1: Full list of hyperspectral indices used in Chapter 2. (C) 2014 IEEE.

\begin{tabular}{|c|c|c|}
\hline INDEX NAME (ABBREV.) & EQUATION & REFERENCE \\
\hline $\begin{array}{l}\text { Anthocyanin Reflectance Index } \\
\text { (ARI) }\end{array}$ & $\left(1 / \mathrm{R}_{550}\right)-\left(1 / \mathrm{R}_{700}\right)$ & (Gitelson et al., 2001) \\
\hline $\begin{array}{l}\text { Atmospherically Resistant } \\
\text { Vegetation Index (ARVI) }^{\text {a }}\end{array}$ & $\begin{array}{l}{\left[\mathrm{R}_{830}-\left(\mathrm{R}_{660}-1 *\left(\mathrm{R}_{485}-\mathrm{R}_{660}\right)\right)\right] /} \\
{\left[\mathrm{R}_{830}+\left(\mathrm{R}_{660}-1 *\left(\mathrm{R}_{485}-\mathrm{R}_{660}\right)\right)\right]}\end{array}$ & $\begin{array}{l}\text { (Kaufman and Tanré, } \\
\text { 1992) }\end{array}$ \\
\hline Blue/Green Index $2\left(\mathrm{BGI}_{2}\right)$ & $\mathrm{R}_{450} / \mathrm{R}_{550}$ & (Zarco-Tejada et al., 2005) \\
\hline Blue/Red Index $1\left(\mathrm{BRI}_{1}\right)$ & $\mathrm{R}_{400} / \mathrm{R}_{690}$ & (Zarco-Tejada et al., 2005) \\
\hline Blue/Red Index $2\left(\mathrm{BRI}_{2}\right)$ & $\mathrm{R}_{450} / \mathrm{R}_{690}$ & (Zarco-Tejada et al., 2005) \\
\hline $\begin{array}{l}\text { Carotenoid Reflectance Index } 1 \\
\left(\mathrm{CRI}_{550}\right)\end{array}$ & $\left(1 / R_{510}\right)-\left(1 / R_{550}\right)$ & (Gitelson et al., 2002b) \\
\hline $\begin{array}{l}\text { Carotenoid Reflectance Index } 2 \\
\left(\mathrm{CRI}_{700}\right)\end{array}$ & $\left(1 / R_{510}\right)-\left(1 / R_{700}\right)$ & (Gitelson et al., 2002b) \\
\hline Carter Index $1\left(\mathrm{CTR}_{1}\right)$ & $\mathrm{R}_{695} / \mathrm{R}_{420}$ & (Carter, 1994) \\
\hline Carter Index $2\left(\mathrm{CTR}_{2}\right)$ & $\mathrm{R}_{695} / \mathrm{R}_{760}$ & (Carter, 1994) \\
\hline Carter Index $3\left(\mathrm{CRT}_{3}\right)$ & $\mathrm{R}_{700} / \mathrm{R}_{420}$ & $\begin{array}{l}\text { (Rodríguez-Pérez et al., } \\
\text { 2007) }\end{array}$ \\
\hline Cellulose Absorption Index (CAI) & $0.5 *\left(\mathrm{R}_{2000}+\mathrm{R}_{2200}\right)-\mathrm{R}_{2100}$ & (Nagler et al., 2003) \\
\hline $\begin{array}{l}\text { Chlorophyll Absorption in } \\
\text { Reflectance Index (CARI) }\end{array}$ & $\begin{array}{l}\mathrm{CAR} *\left(\mathrm{R}_{700} / \mathrm{R}_{670}\right) \\
\text { where } \mathrm{CAR}=\left|\left(\mathrm{a} * 670+\mathrm{R}_{670}+\mathrm{b}\right)\right| /\left(\mathrm{a}^{2}+1\right)^{0.5}, \\
\mathrm{a}=\left(\mathrm{R}_{700}-\mathrm{R}_{550}\right) / 150 \text { and } \mathrm{b}=\mathrm{R}_{500}-(\mathrm{a} * 550)\end{array}$ & $\begin{array}{l}\text { (Broge and Leblanc, 2000; } \\
\text { Kim et al., 1994) }\end{array}$ \\
\hline Curvature Index (CUR) & $\left(\mathrm{R}_{683}^{2}\right) /\left(\mathrm{R}_{675} * \mathrm{R}_{690}\right)$ & (Zarco-Tejada et al., 2000) \\
\hline $\begin{array}{l}\text { Difference Vegetation Index } \\
\text { (DVI) }^{a}\end{array}$ & $\mathrm{R}_{830}-\mathrm{R}_{660}$ & $\begin{array}{l}\text { (Lillesand et al., 2008; } \\
\text { Richardson and Everitt, } \\
\text { 1992) }\end{array}$ \\
\hline $\begin{array}{l}\text { Double-peak Canopy Nitrogen } \\
\text { Index (DCNI) }\end{array}$ & $\begin{array}{l}\left(\mathrm{R}_{720}-\mathrm{R}_{700}\right) /\left(\mathrm{R}_{700}-\mathrm{R}_{670}\right) / \\
\left(\mathrm{R}_{720}-\mathrm{R}_{670}+0.03\right)\end{array}$ & (Chen et al., 2010) \\
\hline $\begin{array}{l}\text { Enhanced Vegetation Index } \\
\left(\text { EVI) }{ }^{a}\right.\end{array}$ & $\begin{array}{l}2.5 *\left(\mathrm{R}_{830}-\mathrm{R}_{660}\right) / \\
\left(\mathrm{R}_{830}+6 * \mathrm{R}_{660}-7.5 * \mathrm{R}_{485}+1\right)\end{array}$ & (Huete et al., 1997) \\
\hline $\begin{array}{l}\text { Floating Position Water Band } \\
\text { (fWBI) }\end{array}$ & $\mathrm{R}_{900} /\left[\min \left(\mathrm{R}_{930}\right.\right.$ to $\left.\left.\mathrm{R}_{980}\right)\right]$ & (Strachan et al., 2002) \\
\hline Gitelson and Merzlyak $1\left(\mathrm{GM}_{1}\right)$ & $\mathrm{R}_{750} / \mathrm{R}_{550}$ & $\begin{array}{l}\text { (Gitelson and Merzlyak, } \\
\text { 1997) }\end{array}$ \\
\hline Gitelson and Merzlyak $2\left(\mathrm{GM}_{2}\right)$ & $\mathrm{R}_{750} / \mathrm{R}_{700}$ & $\begin{array}{l}\text { (Gitelson and Merzlyak, } \\
\text { 1997) }\end{array}$ \\
\hline $\begin{array}{l}\text { Global Environmental } \\
\text { Monitoring Index (GEMI) }\end{array}$ & $\begin{array}{l}\text { eta* }(1-0.25 * \text { eta })-\left[\left(\mathrm{R}_{660}-0.125\right) /\left(1-\mathrm{R}_{660}\right)\right] \\
\text { where eta }=\left[2 *\left(\left(\mathrm{R}_{830}\right)^{2}-\left(\mathrm{R}_{660}\right)^{2}\right)+\right. \\
\left.1.5^{*} \mathrm{R}_{830}+0.5^{*} \mathrm{R}_{660}\right] /\left(\mathrm{R}_{830}+\mathrm{R}_{660}+05\right)\end{array}$ & $\begin{array}{l}\text { (Pinty and Verstraete, } \\
\text { 1992) }\end{array}$ \\
\hline Green Chlorophyll Index $\left(\mathrm{CI}_{\mathrm{g}}\right)^{\mathrm{a}}$ & $\left(\mathrm{R}_{830} / \mathrm{R}_{560}\right)-1$ & (Gitelson et al., 2005) \\
\hline $\begin{array}{l}\text { Green Normalized Difference } \\
\text { Vegetation Index (gNDVI) }^{a}\end{array}$ & $\left(\mathrm{R}_{830}-\mathrm{R}_{560}\right) /\left(\mathrm{R}_{830}+\mathrm{R}_{560}\right)$ & $\begin{array}{l}\text { (Gitelson and Merzlyak, } \\
\text { 1998) }\end{array}$ \\
\hline
\end{tabular}


Table A.1 (continued)

\begin{tabular}{|c|c|c|}
\hline INDEX NAME (ABBREV.) & EQUATION & REFERENCE \\
\hline Green/Red Ratio (GRR) & $\mathrm{R}_{554} / \mathrm{R}_{673}$ & $\begin{array}{l}\text { (Kanemasu, 1974; } \\
\text { Rodríguez-Pérez et al., } \\
\text { 2007) }\end{array}$ \\
\hline Greenness Index (GI) & $\mathrm{R}_{554} / \mathrm{R}_{677}$ & (Smith et al., 1995) \\
\hline Green/Red Ratio $2\left(\mathrm{GRR}_{2}\right)$ & $\mathrm{R}_{550} / \mathrm{R}_{670}$ & This study \\
\hline $\begin{array}{l}\text { Infrared Percentage Vegetation } \\
\text { Index (IPVI) }{ }^{a}\end{array}$ & $\mathrm{R}_{830} /\left(\mathrm{R}_{830}+\mathrm{R}_{660}\right)$ & (Crippen, 1990) \\
\hline Lichtenthaler Index $2\left(\mathrm{LIC}_{2}\right)$ & $\mathrm{R}_{440} / \mathrm{R}_{690}$ & (Lichtenthaler, 1996) \\
\hline Lichtenthaler Index $3\left(\mathrm{LIC}_{3}\right)$ & $\mathrm{R}_{440} / \mathrm{R}_{740}$ & (Lichtenthaler, 1996) \\
\hline $\begin{array}{l}\text { Modified Anthocyanin } \\
\text { Reflectance Index (mARI) }\end{array}$ & {$\left[\left(1 / \mathrm{R}_{550}\right)-\left(1 / \mathrm{R}_{700}\right)\right] * \mathrm{R}_{800}$} & $\begin{array}{l}\text { (Gitelson et al., 2009; } \\
\text { Gitelson et al., 2001) }\end{array}$ \\
\hline $\begin{array}{l}\text { Modified Chlorophyll Absorption } \\
\text { in Reflectance Index (MCARI) }\end{array}$ & {$\left[\left(\mathrm{R}_{700}-\mathrm{R}_{670}\right)-0.2 *\left(\mathrm{R}_{700}-\mathrm{R}_{550}\right)\right]^{*}\left(\mathrm{R}_{700} / \mathrm{R}_{670}\right)$} & (Daughtry et al., 2000) \\
\hline $\begin{array}{l}\text { Modified Chlorophyll Absorption } \\
\left.\text { in Reflectance Index } 1 \text { (MCARI }{ }_{1}\right)\end{array}$ & $1.2 *\left[2.5 *\left(\mathrm{R}_{800}-\mathrm{R}_{670}\right)-1.3 *\left(\mathrm{R}_{800}-\mathrm{R}_{550}\right)\right]$ & (Haboudane et al., 2002) \\
\hline $\begin{array}{l}\text { Modified Chlorophyll Absorption } \\
\text { in Reflectance Index } 2\left(\mathrm{MCARI}_{2}\right)\end{array}$ & $\begin{array}{l}{\left[1.5 *\left[2.5 *\left(\mathrm{R}_{800}-\mathrm{R}_{670}\right)-1.3 *\left(\mathrm{R}_{800}-\mathrm{R}_{550}\right)\right]\right]} \\
/\left[\left(\left(2 * \mathrm{R}_{800}+1\right)^{2}-\left(6 * \mathrm{R}_{800}-5^{*}\left(\mathrm{R}_{670}\right)^{0.5}\right)\right)^{0.5}\right. \\
-0.5]\end{array}$ & (Haboudane et al., 2002) \\
\hline $\begin{array}{l}\text { Modified Red Edge Normalized } \\
\text { Difference Vegetation Index } \\
\left(\mathrm{mNDVI}_{705}\right)\end{array}$ & $\left(\mathrm{R}_{750}-\mathrm{R}_{705}\right) /\left(\mathrm{R}_{750}+\mathrm{R}_{705}-2 * \mathrm{R}_{445}\right)$ & (Sims and Gamon, 2002) \\
\hline Modified Simple Ratio (MSR) ${ }^{a}$ & $\left(\mathrm{R}_{800} / \mathrm{R}_{670}-1\right) /\left[\left(\mathrm{R}_{800} / \mathrm{R}_{670}\right)^{0.5}+1\right]$ & (Chen, 1996) \\
\hline $\begin{array}{l}\text { Modified Simple Red Edge Ratio } \\
\text { Index }\left(\operatorname{mSR}_{705}\right)\end{array}$ & $\left(\mathrm{R}_{750}-\mathrm{R}_{445}\right) /\left(\mathrm{R}_{705}-\mathrm{R}_{445}\right)$ & (Sims and Gamon, 2002) \\
\hline $\begin{array}{l}\text { Modified Soil-Adjusted } \\
{\text { Vegetation Index }\left(\mathrm{MSAVI}_{2}\right)^{\text {a }}}\end{array}$ & $\begin{array}{l}{\left[2 * \mathrm{R}_{800}+1-\left(\left(2 * \mathrm{R}_{800}+1\right)^{2}-\right.\right.} \\
\left.\left.8 *\left(\mathrm{R}_{800}-\mathrm{R}_{670}\right)\right)^{0.5}\right] / 2\end{array}$ & (Qi et al., 1994) \\
\hline $\begin{array}{l}\text { Modified Triangular Vegetation } \\
\text { Index } 1\left(\mathrm{MTVI}_{1}\right)\end{array}$ & $1.2 *\left[1.2 *\left(\mathrm{R}_{800}-\mathrm{R}_{550}\right)-2.5 *\left(\mathrm{R}_{670}-\mathrm{R}_{550}\right)\right]$ & (Haboudane et al., 2002) \\
\hline $\begin{array}{l}\text { Modified Triangular Vegetation } \\
\text { Index } 2\left(\mathrm{MTVI}_{2}\right)\end{array}$ & $\begin{array}{l}{\left[1.5 *\left[1.2 *\left(\mathrm{R}_{800}-\mathrm{R}_{550}\right)-2.5 *\left(\mathrm{R}_{670}-\mathrm{R}_{550}\right)\right]\right]} \\
/\left[\left(\left(2 * \mathrm{R}_{800}+1\right)^{2}-\left(6 * \mathrm{R}_{800}-5 *\left(\mathrm{R}_{670}\right)^{0.5}\right)\right)^{0.5}\right. \\
-0.5]\end{array}$ & (Haboudane et al., 2002) \\
\hline $\begin{array}{l}\text { Modified Triangular Vegetation } \\
\text { Index } 3\left(\mathrm{MTVI}_{3}\right)\end{array}$ & $1.2 *\left[1.2 *\left(\mathrm{R}_{880}-\mathrm{R}_{554}\right)-2.5 *\left(\mathrm{R}_{758}-\mathrm{R}_{554}\right)\right]$ & $\begin{array}{l}\text { (Rodríguez-Pérez et al., } \\
\text { 2007) }\end{array}$ \\
\hline Moisture Stress Index (MSI) & $\begin{array}{l}\text { (Average of } R_{1550} \text { to } R_{1750} \text { )/ } \\
\text { (Average of } R_{760} \text { to } R_{800} \text { ) }\end{array}$ & $\begin{array}{l}\text { (Harris et al., 2005; Rock } \\
\text { et al., 1986) }\end{array}$ \\
\hline Moisture Stress Index $1\left(\mathrm{MSI}_{1}\right)$ & $\mathrm{R}_{1600} / \mathrm{R}_{820}$ & (Hunt and Rock, 1989) \\
\hline Moisture Stress Index $2\left(\mathrm{MSI}_{2}\right)$ & $\mathrm{R}_{1650} / \mathrm{R}_{835}$ & $\begin{array}{l}\text { (Hunt and Rock, 1989; Lee } \\
\text { et al., 2007) }\end{array}$ \\
\hline Moisture Stress Index $3\left(\mathrm{MSI}_{3}\right)$ & $\mathrm{R}_{870} / \mathrm{R}_{1350}$ & $\begin{array}{l}\text { (Rodríguez-Pérez et al., } \\
\text { 2007) }\end{array}$ \\
\hline $\begin{array}{l}\text { Near-infrared / Red Ratio } \\
\text { (NIRRR) }\end{array}$ & $\mathrm{R}_{780} / \mathrm{R}_{670}$ & This study \\
\hline
\end{tabular}


Table A.1 (continued)

\begin{tabular}{|c|c|c|}
\hline INDEX NAME (ABBREV.) & EQUATION & REFERENCE \\
\hline $\begin{array}{l}\text { Normalized Difference Infrared } \\
\text { Index (NDII) }\end{array}$ & $\left(\mathrm{R}_{850}-\mathrm{R}_{1650}\right) /\left(\mathrm{R}_{850}+\mathrm{R}_{1650}\right)$ & (Hardisky et al., 1983) \\
\hline $\begin{array}{l}\text { Normalized Difference Lignin } \\
\text { Index (NDLI) }\end{array}$ & $\begin{array}{l}{\left[\log \left(1 / \mathrm{R}_{1754}\right)-\log \left(1 / \mathrm{R}_{1680}\right)\right] /} \\
\left.\log \left(1 / \mathrm{R}_{1754}\right)+\log \left(1 / \mathrm{R}_{1680}\right)\right]\end{array}$ & (Serrano et al., 2002) \\
\hline $\begin{array}{l}\text { Normalized Difference Nitrogen } \\
\text { Index (NDNI) }\end{array}$ & $\begin{array}{l}{\left[\log \left(1 / \mathrm{R}_{1510}\right)-\log \left(1 / \mathrm{R}_{1680}\right)\right] /} \\
{\left[\log \left(1 / \mathrm{R}_{1510}\right)+\log \left(1 / \mathrm{R}_{1680}\right)\right]}\end{array}$ & (Serrano et al., 2002) \\
\hline $\begin{array}{l}\text { Normalized Difference } \\
\text { Vegetation Index } \\
\text { (green -blue) (NDVIg-b) }\end{array}$ & $\left(\mathrm{R}_{573}-\mathrm{R}_{440}\right) /\left(\mathrm{R}_{573}+\mathrm{R}_{440}\right)$ & $\begin{array}{l}\text { (Chen et al., 2010; Hansen } \\
\text { and Schjoerring, 2003) }\end{array}$ \\
\hline $\begin{array}{l}\text { Normalized Difference } \\
\text { Vegetation Index (NDVI) }{ }^{\text {a }}\end{array}$ & $\left(\mathrm{R}_{830}-\mathrm{R}_{660}\right) /\left(\mathrm{R}_{830}+\mathrm{R}_{660}\right)$ & (Rouse et al., 1974) \\
\hline Normalized Difference & $\left(\mathrm{R}_{800}-\mathrm{R}_{680}\right) /\left(\mathrm{R}_{800}+\mathrm{R}_{680}\right)$ & (Lichtenthaler et al., 1996) \\
\hline \multicolumn{3}{|l|}{ Vegetation Index $2\left(\mathrm{NDVI}_{2}\right)$} \\
\hline $\begin{array}{l}\text { Normalized Difference } \\
\text { Vegetation Index } 3\left(\mathrm{NDVI}_{3}\right)\end{array}$ & $\left(\mathrm{R}_{870}-\mathrm{R}_{673}\right) /\left(\mathrm{R}_{870}+\mathrm{R}_{673}\right)$ & $\begin{array}{l}\text { (Rodríguez-Pérez et al., } \\
\text { 2007) }\end{array}$ \\
\hline $\begin{array}{l}\text { Normalized Difference } \\
\text { Vegetation Index } 4\left(\mathrm{NDVI}_{4}\right)\end{array}$ & $\left(\mathrm{R}_{884}-\mathrm{R}_{680}\right) /\left(\mathrm{R}_{884}+\mathrm{R}_{680}\right)$ & $\begin{array}{l}\text { (Rodríguez-Pérez et al., } \\
\text { 2007) }\end{array}$ \\
\hline $\begin{array}{l}\text { Normalized Difference } \\
\text { Vegetation Index } 5\left(\mathrm{NDVI}_{5}\right)\end{array}$ & $\left(\mathrm{R}_{845}-\mathrm{R}_{665}\right) /\left(\mathrm{R}_{845}+\mathrm{R}_{665}\right)$ & $\begin{array}{l}\text { (Rodríguez-Pérez et al., } \\
\text { 2007; Rouse et al., 1974) }\end{array}$ \\
\hline $\begin{array}{l}\text { Normalized Difference Water } \\
\text { Index }-\mathrm{McF} \text { eeters } \\
\left(\mathrm{NDWI}_{\mathrm{Mc}}\right)^{\mathrm{a}}\end{array}$ & $\left(\mathrm{R}_{560}-\mathrm{R}_{830}\right) /\left(\mathrm{R}_{560}+\mathrm{R}_{830}\right)$ & (McFeeters, 1996) \\
\hline $\begin{array}{l}\text { Normalized Difference Water } \\
\text { Index (NDWI) }{ }^{\text {a }}\end{array}$ & $\left(\mathrm{R}_{859}-\mathrm{R}_{1240}\right) /\left(\mathrm{R}_{859}+\mathrm{R}_{1240}\right)$ & $\begin{array}{l}\text { (Gao, 1996; Rodríguez- } \\
\text { Pérez et al., 2007) }\end{array}$ \\
\hline $\begin{array}{l}\text { Normalized Difference Water } \\
\text { Index } 2\left(\mathrm{NDWI}_{2}\right)\end{array}$ & $\left(\mathrm{R}_{870}-\mathrm{R}_{1260}\right) /\left(\mathrm{R}_{870}+\mathrm{R}_{1260}\right)$ & $\begin{array}{l}\text { (Rodríguez-Pérez et al., } \\
\text { 2007) }\end{array}$ \\
\hline $\begin{array}{l}\text { Normalized Difference Water } \\
\text { Index } 2130\left(\mathrm{NDWI}_{2130}\right)\end{array}$ & $\left(\mathrm{R}_{858}-\mathrm{R}_{2130}\right) /\left(\mathrm{R}_{858}+\mathrm{R}_{2130}\right)$ & (Chen et al., 2005) \\
\hline $\begin{array}{l}\text { Normalized Green/Red Ratio } \\
\text { (NGRR) }\end{array}$ & $\left(\mathrm{R}_{673}-\mathrm{R}_{554}\right) /\left(\mathrm{R}_{673}+\mathrm{R}_{554}\right)$ & $\begin{array}{l}\text { (Rodríguez-Pérez et al., } \\
\text { 2007) }\end{array}$ \\
\hline $\begin{array}{l}\text { Normalized Multi-band Drought } \\
\text { Index (NMDI) }\end{array}$ & {$\left[\mathrm{R}_{660}-\left(\mathrm{R}_{1640}-\mathrm{R}_{2150}\right)\right] /\left[\mathrm{R}_{660}+\left(\mathrm{R}_{1640}-\mathrm{R}_{2150}\right)\right]$} & (Wang and Qu, 2007) \\
\hline $\begin{array}{l}\text { Normalized Phaeophytinization } \\
\text { Index (NPQI) }\end{array}$ & $\left(\mathrm{R}_{415}-\mathrm{R}_{435}\right) /\left(\mathrm{R}_{415}+\mathrm{R}_{435}\right)$ & $\begin{array}{l}\text { (Barnes et al., 1992; } \\
\text { Peñuelas et al., 1995b) }\end{array}$ \\
\hline $\begin{array}{l}\text { Normalized Pigment Chlorophyll } \\
\text { Index (NPCI) }\end{array}$ & $\left(\mathrm{R}_{680}-\mathrm{R}_{430}\right) /\left(\mathrm{R}_{680}+\mathrm{R}_{430}\right)$ & (Peñuelas et al., 1994) \\
\hline $\begin{array}{l}\text { Normalized Soil Moisture Index } \\
\text { (NSMI) }\end{array}$ & $\left(\mathrm{R}_{1800}-\mathrm{R}_{2119}\right) /\left(\mathrm{R}_{1800}+\mathrm{R}_{2119}\right)$ & (Haubrock et al., 2008) \\
\hline $\begin{array}{l}\text { Optimized Soil-Adjusted } \\
\text { Vegetation Index (OSAVI) }^{\text {a }}\end{array}$ & $(1+0.16) *\left(\mathrm{R}_{800}-\mathrm{R}_{670}\right) /\left(\mathrm{R}_{800}+\mathrm{R}_{670}+0.16\right)$ & (Rondeaux et al., 1996) \\
\hline $\begin{array}{l}\text { Photochemical Reflectance } \\
\text { Index } 1\left(\mathrm{PRI}_{1}\right)\end{array}$ & $\left(\mathrm{R}_{528}-\mathrm{R}_{567}\right) /\left(\mathrm{R}_{528}+\mathrm{R}_{567}\right)$ & $\begin{array}{l}\text { (Gamon et al., 1992; } \\
\text { Rodríguez-Pérez et al., } \\
\text { 2007) }\end{array}$ \\
\hline
\end{tabular}


Table A.1 (continued)

\begin{tabular}{|c|c|c|}
\hline INDEX NAME (ABBREV.) & EQUATION & REFERENCE \\
\hline $\begin{array}{l}\text { Photochemical Reflectance } \\
\text { Index } 2\left(\mathrm{PRI}_{2}\right)\end{array}$ & $\left(\mathrm{R}_{531}-\mathrm{R}_{570}\right) /\left(\mathrm{R}_{531}+\mathrm{R}_{570}\right)$ & $\begin{array}{l}\text { (Gamon et al., 1992; } \\
\text { Gamon and Surfus, 1999) }\end{array}$ \\
\hline $\begin{array}{l}\text { Photochemical Reflectance } \\
\text { Index } 3\left(\mathrm{PRI}_{3}\right)\end{array}$ & $\left(\mathrm{R}_{570}-\mathrm{R}_{539}\right) /\left(\mathrm{R}_{570}+\mathrm{R}_{539}\right)$ & $\begin{array}{l}\text { (Rodríguez-Pérez et al., } \\
\text { 2007; Gamon et al., 1992) }\end{array}$ \\
\hline $\begin{array}{l}\text { Plant Senescence Reflectance } \\
\text { Index (PSRI) }\end{array}$ & $\left(\mathrm{R}_{680}-\mathrm{R}_{500}\right) / \mathrm{R}_{750}$ & (Merzlyak et al., 1999) \\
\hline $\begin{array}{l}\text { Ratio Vegetation Index } \\
\left(\text { RVI }{ }^{\text {a }}\right.\end{array}$ & $\mathrm{R}_{800} / \mathrm{R}_{673}$ & $\begin{array}{l}\text { (Rodríguez-Pérez et al., } \\
\text { 2007; Pearson and Miller, } \\
\text { 1973) }\end{array}$ \\
\hline Ratio Vegetation Index $1\left(\mathrm{RVI}_{1}\right)$ & $\mathrm{R}_{810} / \mathrm{R}_{660}$ & (Zhu et al., 2008b) \\
\hline Ratio Vegetation Index $2\left(\mathrm{RVI}_{2}\right)$ & $\mathrm{R}_{810} / \mathrm{R}_{560}$ & (Xue et al., 2004) \\
\hline $\begin{array}{l}\text { Red Edge Normalized Difference } \\
\text { Vegetation Index }\left(\mathrm{NDVI}_{705}\right)\end{array}$ & $\left(\mathrm{R}_{750}-\mathrm{R}_{705}\right) /\left(\mathrm{R}_{750}+\mathrm{R}_{705}\right)$ & (Sims and Gamon, 2002) \\
\hline Red Edge Position Index (REP) & $\begin{array}{l}700+40 *\left[\left(\left(\left(\mathrm{R}_{670}+\mathrm{R}_{780}\right) / 2\right)-\mathrm{R}_{700}\right) /\right. \\
\left.\left(\mathrm{R}_{740}-\mathrm{R}_{700}\right)\right]\end{array}$ & (Guyot and Baret, 1988) \\
\hline Red/Blue Index (RBI) & $\mathrm{R}_{695} / \mathrm{R}_{445}$ & $\begin{array}{l}\text { (Rodríguez-Pérez et al., } \\
\text { 2007) }\end{array}$ \\
\hline Red/Green Index (RGI) & $\mathrm{R}_{690} / \mathrm{R}_{550}$ & (Zarco-Tejada et al., 2005) \\
\hline Red/Green Index $2\left(\mathrm{RGI}_{2}\right)$ & $\mathrm{R}_{695} / \mathrm{R}_{554}$ & $\begin{array}{l}\text { (Rodríguez-Pérez et al., } \\
\text { 2007) }\end{array}$ \\
\hline Red/Green Ratio (RG) ${ }^{a}$ & $\mathrm{R}_{660} / \mathrm{R}_{560}$ & (Gamon and Surfus, 1999) \\
\hline Red-Edge Symmetry (RES) & $\left(\mathrm{R}_{718}-\mathrm{R}_{675}\right) /\left(\mathrm{R}_{755}-\mathrm{R}_{675}\right)$ & (Ju et al., 2010) \\
\hline $\begin{array}{l}\text { Renormalized Difference } \\
\text { Vegetation Index } \\
\text { (RDVI) }^{\mathrm{a}}\end{array}$ & $\left(\mathrm{R}_{800}-\mathrm{R}_{670}\right) /\left[\left(\mathrm{R}_{800}+\mathrm{R}_{670}\right)^{0.5}\right]$ & (Roujean and Breon, 1995) \\
\hline $\begin{array}{l}\text { Shortwave Infrared Water Stress } \\
\text { Index (SIWSI) }\end{array}$ & $\left(\mathrm{R}_{859}-\mathrm{R}_{1640}\right) /\left(\mathrm{R}_{859}+\mathrm{R}_{1640}\right)$ & $\begin{array}{l}\text { (Fensholt and Sandholt, } \\
\text { 2003; Rodríguez-Pérez et } \\
\text { al., 2007) }\end{array}$ \\
\hline Simple Ratio (SR) ${ }^{\text {a }}$ & $\mathrm{R}_{845} / \mathrm{R}_{665}$ & $\begin{array}{l}\text { (Rodríguez-Pérez et al., } \\
\text { 2007; Pearson and Miller, } \\
\text { 1973; Jordan, 1969) }\end{array}$ \\
\hline Simple Ratio $2\left(\mathrm{SR}_{2}\right)$ & $\mathrm{R}_{1070} / \mathrm{R}_{1340}$ & $\begin{array}{l}\text { (Rodríguez-Pérez et al., } \\
\text { 2007) }\end{array}$ \\
\hline Simple Ratio $3\left(\mathrm{SR}_{3}\right)$ & $\mathrm{R}_{673} / \mathrm{R}_{880}$ & $\begin{array}{l}\text { (Rodríguez-Pérez et al., } \\
\text { 2007) }\end{array}$ \\
\hline Simple Ratio $4\left(\mathrm{SR}_{4}\right)$ & $\mathrm{R}_{678} / \mathrm{R}_{1070}$ & $\begin{array}{l}\text { (Rodríguez-Pérez et al., } \\
\text { 2007) }\end{array}$ \\
\hline $\begin{array}{l}\text { Simple Ratio Pigment Index } \\
\text { (SRPI) }\end{array}$ & $\mathrm{R}_{430} / \mathrm{R}_{680}$ & (Peñuelas et al., 1995b) \\
\hline $\begin{array}{l}\text { Simple Ratio Water Index } \\
\text { (SRWI) }\end{array}$ & $\mathrm{R}_{858} / \mathrm{R}_{1240}$ & $\begin{array}{l}\text { (Zarco-Tejada and Ustin, } \\
\text { 2001) }\end{array}$ \\
\hline
\end{tabular}


Table A.1 (continued)

\begin{tabular}{|c|c|c|}
\hline INDEX NAME (ABBREV.) & EQUATION & REFERENCE \\
\hline $\begin{array}{l}\text { Simple Ratio Water Index } 1 \\
\left(\mathrm{SRWI}_{1}\right)\end{array}$ & $\mathrm{R}_{880} / \mathrm{R}_{1265}$ & $\begin{array}{l}\text { (Rodríguez-Pérez et al., } \\
\text { 2007) }\end{array}$ \\
\hline $\begin{array}{l}\text { Simple Ratio Water Index } 2 \\
\left(\mathrm{SRWI}_{2}\right)\end{array}$ & $\mathrm{R}_{1350} / \mathrm{R}_{670}$ & $\begin{array}{l}\text { (Rodríguez-Pérez et al., } \\
\text { 2007) }\end{array}$ \\
\hline $\begin{array}{l}\text { Soil-adjusted Atmospherically } \\
\text { Resistant Vegetation Index } \\
\left(\text { SARVI) }{ }^{\text {a }}\right.\end{array}$ & $\begin{array}{l}{\left[\mathrm{R}_{800}-\left(\mathrm{R}_{670}-1 *\left(\mathrm{R}_{445}-\mathrm{R}_{670}\right)\right)\right] /} \\
{\left[\mathrm{R}_{800}+\left(\mathrm{R}_{670}-1 *\left(\mathrm{R}_{445}-\mathrm{R}_{670}\right)\right)+0.5\right] *(1+0.5)}\end{array}$ & (Huete et al., 1994) \\
\hline $\begin{array}{l}\text { Soil-Adjusted Vegetation Index } \\
\left(\text { SAVI) }{ }^{a}\right.\end{array}$ & {$\left[\left(\mathrm{R}_{800}-\mathrm{R}_{670}\right) /\left(\mathrm{R}_{800}+\mathrm{R}_{670}+0.5\right)\right] *(1+0.5)$} & (Huete, 1988) \\
\hline $\begin{array}{l}\text { Structure Independent Pigment } \\
\text { Index (SIPI) }\end{array}$ & $\left(\mathrm{R}_{800}-\mathrm{R}_{445}\right) /\left(\mathrm{R}_{800}+\mathrm{R}_{680}\right)$ & (Peñuelas et al., 1995a) \\
\hline Sum Green Index (SG) & Average of $R_{500}$ to $R_{600}$ & (Gamon and Surfus, 1999) \\
\hline $\begin{array}{l}\text { Transformed Chlorophyll } \\
\text { Absorption in Reflectance Index } \\
\text { (TCARI) }\end{array}$ & $\begin{array}{l}3 *\left[\left(\mathrm{R}_{700}-\mathrm{R}_{670}\right)-0.2 *\left(\mathrm{R}_{700}-\mathrm{R}_{550}\right) *\right. \\
\left.\left(\mathrm{R}_{700} / \mathrm{R}_{670}\right)\right]\end{array}$ & (Haboudane et al., 2002) \\
\hline $\begin{array}{l}\text { Transformed Normalized } \\
\text { Difference Vegetation Index } \\
\text { (TNDVI) }^{\text {a }}\end{array}$ & {$\left[\left(\mathrm{R}_{830}-\mathrm{R}_{660}\right) /\left(\mathrm{R}_{830}+\mathrm{R}_{660}\right)+0.5\right]^{0.5}$} & $\begin{array}{l}\text { (Rouse et al., 1973; Rouse } \\
\text { et al., 1974) }\end{array}$ \\
\hline $\begin{array}{l}\text { Triangular Vegetation Index } \\
\text { (TVI) }\end{array}$ & $0.5 *\left[120 *\left(\mathrm{R}_{750}-\mathrm{R}_{550}\right)-200 *\left(\mathrm{R}_{670}-\mathrm{R}_{550}\right)\right]$ & (Broge and Leblanc, 2000) \\
\hline $\begin{array}{l}\text { Triangular Vegetation Index } 1 \\
\left(\mathrm{TVI}_{1}\right)\end{array}$ & $0.5^{*}\left[120 *\left(\mathrm{R}_{758}-\mathrm{R}_{554}\right)-200 *\left(\mathrm{R}_{674}-\mathrm{R}_{554}\right)\right]$ & $\begin{array}{l}\text { (Rodríguez-Pérez et al., } \\
\text { 2007) }\end{array}$ \\
\hline $\begin{array}{l}\text { Visible Atmospherically } \\
\text { Resistant Index (VARI) }{ }^{\text {a }}\end{array}$ & $\left(\mathrm{R}_{560}-\mathrm{R}_{660}\right) /\left(\mathrm{R}_{560}+\mathrm{R}_{660}-\mathrm{R}_{485}\right)$ & (Gitelson et al., 2002a) \\
\hline Vogelmann Index (VOG) & $\mathrm{R}_{740} / \mathrm{R}_{720}$ & (Vogelmann et al., 1993) \\
\hline Vogelmann Index $2\left(\mathrm{VOG}_{2}\right)$ & $\left(\mathrm{R}_{734}-\mathrm{R}_{747}\right) /\left(\mathrm{R}_{715}+\mathrm{R}_{726}\right)$ & $\begin{array}{l}\text { (Zarco-Tejada et al., 2005; } \\
\text { Zarco-Tejada et al., 2001) }\end{array}$ \\
\hline Vogelmann Index $3\left(\mathrm{VOG}_{3}\right)$ & $\left(\mathrm{R}_{734}-\mathrm{R}_{747}\right) /\left(\mathrm{R}_{715}+\mathrm{R}_{720}\right)$ & $\begin{array}{l}\text { (Zarco-Tejada et al., 2005; } \\
\text { Zarco-Tejada et al., 2001) }\end{array}$ \\
\hline Water Band Index (WBI) & $\mathrm{R}_{970} / \mathrm{R}_{900}$ & (Peñuelas et al., 1993) \\
\hline Zarco and Miller (ZM) & $\mathrm{R}_{750} / \mathrm{R}_{710}$ & $\begin{array}{l}\text { (Zarco-Tejada et al., 2005; } \\
\text { Zarco-Tejada et al., 2001) }\end{array}$ \\
\hline
\end{tabular}

$\mathrm{R}$ : Reflectance at specified wavelength in nanometres

${ }^{a}$ Original index was for a broadband sensor 
Table A.2: The 48 indices selected based on whether applicable to at least three of the ten sensors investigated in Chapter 3.

\begin{tabular}{|c|c|c|}
\hline INDEX NAME (ABBREV.) & EQUATION & REFERENCE \\
\hline $\begin{array}{l}\text { Anthocyanin Reflectance Index } \\
\text { (ARI) }\end{array}$ & $\left(1 / \mathrm{R}_{550}\right)-\left(1 / \mathrm{R}_{700}\right)$ & (Gitelson et al., 2001) \\
\hline $\begin{array}{l}\text { Atmospherically Resistant } \\
\text { Vegetation Index (ARVI) }\end{array}$ & $\begin{array}{l}{\left[\mathrm{R}_{830}-\left(\mathrm{R}_{660}-1 *\left(\mathrm{R}_{485}-\mathrm{R}_{660}\right)\right)\right] /} \\
{\left[\mathrm{R}_{830}+\left(\mathrm{R}_{660}-1 *\left(\mathrm{R}_{485}-\mathrm{R}_{660}\right)\right)\right]}\end{array}$ & $\begin{array}{l}\text { (Kaufman and Tanré, } \\
\text { 1992) }\end{array}$ \\
\hline Blue/Green Index $2\left(\mathrm{BGI}_{2}\right)$ & $\mathrm{R}_{450} / \mathrm{R}_{550}$ & (Zarco-Tejada et al., 2005) \\
\hline Blue/Red Index 1 (BRI $\left.{ }_{1}\right)$ & $\mathrm{R}_{400} / \mathrm{R}_{690}$ & (Zarco-Tejada et al., 2005) \\
\hline $\begin{array}{l}\text { Carotenoid Reflectance Index } 2 \\
\left(\mathrm{CRI}_{700}\right)\end{array}$ & $\left(1 / \mathrm{R}_{510}\right)-\left(1 / \mathrm{R}_{700}\right)$ & (Gitelson et al., 2002b) \\
\hline Carter Index $1\left(\mathrm{CTR}_{1}\right)$ & $\mathrm{R}_{695} / \mathrm{R}_{420}$ & (Carter, 1994) \\
\hline Carter Index $2\left(\mathrm{CTR}_{2}\right)$ & $\mathrm{R}_{695} / \mathrm{R}_{760}$ & (Carter, 1994) \\
\hline $\begin{array}{l}\text { Chlorophyll Absorption in } \\
\text { Reflectance Index (CARI) }\end{array}$ & $\begin{array}{l}\mathrm{CAR} *\left(\mathrm{R}_{700} / \mathrm{R}_{670}\right) \\
\text { where } \mathrm{CAR}=\left|\left(\mathrm{a} * 670+\mathrm{R}_{670}+\mathrm{b}\right)\right| /\left(\mathrm{a}^{2}+1\right)^{0.5}, \\
\mathrm{a}=\left(\mathrm{R}_{700}-\mathrm{R}_{550}\right) / 150 \text { and } \mathrm{b}=\mathrm{R}_{500}-\left(\mathrm{a}^{*} 550\right)\end{array}$ & $\begin{array}{l}\text { (Broge and Leblanc, 2000; } \\
\text { Kim et al., 1994) }\end{array}$ \\
\hline $\begin{array}{l}\text { Difference Vegetation Index } \\
\text { (DVI) }^{\mathrm{a}}\end{array}$ & $\mathrm{R}_{830}-\mathrm{R}_{660}$ & $\begin{array}{l}\text { (Lillesand et al., 2008; } \\
\text { Richardson and Everitt, } \\
\text { 1992) }\end{array}$ \\
\hline $\begin{array}{l}\text { Enhanced Vegetation Index } \\
\text { (EVI) }^{\mathrm{a}}\end{array}$ & $2.5 *\left(\mathrm{R}_{830}-\mathrm{R}_{660}\right) /\left(\mathrm{R}_{830}+6 * \mathrm{R}_{660}-7.5 * \mathrm{R}_{485}+1\right)$ & (Huete et al., 1997) \\
\hline Gitelson and Merzlyak $1\left(\mathrm{GM}_{1}\right)$ & $\mathrm{R}_{750} / \mathrm{R}_{550}$ & $\begin{array}{l}\text { (Gitelson and Merzlyak, } \\
\text { 1997) }\end{array}$ \\
\hline Gitelson and Merzlyak $2\left(\mathrm{GM}_{2}\right)$ & $\mathrm{R}_{750} / \mathrm{R}_{700}$ & $\begin{array}{l}\text { (Gitelson and Merzlyak, } \\
\text { 1997) }\end{array}$ \\
\hline $\begin{array}{l}\text { Global Environmental } \\
\text { Monitoring Index (GEMI) }\end{array}$ & $\begin{array}{l}\text { eta*(1-0.25*eta) }-\left[\left(\mathrm{R}_{660}-0.125\right) /\left(1-\mathrm{R}_{660}\right)\right] \\
\text { where eta }=\left[2 *\left(\left(\mathrm{R}_{830}\right)^{2}-\left(\mathrm{R}_{660}\right)^{2}\right)+\right. \\
\left.1.5 * \mathrm{R}_{830}+0.5 * \mathrm{R}_{660}\right] /\left(\mathrm{R}_{830}+\mathrm{R}_{660}+0.5\right)\end{array}$ & $\begin{array}{l}\text { (Pinty and Verstraete, } \\
\text { 1992) }\end{array}$ \\
\hline Green Chlorophyll Index $\left(\mathrm{CI}_{\mathrm{g}}\right)^{\mathrm{a}}$ & $\left(\mathrm{R}_{830} / \mathrm{R}_{560}\right)-1$ & (Gitelson et al., 2005) \\
\hline $\begin{array}{l}\text { Green Normalized Difference } \\
{\text { Vegetation Index }(\mathrm{gNDVI})^{\mathrm{a}}}\end{array}$ & $\left(\mathrm{R}_{830}-\mathrm{R}_{560}\right) /\left(\mathrm{R}_{830}+\mathrm{R}_{560}\right)$ & $\begin{array}{l}\text { (Gitelson and Merzlyak, } \\
\text { 1998) }\end{array}$ \\
\hline Green/Red Ratio (GRR) & $\mathrm{R}_{554} / \mathrm{R}_{673}$ & $\begin{array}{l}\text { (Kanemasu, 1974; } \\
\text { Rodríguez-Pérez et al., } \\
\text { 2007) }\end{array}$ \\
\hline $\begin{array}{l}\text { Infrared Percentage Vegetation } \\
\text { Index (IPVI) }^{\text {a }}\end{array}$ & $\mathrm{R}_{830} /\left(\mathrm{R}_{830}+\mathrm{R}_{660}\right)$ & (Crippen, 1990) \\
\hline Lichtenthaler Index $2\left(\mathrm{LIC}_{2}\right)$ & $\mathrm{R}_{440} / \mathrm{R}_{690}$ & (Lichtenthaler, 1996) \\
\hline Lichtenthaler Index $3\left(\mathrm{LIC}_{3}\right)$ & $\mathrm{R}_{440} / \mathrm{R}_{740}$ & (Lichtenthaler, 1996) \\
\hline $\begin{array}{l}\text { Modified Anthocyanin } \\
\text { Reflectance Index (mARI) }\end{array}$ & {$\left[\left(1 / \mathrm{R}_{550}\right)-\left(1 / \mathrm{R}_{700}\right)\right] * \mathrm{R}_{800}$} & $\begin{array}{l}\text { (Gitelson et al., 2009; } \\
\text { Gitelson } \text { et al., 2001) }\end{array}$ \\
\hline $\begin{array}{l}\text { Modified Chlorophyll Absorption } \\
\text { in Reflectance Index (MCARI) }\end{array}$ & {$\left[\left(\mathrm{R}_{700}-\mathrm{R}_{670}\right)-0.2 *\left(\mathrm{R}_{700}-\mathrm{R}_{550}\right)\right] *\left(\mathrm{R}_{700} / \mathrm{R}_{670}\right)$} & (Daughtry et al., 2000) \\
\hline $\begin{array}{l}\text { Modified Chlorophyll Absorption } \\
\left.\text { in Reflectance Index } 1 \text { (MCARI }{ }_{1}\right)\end{array}$ & $1.2 *\left[2.5 *\left(\mathrm{R}_{800}-\mathrm{R}_{670}\right)-1.3 *\left(\mathrm{R}_{800}-\mathrm{R}_{550}\right)\right]$ & (Haboudane et al., 2002) \\
\hline
\end{tabular}


Table A.2 (continued)

\begin{tabular}{|c|c|c|}
\hline INDEX NAME (ABBREV.) & EQUATION & REFERENCE \\
\hline $\begin{array}{l}\text { Modified Chlorophyll Absorption } \\
\text { in Reflectance Index } 2\left(\mathrm{MCARI}_{2}\right)\end{array}$ & $\begin{array}{l}{\left[1.5 *\left[2.5 *\left(\mathrm{R}_{800}-\mathrm{R}_{670}\right)-1.3 *\left(\mathrm{R}_{800}-\mathrm{R}_{550}\right)\right]\right] /} \\
{\left[\left(\left(2 * \mathrm{R}_{800}+1\right)^{2}-\left(6 * \mathrm{R}_{800}-5 *\left(\mathrm{R}_{670}\right)^{0.5}\right)\right)^{0.5}\right.} \\
-0.5]\end{array}$ & (Haboudane et al., 2002) \\
\hline $\begin{array}{l}\text { Modified Red Edge Normalized } \\
\text { Difference Vegetation Index } \\
\left(\mathrm{mNDVI}_{705}\right)\end{array}$ & $\left(\mathrm{R}_{750}-\mathrm{R}_{705}\right) /\left(\mathrm{R}_{750}+\mathrm{R}_{705}-2 * \mathrm{R}_{445}\right)$ & (Sims and Gamon, 2002) \\
\hline Modified Simple Ratio (MSR) ${ }^{a}$ & $\left(\mathrm{R}_{800} / \mathrm{R}_{670}-1\right) /\left[\left(\mathrm{R}_{800} / \mathrm{R}_{670}\right)^{0.5}+1\right]$ & (Chen, 1996) \\
\hline $\begin{array}{l}\text { Modified Simple Red Edge Ratio } \\
\text { Index }\left(\mathrm{mSR}_{705}\right)\end{array}$ & $\left(\mathrm{R}_{750}-\mathrm{R}_{445}\right) /\left(\mathrm{R}_{705}-\mathrm{R}_{445}\right)$ & (Sims and Gamon, 2002) \\
\hline $\begin{array}{l}\text { Modified Soil-Adjusted } \\
\text { Vegetation Index }\left(\mathrm{MSAVI}_{2}\right)^{a}\end{array}$ & $\begin{array}{l}{\left[2 * \mathrm{R}_{800}+1-\left(\left(2 * \mathrm{R}_{800}+1\right)^{2}-\right.\right.} \\
\left.\left.8 *\left(\mathrm{R}_{800}-\mathrm{R}_{670}\right)\right)^{0.5}\right] / 2\end{array}$ & (Qi et al., 1994) \\
\hline $\begin{array}{l}\text { Modified Triangular Vegetation } \\
\text { Index } 1\left(\mathrm{MTVI}_{1}\right)\end{array}$ & $1.2 *\left[1.2 *\left(\mathrm{R}_{800}-\mathrm{R}_{550}\right)-2.5 *\left(\mathrm{R}_{670}-\mathrm{R}_{550}\right)\right]$ & (Haboudane et al., 2002) \\
\hline $\begin{array}{l}\text { Modified Triangular Vegetation } \\
\text { Index } 2\left(\mathrm{MTVI}_{2}\right)\end{array}$ & $\begin{array}{l}{\left[1.5 *\left[1.2 *\left(\mathrm{R}_{800}-\mathrm{R}_{550}\right)-2.5^{*}\left(\mathrm{R}_{670}-\mathrm{R}_{550}\right)\right]\right] /} \\
{\left[\left(\left(2 * \mathrm{R}_{800}+1\right)^{2}-\left(6 * \mathrm{R}_{800}-5 *\left(\mathrm{R}_{670}\right)^{0.5}\right)\right)^{0.5}\right.} \\
-0.5]\end{array}$ & (Haboudane et al., 2002) \\
\hline $\begin{array}{l}\text { Normalized Difference } \\
\text { Vegetation Index (green -blue) } \\
\text { (NDVIg-b) }\end{array}$ & $\left(\mathrm{R}_{573}-\mathrm{R}_{440}\right) /\left(\mathrm{R}_{573}+\mathrm{R}_{440}\right)$ & $\begin{array}{l}\text { (Chen et al., 2010; Hansen } \\
\text { and Schjoerring, 2003) }\end{array}$ \\
\hline $\begin{array}{l}\text { Normalized Difference } \\
\text { Vegetation Index (NDVI) }\end{array}$ & $\left(\mathrm{R}_{830}-\mathrm{R}_{660}\right) /\left(\mathrm{R}_{830}+\mathrm{R}_{660}\right)$ & $\begin{array}{l}\text { (Rouse } \text { et al., 1974; Rouse } \\
\text { et al., 1973) }\end{array}$ \\
\hline $\begin{array}{l}\text { Normalized Difference Water } \\
\text { Index - McFeeters }\left(\mathrm{NDWI}_{\mathrm{Mc}}\right)^{\text {a }}\end{array}$ & $\left(\mathrm{R}_{560}-\mathrm{R}_{830}\right) /\left(\mathrm{R}_{560}+\mathrm{R}_{830}\right)$ & (McFeeters, 1996) \\
\hline $\begin{array}{l}\text { Normalized Green/Red Ratio } \\
\text { (NGRR) }\end{array}$ & $\left(\mathrm{R}_{673}-\mathrm{R}_{554}\right) /\left(\mathrm{R}_{673}+\mathrm{R}_{554}\right)$ & $\begin{array}{l}\text { (Rodríguez-Pérez et al., } \\
\text { 2007) }\end{array}$ \\
\hline $\begin{array}{l}\text { Normalized Pigment Chlorophyll } \\
\text { Index (NPCI) }\end{array}$ & $\left(\mathrm{R}_{680}-\mathrm{R}_{430}\right) /\left(\mathrm{R}_{680}+\mathrm{R}_{430}\right)$ & (Peñuelas et al., 1994) \\
\hline $\begin{array}{l}\text { Optimized Soil-Adjusted } \\
\text { Vegetation Index(OSAVI) }^{\text {a }}\end{array}$ & $(1+0.16) *\left(\mathrm{R}_{800}-\mathrm{R}_{670}\right) /\left(\mathrm{R}_{800}+\mathrm{R}_{670}+0.16\right)$ & (Rondeaux et al., 1996) \\
\hline $\begin{array}{l}\text { Plant Senescence Reflectance } \\
\text { Index (PSRI) }\end{array}$ & $\left(\mathrm{R}_{680}-\mathrm{R}_{500}\right) / \mathrm{R}_{750}$ & (Merzlyak et al., 1999) \\
\hline Ratio Vegetation Index (RVI) ${ }^{\text {a }}$ & $\mathrm{R}_{800} / \mathrm{R}_{673}$ & $\begin{array}{l}\text { (Jordan, 1969; Rodríguez- } \\
\text { Pérez et al., 2007), }\end{array}$ \\
\hline $\begin{array}{l}\text { Red Edge Normalized Difference } \\
\text { Vegetation Index }\left(\mathrm{NDVI}_{705}\right)\end{array}$ & $\left(\mathrm{R}_{750}-\mathrm{R}_{705}\right) /\left(\mathrm{R}_{750}+\mathrm{R}_{705}\right)$ & (Sims and Gamon, 2002) \\
\hline Red/Blue Index (RBI) & $\mathrm{R}_{695} / \mathrm{R}_{445}$ & $\begin{array}{l}\text { (Rodríguez-Pérez et al., } \\
\text { 2007) }\end{array}$ \\
\hline Red/Green Index (RGI) & $\mathrm{R}_{690} / \mathrm{R}_{550}$ & (Zarco-Tejada et al., 2005) \\
\hline $\begin{array}{l}\text { Renormalized Difference } \\
\text { Vegetation Index (RDVI) }^{\text {a }}\end{array}$ & $\left(\mathrm{R}_{800}-\mathrm{R}_{670}\right) /\left[\left(\mathrm{R}_{800}+\mathrm{R}_{670}\right)^{0.5}\right]$ & (Roujean and Breon, 1995) \\
\hline $\begin{array}{l}\text { Soil-adjusted Atmospherically } \\
\text { Resistant Vegetation Index } \\
\text { (SARVI) }^{\text {a }}\end{array}$ & $\begin{array}{l}{\left[\mathrm{R}_{800}-\left(\mathrm{R}_{670}-1 *\left(\mathrm{R}_{445}-\mathrm{R}_{670}\right)\right)\right] /} \\
{\left[\mathrm{R}_{800}+\left(\mathrm{R}_{670}-1 *\left(\mathrm{R}_{445}-\mathrm{R}_{670}\right)\right)+0.5\right] *(1+05)}\end{array}$ & (Huete et al., 1994) \\
\hline
\end{tabular}


Table A.2 (continued)

\begin{tabular}{lll}
\hline INDEX NAME (ABBREV.) & EQUATION & REFERENCE \\
\hline $\begin{array}{l}\text { Soil-Adjusted Vegetation Index } \\
(\mathrm{SAVI})^{\mathrm{a}}\end{array}$ & {$\left[\left(\mathrm{R}_{800}-\mathrm{R}_{670}\right) /\left(\mathrm{R}_{800}+\mathrm{R}_{670}+0.5\right)\right] *(1+0.5)$} & (Huete, 1988) \\
$\begin{array}{l}\text { Structure Independent Pigment } \\
\text { Index (SIPI) }\end{array}$ & $\left(\mathrm{R}_{800}-\mathrm{R}_{445}\right) /\left(\mathrm{R}_{800}+\mathrm{R}_{680}\right)$ & (Peñuelas et al., 1995a) \\
$\begin{array}{l}\text { Transformed Chlorophyll } \\
\text { Absorption in Reflectance Index } \\
\text { (TCARI) }\end{array}$ & $\begin{array}{l}3 *\left[\left(\mathrm{R}_{700}-\mathrm{R}_{670}\right)-0.2 *\left(\mathrm{R}_{700}-\mathrm{R}_{550}\right)^{*}\right. \\
\left.\left(\mathrm{R}_{700} / \mathrm{R}_{670}\right)\right]\end{array}$ & (Haboudane et al., 2002) \\
$\begin{array}{l}\text { Transformed Normalized } \\
\text { Difference Vegetation Index } \\
\text { (TNDVI) }\end{array}$ & {$\left[\left(\mathrm{R}_{830}-\mathrm{R}_{660}\right) /\left(\mathrm{R}_{830}+\mathrm{R}_{660}\right)+0.5\right]^{0.5}$} & (Rouse et al., 1974; Rouse \\
$\begin{array}{l}\text { Triangular Vegetation Index } \\
\text { (TVI) }\end{array}$ & $0.5 *\left[120 *\left(\mathrm{R}_{750}-\mathrm{R}_{550}\right)-200 *\left(\mathrm{R}_{670}-\mathrm{R}_{550}\right)\right]$ & (Broge and Leblanc, 2000) \\
$\begin{array}{l}\text { Visible Atmospherically } \\
\text { Resistant Index (VARI) }\end{array}$ & $\left(\mathrm{R}_{560}-\mathrm{R}_{660}\right) /\left(\mathrm{R}_{560}+\mathrm{R}_{660}-\mathrm{R}_{485}\right)$ & (Gitelson et al., 2002a) \\
\hline
\end{tabular}

$\mathrm{R}:$ Reflectance at specified wavelength in nanometres

${ }^{a}$ Original index was for a broadband sensor 


\section{Appendix B:}

Statistical measures per index, comparing index values generated from convolved narrow- and broadband data to index values obtained from original narrowband ASD data 
Table B.1: Mean values (per index) of the statistical measures for the ten sensors studied in Chapter 3, comparing index values generated from convolved narrow- and broadband data to index values obtained from original narrowband ASD data.

\begin{tabular}{|c|c|c|c|c|c|}
\hline INDEX & $\begin{array}{l}\text { MEAN } \\
{ }_{1: 1} R^{2}\end{array}$ & $\begin{array}{c}\text { MEAN } \\
\mid \text { SLOPE-1| }\end{array}$ & $\begin{array}{c}\text { MEAN } \\
\mid \text { INTERCEPT } \mid\end{array}$ & $\begin{array}{c}\text { MEAN } \\
\text { |NORMALIZED } \\
\text { INTERCEPT } \mid\end{array}$ & $\begin{array}{l}\text { MEAN } \\
\text { CCR }^{2}\end{array}$ \\
\hline ARI & -13.558 & 1.654 & 10.488 & 7.166 & 0.534 \\
\hline ARVI & 0.874 & 0.093 & 0.054 & 0.077 & 0.997 \\
\hline $\mathrm{BGI}_{2}$ & -3.353 & 0.161 & 0.199 & 0.430 & 0.979 \\
\hline $\mathrm{BRI}_{1}$ & -4.090 & 0.284 & 0.257 & 0.529 & 0.876 \\
\hline $\mathrm{CRI}_{700}$ & -0.463 & 0.435 & 2.424 & 0.130 & 0.652 \\
\hline $\mathrm{CTR}_{1}$ & -22.910 & 0.558 & 4.341 & 1.702 & 0.221 \\
\hline $\mathrm{CTR}_{2}$ & -3.203 & 0.307 & 0.240 & 1.005 & 0.918 \\
\hline CARI & -0.318 & 0.979 & 0.403 & 0.148 & 0.353 \\
\hline DVI & 0.976 & 0.044 & 0.001 & 0.004 & 0.998 \\
\hline EVI & 0.962 & 0.037 & 0.006 & 0.012 & 0.998 \\
\hline $\mathrm{GM}_{1}$ & -0.155 & 0.304 & 0.503 & 0.117 & 0.994 \\
\hline $\mathrm{GM}_{2}$ & -0.276 & 0.508 & 0.882 & 0.232 & 0.984 \\
\hline GEMI & 0.978 & 0.023 & 0.008 & 0.012 & 0.999 \\
\hline $\mathrm{CIg}$ & 0.825 & 0.138 & 0.229 & 0.058 & 0.995 \\
\hline gNDVI & 0.876 & 0.048 & 0.038 & 0.058 & 0.993 \\
\hline GRR & 0.363 & 0.424 & 0.372 & 0.172 & 0.976 \\
\hline IPVI & 0.892 & 0.047 & 0.033 & 0.036 & 0.999 \\
\hline $\mathrm{LIC}_{2}$ & 0.205 & 0.261 & 0.180 & 0.273 & 0.968 \\
\hline $\mathrm{LIC}_{3}$ & -1.273 & 0.070 & 0.039 & 0.342 & 0.973 \\
\hline mARI & -12.774 & 1.319 & 2.412 & 5.851 & 0.503 \\
\hline MCARI & -70.250 & 2.776 & 0.031 & 0.522 & 0.894 \\
\hline $\mathrm{MCARI}_{1}$ & 0.950 & 0.066 & 0.002 & 0.006 & 0.997 \\
\hline $\mathrm{MCARI}_{2}$ & -2.669 & 0.539 & 0.050 & 0.166 & 0.953 \\
\hline $\mathrm{mNDVI}_{705}$ & -1.445 & 0.370 & 0.100 & 0.174 & 0.928 \\
\hline MSR & 0.417 & 0.305 & 0.154 & 0.054 & 0.996 \\
\hline $\mathrm{mSR}_{705}$ & -0.706 & 0.641 & 1.101 & 0.291 & 0.969 \\
\hline $\mathrm{MSAVI}_{2}$ & 0.963 & 0.053 & 0.013 & 0.031 & 0.997 \\
\hline $\mathrm{MTVI}_{1}$ & 0.950 & 0.066 & 0.002 & 0.006 & 0.997 \\
\hline $\mathrm{MTVI}_{2}$ & -0.073 & 0.231 & 0.040 & 0.133 & 0.953 \\
\hline NDVIg-b & -1.348 & 0.318 & 0.058 & 0.167 & 0.708 \\
\hline NDVI & 0.892 & 0.047 & 0.033 & 0.043 & 0.999 \\
\hline $\mathrm{NDWI}_{\mathrm{Mc}}$ & 0.876 & 0.048 & 0.038 & 0.058 & 0.993 \\
\hline NGRR & 0.428 & 0.228 & 0.050 & 0.159 & 0.994 \\
\hline NPCI & 0.747 & 0.320 & 0.057 & 0.271 & 0.981 \\
\hline OSAVI & 0.933 & 0.067 & 0.025 & 0.045 & 0.997 \\
\hline PSRI & 0.909 & 0.138 & 0.014 & 0.343 & 0.991 \\
\hline RVI & 0.748 & 0.290 & 1.241 & 0.114 & 0.989 \\
\hline $\mathrm{NDVI}_{705}$ & -0.544 & 0.309 & 0.089 & 0.186 & 0.967 \\
\hline
\end{tabular}


Table B.1 (continued)

\begin{tabular}{lrrrrr}
\hline \multicolumn{1}{c}{ INDEX } & $\begin{array}{c}\text { MEAN } \\
1: 1 \mathrm{R}^{2}\end{array}$ & $\begin{array}{c}\text { MEAN } \\
\mid \text { SLOPE-1 } \mid\end{array}$ & $\begin{array}{c}\text { MEAN } \\
\text { |INTERCEPT } \mid\end{array}$ & $\begin{array}{c}\text { MEAN } \\
\text { |NORMALIZED } \\
\text { INTERCEPT } \mid\end{array}$ & $\begin{array}{c}\text { MEAN } \\
\text { CCR }^{2}\end{array}$ \\
\hline RBI & -0.730 & 0.333 & 0.281 & 0.142 & 0.903 \\
RGI & 0.795 & 0.152 & 0.184 & 0.222 & 0.996 \\
RDVI & 0.953 & 0.043 & 0.010 & 0.024 & 0.996 \\
SARVI & 0.948 & 0.069 & 0.013 & 0.035 & 0.996 \\
SAVI & 0.963 & 0.042 & 0.011 & 0.026 & 0.997 \\
SIPI & 0.823 & 0.055 & 0.036 & 0.044 & 0.998 \\
TCARI & -2.619 & 0.134 & 0.009 & 0.119 & 0.646 \\
TNDVI & 0.894 & 0.042 & 0.045 & 0.038 & 0.999 \\
TVI & 0.939 & 0.066 & 0.181 & 0.014 & 0.990 \\
VARI & -0.343 & 0.548 & 0.042 & 0.107 & 0.992 \\
\hline
\end{tabular}


Table B.2: Individual values (per index) for the statistical measures for the ten sensors studied in Chapter 3, comparing index values generated from convolved narrow- and broadband data to index values obtained from original narrowband ASD data.

\begin{tabular}{|c|c|c|c|c|c|c|c|c|c|c|}
\hline \multicolumn{11}{|c|}{${ }_{1: 1} \mathbf{R}^{2}$} \\
\hline INDEX & TC10 & $\begin{array}{l}\text { HY- } \\
\text { MAP* }\end{array}$ & TC05 & $\begin{array}{l}\text { RAPID- } \\
\text { EYE }\end{array}$ & $\begin{array}{l}\text { IKO- } \\
\text { NOS }\end{array}$ & $\begin{array}{l}\text { GEO- } \\
\text { EYE }\end{array}$ & WV3* & WV2 & $\begin{array}{l}\text { PLÉIA- } \\
\text { DES } \dagger\end{array}$ & QB \\
\hline ARI & 0.576 & -3.853 & -0.624 & -14.216 & NA & NA & -34.998 & -28.234 & NA & NA \\
\hline ARVI & NA & 0.685 & 0.971 & 0.989 & 0.537 & 0.998 & 0.854 & 0.995 & 0.959 & 0.876 \\
\hline $\mathrm{BGI}_{2}$ & NA & 0.944 & 0.646 & -0.260 & -8.842 & -1.320 & -3.378 & -0.670 & -10.049 & -7.247 \\
\hline $\mathrm{BRI}_{1}$ & NA & NA & -5.733 & -3.849 & -2.346 & -5.785 & -1.510 & -3.714 & -6.761 & -3.022 \\
\hline $\mathrm{CRI}_{700}$ & -2.806 & 0.985 & -2.807 & 0.101 & NA & NA & 0.921 & 0.830 & NA & NA \\
\hline $\mathrm{CTR}_{1}$ & NA & NA & 0.378 & -4.199 & NA & NA & -47.760 & -40.060 & NA & NA \\
\hline $\mathrm{CTR}_{2}$ & 0.784 & 0.985 & 0.604 & -1.604 & NA & NA & -10.568 & -9.421 & NA & NA \\
\hline CARI & -0.376 & -0.348 & -0.377 & -0.324 & NA & NA & -0.244 & -0.238 & NA & NA \\
\hline DVI & 0.966 & 0.999 & 0.983 & 0.993 & 0.877 & 1.000 & 0.986 & 1.000 & 0.995 & 0.958 \\
\hline EVI & NA & 0.999 & 0.972 & 0.989 & 0.806 & 0.999 & 0.954 & 0.999 & 0.998 & 0.939 \\
\hline $\mathrm{GM}_{1}$ & 0.352 & 0.998 & 0.247 & -0.214 & 0.562 & -0.748 & -1.421 & -0.664 & 0.324 & -0.989 \\
\hline $\mathrm{GM}_{2}$ & 0.945 & 0.220 & 0.995 & -0.091 & NA & NA & -1.942 & -1.784 & NA & NA \\
\hline GEMI & 0.972 & 1.000 & 0.986 & 0.994 & 0.887 & 1.000 & 0.988 & 1.000 & 0.995 & 0.962 \\
\hline CIg & 0.953 & 0.991 & 0.966 & 0.864 & 0.990 & 0.707 & 0.454 & 0.734 & 0.982 & 0.612 \\
\hline gNDVI & 0.914 & 0.993 & 0.968 & 0.925 & 0.979 & 0.778 & 0.644 & 0.811 & 0.981 & 0.766 \\
\hline GRR & 1.000 & 0.933 & 0.942 & 0.621 & -0.577 & 0.715 & -0.225 & 0.572 & -0.054 & -0.296 \\
\hline IPVI & 0.969 & 0.999 & 0.986 & 0.989 & 0.407 & 0.999 & 0.884 & 0.996 & 0.852 & 0.839 \\
\hline $\mathrm{LIC}_{2}$ & NA & 0.565 & -0.379 & 0.261 & 0.511 & -0.370 & 0.742 & 0.901 & -0.804 & 0.416 \\
\hline $\mathrm{LIC}_{3}$ & NA & 0.861 & 0.817 & -9.158 & NA & NA & 0.655 & 0.458 & NA & NA \\
\hline mARI & 0.534 & -3.548 & -0.624 & -13.057 & NA & NA & -32.601 & -27.345 & NA & NA \\
\hline MCARI & 0.724 & -4.841 & 0.805 & -15.919 & NA & NA & -149.38 & -252.88 & NA & NA \\
\hline $\mathrm{MCARI}_{1}$ & 0.942 & 0.999 & 0.987 & 0.989 & 0.776 & 0.998 & 0.941 & 0.995 & 0.976 & 0.898 \\
\hline $\mathrm{MCARI}_{2}$ & -5.734 & -3.837 & -3.520 & -2.942 & 0.049 & -3.595 & -1.333 & -3.174 & -1.671 & -0.930 \\
\hline $\mathrm{mNDVI}_{705}$ & NA & 0.928 & 0.340 & 0.687 & NA & NA & -4.973 & -4.206 & NA & NA \\
\hline MSR & 0.860 & 0.734 & 0.773 & 0.613 & -0.450 & 0.716 & 0.177 & 0.625 & 0.039 & 0.085 \\
\hline $\mathrm{mSR}_{705}$ & NA & 0.866 & -0.886 & 0.485 & NA & NA & -2.108 & -1.886 & NA & NA \\
\hline $\mathrm{MSAVI}_{2}$ & 0.941 & 1.000 & 0.997 & 0.997 & 0.809 & 0.995 & 0.974 & 0.998 & 0.978 & 0.943 \\
\hline $\mathrm{MTVI}_{1}$ & 0.942 & 0.999 & 0.987 & 0.989 & 0.776 & 0.998 & 0.941 & 0.995 & 0.976 & 0.898 \\
\hline $\mathrm{MTVI}_{2}$ & -1.408 & -0.545 & -0.411 & -0.142 & 0.913 & -0.429 & 0.501 & -0.240 & 0.384 & 0.644 \\
\hline NDVIg-b & NA & 0.806 & 0.485 & 0.222 & -4.923 & -0.475 & 0.759 & 0.592 & -5.693 & -3.902 \\
\hline NDVI & 0.969 & 0.999 & 0.986 & 0.989 & 0.407 & 0.999 & 0.884 & 0.996 & 0.852 & 0.839 \\
\hline $\mathrm{NDWI}_{\mathrm{Mc}}$ & 0.914 & 0.993 & 0.968 & 0.925 & 0.979 & 0.778 & 0.644 & 0.811 & 0.981 & 0.766 \\
\hline NGRR & 1.000 & 0.968 & 0.940 & 0.777 & -0.683 & 0.800 & -0.177 & 0.722 & 0.175 & -0.242 \\
\hline NPCI & NA & 0.960 & 0.948 & 0.862 & 0.664 & 0.831 & 0.284 & 0.894 & 0.533 & 0.743 \\
\hline OSAVI & 0.928 & 0.999 & 0.996 & 0.994 & 0.639 & 0.996 & 0.943 & 0.996 & 0.943 & 0.898 \\
\hline PSRI & NA & 1.000 & 0.950 & 0.954 & 0.754 & 0.982 & 0.791 & 0.948 & 0.910 & 0.892 \\
\hline RVI & 0.993 & 0.989 & 0.999 & 0.922 & 0.122 & 0.976 & 0.588 & 0.923 & 0.457 & 0.515 \\
\hline $\mathrm{NDVI}_{705}$ & -0.016 & 0.940 & 0.523 & 0.798 & NA & NA & -3.031 & -2.480 & NA & NA \\
\hline
\end{tabular}


Appendix B

Table B.2 (continued)

\begin{tabular}{|c|c|c|c|c|c|c|c|c|c|c|}
\hline \multicolumn{11}{|c|}{${ }_{1: 1} \mathbf{R}^{2}$} \\
\hline INDEX & TC10 & $\begin{array}{l}\text { HY- } \\
\text { MAP* }\end{array}$ & TC05 & $\begin{array}{l}\text { RAPID- } \\
\text { EYE }\end{array}$ & $\begin{array}{l}\text { IKO- } \\
\text { NOS }\end{array}$ & $\begin{array}{l}\text { GEO- } \\
\text { EYE }\end{array}$ & WV3* & WV2 & $\begin{array}{l}\text { PLÉIA- } \\
\text { DES'† }\end{array}$ & QB \\
\hline RBI & NA & 0.851 & -0.962 & -1.181 & -1.170 & -1.517 & 0.847 & 0.145 & -2.314 & -1.271 \\
\hline RGI & 0.732 & 0.694 & 0.919 & 0.959 & 0.419 & 0.987 & 0.715 & 0.984 & 0.852 & 0.686 \\
\hline RDVI & 0.926 & 1.000 & 0.996 & 0.997 & 0.751 & 0.995 & 0.968 & 0.997 & 0.972 & 0.931 \\
\hline SARVI & NA & 0.999 & 0.998 & 0.995 & 0.759 & 0.986 & 0.889 & 0.993 & 0.977 & 0.935 \\
\hline SAVI & 0.932 & 1.000 & 0.997 & 0.998 & 0.806 & 0.994 & 0.977 & 0.997 & 0.982 & 0.947 \\
\hline SIPI & NA & 0.998 & 0.998 & 0.981 & 0.168 & 0.990 & 0.975 & 0.982 & 0.566 & 0.747 \\
\hline TCARI & 0.959 & 0.646 & 0.995 & 0.309 & NA & NA & -5.720 & -12.903 & NA & NA \\
\hline TNDVI & 0.968 & 0.999 & 0.983 & 0.989 & 0.409 & 0.999 & 0.889 & 0.996 & 0.861 & 0.844 \\
\hline TVI & 0.724 & 0.994 & 0.973 & 0.962 & 0.959 & 0.915 & 0.984 & 0.933 & 0.959 & 0.991 \\
\hline VARI & NA & 0.344 & 0.325 & 0.012 & -1.267 & 0.044 & -0.863 & -0.048 & -0.677 & -0.952 \\
\hline
\end{tabular}

\begin{tabular}{|c|c|c|c|c|c|c|c|c|c|c|}
\hline \multicolumn{11}{|c|}{ slope } \\
\hline INDEX & TC10 & $\begin{array}{l}\text { HY- } \\
\text { MAP* }\end{array}$ & TC05 & $\begin{array}{l}\text { RAPID- } \\
\text { EYE }\end{array}$ & $\begin{array}{l}\text { IKO- } \\
\text { NOS }\end{array}$ & $\begin{array}{l}\text { GEO- } \\
\text { EYE }\end{array}$ & WV3* & WV2 & $\begin{array}{l}\text { PLÉIA- } \\
\text { DES'† }\end{array}$ & QB \\
\hline ARI & 0.616 & -0.176 & 0.486 & -1.135 & NA & NA & -2.000 & -1.715 & NA & NA \\
\hline ARVI & NA & 0.692 & 1.158 & 1.031 & 0.926 & 1.043 & 0.938 & 0.997 & 0.895 & 0.944 \\
\hline $\mathrm{BGI}_{2}$ & NA & 1.019 & 1.012 & 0.953 & 0.594 & 0.967 & 0.848 & 0.984 & 0.544 & 0.693 \\
\hline $\mathrm{BRI}_{1}$ & NA & NA & 1.802 & 1.265 & 0.749 & 1.468 & 0.873 & 1.231 & 1.063 & 0.933 \\
\hline $\mathrm{CRI}_{700}$ & -0.051 & 0.994 & -0.051 & 0.626 & NA & NA & 1.035 & 0.907 & NA & NA \\
\hline $\mathrm{CTR}_{1}$ & NA & NA & 0.670 & 0.186 & NA & NA & 0.423 & 0.489 & NA & NA \\
\hline $\mathrm{CTR}_{2}$ & 0.703 & 0.964 & 0.928 & 0.752 & NA & NA & 0.368 & 0.440 & NA & NA \\
\hline CARI & 0.022 & 0.023 & 0.022 & 0.024 & NA & NA & 0.020 & 0.013 & NA & NA \\
\hline DVI & 1.058 & 1.012 & 0.959 & 0.971 & 0.859 & 1.009 & 0.953 & 0.999 & 0.974 & 0.920 \\
\hline EVI & NA & 1.011 & 0.992 & 0.984 & 0.879 & 1.010 & 0.919 & 0.991 & 1.011 & 0.934 \\
\hline $\mathrm{GM}_{1}$ & 1.021 & 0.985 & 1.242 & 1.435 & 1.232 & 1.404 & 1.526 & 1.421 & 1.212 & 1.526 \\
\hline $\mathrm{GM}_{2}$ & 0.905 & 0.519 & 0.938 & 0.384 & NA & NA & 0.089 & 0.115 & NA & NA \\
\hline GEMI & 1.004 & 1.005 & 1.001 & 0.994 & 0.909 & 0.998 & 0.961 & 0.998 & 0.965 & 0.956 \\
\hline $\mathrm{CIg}$ & 0.859 & 1.035 & 1.036 & 1.202 & 1.030 & 1.176 & 1.278 & 1.190 & 1.014 & 1.276 \\
\hline gNDVI & 0.804 & 0.998 & 0.998 & 1.086 & 1.078 & 0.978 & 1.009 & 1.005 & 0.988 & 1.071 \\
\hline GRR & 0.989 & 0.833 & 0.902 & 0.600 & 0.217 & 0.691 & 0.327 & 0.591 & 0.316 & 0.293 \\
\hline IPVI & 0.938 & 0.998 & 1.106 & 1.027 & 0.956 & 1.020 & 0.949 & 0.992 & 0.889 & 0.959 \\
\hline $\mathrm{LIC}_{2}$ & NA & 0.571 & 1.496 & 1.047 & 0.617 & 1.229 & 0.715 & 1.138 & 0.893 & 0.769 \\
\hline $\mathrm{LIC}_{3}$ & NA & 1.087 & 1.066 & 1.170 & NA & NA & 1.020 & 1.009 & NA & NA \\
\hline mARI & 0.770 & 0.037 & 0.601 & -0.766 & NA & NA & -1.359 & -1.197 & NA & NA \\
\hline MCARI & 1.244 & 2.123 & 1.206 & 2.911 & NA & NA & 6.696 & 8.475 & NA & NA \\
\hline $\mathrm{MCARI}_{1}$ & 1.058 & 0.986 & 0.962 & 0.961 & 0.813 & 0.988 & 0.900 & 0.977 & 0.942 & 0.873 \\
\hline $\mathrm{MCARI}_{2}$ & 1.697 & 1.683 & 1.690 & 1.604 & 1.256 & 1.627 & 1.415 & 1.599 & 1.422 & 1.393 \\
\hline $\mathrm{mNDVI}_{705}$ & NA & 0.921 & 0.995 & 0.659 & NA & NA & 0.253 & 0.323 & NA & NA \\
\hline MSR & 0.868 & 0.849 & 0.886 & 0.757 & 0.423 & 0.810 & 0.567 & 0.747 & 0.500 & 0.542 \\
\hline $\mathrm{mSR}_{705}$ & NA & 0.779 & 1.707 & 0.502 & NA & NA & 0.095 & 0.128 & NA & NA \\
\hline
\end{tabular}


Table B.2 (continued)

\begin{tabular}{|c|c|c|c|c|c|c|c|c|c|c|}
\hline \multicolumn{11}{|c|}{ slope } \\
\hline INDEX & TC10 & $\begin{array}{l}\text { HY- } \\
\text { MAP* }\end{array}$ & TC05 & $\begin{array}{c}\text { RAPID- } \\
\text { EYE }\end{array}$ & $\begin{array}{l}\text { IKO- } \\
\text { NOS }\end{array}$ & $\begin{array}{l}\text { GEO- } \\
\text { EYE }\end{array}$ & WV3* & WV2 & $\begin{array}{l}\text { PLÉIA- } \\
\text { DES† }\end{array}$ & QB \\
\hline $\mathrm{MSAVI}_{2}$ & 0.994 & 0.989 & 0.998 & 0.975 & 0.832 & 0.985 & 0.912 & 0.978 & 0.909 & 0.900 \\
\hline $\mathrm{MTVI}_{1}$ & 1.058 & 0.986 & 0.962 & 0.961 & 0.813 & 0.988 & 0.900 & 0.977 & 0.942 & 0.873 \\
\hline $\mathrm{MTVI}_{2}$ & 1.358 & 1.346 & 1.352 & 1.283 & 1.005 & 1.302 & 1.132 & 1.279 & 1.138 & 1.114 \\
\hline NDVIg-b & NA & 0.879 & 0.787 & 0.674 & 0.415 & 0.584 & 0.974 & 0.966 & 0.380 & 0.481 \\
\hline NDVI & 0.938 & 0.998 & 1.106 & 1.027 & 0.956 & 1.020 & 0.949 & 0.992 & 0.889 & 0.959 \\
\hline $\mathrm{NDWI}_{\mathrm{Mc}}$ & 0.804 & 0.998 & 0.998 & 1.086 & 1.078 & 0.978 & 1.009 & 1.005 & 0.988 & 1.071 \\
\hline NGRR & 0.999 & 0.941 & 1.029 & 0.816 & 0.474 & 0.914 & 0.630 & 0.831 & 0.566 & 0.576 \\
\hline NPCI & NA & 0.868 & 0.921 & 0.674 & 0.427 & 0.748 & 0.611 & 0.826 & 0.527 & 0.513 \\
\hline OSAVI & 0.906 & 0.994 & 1.019 & 0.971 & 0.879 & 0.957 & 0.901 & 0.950 & 0.881 & 0.910 \\
\hline PSRI & NA & 1.001 & 1.088 & 0.881 & 0.851 & 0.890 & 0.835 & 0.842 & 0.733 & 0.814 \\
\hline RVI & 1.003 & 0.925 & 0.984 & 0.784 & 0.329 & 0.875 & 0.516 & 0.778 & 0.435 & 0.479 \\
\hline $\mathrm{NDVI}_{705}$ & 0.843 & 0.937 & 1.030 & 0.738 & NA & NA & 0.297 & 0.364 & NA & NA \\
\hline RBI & NA & 0.837 & 0.807 & 0.583 & 0.395 & 0.588 & 1.001 & 0.971 & 0.368 & 0.454 \\
\hline RGI & 0.949 & 0.947 & 1.052 & 0.863 & 0.652 & 0.980 & 0.815 & 0.902 & 0.675 & 0.745 \\
\hline RDVI & 0.974 & 0.995 & 1.004 & 0.981 & 0.879 & 0.986 & 0.931 & 0.980 & 0.930 & 0.923 \\
\hline SARVI & NA & 0.992 & 1.010 & 0.961 & 0.843 & 0.970 & 0.876 & 0.952 & 0.904 & 0.890 \\
\hline SAVI & 0.976 & 0.992 & 1.003 & 0.982 & 0.878 & 0.984 & 0.932 & 0.981 & 0.931 & 0.927 \\
\hline SIPI & NA & 1.006 & 1.029 & 1.012 & 0.952 & 0.990 & 0.865 & 0.899 & 0.888 & 0.959 \\
\hline TCARI & 1.080 & 1.221 & 0.979 & 1.219 & NA & NA & 0.954 & 0.785 & NA & NA \\
\hline TNDVI & 0.928 & 0.997 & 1.114 & 1.034 & 0.992 & 1.021 & 0.961 & 0.994 & 0.902 & 0.977 \\
\hline TVI & 1.159 & 0.969 & 1.063 & 1.064 & 0.916 & 1.096 & 1.012 & 1.085 & 1.049 & 0.981 \\
\hline VARI & NA & 0.555 & 0.630 & 0.496 & 0.281 & 0.549 & 0.384 & 0.506 & 0.322 & 0.340 \\
\hline
\end{tabular}

\begin{tabular}{|c|c|c|c|c|c|c|c|c|c|c|}
\hline \multicolumn{11}{|c|}{ intercept } \\
\hline INDEX & TC10 & $\begin{array}{l}\text { HY- } \\
\text { MAP* }\end{array}$ & TC05 & $\begin{array}{l}\text { RAPID- } \\
\text { EYE }\end{array}$ & $\begin{array}{l}\text { IKO- } \\
\text { NOS }\end{array}$ & $\begin{array}{l}\text { GEO- } \\
\text { EYE }\end{array}$ & WV3* & WV2 & $\begin{array}{l}\text { PLÉIA- } \\
\text { DES } \dagger\end{array}$ & QB \\
\hline ARI & 2.071 & 7.105 & 4.196 & 12.547 & NA & NA & 19.477 & 17.531 & NA & NA \\
\hline ARVI & NA & 0.138 & -0.120 & -0.039 & -0.064 & -0.029 & -0.021 & -0.011 & 0.044 & -0.020 \\
\hline $\mathrm{BGI}_{2}$ & NA & 0.008 & 0.039 & 0.103 & 0.406 & 0.126 & 0.220 & 0.102 & 0.441 & 0.344 \\
\hline $\mathrm{BRI}_{1}$ & NA & NA & -0.004 & 0.212 & 0.399 & 0.172 & 0.303 & 0.224 & 0.401 & 0.342 \\
\hline $\mathrm{CRI}_{700}$ & 5.792 & -0.236 & 5.794 & -0.124 & NA & NA & -1.654 & -0.944 & NA & NA \\
\hline $\mathrm{CTR}_{1}$ & NA & NA & 1.312 & 3.520 & NA & NA & 6.547 & 5.983 & NA & NA \\
\hline $\mathrm{CTR}_{2}$ & 0.106 & -0.005 & 0.086 & 0.236 & NA & NA & 0.522 & 0.486 & NA & NA \\
\hline CARI & 0.178 & 0.264 & 0.176 & 0.336 & NA & NA & 0.676 & 0.785 & NA & NA \\
\hline DVI & 0.003 & -0.001 & -0.001 & -0.001 & -0.001 & 0.000 & 0.000 & -0.001 & -0.001 & -0.001 \\
\hline EVI & NA & 0.000 & -0.015 & -0.007 & -0.008 & -0.001 & 0.007 & -0.001 & -0.007 & -0.006 \\
\hline $\mathrm{GM}_{1}$ & 0.667 & 0.091 & -0.205 & -0.834 & -0.372 & -0.467 & -0.775 & -0.577 & -0.118 & -0.923 \\
\hline $\mathrm{GM}_{2}$ & 0.655 & 0.737 & 0.202 & 1.095 & NA & NA & 1.320 & 1.280 & NA & NA \\
\hline GEMI & 0.019 & -0.001 & -0.015 & -0.006 & 0.014 & 0.004 & 0.010 & 0.000 & 0.014 & 0.002 \\
\hline $\mathrm{CIg}$ & 0.667 & -0.032 & 0.039 & -0.412 & -0.144 & -0.077 & -0.262 & -0.168 & 0.087 & -0.405 \\
\hline
\end{tabular}


Appendix B

Table B.2 (continued)

\begin{tabular}{|c|c|c|c|c|c|c|c|c|c|c|}
\hline \multicolumn{11}{|c|}{ intercept } \\
\hline INDEX & TC10 & $\begin{array}{l}\text { HY- } \\
\text { MAP* }\end{array}$ & TC05 & $\begin{array}{l}\text { RAPID- } \\
\text { EYE }\end{array}$ & $\begin{array}{l}\text { IKO- } \\
\text { NOS }\end{array}$ & $\begin{array}{l}\text { GEO- } \\
\text { EYE }\end{array}$ & WV3* & WV2 & $\begin{array}{l}\text { PLÉIA- } \\
\text { DES } \dagger\end{array}$ & QB \\
\hline gNDVI & 0.137 & 0.007 & 0.011 & -0.038 & -0.054 & 0.046 & 0.034 & 0.026 & 0.016 & -0.014 \\
\hline GRR & 0.006 & 0.157 & -0.002 & 0.388 & 0.693 & 0.230 & 0.566 & 0.366 & 0.692 & 0.622 \\
\hline IPVI & 0.064 & 0.003 & -0.095 & -0.030 & -0.008 & -0.019 & 0.024 & 0.003 & 0.075 & 0.011 \\
\hline $\mathrm{LIC}_{2}$ & NA & 0.176 & -0.110 & 0.139 & 0.358 & 0.079 & 0.102 & -0.035 & 0.332 & 0.290 \\
\hline $\mathrm{LIC}_{3}$ & NA & 0.006 & 0.011 & 0.123 & NA & NA & 0.023 & 0.031 & NA & NA \\
\hline mARI & 0.515 & 1.631 & 0.951 & 2.869 & NA & NA & 4.434 & 4.076 & NA & NA \\
\hline MCARI & -0.002 & -0.011 & -0.002 & -0.018 & NA & NA & -0.063 & -0.093 & NA & NA \\
\hline MCARI $_{1}$ & 0.011 & 0.000 & -0.002 & -0.001 & -0.002 & 0.002 & 0.001 & 0.000 & 0.001 & -0.001 \\
\hline $\mathrm{MCARI}_{2}$ & 0.090 & 0.041 & 0.028 & 0.043 & 0.034 & 0.055 & 0.050 & 0.053 & 0.063 & 0.040 \\
\hline $\mathrm{mNDVI}_{705}$ & NA & 0.013 & 0.098 & 0.135 & NA & NA & 0.136 & 0.115 & NA & NA \\
\hline MSR & -0.064 & -0.179 & -0.238 & -0.038 & 0.251 & -0.087 & 0.183 & 0.003 & 0.301 & 0.199 \\
\hline $\mathrm{mSR}_{705}$ & NA & 0.449 & -1.107 & 1.187 & NA & NA & 1.407 & 1.356 & NA & NA \\
\hline $\mathrm{MSAVI}_{2}$ & 0.034 & 0.003 & -0.006 & 0.004 & 0.008 & 0.014 & 0.016 & 0.012 & 0.021 & 0.009 \\
\hline $\mathrm{MTVI}_{1}$ & 0.011 & 0.000 & -0.002 & -0.001 & -0.002 & 0.002 & 0.001 & 0.000 & 0.001 & -0.001 \\
\hline $\mathrm{MTVI}_{2}$ & 0.072 & 0.033 & 0.023 & 0.034 & 0.027 & 0.044 & 0.040 & 0.042 & 0.050 & 0.032 \\
\hline NDVIg-b & NA & 0.017 & 0.080 & 0.085 & 0.057 & 0.092 & 0.035 & 0.048 & 0.060 & 0.048 \\
\hline NDVI & 0.066 & 0.005 & -0.084 & -0.033 & -0.060 & -0.017 & -0.002 & -0.001 & 0.039 & -0.018 \\
\hline $\mathrm{NDWI}_{\mathrm{Mc}}$ & -0.137 & -0.007 & -0.011 & 0.038 & 0.054 & -0.046 & -0.034 & -0.026 & -0.016 & 0.014 \\
\hline NGRR & 0.003 & 0.016 & 0.055 & 0.032 & 0.080 & 0.061 & 0.093 & 0.049 & 0.031 & 0.079 \\
\hline NPCI & NA & -0.007 & -0.028 & 0.018 & 0.083 & -0.022 & 0.202 & 0.078 & -0.020 & 0.053 \\
\hline OSAVI & 0.079 & 0.000 & -0.017 & 0.008 & -0.002 & 0.028 & 0.030 & 0.027 & 0.043 & 0.014 \\
\hline PSRI & NA & -0.001 & 0.008 & 0.013 & 0.031 & 0.007 & 0.029 & 0.014 & 0.003 & 0.021 \\
\hline RVI & 0.528 & 0.278 & -0.022 & 0.990 & 2.259 & 0.671 & 1.992 & 1.134 & 2.453 & 2.083 \\
\hline $\mathrm{NDVI}_{705}$ & 0.189 & 0.002 & 0.067 & 0.080 & NA & NA & 0.107 & 0.091 & NA & NA \\
\hline RBI & NA & 0.146 & -0.385 & 0.072 & 0.518 & -0.004 & -0.221 & -0.466 & 0.363 & 0.355 \\
\hline RGI & -0.098 & 0.184 & -0.112 & 0.063 & 0.434 & -0.014 & 0.267 & 0.054 & 0.292 & 0.318 \\
\hline RDVI & 0.035 & 0.000 & -0.007 & 0.003 & -0.001 & 0.012 & 0.012 & 0.010 & 0.015 & 0.005 \\
\hline SARVI & NA & 0.001 & -0.009 & 0.011 & 0.003 & 0.023 & 0.010 & 0.011 & 0.035 & 0.015 \\
\hline SAVI & 0.037 & 0.002 & -0.007 & 0.003 & 0.000 & 0.014 & 0.013 & 0.011 & 0.017 & 0.004 \\
\hline SIPI & NA & -0.008 & -0.026 & -0.021 & -0.043 & 0.000 & 0.100 & 0.087 & 0.031 & -0.012 \\
\hline TCARI & -0.001 & -0.001 & 0.001 & -0.006 & NA & NA & -0.019 & -0.028 & NA & NA \\
\hline TNDVI & 0.089 & 0.005 & -0.130 & -0.043 & -0.033 & -0.025 & 0.025 & 0.003 & 0.089 & 0.004 \\
\hline TVI & 0.628 & -0.003 & 0.044 & 0.124 & 0.059 & 0.237 & 0.212 & 0.182 & 0.214 & 0.111 \\
\hline VARI & NA & -0.003 & -0.044 & -0.026 & -0.062 & -0.048 & -0.073 & -0.039 & -0.023 & -0.061 \\
\hline
\end{tabular}


Table B.2 (continued)

\begin{tabular}{|c|c|c|c|c|c|c|c|c|c|c|}
\hline \multicolumn{11}{|c|}{ normalized intercept } \\
\hline INDEX & TC10 & $\begin{array}{c}\text { HY- } \\
\text { MAP* }\end{array}$ & TC05 & $\begin{array}{c}\text { RAPID- } \\
\text { EYE }\end{array}$ & $\begin{array}{l}\text { IKO- } \\
\text { NOS }\end{array}$ & $\begin{array}{l}\text { GEO- } \\
\text { EYE }\end{array}$ & WV3* & WV2 & $\begin{array}{c}\text { PLÉIA- } \\
\text { DES } \dagger \\
\end{array}$ & QB \\
\hline ARI & 1.460 & 5.010 & 2.958 & 8.846 & NA & NA & 12.361 & 12.361 & NA & NA \\
\hline ARVI & NA & 0.197 & -0.171 & -0.055 & -0.091 & -0.041 & -0.029 & -0.015 & 0.063 & -0.029 \\
\hline $\mathrm{BGI}_{2}$ & NA & 0.018 & 0.090 & 0.239 & 0.942 & 0.292 & 0.236 & 0.236 & 1.023 & 0.798 \\
\hline $\mathrm{BRI}_{1}$ & NA & NA & -0.009 & 0.454 & 0.853 & 0.367 & 0.480 & 0.480 & 0.859 & 0.732 \\
\hline $\mathrm{CRI}_{700}$ & 0.328 & -0.013 & 0.328 & -0.007 & NA & NA & -0.053 & -0.053 & NA & NA \\
\hline $\mathrm{CTR}_{1}$ & NA & NA & 0.532 & 1.426 & NA & NA & 2.425 & 2.425 & NA & NA \\
\hline $\mathrm{CTR}_{2}$ & 0.456 & -0.020 & 0.369 & 1.012 & NA & NA & 2.086 & 2.086 & NA & NA \\
\hline CARI & 0.063 & 0.093 & 0.062 & 0.118 & NA & NA & 0.275 & 0.275 & NA & NA \\
\hline DVI & 0.012 & -0.003 & -0.004 & -0.004 & -0.004 & -0.001 & -0.004 & -0.004 & -0.004 & -0.004 \\
\hline EVI & NA & -0.001 & -0.034 & -0.016 & -0.019 & -0.002 & -0.001 & -0.001 & -0.017 & -0.014 \\
\hline $\mathrm{GM}_{1}$ & 0.161 & 0.022 & -0.049 & -0.202 & -0.090 & -0.113 & -0.139 & -0.139 & -0.029 & -0.223 \\
\hline $\mathrm{GM}_{2}$ & 0.174 & 0.195 & 0.054 & 0.290 & NA & NA & 0.339 & 0.339 & NA & NA \\
\hline GEMI & 0.029 & -0.001 & -0.024 & -0.010 & 0.021 & 0.006 & 0.000 & 0.000 & 0.022 & 0.003 \\
\hline CIg & 0.177 & -0.008 & 0.010 & -0.109 & -0.038 & -0.020 & -0.045 & -0.045 & 0.023 & -0.108 \\
\hline gNDVI & 0.214 & 0.010 & 0.017 & -0.060 & -0.084 & 0.071 & 0.040 & 0.040 & 0.025 & -0.022 \\
\hline GRR & 0.003 & 0.077 & -0.001 & 0.190 & 0.339 & 0.112 & 0.179 & 0.179 & 0.338 & 0.304 \\
\hline IPVI & 0.073 & 0.004 & -0.109 & -0.034 & -0.009 & -0.021 & 0.004 & 0.004 & 0.085 & 0.013 \\
\hline $\mathrm{LIC}_{2}$ & NA & 0.278 & -0.173 & 0.220 & 0.565 & 0.124 & -0.055 & -0.055 & 0.525 & 0.459 \\
\hline $\mathrm{LIC}_{3}$ & NA & 0.050 & 0.095 & 1.038 & NA & NA & 0.262 & 0.262 & NA & NA \\
\hline mARI & 1.280 & 4.055 & 2.364 & 7.135 & NA & NA & 10.135 & 10.135 & NA & NA \\
\hline MCARI & -0.030 & -0.152 & -0.029 & -0.263 & NA & NA & -1.329 & -1.329 & NA & NA \\
\hline $\mathrm{MCARI}_{1}$ & 0.030 & 0.001 & -0.006 & -0.002 & -0.006 & 0.004 & 0.001 & 0.001 & 0.003 & -0.003 \\
\hline $\mathrm{MCARI}_{2}$ & 0.299 & 0.137 & 0.094 & 0.143 & 0.112 & 0.182 & 0.175 & 0.175 & 0.208 & 0.134 \\
\hline $\mathrm{mNDVI}_{705}$ & NA & 0.024 & 0.179 & 0.247 & NA & NA & 0.211 & 0.211 & NA & NA \\
\hline MSR & -0.026 & -0.071 & -0.095 & -0.015 & 0.100 & -0.035 & 0.001 & 0.001 & 0.120 & 0.079 \\
\hline $\mathrm{mSR}_{705}$ & NA & 0.120 & -0.296 & 0.317 & NA & NA & 0.362 & 0.362 & NA & NA \\
\hline $\mathrm{MSAVI}_{2}$ & 0.087 & 0.006 & -0.016 & 0.010 & 0.020 & 0.036 & 0.029 & 0.029 & 0.055 & 0.022 \\
\hline $\mathrm{MTVI}_{1}$ & 0.030 & 0.001 & -0.006 & -0.002 & -0.006 & 0.004 & 0.001 & 0.001 & 0.003 & -0.003 \\
\hline $\mathrm{MTVI}_{2}$ & 0.239 & 0.110 & 0.075 & 0.114 & 0.089 & 0.146 & 0.140 & 0.140 & 0.166 & 0.107 \\
\hline NDVIg-b & NA & 0.048 & 0.225 & 0.238 & 0.161 & 0.259 & 0.134 & 0.134 & 0.168 & 0.135 \\
\hline NDVI & 0.088 & 0.006 & -0.112 & -0.043 & -0.080 & -0.023 & -0.002 & -0.002 & 0.052 & -0.024 \\
\hline $\mathrm{NDWI}_{\mathrm{Mc}}$ & 0.214 & 0.010 & 0.017 & -0.060 & -0.084 & 0.071 & 0.040 & 0.040 & 0.025 & -0.022 \\
\hline NGRR & -0.010 & -0.056 & -0.192 & -0.111 & -0.281 & -0.212 & -0.170 & -0.170 & -0.110 & -0.277 \\
\hline NPCI & NA & -0.045 & -0.176 & 0.115 & 0.523 & -0.137 & 0.493 & 0.493 & -0.124 & 0.335 \\
\hline OSAVI & 0.143 & 0.000 & -0.031 & 0.015 & -0.003 & 0.052 & 0.050 & 0.050 & 0.078 & 0.026 \\
\hline PSRI & NA & -0.029 & 0.216 & 0.369 & 0.859 & 0.184 & 0.380 & 0.380 & 0.094 & 0.573 \\
\hline RVI & 0.052 & 0.028 & -0.002 & 0.098 & 0.223 & 0.066 & 0.112 & 0.112 & 0.242 & 0.206 \\
\hline $\mathrm{NDVI}_{705}$ & 0.407 & 0.004 & 0.143 & 0.171 & NA & NA & 0.196 & 0.196 & NA & NA \\
\hline RBI & NA & 0.067 & -0.177 & 0.033 & 0.239 & -0.002 & -0.215 & -0.215 & 0.167 & 0.163 \\
\hline RGI & -0.134 & 0.251 & -0.152 & 0.086 & 0.593 & -0.019 & 0.074 & 0.074 & 0.399 & 0.435 \\
\hline
\end{tabular}


Appendix B

Table B.2 (continued)

\begin{tabular}{|l|cccccccccc|}
\hline \multicolumn{10}{|c|}{ normalized intercept } \\
\hline INDEX & TC10 & $\begin{array}{c}\text { HY- } \\
\text { MAP* }\end{array}$ & TC05 & $\begin{array}{c}\text { RAPID- } \\
\text { EYE }\end{array}$ & $\begin{array}{c}\text { IKO- } \\
\text { NOS }\end{array}$ & $\begin{array}{c}\text { GEO- } \\
\text { EYE }\end{array}$ & WV3* & WV2 & $\begin{array}{c}\text { PLÉIA- } \\
\text { DES } \dagger\end{array}$ & QB \\
\hline RDVI & 0.086 & 0.001 & -0.017 & 0.007 & -0.003 & 0.029 & 0.025 & 0.025 & 0.037 & 0.013 \\
SARVI & NA & 0.001 & -0.024 & 0.029 & 0.008 & 0.059 & 0.030 & 0.030 & 0.091 & 0.039 \\
SAVI & 0.091 & 0.004 & -0.018 & 0.007 & -0.001 & 0.034 & 0.027 & 0.027 & 0.042 & 0.010 \\
SIPI & NA & -0.010 & -0.033 & -0.027 & -0.054 & 0.000 & 0.110 & 0.110 & 0.040 & -0.015 \\
TCARI & -0.006 & -0.016 & 0.010 & -0.061 & NA & NA & -0.310 & -0.310 & NA & NA \\
TNDVI & 0.080 & 0.004 & -0.116 & -0.039 & -0.030 & -0.022 & 0.003 & 0.003 & 0.080 & 0.004 \\
TVI & 0.048 & 0.000 & 0.003 & 0.009 & 0.004 & 0.018 & 0.014 & 0.014 & 0.016 & 0.008 \\
VARI & NA & -0.009 & -0.123 & -0.072 & -0.171 & -0.133 & -0.109 & -0.109 & -0.065 & -0.169 \\
\hline
\end{tabular}

\begin{tabular}{|c|c|c|c|c|c|c|c|c|c|c|}
\hline \multicolumn{11}{|c|}{$\mathbf{c c R}^{2}$} \\
\hline INDEX & TC10 & $\begin{array}{l}\text { HY- } \\
\text { MAP* }\end{array}$ & TC05 & $\begin{array}{l}\text { RAPID- } \\
\text { EYE }\end{array}$ & $\begin{array}{l}\text { IKO- } \\
\text { NOS }\end{array}$ & $\begin{array}{l}\text { GEO- } \\
\text { EYE }\end{array}$ & WV3* & WV2 & $\begin{array}{c}\text { PLÉIA- } \\
\text { DES } \dagger\end{array}$ & QB \\
\hline ARI & 0.910 & 0.067 & 0.654 & 0.489 & NA & NA & 0.556 & 0.528 & NA & NA \\
\hline ARVI & NA & 0.976 & 0.999 & 1.000 & 0.998 & 1.000 & 0.998 & 1.000 & 0.999 & 0.999 \\
\hline $\mathrm{BGI}_{2}$ & NA & 0.991 & 0.997 & 0.984 & 0.978 & 0.946 & 0.990 & 0.962 & 0.972 & 0.989 \\
\hline $\mathrm{BRI}_{1}$ & NA & NA & 0.862 & 0.887 & 0.889 & 0.844 & 0.907 & 0.886 & 0.835 & 0.895 \\
\hline $\mathrm{CRI}_{700}$ & 0.046 & 0.987 & 0.047 & 0.944 & NA & NA & 0.946 & 0.939 & NA & NA \\
\hline $\mathrm{CTR}_{1}$ & NA & NA & 0.785 & 0.035 & NA & NA & 0.024 & 0.040 & NA & NA \\
\hline $\mathrm{CTR}_{2}$ & 0.963 & 1.000 & 0.989 & 0.956 & NA & NA & 0.789 & 0.808 & NA & NA \\
\hline CARI & 0.660 & 0.425 & 0.664 & 0.298 & NA & NA & 0.054 & 0.017 & NA & NA \\
\hline DVI & 0.994 & 1.000 & 0.995 & 0.999 & 0.998 & 1.000 & 1.000 & 1.000 & 1.000 & 1.000 \\
\hline EVI & NA & 1.000 & 0.987 & 0.998 & 0.998 & 1.000 & 1.000 & 1.000 & 0.999 & 1.000 \\
\hline $\mathrm{GM}_{1}$ & 0.974 & 0.999 & 0.996 & 0.996 & 0.995 & 0.996 & 0.996 & 0.997 & 0.997 & 0.996 \\
\hline $\mathrm{GM}_{2}$ & 0.994 & 0.998 & 0.999 & 0.994 & NA & NA & 0.952 & 0.965 & NA & NA \\
\hline GEMI & 0.995 & 1.000 & 0.997 & 0.999 & 0.998 & 1.000 & 1.000 & 1.000 & 1.000 & 1.000 \\
\hline CIg & 0.983 & 1.000 & 0.991 & 0.997 & 0.992 & 0.998 & 0.997 & 0.998 & 0.997 & 0.995 \\
\hline gNDVI & 0.975 & 1.000 & 0.991 & 0.995 & 0.990 & 0.998 & 0.996 & 0.997 & 0.997 & 0.991 \\
\hline GRR & 1.000 & 0.999 & 0.999 & 0.994 & 0.916 & 0.997 & 0.960 & 0.993 & 0.953 & 0.953 \\
\hline IPVI & 0.999 & 1.000 & 0.998 & 1.000 & 0.999 & 1.000 & 0.999 & 1.000 & 0.999 & 0.999 \\
\hline $\mathrm{LIC}_{2}$ & NA & 0.936 & 0.961 & 0.984 & 0.976 & 0.959 & 0.963 & 0.990 & 0.954 & 0.986 \\
\hline $\mathrm{LIC}_{3}$ & NA & 0.997 & 0.999 & 0.930 & NA & NA & 0.974 & 0.966 & NA & NA \\
\hline mARI & 0.950 & 0.005 & 0.741 & 0.383 & NA & NA & 0.480 & 0.462 & NA & NA \\
\hline MCARI & 0.995 & 0.943 & 0.994 & 0.910 & NA & NA & 0.781 & 0.740 & NA & NA \\
\hline $\mathrm{MCARI}_{1}$ & 0.985 & 1.000 & 0.998 & 0.999 & 0.999 & 0.998 & 0.998 & 0.998 & 0.994 & 0.999 \\
\hline $\mathrm{MCARI}_{2}$ & 0.956 & 0.928 & 0.918 & 0.950 & 0.969 & 0.943 & 0.965 & 0.953 & 0.980 & 0.969 \\
\hline $\mathrm{mNDVI}_{705}$ & NA & 1.000 & 0.999 & 0.988 & NA & NA & 0.806 & 0.848 & NA & NA \\
\hline MSR & 0.998 & 0.999 & 0.999 & 0.999 & 0.989 & 0.999 & 0.996 & 0.999 & 0.992 & 0.995 \\
\hline $\mathrm{mSR}_{705}$ & NA & 0.999 & 0.998 & 0.994 & NA & NA & 0.913 & 0.943 & NA & NA \\
\hline $\mathrm{MSAVI}_{2}$ & 0.989 & 1.000 & 0.999 & 1.000 & 0.999 & 0.999 & 0.997 & 0.998 & 0.995 & 0.998 \\
\hline $\mathrm{MTVI}_{1}$ & 0.985 & 1.000 & 0.998 & 0.999 & 0.999 & 0.998 & 0.998 & 0.998 & 0.994 & 0.999 \\
\hline
\end{tabular}


Table B.2 (continued)

\begin{tabular}{|c|c|c|c|c|c|c|c|c|c|c|}
\hline \multicolumn{11}{|c|}{$\operatorname{ccR}^{2}$} \\
\hline INDEX & TC10 & $\begin{array}{l}\text { HY- } \\
\text { MAP* }\end{array}$ & TC05 & $\begin{array}{c}\text { RAPID- } \\
\text { EYE }\end{array}$ & $\begin{array}{l}\text { IKO- } \\
\text { NOS }\end{array}$ & $\begin{array}{l}\text { GEO- } \\
\text { EYE }\end{array}$ & WV3* & WV2 & $\begin{array}{c}\text { PLÉIA- } \\
\text { DES } \dagger \\
\end{array}$ & QB \\
\hline $\mathrm{MTVI}_{2}$ & 0.956 & 0.928 & 0.918 & 0.950 & 0.969 & 0.943 & 0.965 & 0.953 & 0.980 & 0.969 \\
\hline NDVIg-b & NA & 0.978 & 0.571 & 0.509 & 0.709 & 0.384 & 0.918 & 0.901 & 0.727 & 0.674 \\
\hline NDVI & 0.999 & 1.000 & 0.998 & 1.000 & 0.999 & 1.000 & 0.999 & 1.000 & 0.999 & 0.999 \\
\hline $\mathrm{NDWI}_{\mathrm{Mc}}$ & 0.975 & 1.000 & 0.991 & 0.995 & 0.990 & 0.998 & 0.996 & 0.997 & 0.997 & 0.991 \\
\hline NGRR & 1.000 & 1.000 & 0.998 & 0.998 & 0.979 & 0.998 & 0.987 & 0.997 & 0.995 & 0.988 \\
\hline NPCI & NA & 0.997 & 0.998 & 0.994 & 0.971 & 0.993 & 0.919 & 0.990 & 0.982 & 0.984 \\
\hline OSAVI & 0.989 & 1.000 & 1.000 & 0.999 & 0.999 & 0.999 & 0.997 & 0.998 & 0.995 & 0.998 \\
\hline PSRI & NA & 1.000 & 0.997 & 0.992 & 0.983 & 0.996 & 0.982 & 0.991 & 0.990 & 0.985 \\
\hline RVI & 1.000 & 1.000 & 1.000 & 0.996 & 0.963 & 0.999 & 0.984 & 0.995 & 0.972 & 0.979 \\
\hline $\mathrm{NDVI}_{705}$ & 0.993 & 1.000 & 0.999 & 0.993 & NA & NA & 0.900 & 0.916 & NA & NA \\
\hline RBI & NA & 0.997 & 0.875 & 0.885 & 0.911 & 0.839 & 0.983 & 0.938 & 0.797 & 0.900 \\
\hline RGI & 0.994 & 0.995 & 0.998 & 0.997 & 0.993 & 0.998 & 0.994 & 0.998 & 0.999 & 0.995 \\
\hline RDVI & 0.981 & 1.000 & 0.999 & 1.000 & 0.999 & 0.998 & 0.996 & 0.997 & 0.993 & 0.998 \\
\hline SARVI & NA & 1.000 & 1.000 & 0.997 & 0.999 & 0.995 & 0.997 & 0.998 & 0.984 & 0.994 \\
\hline SAVI & 0.985 & 1.000 & 0.999 & 1.000 & 1.000 & 0.998 & 0.997 & 0.998 & 0.996 & 0.999 \\
\hline SIPI & NA & 1.000 & 1.000 & 0.999 & 0.996 & 0.998 & 0.998 & 0.999 & 0.995 & 0.997 \\
\hline TCARI & 0.999 & 0.960 & 0.996 & 0.749 & NA & NA & 0.125 & 0.048 & NA & NA \\
\hline TNDVI & 0.999 & 1.000 & 0.998 & 1.000 & 0.999 & 1.000 & 0.999 & 1.000 & 0.999 & 0.999 \\
\hline TVI & 0.970 & 1.000 & 0.999 & 0.994 & 0.996 & 0.990 & 0.989 & 0.990 & 0.984 & 0.992 \\
\hline VARI & NA & 0.991 & 0.993 & 0.993 & 0.984 & 0.994 & 0.991 & 0.994 & 0.995 & 0.991 \\
\hline
\end{tabular}

*Convolved using Gaussian curves and not actual spectral response functions (SRFs)

$\dagger$ Pléiades-1A 


\section{Appendix C:}

Correlation coefficients between inspection indictors and index values for simulated data sets used in Chapter 3 
Table C.1: Pearson correlation coefficients between soil moisture indicator and index values for simulated data sets used in Chapter 3.

\begin{tabular}{|c|c|c|c|c|c|c|c|c|c|c|c|c|}
\hline Index & ASD & TC10 & $\begin{array}{l}\text { Hy- } \\
\text { Map }\end{array}$ & TC05 & $\begin{array}{c}\text { Rapid- } \\
\text { Eye }\end{array}$ & $\begin{array}{l}\text { IKO- } \\
\text { NOS }\end{array}$ & $\begin{array}{c}\text { Geo- } \\
\text { Eye }\end{array}$ & WV3 & WV2 & $\begin{array}{c}\text { Pléia- } \\
\text { des }\end{array}$ & QB & $\begin{array}{c}\text { Mean } \\
|\mathrm{r}|\end{array}$ \\
\hline ARI & 0.461 & -0.399 & 0.233 & -0.293 & 0.409 & NA & NA & 0.421 & 0.412 & NA & NA & 0.375 \\
\hline ARVI & 0.460 & NA & 0.485 & 0.452 & 0.460 & 0.471 & 0.457 & 0.473 & 0.461 & 0.464 & 0.468 & 0.465 \\
\hline $\mathrm{BGI}_{2}$ & -0.240 & NA & -0.282 & -0.266 & -0.300 & -0.182 & -0.347 & -0.287 & -0.332 & -0.162 & -0.220 & 0.262 \\
\hline $\mathrm{BRI}_{1}$ & 0.460 & NA & NA & 0.548 & 0.541 & 0.504 & 0.551 & 0.498 & 0.539 & 0.550 & 0.524 & 0.524 \\
\hline $\mathrm{CRI}_{700}$ & 0.459 & -0.293 & 0.439 & -0.293 & 0.409 & NA & NA & 0.421 & 0.412 & NA & NA & 0.389 \\
\hline $\mathrm{CTR}_{1}$ & -0.428 & NA & NA & -0.219 & 0.301 & NA & NA & 0.324 & 0.294 & NA & NA & 0.313 \\
\hline $\mathrm{CTR}_{2}$ & -0.402 & -0.469 & -0.398 & -0.443 & -0.480 & NA & NA & -0.520 & -0.526 & NA & NA & 0.463 \\
\hline CARI & -0.479 & -0.263 & -0.132 & -0.265 & -0.045 & NA & NA & 0.170 & 0.245 & NA & NA & 0.228 \\
\hline DVI & -0.051 & -0.092 & -0.056 & -0.017 & -0.034 & -0.030 & -0.054 & -0.054 & -0.050 & -0.056 & -0.042 & 0.049 \\
\hline EVI & 0.070 & NA & 0.065 & 0.125 & 0.092 & 0.095 & 0.075 & 0.078 & 0.077 & 0.054 & 0.078 & 0.081 \\
\hline $\mathrm{GM}_{1}$ & 0.500 & 0.471 & 0.494 & 0.491 & 0.522 & 0.522 & 0.506 & 0.513 & 0.509 & 0.513 & 0.522 & 0.506 \\
\hline $\mathrm{GM}_{2}$ & 0.574 & 0.565 & 0.564 & 0.572 & 0.557 & NA & NA & 0.536 & 0.545 & NA & NA & 0.559 \\
\hline GEMI & -0.046 & -0.080 & -0.049 & -0.020 & -0.032 & -0.028 & -0.047 & -0.048 & -0.044 & -0.047 & -0.040 & 0.044 \\
\hline $\mathrm{CIg}$ & 0.511 & 0.471 & 0.511 & 0.491 & 0.522 & 0.522 & 0.506 & 0.513 & 0.509 & 0.513 & 0.522 & 0.508 \\
\hline gNDVI & 0.440 & 0.418 & 0.438 & 0.407 & 0.433 & 0.432 & 0.425 & 0.424 & 0.425 & 0.431 & 0.425 & 0.427 \\
\hline GRR & 0.585 & 0.586 & 0.582 & 0.586 & 0.584 & 0.543 & 0.582 & 0.568 & 0.584 & 0.562 & 0.565 & 0.575 \\
\hline IPVI & 0.438 & 0.440 & 0.436 & 0.427 & 0.437 & 0.450 & 0.438 & 0.450 & 0.439 & 0.445 & 0.445 & 0.440 \\
\hline $\mathrm{LIC}_{2}$ & 0.508 & NA & 0.433 & 0.548 & 0.541 & 0.504 & 0.551 & 0.462 & 0.525 & 0.550 & 0.524 & 0.515 \\
\hline $\mathrm{LIC}_{3}$ & -0.258 & NA & -0.281 & -0.266 & -0.244 & NA & NA & -0.224 & -0.211 & NA & NA & 0.247 \\
\hline mARI & -0.576 & -0.517 & 0.118 & -0.412 & 0.483 & NA & NA & 0.509 & 0.502 & NA & NA & 0.445 \\
\hline MCARI & 0.131 & 0.172 & 0.273 & 0.179 & 0.299 & NA & NA & 0.385 & 0.426 & NA & NA & 0.266 \\
\hline $\mathrm{MCARI}_{1}$ & 0.004 & -0.057 & 0.010 & 0.027 & -0.001 & 0.018 & -0.013 & -0.008 & -0.012 & -0.024 & 0.000 & 0.016 \\
\hline $\mathrm{MCARI}_{2}$ & 0.131 & 0.241 & 0.283 & 0.294 & 0.260 & 0.229 & 0.265 & 0.236 & 0.254 & 0.205 & 0.231 & 0.239 \\
\hline $\mathrm{mNDVI}_{705}$ & 0.487 & NA & & & 0.513 & NA & & & 551 & & NA & 0.510 \\
\hline MSR & 0.573 & 0.577 & 0.578 & 0.579 & 0.576 & 0.555 & 0.576 & 0.566 & 0.575 & 0.560 & 0.564 & 0.571 \\
\hline $\mathrm{mSR}_{705}$ & 0.554 & NA & 0.553 & 0.553 & 0.552 & NA & NA & 0.544 & 0.554 & NA & NA & 0.552 \\
\hline $\mathrm{MSAVI}_{2}$ & 0.102 & 0.048 & 0.104 & 0.112 & 0.096 & 0.091 & 0.084 & 0.075 & 0.083 & 0.068 & 0.080 & 0.086 \\
\hline $\mathrm{MTVI}_{1}$ & 0.004 & -0.057 & 0.010 & 0.027 & -0.001 & 0.018 & -0.013 & -0.008 & & -0.024 & 0.000 & 0.016 \\
\hline $\mathrm{MTVI}_{2}$ & 0.131 & 0.241 & 0.283 & 0.294 & 0.260 & 0.229 & 0.265 & 0.236 & 0.254 & 0.205 & 0.231 & 0.239 \\
\hline NDVIg-b & -0.083 & NA & -0.001 & 0.285 & 0.320 & 0.187 & 0.372 & 0.046 & 0.069 & 0.166 & 0.227 & 0.176 \\
\hline NDVI & 0.438 & 0.440 & 0.436 & 0.427 & 0.437 & 0.450 & 0.438 & 0.450 & 0.439 & 0.445 & 0.445 & 0.440 \\
\hline $\mathrm{NDWI}_{\mathrm{Mc}}$ & -0.440 & -0.418 & -0.438 & -0.407 & -0.433 & -0.432 & -0.425 & -0.424 & -0.425 & -0.431 & -0.425 & 0.427 \\
\hline NGRR & -0.531 & -0.532 & -0.534 & -0.539 & -0.544 & -0.519 & -0.542 & -0.539 & -0.544 & -0.528 & -0.537 & 0.535 \\
\hline NPCI & -0.539 & NA & -0.539 & -0.544 & -0.535 & -0.497 & -0.543 & -0.467 & -0.527 & -0.535 & -0.516 & 0.524 \\
\hline OSAVI & 0.226 & 0.186 & 0.233 & 0.234 & 0.226 & 0.242 & 0.219 & 0.222 & 0.216 & 0.210 & 0.223 & 0.222 \\
\hline PSRI & -0.362 & NA & -0.366 & -0.380 & -0.395 & -0.414 & -0.389 & -0.417 & -0.400 & -0.405 & -0.410 & 0.394 \\
\hline RVI & 0.590 & 0.585 & 0.589 & 0.591 & 0.591 & 0.580 & 0.588 & 0.585 & 0.590 & 0.584 & 0.586 & 0.587 \\
\hline $\mathrm{NDVI}_{705}$ & 0.497 & 0.501 & 0.499 & 0.489 & 0.510 & NA & NA & 0.527 & 0.535 & NA & NA & 0.508 \\
\hline RBI & -0.422 & NA & -0.429 & -0.505 & -0.509 & -0.481 & -0.513 & -0.448 & -0.491 & -0.510 & -0.496 & 0.480 \\
\hline
\end{tabular}


Table C.1 (continued)

\begin{tabular}{lcccccccccccc}
\hline Index & ASD & TC10 & $\begin{array}{c}\text { Hy- } \\
\text { Map }\end{array}$ & $\begin{array}{c}\text { TC05 } \\
\text { Rapid- } \\
\text { Eye }\end{array}$ & $\begin{array}{c}\text { IKO- } \\
\text { NOS }\end{array}$ & $\begin{array}{c}\text { Geo- } \\
\text { Eye }\end{array}$ & WV3 & WV2 & $\begin{array}{c}\text { Pléia- } \\
\text { des }\end{array}$ & $\begin{array}{c}\text { QB } \\
|\mathbf{r}|\end{array}$ \\
\hline RGI & -0.484 & -0.472 & -0.493 & -0.480 & -0.497 & -0.492 & -0.491 & -0.505 & -0.497 & -0.493 & -0.505 & 0.492 \\
RDVI & 0.130 & 0.064 & 0.133 & 0.143 & 0.126 & 0.140 & 0.109 & 0.110 & 0.110 & 0.098 & 0.120 & 0.117 \\
SARVI & 0.219 & NA & 0.222 & 0.227 & 0.203 & 0.224 & 0.188 & 0.232 & 0.217 & 0.170 & 0.197 & 0.210 \\
SAVI & 0.088 & 0.029 & 0.092 & 0.100 & 0.085 & 0.096 & 0.070 & 0.070 & 0.071 & 0.063 & 0.078 & 0.077 \\
SIPI & 0.411 & NA & 0.416 & 0.410 & 0.421 & 0.432 & 0.426 & 0.417 & 0.410 & 0.429 & 0.427 & 0.420 \\
TCARI & -0.154 & -0.178 & -0.282 & -0.192 & -0.457 & NA & NA & -0.665 & -0.671 & NA & NA & 0.371 \\
TNDVI & 0.421 & 0.425 & 0.419 & 0.407 & 0.419 & 0.433 & 0.421 & 0.434 & 0.423 & 0.429 & 0.429 & 0.424 \\
TVI & 0.007 & -0.070 & 0.011 & 0.011 & -0.013 & 0.000 & -0.029 & -0.026 & -0.026 & -0.036 & -0.017 & 0.022 \\
VARI & 0.527 & NA & 0.541 & 0.542 & 0.546 & 0.518 & 0.544 & 0.542 & 0.547 & 0.525 & 0.537 & 0.537 \\
\hline
\end{tabular}

Table C.2: Spearman correlation coefficients between cover quality indicator and index values for simulated data sets used in Chapter 3.

\begin{tabular}{|c|c|c|c|c|c|c|c|c|c|c|c|c|}
\hline dex & SD & TC10 & $\begin{array}{l}\text { Hy- } \\
\text { Map }\end{array}$ & 05 & $\begin{array}{l}\text { Rapid- } \\
\text { Eye }\end{array}$ & $\begin{array}{l}\mathrm{IKO}- \\
\text { NOS } \\
\end{array}$ & $\begin{array}{l}\text { Geo- } \\
\text { Eye }\end{array}$ & & & $\begin{array}{c}\begin{array}{c}\text { Pléia- } \\
\text { des }\end{array} \\
\end{array}$ & QB & $\begin{array}{c}\text { Mean } \\
|\mathrm{r}|\end{array}$ \\
\hline ARI & 570 & 0.529 & -0.361 & 0.364 & -0.555 & NA & NA & -0.584 & -0.573 & NA & NA & 0.505 \\
\hline ARV & 577 & NA & -0.575 & -0.577 & -0.577 & -0.584 & -0.581 & -0.586 & -0.579 & -0.582 & -0.579 & 0.580 \\
\hline $\mathrm{BGI}_{2}$ & 0.433 & NA & 0.484 & 0.451 & 0.496 & 0.391 & 0.529 & 0.476 & 0.523 & 0.369 & 0.412 & 0.456 \\
\hline $\mathrm{BRI}_{1}$ & .473 & NA & NA & -0.555 & -0.546 & -0.528 & -0.551 & -0.516 & -0.543 & -0.561 & -0.530 & 0.534 \\
\hline $\mathrm{CRI}_{700}$ & -0.611 & 0.362 & -0.590 & 0.364 & -0.555 & NA & NA & -0.584 & -0.573 & NA & NA & 0.520 \\
\hline $\mathrm{TR}_{1}$ & 0.465 & NA & NA & 0.070 & -0.447 & NA & NA & -0.484 & -0.460 & $\mathrm{NA}$ & 171 & 0.385 \\
\hline $\mathrm{TR}_{2}$ & 0.570 & 0.584 & 0.570 & 0.572 & 0.588 & NA & NA & 0.598 & 0.603 & $1 \mathrm{~N}$ & $1 \mathrm{~N}$ & 0.584 \\
\hline & 0.579 & 0.324 & 0.173 & 0.329 & 0.056 & NA & NA & -0.159 & -0.224 & NA & NA & 0.264 \\
\hline DVI & 940 & 0.094 & & & 0.027 & 0.025 & & & & 0.047 & & \\
\hline EVI & -0.039 & NA & -0.036 & -0.085 & -0.058 & -0.069 & -0.041 & -0.053 & -0.049 & -0.017 & -0.051 & 0.050 \\
\hline $\mathrm{GM}_{1}$ & -0.574 & -0.548 & -0.574 & -0.564 & -0.582 & -0.582 & -0.577 & -0.576 & -0.577 & -0.582 & -0.587 & 0.575 \\
\hline $\mathrm{GM}_{2}$ & -0.567 & -0.584 & -0.574 & -0.572 & -0.588 & NA & NA & -0.598 & -0.603 & NA & NA & 0.584 \\
\hline GEMI & 0.088 & 0.131 & 0.091 & 0.064 & 0.074 & 0.078 & 0.091 & 0.091 & 0.088 & 0.090 & 0.088 & 0.089 \\
\hline $\lg$ & .571 & .548 & -0.573 & -0.564 & -0.582 & .582 & -0.577 & -0.576 & -0.577 & -0.582 & -0.587 & 0.574 \\
\hline gNDVI & -0.571 & -0.548 & -0.573 & -0.564 & -0.582 & -0.582 & -0.577 & -0.576 & -0.577 & -0.582 & -0.587 & 0.574 \\
\hline GRR & -0.579 & -0.580 & -0.581 & -0.578 & -0.578 & -0.588 & -0.579 & -0.585 & -0.579 & -0.583 & & 0.581 \\
\hline IPVI & -0.583 & -0.581 & -0.585 & -0.579 & -0.580 & -0.573 & -0.585 & -0.573 & -0.582 & & & 0.579 \\
\hline $\mathrm{LIC}_{2}$ & -0.517 & NA & -0.450 & -0.555 & -0.546 & -0.528 & -0.551 & -0.482 & -0.536 & -0.561 & -0.530 & 0.526 \\
\hline $\mathrm{LIC}_{3}$ & 0.525 & NA & 0.540 & 0.519 & 0.447 & NA & NA & 0.484 & 0.460 & NA & NA & 0.496 \\
\hline mARI & 0.535 & 0.506 & -0.246 & 0.363 & -0.546 & NA & NA & -0.569 & -0.561 & NA & NA & 0.475 \\
\hline MCARI & -0.149 & -0.177 & -0.266 & -0.178 & -0.288 & NA & NA & -0.355 & -0.383 & NA & NA & 0.256 \\
\hline $\mathrm{MCARI}_{1}$ & -0.004 & 0.066 & -0.008 & -0.029 & 0.003 & -0.016 & 0.020 & 0.012 & 0.020 & 0.027 & -0.001 & 0.019 \\
\hline $\mathrm{MCARI}_{2}$ & -0.120 & -0.192 & -0.254 & -0.262 & -0.227 & -0.207 & -0.221 & -0.206 & -0.218 & -0.189 & -0.206 & 0.209 \\
\hline
\end{tabular}


Table C.2 (continued)

\begin{tabular}{|c|c|c|c|c|c|c|c|c|c|c|c|c|}
\hline Index & SD & $\mathrm{C} 10$ & $\begin{array}{l}\text { Hy- } \\
\text { Map }\end{array}$ & C05 & $\begin{array}{l}\text { Rapid- } \\
\text { Eye }\end{array}$ & $\begin{array}{l}\text { IKO- } \\
\text { NOS }\end{array}$ & $\begin{array}{l}\text { Geo- } \\
\text { Eye }\end{array}$ & IV3 & & $\begin{array}{c}\text { Pléia- } \\
\text { des }\end{array}$ & QB & $\begin{array}{c}\text { Mean } \\
|\mathrm{r}|\end{array}$ \\
\hline & & NA & & & & NA & & & & & NA & .581 \\
\hline & & -0.581 & -0.579 & -0.579 & -0.580 & -0.573 & -0.585 & & -0.582 & -0.577 & -0.573 & .578 \\
\hline $\mathrm{mSR}_{705}$ & -0.579 & NA & -0.579 & -0.579 & -0.589 & NA & NA & -0.574 & -0.585 & NA & NA & .581 \\
\hline $\mathrm{MSAVI}_{2}$ & -0.077 & -0.002 & -0.081 & -0.086 & -0.068 & -0.075 & -0.055 & -0.053 & -0.057 & -0.050 & -0.062 & 0.060 \\
\hline MTVI & -0.004 & 0.066 & -0.008 & -0.029 & 0.003 & -0.016 & 0.020 & 0.012 & 0.020 & 0.027 & -0.001 & 0.019 \\
\hline $\mathrm{TVI}_{2}$ & -0.120 & -0.192 & -0.254 & -0.262 & -0.227 & -0.207 & -0.221 & -0.206 & -0.218 & -0.189 & -0.206 & 0.209 \\
\hline & -0.083 & NA & -0.173 & -0.451 & -0.496 & -0.391 & -0.529 & -0.233 & -0.244 & -0.369 & -0.412 & 0.338 \\
\hline & -0.583 & -0.581 & -0.585 & -0.579 & -0.580 & -0.573 & -0.585 & -0.573 & -0.582 & -0.577 & -0.573 & 0.579 \\
\hline & & & 0.573 & 0.564 & & & & & & & & 574 \\
\hline & 0.579 & 0.580 & 0.581 & 0.578 & 0.578 & 0.588 & 0.579 & & & & & .581 \\
\hline NPCI & 0.551 & NA & 0.556 & 0.555 & 0.546 & 0.528 & 0.551 & 0.482 & 0.536 & 0.561 & .530 & 0.540 \\
\hline OSA & -0.252 & -0.197 & -0.261 & -0.262 & -0.250 & 0.270 & -0.244 & -0.235 & -0.233 & -0.222 & -0.235 & 0.242 \\
\hline SRI & 575 & NA & 0.575 & 0.571 & 0.574 & 0.565 & 0.579 & 0.568 & 0.572 & 0.571 & 0.567 & 0.572 \\
\hline$\nabla 1$ & .581 & .581 & -0.579 & -0.579 & -0.580 & -0.573 & -0.585 & -0.573 & -0.582 & -0.577 & -0.573 & 0.578 \\
\hline & -0.573 & .584 & -0.574 & -0.572 & -0.588 & NA & NA & -0.598 & -0.603 & NA & NA & 0.585 \\
\hline & & & & & & 0.528 & 0.551 & & & & 0.530 & 0.517 \\
\hline & 0.580 & 0.580 & 0.581 & 0.578 & 0.578 & 0.588 & 0.579 & & & 0.583 & 58 & 0.581 \\
\hline RDVI & -0.161 & -0.087 & -0.171 & -0.176 & -0.166 & -0.180 & -0.155 & -0.161 & -0.158 & -0.144 & -0.170 & 0.157 \\
\hline SARVI & -0.215 & NA & -0.219 & -0.229 & -0.186 & -0.231 & -0.167 & -0.226 & -0.207 & -0.151 & -0.184 & 0.201 \\
\hline SAVI & -0.087 & -0.009 & -0.091 & -0.108 & -0.087 & -0.093 & -0.065 & -0.065 & -0.069 & -0.063 & -0.077 & 0.074 \\
\hline SIPI & -0.585 & NA & -0.587 & -0.582 & -0.580 & -0.577 & -0.585 & -0.576 & -0.578 & -0.571 & -0.573 & 0.579 \\
\hline TCAR & 0.169 & 0.181 & 0.256 & 0.205 & 0.449 & NA & NA & 0.547 & 0.516 & NA & NA & 0.332 \\
\hline TND & -0.583 & -0.581 & -0.585 & -0.579 & -0.580 & -0.573 & -0.585 & -0.573 & -0.582 & -0.577 & -0.573 & 0.579 \\
\hline TVI & & 0.076 & -0.020 & -0.01 & & & & & & 0.028 & 0.012 & 0.024 \\
\hline VARI & דo. & & -0.566 & -0.574 & -0.573 & -0.590 & -0.578 & -0.583 & -0.576 & -0.585 & -0.583 & 0.579 \\
\hline
\end{tabular}


Appendix D:

Bivariate statistical measures for the ten indices investigated in Chapter 4 
Table D.1: Values for the three bivariate statistical measures for the ten indices investigated in Chapter 4, comparing index values generated from WorldView-2 simulated and image data to index values obtained from original narrowband ASD data. Data sets are defined in Table 4.2

\begin{tabular}{|c|c|c|c|c|}
\hline INDEX & SIM & SIMADJ & IMG54 & IMG54ADJ \\
\hline \multicolumn{5}{|c|}{$\mathbf{r}_{1: 1}^{2}$} \\
\hline $\mathrm{CTR}_{2}$ & -9.421 & 0.917 & -13.376 & -2.231 \\
\hline $\mathrm{GM}_{2}$ & -1.784 & 0.965 & -2.207 & -0.327 \\
\hline GRR & 0.572 & 0.997 & -0.450 & 0.066 \\
\hline $\mathrm{mNDVI}_{705}$ & -4.206 & 0.882 & -6.857 & -2.943 \\
\hline MSR & 0.625 & 0.999 & -0.442 & 0.250 \\
\hline $\mathrm{mSR}_{705}$ & -1.886 & 0.944 & -2.516 & -1.125 \\
\hline NGRR & 0.722 & 0.998 & -0.976 & -0.273 \\
\hline RVI & 0.923 & 0.997 & 0.218 & 0.325 \\
\hline $\mathrm{NDVI}_{705}$ & -2.480 & 0.951 & -4.257 & -1.181 \\
\hline RGI & 0.984 & 0.999 & -0.205 & -0.582 \\
\hline \multicolumn{5}{|c|}{ mean $\%$ diff. } \\
\hline $\mathrm{CTR}_{2}$ & 92.529 & 9.532 & 99.232 & 52.332 \\
\hline $\mathrm{GM}_{2}$ & 68.100 & 6.979 & 76.057 & 47.031 \\
\hline GRR & 22.121 & 1.830 & 50.846 & 38.834 \\
\hline $\mathrm{mNDVI}_{705}$ & 59.170 & 6.257 & 78.677 & 50.934 \\
\hline MSR & 28.578 & 1.051 & 59.136 & 38.313 \\
\hline $\mathrm{mSR}_{705}$ & 62.604 & 7.915 & 73.368 & 61.656 \\
\hline NGRR & 101.058 & 12.577 & 1349.163 & 254.774 \\
\hline RVI & 8.142 & 1.709 & 49.409 & 47.750 \\
\hline $\mathrm{NDVI}_{705}$ & 54.465 & 4.756 & 71.702 & 41.261 \\
\hline RGI & 2.567 & 0.909 & 30.476 & 33.361 \\
\hline \multicolumn{5}{|c|}{ Hedge's $g$} \\
\hline $\mathrm{CTR}_{2}$ & 3.991 & 0.002 & 5.175 & 1.901 \\
\hline $\mathrm{GM}_{2}$ & 1.968 & 0.000 & 2.137 & 1.326 \\
\hline GRR & 0.612 & 0.000 & 1.352 & 1.027 \\
\hline $\mathrm{mNDVI}_{705}$ & 2.875 & 0.000 & 3.747 & 2.439 \\
\hline MSR & 0.625 & 0.000 & 1.407 & 0.844 \\
\hline $\mathrm{mSR}_{705}$ & 2.024 & 0.000 & 2.279 & 1.819 \\
\hline NGRR & 0.535 & 0.000 & 1.716 & 1.240 \\
\hline RVI & 0.176 & 0.001 & 0.818 & 0.740 \\
\hline $\mathrm{NDVI}_{705}$ & 2.292 & 0.000 & 2.997 & 1.674 \\
\hline RGI & 0.069 & 0.000 & 1.104 & 1.346 \\
\hline
\end{tabular}




\section{About the author}

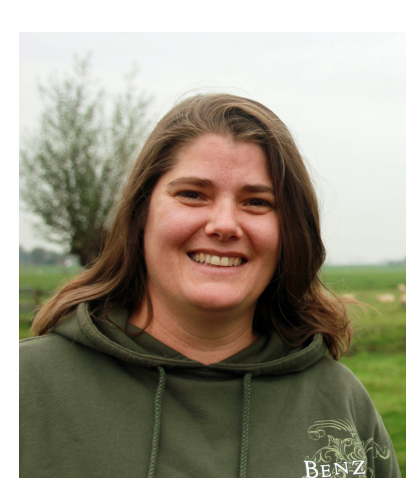

Sharon Cundill was born on 3 April 1974 in Durban, South Africa. After completing her secondary education in 1991, she worked in accounts and then in IT in the manufacturing industry before choosing to pursue a higher education in Earth Sciences. From 1997 to 2000, she studied at the then Rand Afrikaans University (now the University of Johannesburg), South Africa, where she obtained a BSc. in geography and botany and a BSc. (Hons) in geography. From 2001 to 2006, she worked as a remote sensing specialist at GEOTERRA IMAGE, a remote sensing and geospatial consultancy in Pretoria, South Africa, where she gained extensive experience in image processing, interpretation and classification as well as in spatial modelling and presenting remote sensing courses.

In 2006, she was awarded an Erasmus Mundus scholarship to read for her MSc. in Geo-Information Science and Earth Observation for Environmental Modelling and Management, a joint degree of the University of Southampton (UK), Lund University (Sweden), Warsaw University (Poland) and International Institute of Geo-Information Science and Earth Observation: ITC (the Netherlands), which she obtained in 2008. The title of her MSc. thesis is 'Investigation of soil reflectances for detecting hydrocarbon pipeline leakages'. From 2008 to 2010, she returned to GEOTERRA IMAGE to work as a remote sensing specialist. In 2010, she joined the RSDYK project, part of the Flood Control 2015 programme, as a $\mathrm{PhD}$ candidate at the University of Twente, Faculty of Geo-information Science and Earth Observation (ITC), the Netherlands. This thesis is the outcome of her research.

Sharon currently lives in Hanover, Germany, with her wife Wiebke. 


\section{Author's publications}

\section{Peer-reviewed journal articles}

Cundill, S.L., van der Werff, H.M.A., van der Meijde, M., van der Meer, F.D. \& Hack, H.R.G.K. (in review) Comparison of indices from field spectral measurements and satellite imagery as proxies for dike inspection indicators.

Cundill, S. L., van der Werff, H. M. A. \& van der Meijde, M. (2015). Adjusting spectral indices for spectral response function differences of very high spatial resolution sensors simulated from field spectra. Sensors, 15 (3), 6221-6240.

Cundill, S. L., van der Meijde, M. \& Hack, H. R. G. K. (2014). Investigation of remote sensing for potential use in dike inspection. Selected Topics in Applied Earth Observations and Remote Sensing, IEEE Journal of, 7 (2), 733-746.

van der Meijde, M., Knox, N. M., Cundill, S. L., Noomen, M. F., van der Werff, H. M. A. \& Hecker, C. A. (2013). Detection of hydrocarbons in clay soils: a laboratory experiment using spectroscopy in the mid- and thermal infrared. International Journal of Applied Earth Observation and Geoinformation : JAG, 23, 384-388.

\section{Conference proceedings and book chapters}

Cundill, S. L., Hack, H. R. G. K., van der Meijde, M., van der Schrier, J. S. \& Ngan-Tillard, D. J. M. (2013). Quality of peat dykes evaluated by remote sensing. In: Klijn, F. \& Schweckediek, T. (Eds.) Comprehensive Flood Risk Management: Research for policy and practice. Leiden: CRC Press (Taylor \& Francis). ISBN 978-0-415-62144-1. 463-469.

Cundill, S. L., Hack, H. R. G. K., van der Meijde, M., van der Schrier, J. S. \& Ngan-Tillard, D. J. M. (2013). Potential of using remote sensing data for dike inspection. In: Huang, Y., Wu, F., Shi, Z. \& Ye, B. (Eds.) New Frontiers in Engineering Geology and the Environment. Springer Geology, 9. Berlin: Springer. ISBN: 978-3-642-31671-5. 203-206.

Cundill, S. L., Sevenhuysen, P. \& Thompson, M. W. (2009). The evolution of land cover data, in a South African context, in line with ever increasing user demands. In: 2009 IEEE International Geoscience \& Remote Sensing Symposium (IGARSS 2009), ISBN 978-1-4244-3394-0, 12-17 July 2009, Cape Town, South Africa. IV1027-IV1029. 


\section{Conference, workshop, symposium presentations}

Cundill, S.L., van der Werff, H.M.A. \& van der Meijde, M. (2014). Transferability of indices across multiple sensors with differing spectral resolutions [poster abstract]. In: Bendig, J. \& Bareth G. (Eds.) Proceedings of the Workshop on UAV-based Remote Sensing Methods for Monitoring Vegetation, Selbstverlag: Geographisches Institut der Universität zu Köln, Kölner Geographische Arbeiten Helft 94, 9-10 September 2013, Cologne, Germany, 145-146.

Cundill, S. L., Hack, H. R. G. K. \& van der Meijde, M. (2012). Investigation of remote sensing for dike inspection [poster]. Presented at: IEEE International Geoscience and Remote Sensing Symposium (IGARSS 2012): Remote sensing for a dynamic earth, 22-27 July 2012, Munich, Germany.

Cundill, S. L., Hack, H. R. G. K., van der Meijde, M., van der Schrier, J. S. \& Ngan-Tillard, D. J. M. (2012). Remote sensing data for use in regional dike inspection [presentation]. Presented at: Nederlands Aardwetenschappelijk Congres 11, 29-30 March 2012 Koningshof, Veldhoven.

Hack, H. R. G. K., Cundill, S. L., van der Meijde, M., van der Schrier, J. S. \& Ngan-Tillard, D. J. M. (2011). Remote sensing and dykes: are dykes a mischief for establishing quality by remote sensing or a wonderful testing environment [presentation]. Presented at: the Autumn Ingeokring Symposium, 26 September 2011, Delft, the Netherlands.

Cundill, S.L. (2002). Vegetation of the Niger Delta: Vegetation classification of the Niger Delta from satellite imagery [poster abstract]. In: Bernard, T., Mosepele, K., Ramberg, L. (Eds.) Environmental Monitoring of Tropical and Subtropical Wetlands, Vol. 1, 4-8 December 2002, Maun, Botswana. Maun: Harry Oppenheimer Okavango Research Center. p. 91.

\section{Other}

Cundill, S. L., van Dongen, K., de Gooijer, K., Hack, H. R. G. K., Hillen, M. M., Janssen, A., Kolen, B., Lescinski, J., van der Meer, M., Pals, N., Termes, P., Vermeulen, C., Vreugdenhil, H., Wagemaker, J. \& Wojciechowska, K. (2012). Flood Control 2015: five years of innovation in flood risk. In: Vermeer, K., de Bruijne, J., Heynert, K. \& Nijhof, A. (Eds.). Delft: Foundation Flood Control 2015. 


\section{ITC Dissertation List}

A complete list of ITC dissertations is online on the ITC website:

http://www.itc.nl/research/phd/phd_graduates.aspx

This dissertation has number 283 . 
